\title{
Las ONGD aragonesas en Colombia Ejecución y evaluación de los proyectos de desarrollo
}



LAS ONGD ARAGONESAS EN COLOMBIA

Ejecución y evaluación de los proyectos de desarrollo 



\title{
LAS ONGD ARAGONESAS EN COLOMBIA
}

\author{
Ejecución y evaluación \\ de los proyectos de desarrollo
}

Juan David Gómez Quintero

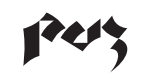

Prensas Universitarias de Zaragoza 


\section{FICHA CATALOGRÁFICA}

\section{GÓMEZ QUINTERO, Juan David}

Las ONGD aragonesas en Colombia : ejecución y evaluación de los proyectos de desarrollo / Juan David Gómez Quintero. — Zaragoza : Prensas Universitarias de Zaragoza, 2007

311 p. ; $22 \mathrm{~cm}$. - (Ciencias sociales ; 64)

ISBN 978-84-7733-951-9

1. Organizaciones no gubernamentales-Aragón. 2. Organizaciones no gubernamentales-Colombia. I. Prensas Universitarias de Zaragoza. II. Título. III. Serie: Ciencias sociales (Prensas Universitarias de Zaragoza) ; 64

061.235(460.22:861)

No está permitida la reproducción total o parcial de este libro, ni su tratamiento informático, ni la transmisión de ninguna forma o por cualquier medio, ya sea electrónico, mecánico, por fotocopia, por registro u otros métodos, ni su préstamo, alquiler o cualquier forma de cesión de uso del ejemplar, sin el permiso previo y por escrito de los titulares del Copyright.

(C) Juan David Gómez Quintero

(C) De la presente edición, Prensas Universitarias de Zaragoza

1. a edición, 2007

La edición de este libro ha sido parcialmente financiada por la Federación Aragonesa de Solidaridad, la Universidad de Zaragoza y el Departamento de Economía, Hacienda y Empleo del Gobierno de Aragón.

Ilustración de la cubierta: José Luis Cano

Colección Ciencias Sociales, n. ${ }^{\circ} 64$

Director de la colección: Pedro Víctor Rújula López

Prensas Universitarias de Zaragoza. Edificio de Ciencias Geológicas, c/ Pedro Cerbuna, 12 50009 Zaragoza, España. Tel.: 976761 330. Fax: 976761063

puz@unizar.es http://puz.unizar.es

Prensas Universitarias de Zaragoza es la editorial de la Universidad de Zaragoza, que edita e imprime libros desde su fundación en 1542.

Impreso en España

Imprime: Línea 2015

D.L.: Z-3698-2007 
A mis padres Juan y Marta, porque me enseñaron a creer en el amor 



\section{PREFACIO}

Desde siempre, la politica aragonesa de cooperación para el desarrollo ha venido contemplando, entre otras lineas de ayuda, la destinada a acciones de educación para el desarrollo y sensibilización sobre la realidad de los países más desfavorecidos. En este marco se encuadran las sucesivas ediciones del Curso de Cooperación al Desarrollo que se viene realizando desde el año 2000 en el marco del convenio suscrito entre el Gobierno de Aragón, la Federación Aragonesa de Solidaridad y la Universidad de Zaragoza.

El citado Curso incluye la convocatoria anual de una beca, con la que se pretende apoyar una linea de estudio y de investigación sobre la cooperación al desarrollo. La actual publicación corresponde a la investigación llevada a cabo en el segundo año de convocatoria de la beca y responde al título Evaluación de la cooperación de las ONGD aragonesas. Estudio de caso.

El Gobierno de Aragón es consciente de la importancia y utilidad de la evaluación en el ámbito de la cooperación para el desarrollo, y, por ello, impulsa y promueve la cooperación con letras mayúsculas. Este interés es común al resto de los actores de la cooperación aragonesa, y buena prueba de ello la encontramos en el Plan Director 2004-2007, fruto del diálogo entre todos ellos. Por tanto, esperamos que esta investigación pueda servir de instrumento de mejora de la cooperación aragonesa y de su evaluación.

ANA FERnÁNDEZ ABADÍA

Consejera de Servicios Sociales y Familia 



\section{PRÓLOGO}

La obra que el lector tiene en sus manos es el resultado de un largo proceso. Primero, fue un proyecto que se presentó a una convocatoria de becas en el marco del convenio de cooperación de la Federación Aragonesa de Solidaridad (FAS), el Gobierno de Aragón y la Universidad de Zaragoza. Segundo, una vez concedida, se tradujo en una intensa y densa investigación, que abordó tanto las fuentes secundarias existentes como la realización de un trabajo de campo complejo y, en algunas ocasiones, arriesgado. Tercero, ha sido una meticulosa y discutida tarea de sintesis de la información recabada, donde se hace un riguroso esfuerzo hermenéutico de interpretar la realidad social investiga$d a$. Cuarto, superó las etapas de evaluación de la comisión de seguimiento, donde el papel de Carmen Cornago y Pepa Rubio resultó ser un estímulo permanente para mejorar. Por último, en quinto lugar, se ha convertido en este libro. Aqui se presenta una versión depurada y cuidadosamente editada por Prensas Universitarias de Zaragoza, gracias a la labor del equipo que dirige Antonio Pérez Lasheras, donde el papel de Concha Relancio ha sido fundamental.

En ese camino, he tenido la fortuna de ser el director académico de Juan David Gómez Quintero. Fortuna, sí..., porque no es fácil encontrar a alguien dispuesto a trabajar, con ganas de invertir esfuerzos y discutir apasionadamente, con constancia para superar las dificultades y las críticas, con la calidad humana y la bondad que en el trabajo diario ha ido haciendo que la relación de director dirigido se haya convertido en amistad. Y sobre todo, con un investigador del que he aprendido más de lo que en estas lineas cabe expresar. Por eso, más que director tengo la sensación de ser un compañero de camino en una ruta muy poco explorada donde se abre una modesta senda para quienes están interesados en los temas de cooperación al desarrollo. 
El texto aborda la ejecución y evaluación de los proyectos de las Organizaciones No Gubernamentales de Desarrollo (ONGD) aragonesas en Colombia. Lo hace con un lenguaje claro y de fácil lectura, sin renunciar al rigor y seriedad de la academia. No pretendo sintetizar el contenido, pero al lector puede serle de utilidad saber que tras la pertinente aclaración metodológica el libro sigue un orden lógico que va desde la visión general de las ONGD, la situación en Colombia, el contexto aragonés hasta el análisis del trabajo de campo realizado sobre la ejecución y evaluación de los proyectos de cooperación. Termina con un capitulo dedicado a presentar las conclusiones, que, además, asume el riesgo de ofrecer unas recomendaciones especialmente dirigidas a las gentes implicadas en las ONGD.

Pero este orden también se puede leer de un modo no lineal. Porque el texto permite la lectura de los distintos capitulos con recorridos alternativos. Es cierto que algunos datos son fotografias de una realidad social por naturaleza efimera. Por eso, habrá que leerlos como el acta notarial de lo que está siendo y pronto dejará de ser. Otros elementos del texto, en tanto que reflexiones que trascienden el presente, tienen una validez que perdura y perdurará. Cada persona que quiera invertir el tiempo necesario para recorrer este libro con su lectura tiene ante si la oportunidad de disfrutar de ambos elementos.

Termino agradeciendo a la FAS, al Gobierno de Aragón y a la Universidad de Zaragoza el apoyo prestado a esta investigación tanto en sus fases previas como en la edición de los resultados porque es una apuesta que merece la pena seguir apoyando.

Chaime Marcuello Servós Universidad de Zaragoza

Zaragoza, septiembre de 2007 


\section{AGRADECIMIENTOS}

Financiar becas de investigación es arriesgarse a invertir en la paciencia, porque la investigación no ofrece rendimientos inmediatos ni mucho menos cautiva al "gran público» o al electorado. Incluso, la investigación puede arrojar resultados inesperados o preocupantes, porque su principal motivación es la búsqueda de la verdad, una verdad que intenta anteponerse a las manipulaciones ideológicas, a los intereses políticos o económicos y, especialmente, a la frivolidad propia de una época en la que hacer y consumir no dejan tiempo para explorar y pensar.

Por esas razones, gracias a las personas e instituciones que hace algunos años creyeron en este programa de becas de investigación de cooperación al desarrollo. Deseamos que la confianza puesta en las investigaciones, y por tanto en sus autores, sirva para aportar conocimientos que mejoren el esfuerzo de quienes han optado por la solidaridad, la cooperación y el voluntariado como mecanismos para hacer del mundo un lugar menos cruel para cientos de millones de personas. A ellos, por la admiración y respeto que inspira esa opción, también va dirigido este libro.

Asimismo, gracias a las ONGD aragonesas federadas en la FAS; su disponibilidad y apertura tiene un gran mérito, especialmente cuando desde dentro se observa el elevado volumen de trabajo, la inmediatez de los plazos y la dedicación para sacar adelante campañas, subvenciones y justificaciones.

A las ONG colombianas, cuyo trabajo refleja una parte de un país al que creía conocer, y cuyas historias están muchas veces marcadas por la tragedia de algunos muertos, otros secuestrados y muchos amenazados. En especial, debo reconocer la aportación de COCOMACIA, Federación de 
ONG del Chocó, Pastoral social de la diócesis de Quibdó, Seglares Claretianas región occidental, UNICEF Colombia, Fe y Alegría, CINEP, Región, IPC, ENS, Federación Antioqueña de ONG, Confederación Colombiana de ONG, ACARPIN, Codesarrollo y Paisajoven.

Por último, deseo mencionar unos nombres que tendrán poco sentido para el lector, pero gracias a los cuales este libro tiene algún sentido. Las valiosas y sosegadas aportaciones de Nuria Espeleta, los sueños y pesadillas compartidas con Santiago Martínez y Paula Durán, la lucidez de las aportaciones de Chaime Marcuello, Milagros Vicente, Montse Reclusa (Seminario de Investigación para la Paz), Lara González y Ana M. ${ }^{a}$ Carreira (Universidad de Antioquia), Concha Martínez, José Antonio Sanahuja, el CIP y el grupo GESES de la Universidad de Zaragoza. 


\section{ABREVIACIONES}

ACCI

ACIA

ACNUR

ACPP

AECI

AFADA

AL

ALOP

AMAT

AOD

ASA

ASFADDES

AUC

AVRE

BID

BIRF

$B O C A$

$B O P Z$

$\mathrm{CAD}$

CAN

CASCOL

CCONG

CDC

CE

CEIS
Agencia Colombiana de Cooperación Internacional (recientemente ha pasado a denominarse Agencia Presidencial para la Acción Social y la Cooperación Internacional) Asociación Campesina Integral del Atrato Agencia de las Naciones Unidas para los Refugiados Asamblea de Cooperación por la Paz Agencia Española de Cooperación Internacional Asociación de Familias Adoptantes de Aragón América Latina Asociación Latinoamericana de Organizaciones de Promoción Asociación Marianista de Ayuda al Tercer Mundo ayuda oficial al desarrollo Acción Solidaria Aragonesa Asociación de Familiares de Detenidos Desaparecidos Autodefensas Unidas de Colombia Ayuda a Víctimas de Violencia Socio-Política Pro Recuperación Emocional

Banco Interamericano de Desarrollo

Banco Internacional de Reconstrucción y Fomento

Boletín Oficial de las Cortes de Aragón

Boletin Oficial de la Provincia de Zaragoza

Comité de Ayuda al Desarrollo

Comunidad Andina de Naciones

Coordinadora Aragonesa de Solidaridad con Colombia

Confederación Colombiana de ONG

Corporación para el Desarrollo de la Comunidad

Comisión Europea

Centro de Estudios e Investigaciones Sociales 


\begin{tabular}{|c|c|}
\hline CEPAL & Comisión Económica para América Latina \\
\hline CEPALC & Centro Popular para América Latina de Comunicación \\
\hline CEPECS & Centro de Promoción Ecuménica y Social \\
\hline CEPEI & Centro de Pensamiento Estratégico Internacional \\
\hline CIDEAL & Centro de Investigación y Desarrollo de América Latina \\
\hline CIDOB & Centro de Información y Documentación en Barcelona \\
\hline CIEPAC & $\begin{array}{l}\text { Centro de Investigaciones Económicas y Políticas de Acción } \\
\text { Comunitaria (México) }\end{array}$ \\
\hline CINEP & Centro de Investigación y Educación Popular \\
\hline CIP & Centro de Investigaciones para la Paz \\
\hline COCOMACIA & $\begin{array}{l}\text { Consejo Comunitario Mayor de la Asociación Campesina } \\
\text { Integral del Atrato }\end{array}$ \\
\hline CODHES & Consultoría para los Derechos Humanos y el Desplazamiento \\
\hline CONGDE & Coordinadora de ONG para el Desarrollo \\
\hline COR & Comité Óscar Romero \\
\hline CORFAS & Corporación Fondo de Apoyo de Empresas Asociativas \\
\hline CORREPI & $\begin{array}{l}\text { Coordinadora contra la Represión Policial e Institucional } \\
\text { (Argentina) }\end{array}$ \\
\hline $\mathrm{CPDH}$ & Comité Permanente por la Defensa de los Derechos Humanos \\
\hline $\mathrm{CPP}$ & Corporación para la Promoción Popular \\
\hline CRC & Conferencia de Religiosos de Colombia \\
\hline CREDHOS & $\begin{array}{l}\text { Corporación Regional para la Defensa de los Derechos Huma- } \\
\text { nos }\end{array}$ \\
\hline CRIC & Consejo Regional Indígena del Cauca \\
\hline CSOR & Comité Cristiano de Solidaridad Óscar Romero \\
\hline CSPP & Comité de Solidaridad con los Presos Políticos \\
\hline CTPD & cooperación técnica entre países en desarrollo \\
\hline CYTED & $\begin{array}{l}\text { Programa Iberoamericano de Ciencia y Tecnología para el } \\
\text { Desarrollo }\end{array}$ \\
\hline DAS & Departamento Administrativo de Seguridad \\
\hline DD. HH. & derechos humanos \\
\hline DIH & derecho internacional humanitario \\
\hline DNI & Defensas de los Niños Internacional \\
\hline DNP & Departamento Nacional de Planeación \\
\hline DPZ & Diputación Provincial de Zaragoza \\
\hline $\mathrm{ECHO}$ & Ayuda Humanitaria de la Comisión Europea \\
\hline EES & Sociedad de Evaluación Europea \\
\hline ELN & Ejército de Liberación Nacional \\
\hline EML & Enfoque del Marco Lógico \\
\hline ENS & Escuela Nacional Sindical \\
\hline EPL & Ejército Popular de Liberación \\
\hline
\end{tabular}


ERG

ERP

ESAL

FAD

FAES

FAO

FARC

FISC

FODEPAL

FUCAI

FUHEM

GAD

GESES

IAEST

IBASE

ICRAF

IDH

IECAH

IEDDH

IEPALA

IEPRI

ILSA

IPC

IRELA

ISCOD

ISMAC

JTC

MAE

MERCOSUR

MOC

OCDE

OEA

OFP

OIA

OIT

OMS

ONG
Ejército Revolucionario Guevarista

Ejército Revolucionario del Pueblo

entidades sin ánimo de lucro

Fondo de Ayuda al Desarrollo

Fundación para el Análisis y los Estudios Sociales

Organización de las Naciones Unidas para la Agricultura y la Alimentación

Fuerzas Armadas Revolucionarias de Colombia

Foro Interétnico de Solidaridad Chocó

Formación en Economía y Política Agrarias de Desarrollo

Rural en América Latina

Fundación Caminos de Identidad

Fundación Hogar del Empleado

Grupo de Apoyo a Organizaciones de Desplazados

Grupo de Estudios Sociales y Económicos del Tercer Sector

Instituto Aragonés de Estadística

Instituto Brasileiro de Análises Sociais e Econômicas

International Centre for Research in Agroforestry

índice de desarrollo humano

Instituto de Estudios sobre Conflictos y Acción Humanitaria

Iniciativa Europea para la Democracia y los Derechos Humanos

Instituto de Estudios Políticos para América Latina y África

Instituto de Estudios Políticos y Relaciones Internacionales

Instituto Latinoamericano de Servicios Legales Alternativos

Instituto Popular de Capacitación

Instituto de Relaciones Euro-Latinoamericanas

Instituto Sindical de Cooperación al Desarrollo

Instituto Sindical María Cano

Juventud Trabajadora de Colombia

Ministerio de Asuntos Exteriores de España

Mercado Común del Sur

Movimiento de Organização Comunitária

Organización para la Cooperación y el Desarrollo Económico

Organización de Estados Americanos

Organización Femenina Popular

Organización Indígena de Antioquia

Organización Internacional del Trabajo

Organización Mundial de la Salud

organización no gubernamental / organizaciones no gubernamentales 
ONGD organización no gubernamental para el desarrollo / organizaciones no gubernamentales para el desarrollo

ONIC Organización Indígena de Colombia

OSC Organización de la Sociedad Civil

OPS

Organización Panamericana de la Salud

OSPAAL Organización de Solidaridad de los Pueblos de África, Asia y América

OTAN Organización del Tratado del Atlántico Norte

OTC Oficina Técnica de Cooperación

PNUD Programa de las Naciones Unidas para el Desarrollo

PROCLADE Promoción Claretiana para el Desarrollo

PTM

Paz y Tercer Mundo

PVD/ALA países en vías de desarrollo de América Latina y Asia

SCCS

Servicio Colombiano de Comunicación Social

SECIPI

Secretaría de Estado para la Cooperación Internacional para Iberoamérica

SEGAB Secretaría Ejecutiva del Convenio Andrés Bello

SIMEP Sistema de Seguimiento y Monitoreo a Proyectos

SINALTRAINAL Sindicato Nacional de Trabajadores de la Industria de Alimentos

SIP Sociedad Interamericana de Prensa

SPG

Sistema de Preferencias Generalizadas

UE Unión Europea

UNDCP

Oficina de las Naciones Unidas contra la Droga y el Delito

UNESCO

UNFPA Organización de las Naciones Unidas para la Educación, la Ciencia y la Cultura

UNICEF

Fondo de Población de las Naciones Unidas

Fondo de las Naciones Unidas para la Infancia 


\section{PRESENTACIÓN}

Aunque este estudio lo pudiera parecer, debido a la referencia explícita de dos contextos geográficos tan concretos como Colombia y Aragón, no necesariamente puede resultar de utilidad o interés sólo a las personas que intervengan en estas dos circunscripciones administrativas. Algunos de los resultados podrían ser plenamente transferibles a otros contextos. Por un lado, buena parte de lo que denomino «organizaciones aragonesas» corresponde a delegaciones autonómicas de entidades nacionales o internacionales, lo cual significa que lo eminentemente aragonés es un artificio para la definición de una muestra estadística. Por otro lado, las contrapartes locales y los «beneficiarios» colombianos pueden compartir situaciones de exclusión, opresión o violación de sus derechos con otros grupos o poblaciones colombianas, latinoamericanas o «sureñas». Es decir, además de colombianos, los «beneficiarios» pueden ser indígenas, mujeres, negros o campesinos, y esos rasgos superan un criterio tan relativo como la nacionalidad.

El carácter crítico de algunos apartados pretende promover la reflexión en torno al trabajo que llevan a cabo los actores de la cooperación, y, en definitiva, comparte la misma finalidad que dichos actores: mejorar las condiciones en las que viven millones de personas excluidas. El trabajo solidario, altruista y desinteresado también puede analizarse y criticarse. Precisamente porque un trabajo voluntario y con alta valoración social no debe ser de menos calidad que un trabajo remunerado o con pretensiones menos nobles.

La estructura del texto consta fundamentalmente de tres grandes apartados. El primer bloque, de carácter contextual y metodológico, se ini- 
cia con las dificultades que surgieron en el transcurso de la investigación, especialmente en cuanto a la construcción de un objeto que incorpora dos referentes geográficos tan diferentes como España y Colombia. Por esta razón, se aprecia una sección sobre Colombia que va dirigida al lector que desconozca las mínimas generalidades sociales, políticas y geográficas de este país. Asimismo, se expone una breve descripción socio-histórica de dos actores armados del conflicto sin pretender reducir éste al enfrentamiento de dos partes. El apartado metodológico explica los supuestos iniciales que orientaron el curso del trabajo, las directrices que incorporó el trabajo como un estudio de caso y las fases recorridas antes, durante y después de la elaboración del trabajo de campo.

El segundo bloque es una revisión documental que enmarca algunos conceptos y teorías básicas para comprender el fenómeno de la cooperación no gubernamental al desarrollo entre España y Colombia, especialmente la que llevan a cabo unos actores de creciente protagonismo como han sido las ONGD. Posteriormente, se describe la cooperación internacional con Colombia y su relación con distintos ámbitos geográfico-administrativos: Europa, España y Aragón. En este apartado se enuncian las ONGD aragonesas que participaron en el estudio y se expone un análisis cuantitativo que mide su presencia en comunidades concretas del territorio colombiano, cuantificando el tipo de proyectos, las fuentes de financiación, las contrapartes locales y los sectores CAD comprendidos.

El último de los tres bloques es el resultado del trabajo de campo. En esta parte se analizan una serie de factores sociológicos que caracterizan los procesos de ejecución de los proyectos. Al referirnos a estos factores, priorizamos variables de carácter sociológico por encima de variables técnicas más cercanas a la ingeniería de procesos. En este capítulo se analiza, por tanto, la influencia de estos factores sociológicos en el trabajo de las organizaciones, entre los que cabe destacar: la identidad de las organizaciones, las relaciones entre los actores de la cooperación, la confianza y la reciprocidad (lo que algunos denominan capital social), las repercusiones del conflicto armado, la percepción de la cooperación y la participación de los «beneficiarios» en los proyectos de desarrollo. Como un apéndice de esta sección, incluimos unas reflexiones y propuestas sobre la evaluación de los proyectos con el propósito de poner el acento en la importancia de detenerse a evaluar el trabajo cooperante. 


\subsection{La cooperación, un objeto difuso de investigación}

Hoy, más que hace unos años, el papel de las ONG resulta fundamental en la construcción de la paz en Colombia; así como la violencia ha colonizado los espacios de la vida social, también la proliferación de organizaciones y el compromiso de muchas de ellas por construir una paz basada en la justicia y los derechos humanos son una muestra clara de esperanza para las aspiraciones de una nación que lleva casi medio siglo de conflicto. Las reiteradas cifras de los retrocesos en la consecución de la reducción de la desigualdad, el hambre y las enfermedades que acompañan informes y ponencias también deberían acompañarse de datos o estudios que resalten los esfuerzos de la gente por su emancipación y el apoyo que brindan determinados actores sociales en esa dirección. La sensibilización no debería ser sólo la identificación de las causas y consecuencias de la pobreza y la violencia, sino la relevancia de los grandes y, sobre todo, de los pequeños esfuerzos por combatirlas. Colombia proporciona una fuente de experiencias tan destacadas como desconocidas.

En Colombia, la cooperación no gubernamental al desarrollo es un tema que despierta sospechas de muchos calibres y perspectivas. Durante la realización del trabajo de campo hubo bastante apertura por parte de las entidades que decidieron participar en la investigación. Algunas en Colombia se mostraron más tranquilas cuando se les advirtió que no iba a haber preguntas sobre presupuestos para programas y proyectos, o sobre las fuentes de financiación. También se dieron algunas paradojas. Por ejemplo, los controles y protocolos previos a la concesión de citas eran inmediatos en las entidades que aparentaban mayor dificultad, y complejos en los que, por su naturaleza internacional o multilateral, parecían de acceso público.

No obstante, los principales controles para el acceso a las organizaciones se establecían sobre la base de la seguridad de la entidad y sus miembros. En Colombia muchas ONG están amenazadas por parte de algunos actores del conflicto armado, y los estrictos controles para ingresar a sus respectivas sedes alteran, aún más, las incertidumbres propias de una investigación social.

Durante el trabajo de campo, el carné de la Universidad de Zaragoza y una carta de la FAS eran la puerta de entrada a casi todas las organiza- 
ciones. Una vez realizada la inspección de la mochila, la identificación previa en recepción, la comprobación de la cita solicitada y la correspondiente requisa, se habían superado los obstáculos para iniciar la búsqueda de la información.

Por mi parte, mi posición ante la realización del trabajo de campo no era plenamente neutral, objetiva y carente de prejuicios. En los inicios, estaba presente la percepción exagerada de una realidad que, a pesar de lo que se pueda suponer, ${ }^{1}$ resultaba desconocida. Estas percepciones contaban con el ingrediente del temor obsesivo, tanto al casual ataque de la delincuencia como a una precisa estrategia de seguimiento a personas que frecuentaran los locales de determinadas ONG.

Lo real y lo imaginario se entremezclan cuando está de por medio el temor, cualquier exceso de confianza puede ser castigado por la sorpresa del ataque, pero la constante actitud de vigilancia y precaución genera una ansiedad tan desgastante física y mentalmente como a veces inútil. Sin embargo, todo aquello no era objeto de la imaginación. Dos meses después de la finalización del trabajo de campo en Chocó fueron secuestrados en ese departamento varios investigadores que se encontraban realizando un estudio en la zona. ${ }^{2}$

Asimismo, algunas de las sedes visitadas durante el trabajo ya habían sido objeto de atentados por parte de grupos armados. Recordaba con frecuencia el secuestro de un grupo de personas de la ONG Instituto Popular de Capacitación (IPC), entre los que se encontraba una investigadora en una visita académica ocasional. ${ }^{3}$ La Escuela Nacional Sindical, visitada en más de tres ocasiones, también había recibido amenazas y es, del conjun-

1 Mi nacionalidad es colombiana y he vivido en ese país 27 años.

2 El ELN secuestró en el alto Baudó a una delegación de la Universidad de Chocó. A la comisión universitaria le tocó vivir las paradojas de la guerra: «pedirle permiso a la guerrilla para que la dejara trabajar». El coordinador del estudio, una psicóloga, un comunicador y dos practicantes, todos vinculados con la Universidad, tuvieron que justificarle al comandante del bloque Cimarrón su presencia en la región antes de proseguir con su labor. El Colombiano (Medellín), 23 de noviembre de 2004. «Recuperan la libertad los cuatro investigadores secuestrados en el Chocó el fin de semana». El Tiempo (Bogotá), 22 de noviembre 2004, sección "Acciones Armadas".

3 El 28 de enero de 1999 fueron secuestrados cuatro investigadores por las Autodefensas de Córdoba y Urabá, y el 29 agosto del mismo año fueron víctimas de un atentado con explosivos contra su sede en la ciudad de Medellín. 
to de ONG y movimientos sociales, uno de los sectores más afectados por la violencia. Tan sólo durante 2003 fueron asesinados en el país 90 sindicalistas, 295 fueron víctimas de amenazas de muerte, 20 sufrieron atentados contra su integridad personal, a 6 se les hizo «desaparecer» y 6 más fueron secuestrados. ${ }^{4}$

Las dificultades de investigar también pasan por un plano metodológico que atraviesa a toda la acción social y cooperante: no se acostumbra escribir y sistematizar la práctica. Parece que escribir no es hacer, que investigar es una tarea menos urgente que conseguir recursos y adelantar proyectos. Si se escribieran tantos informes, reflexiones o estudios como borradores de proyectos para pedir una ayuda o financiar un programa, estaríamos sobre-diagnosticados y saturados de conocer los resultados del trabajo cooperante. Sin embargo, en los últimos años viene ocurriendo una interacción interesante entre académicos que pertenecen a organizaciones no gubernamentales y activistas que reflexionan e investigan sobre las acciones de cooperación; esta tendencia se puede apreciar en revistas internacionales (Develoment in Practice, por ejemplo), nacionales (Revista Española de Desarrollo y Cooperación) y en las publicaciones como los Cuadernos de Cooperación de Intermón-Oxfam. En otros casos puede haber rivalidad, ya que, tal como refleja Slim, ${ }^{5}$ "el mundo académico está prestando más atención a los efectos negativos» del trabajo de las ONG.

Otra dificultad también se puede comprobar en la movilidad de los objetos de estudio de las ciencias sociales: mientras realizaba el trabajo de campo, solicitaron su ingreso en la FAS cuatro organizaciones, de las cuales dos (Asamblea de Cooperación por la Paz y la Fundación Juan Bonal) habían realizado proyectos en Colombia, ante lo cual cambiaba la población y, por tanto, la muestra y algunos de los resultados obtenidos. De igual manera, poco tiempo antes de entregar el informe final del estudio, la Agencia Colombiana de Cooperación Internacional fue reformada completamente durante el primer Gobierno de Uribe Vélez (2002-2006) y pasó a denominarse Agencia Presidencial para la Acción Social y la Cooperación Internacional.

4 «Resumen ejecutivo sobre la violación a los derechos humanos de los sindicalistas colombianos en el año 2003» (ENS, 2004).

5 Citado por Roche $(2004,206)$. 
El trabajo de campo en España ha permitido identificar los grupos humanos con los que intervienen las ONGD aragonesas; no obstante, en dicho trabajo con las comunidades colombianas, resultaba prácticamente imposible que hicieran una referencia exclusiva a la cooperación aragonesa; a lo sumo, se referían a España, cuando no a Europa. La dificultad para esta diferenciación se basaba en la cantidad y pluralidad de contrapartes del «Norte» y en la especificidad geográfica y administrativa que integran los bloques «emisor»y «receptor» de la cooperación. La generalización de las expresiones «Norte» y «Sur» nos evita la complicada tarea de hacer minuciosas referencias a federaciones autonómicas, ayuntamientos, organizaciones comarcales, comunidades rurales, etc., pero también es una trampa para la descripción detallada, en este caso, de los objetos de estudio.

Este desconocimiento puede llegar a producirnos desánimo, no sólo a quien investiga sino también a quien coopera. Los valiosos esfuerzos realizados desde una zona específica (barrio, municipio o región) pueden resultar muy ingratos si se espera reconocimiento. El desconocimiento de los ámbitos geográficos desde los cuales se originan proyectos no es un hecho esporádico, y pedir a las «comunidades» que diferencien, por ejemplo, a Andalucía de Aragón es una exigencia tan cómoda como imposible. Cuando nos referimos al «Tercer Mundo» y al «Primer Mundo» hacemos una generalización operativa pero injusta, especialmente con la heterogeneidad y especificidad de los pueblos. Durante el trabajo de campo algunos entrevistados enunciaron algunas expresiones, muchas veces inconscientes, que ratificaban esta exigente solicitud: «Ecofondo recibe ayudas de Holanda, de España y de todo eso» (EC-01). En otros casos, cuando han existido fuertes vinculaciones a través del tiempo y de las personas, el conocimiento de los ámbitos geográficos de los socios puede resultar factible: «En ese pueblo [Gilgal] saben dónde está Zaragoza y Aragón, porque es una relación de 20 años» (EE-03). Asimismo, representantes de las entidades aragonesas que no habían estado o desconocían la trayectoria de la presencia en Colombia tenían algunas dificultades para hablar del país. En ocasiones se referían a "Latinoamérica» o «Sudamérica», en lugar de Colombia. Un caso similar ocurrió hace unos años con un estudio realizado por la cooperación holandesa que pretendía medir el impacto de 27 años de cooperación con Bolivia. En este estudio los evaluadores hallaron con sorpresa que «los pobladores conocían los diferentes proyectos, pero a veces los confundían. [...] Tenían la tendencia a identificar las organiza- 
ciones implementadoras con su personal de campo" (Ministerio de Asuntos Exteriores de los Países Bajos, 1997, 59).

Un anhelo bastante frecuente que encierra dificultades y muchas contradicciones, que asumí ingenuamente, fue querer que "hablaran las comunidades». Este arduo esfuerzo de procurar «dar voz a los sin voz» no puede ser asumido por las ciencias sociales sin más; es, en todo caso, un propósito de los actores sociales de la solidaridad y la cooperación. Aun así, organismos tan criticados por las ONG como el Banco Mundial tienen un conjunto de publicaciones, noticias y estudios denominado Voices of the Poor (Las voces de los pobres). ${ }^{6}$ Por tanto, puede resultar impactante, atractivo, incluso sencillo, propugnar por un conjunto de esfuerzos que "den la voz» a los que no la tienen, pero el reto factible es demostrar que ha sido posible esa noble pretensión. Una de las posibilidades de asumir semejante compromiso podría alcanzarse, desde las ciencias sociales, en manos de enfoques socio-críticos tales como la IAP (Investigación Acción Participación). ${ }^{7}$ Sin embargo, ésa no ha sido la vía metodológica elegida para esta investigación. Esta dificultad epistemológica está sustentada en varios autores y estudios, de los cuales destaco el análisis de las ONG y los movimientos indígenas en los Andes ecuatorianos, a través del cual el antropólogo Víctor Bretón (2001) observaba que muchos canales de representación de las comunidades terminaban siendo formas ventrílocuas de representación.

Los pocos estudios sobre la cooperación al desarrollo en Colombia lamentan en sus preámbulos no emprender ni fomentar investigaciones que den cuenta del trabajo realizado. En 1991 se llevó a cabo en Colombia uno de los primeros estudios que recogía «el origen, el desarrollo en el tiempo y las tendencias de las tres grandes ramas de la Cooperación: Multilateral, Bilateral y de Organizaciones No Gubernamentales» (Henao, 1991). Sin embargo, tal como lo afirma Juanita Henao (1991, 23-25), el estudio no obtuvo los resultados esperados debido a que «las ONG del Norte [...] se resistieron a responder el cuestionario». De un total de 120 Organizaciones de Ayuda al Desarrollo encuestadas, sólo se obtuvo infor-

6 The World Bank (2002), Voices of the Poor. From Many Lands, Washington, Oxford University Press and the World Bank.

7 Al menos, eso creen sociólogos como Fals Borda (1986) cuando afirma que el pueblo usurpa la ciencia a las elites científicas y la hace suya. 
mación de 16. Aunque la autora no profundiza ni formula hipótesis sobre las posibles causas, quizás dicho comportamiento se explique, de alguna manera, por el giro respecto al tipo de relación sostenida entre las partes. El binomio sujeto-objeto de investigación/intervención se había alternado, es decir, una ONG colombiana investigaba a las ONGD y agencias del «Norte».

Henao (1991) empezaba a advertir un fenómeno que aún persiste en la cooperación, esto es, la descoordinación entre los organismos que intervienen en un sector de la población:

Esta reticencia de las agencias a suministrar datos que puedan contribuir a una mayor comprensión de la totalidad de la acción de todos a una causa común pone en evidencia uno de los problemas delicados de la cooperación internacional: la compartimentación y la prevención que mantenemos tanto agencias como organizaciones y gobiernos para colectivizar información que necesitamos todos (Henao, 1991, 10).

Otro de los estudios relevantes que profundiza en el origen y trayectoria de las ONG en Colombia es el realizado por la Fundación Social ${ }^{8}$ en 1992, que recoge los resultados de 1476 encuestas al mismo número de entidades. Este estudio reconoce la dificultad de producir investigaciones sobre el fenómeno de las ONG:

A tono con la preocupación mundial que existe por conocer aspectos de estas organizaciones, en Latinoamérica su notable crecimiento también ha despertado en algunos investigadores el interés por estudiar el fenómeno [...]. En esta dirección, los mayores desarrollos se han producido en Chile, Brasil y Perú. En Colombia, la investigación en este campo es muy exigua. Los pocos estudios que se han realizado en el país se han propuesto construir definiciones, elaborar tipologías, identificar los campos de acción y las formas de autogestión administrativa de estas organizaciones (Vargas y otros, 1992, 19).

No obstante, la diversidad y ambigüedad del término también es un serio obstáculo metodológico. Sus áreas de acción, su imprecisión jurídica y su alto grado de atomización y dispersión las constituyen en un objeto de estudio bastante difuso (Vargas y otros, 1992).

8 La Fundación Social es una entidad fundada en Colombia por los jesuitas en 1911. Actualmente es el accionista mayoritario del Banco Colmena y del Banco Caja Social (aliado de La Caixa para el envío de giros de España a Colombia); también posee acciones en constructoras y otras entidades financieras más pequeñas. 
Sin duda, entre los factores que obstaculizan la realización de esfuerzos en la línea de investigar el surgimiento y evolución institucional de las ONG está «la falta de sistematización de experiencias y la escasez de fuentes primarias y secundarias, así como inexistencia de estadísticas que den cuenta sobre la conformación y los cambios operados en el fenómeno en su evolución histórica» (Vargas y otros, 1992, 31). En los últimos años se ha incrementado el número de estudios en este campo en universidades y centros de investigación especializados en Colombia. ${ }^{9}$ En España, en cambio, la producción sociológica, económica, política y antropológica sobre la cooperación al desarrollo y las ONG ha sido abundante desde 1995.

\subsection{Colombia: un país difícil de explicar}

Desde la sociología es difícil acercarse a cualquier sociedad, pueblo o país, y aún más si se trata del propio. ${ }^{10}$ Por ejemplo, la literatura sobre el conflicto armado en Colombia es abundante y variada. La Biblioteca de la Universidad Complutense de Madrid cuenta con más de doscientas publicaciones impresas sobre el conflicto en Colombia. Algo similar ocurre con entidades especializadas como el Centro de Investigación para la Paz, que tienen un volumen de fondos importante sobre Colombia. Tan sólo el Seminario de Investigación para la Paz de Zaragoza cuenta con casi un centenar de libros sobre la crisis colombiana. La producción de información sobre el conflicto colombiano en Internet es abundante, ${ }^{11}$ y en más de cincuenta años de conflicto, las universidades y centros de investigación nacionales e internacionales han estudiado el fenómeno desde muchos puntos de vista.

9 En 2004 el CEPEI presentó el informe Diagnóstico de la Cooperación Internacional en Colombia. Otras instituciones que estudian la materia son CINEP, Fescol y las universidades de los Andes, Externado, Javeriana y Nacional.

10 El conjunto de sensaciones, emociones y percepciones que despierta el Estado al que se pertenece puede resultar un elemento adicional para hacer más compleja la observación. Sin embargo, la distancia temporal y geográfica ha permitido depurar la exaltación propia del desarraigo y aplacar los fervores o rencores albergados.

11 Un ejemplo curioso puede ilustrarse a través de la información en Internet. El buscador Google reporta casi un millón de resultados con la clave «conflicto armado en Colombia» y 2010000 con la clave "guerra en Colombia». Ni la búsqueda bajo la clave "guerra en Irak» llega a 1800000 resultados. La clave "war and Colombia» cuadriplica su equivalente en castellano, con más de 9000000 de resultados (enero de 2007). 
CUADRO 1.1

COLOMBIA SEGÚN LA CONSTITUCIÓN POLÍTICA

Título I.

De los principios fundamentales

Artículo $1 .^{\circ}$ Colombia es un Estado social de derecho, organizado en forma de República unitaria, descentralizada, con autonomía de sus entidades territoriales, democrática, participativa y pluralista, fundada en el respeto de la dignidad humana, en el trabajo y la solidaridad de las personas que la integran y en la prevalencia del interés general (Ministerio del Interior de la República de Colombia, 1991, 2).

Esta dificultad en el tratamiento académico se extiende al plano de las observaciones empíricas, pues un país entero es una unidad de análisis bastante amplia que encierra diversidades internas que se unifican temporalmente con la finalidad metodológica de constituir un objeto de estudio que pueda ser operativo.

En cuanto a su definición constitucional, Colombia es un «Estado social de derecho» (ver cuadro 1.1), pero la constatación práctica de ese concepto deja muchas sombras y dudas, como se observará en el presente estudio.

En estas breves líneas sólo se ponen de manifiesto algunos aspectos relevantes para advertir al lector unos cuantos puntos que condicionan el acercamiento a la realidad colombiana.

A pesar de que la división administrativa del país se realiza por departamentos y municipios (44 millones de habitantes distribuidos en más de 1000 municipios y agrupados en 32 departamentos), el territorio nacional comprende cinco regiones naturales y culturales bien diferenciadas. Las regiones comprendidas en este estudio han sido una minúscula muestra de la costa Pacífica y de la región andina. En cuanto a los departamentos, el trabajo de campo incluyó a Chocó, que es parte de la costa Pacífica, y a Antioquia dentro de la región andina (ver mapa 1.1). Santa Fe de Bogotá fue incluida como distrito capital, lo cual le confiere un estatus privilegiado que, para algunos efectos, se equipara al de un departamento. ${ }^{12}$ El tra-

12 Bogotá es la capital del departamento de Cundinamarca; no obstante, para este trabajo, se constituye como unidad de análisis independiente de la pertenencia a un departamento. 
MAPA 1.1

IDENTIFICACIÓN DE LOS DEPARTAMENTOS COLOMBIANOS

EN LOS QUE SE REALIZÓ EL TRABAJO DE CAMPO

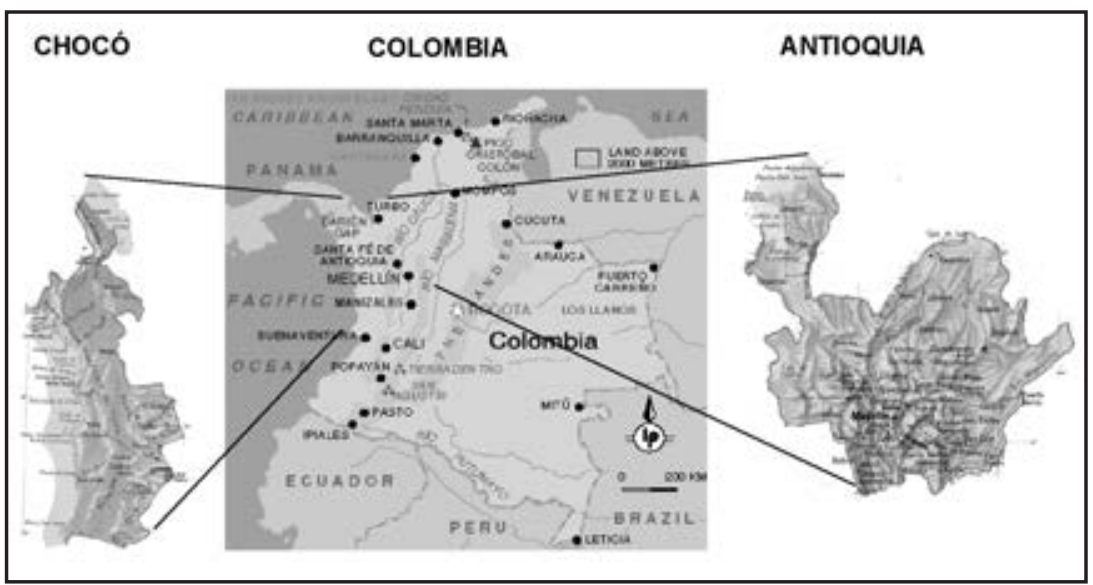

FUENTE: Elaboración propia a partir de <www.web.net/icchrla/Colombia.htm> (junio de 2005).

bajo de campo en Bogotá consistió en identificar entidades públicas y privadas que tienen su sede en la capital del país; en este sentido, en lugar de identificar las necesidades propias de esta ciudad o su departamento, sirvió como espacio estratégico para la búsqueda de la información. Bogotá, como capital del país, es lugar de referencia para identificar organismos internacionales con presencia en Colombia (UNICEF, Fe y Alegría), organismos nacionales que tienen su base en esta ciudad (CINEP, CCONG, CODHES...) y entidades públicas (Ministerio de Relaciones Exteriores y Agencia Colombiana de Cooperación Internacional, ACCI).

\section{Departamento del Chocó}

Departamento localizado en la costa del océano Pacífico, limita por el norte con Panamá y el mar Caribe y al oriente con Antioquia, tiene una población que sobrepasa los 500000 habitantes ${ }^{13}$ y su capital es Quibdó.

13 Información obtenida de la pagina oficial del Departamento Administrativo Nacional de Estadística, DANE. <www.dane.gov.co> (9 de octubre de 2005). 
La población negra es el $80 \%$ del departamento, el $9 \%$ es indígena y el resto mestiza. En el departamento se encuentran 82 resguardos indígenas, 6 de los cuales comparte con el departamento del Valle del Cauca; entre sus familias indígenas sobresalen la embera, waunana y kuna, con una población de 21416 indígenas, que corresponde al 5,8\% de la población y ocupa el $24 \%$ del área departamental. ${ }^{14} \mathrm{El}$ analfabetismo afecta al $43 \%$ de la población rural, la cobertura de la educación primaria es del $60 \%$ y el ingreso a la universidad del 2\%. El $80 \%$ vive en extrema pobreza. El ingreso per cápita es 3 veces inferior al promedio nacional. Dentro de los 1000 municipios de Colombia, ordenados por grado de incidencia de pobreza, siete son municipios chocoanos, con el porcentaje más alto de necesidades básicas insatisfechas del país. En términos de morbi-mortalidad, la población está gravemente afectada por el pobre saneamiento ambiental. Las muertes están relacionadas con la carencia de alcantarillados, la deficiente disposición de basura y la calidad del agua para uso humano. Los ríos del Chocó son acueductos, alcantarillados, vertederos de sedimentos de la explotación minera y maderera, algunos de alta toxicidad, como el mercurio, bañaderos y vías. La esperanza de vida es un $20 \%$ inferior a la del promedio nacional. ${ }^{15}$

Paradójicamente, es una de las regiones más ricas del mundo en recursos maderables y minerales, entre los cuales se destacan el oro y el platino. Es la segunda región más lluviosa del planeta y tiene el punto más húmedo del globo. Se encuentra, además, la mayor concentración de aves endémicas del mundo y una extraordinaria diversidad de especies de anfibios y de mariposas.

\section{Departamento de Antioquia}

Este departamento limita al occidente con Chocó y al norte con el mar Caribe y el departamento de Córdoba, su capital es Medellín y tiene una población de 5530000 habitantes (ib., DANE). La mayor parte de su población es mestiza, aunque también hay grupos indígenas y afroameri-

14 <http://www.memo.com.co/fenonino/aprenda/geografia/choco.html> (2 de noviembre de 2005).

15 <http://www.derechoshumanos.gov.co/observatorio/04_publicaciones/04_01_ boletines/04_boletin_22/cifra22.htm> (2 de noviembre de 2005). 
canos en zonas como Urabá. Ocupa el 5. lugar en el índice de desarrollo humano de los departamentos colombianos, tiene una tasa de homicidios superior a la media debido principalmente a la violencia en la capital del departamento. ${ }^{16}$ En indicadores sociales destacan los municipios del área metropolitana del valle de Aburrá que han crecido alrededor de Medellín, de los cuales hay tres que están entre los municipios colombianos con mayor cobertura de NBI (necesidades básicas insatisfechas). No obstante, hay quienes afirman (Santos Gómez, 2005) que hay dos Antioquias, la urbana, con un $30 \%$ de pobreza y la rural, con el $78 \%$. Es el más desigual de todos los departamentos: «si se analiza la diferencia entre municipios que cubren las necesidad básicas de sus habitantes y aquellos que tienen más dificultades para hacerlo, Antioquia se convierte en el departamento más inequitativo de Colombia» (Santos Gómez, 2005).

\subsubsection{Dos de los múltiples actores del conflicto: «la guerrilla»y "los paramilitares» ${ }^{17}$}

El presente apartado pretende dedicar unas líneas que describan, de forma muy general, las principales características de estos actores armados sin que, en ningún caso, se suponga que el conflicto colombiano es el enfrentamiento bélico de dos partes claramente diferenciadas. Por supuesto, son más los actores de un conflicto tan viejo y estructural como el colombiano, pero las constantes referencias en el texto a "la guerrilla» y "los paramilitares» me han empujado a establecer una conceptualización mínima que precise las referencias a estos grupos. En algunos apartados del texto se utiliza la expresión «actores armados», en los que también se incluyen las Fuerzas Militares de Colombia, que, a pesar de su legalidad, han cometido reiterados atropellos contra la población civil y violaciones de los derechos humanos.

Quienes más han sufrido las consecuencias del conflicto armado han sido los ciudadanos más vulnerables, aquellos que se encuentran en medio

16 <http://www.memo.com.co/fenonino/aprenda/geografia/antioquia.html> (2 de noviembre de 2005).

17 Para evitar confusiones terminológicas que evidencian las múltiples lecturas sobre el conflicto, he optado por recoger la definición de los actores que ofrece el informe del PNUD (2003, 28-29) elaborado por un grupo de investigadores colombianos dirigido por Fernán González (historiador) y Marco Palacios (ex rector de la Universidad Nacional de Colombia). 
de un fuego cruzado, que no tienen posibilidades de contratar seguridad privada ni usar escolta. La población civil no ha sido víctima "colateral», como se suele denominar a los asesinatos fortuitos de personal no uniformado. Todo lo contrario: buena parte de la guerra librada en Colombia ha tenido como blanco estratégico a decenas de miles de ciudadanos, campesinos, activistas, líderes o familiares que, previa estigmatización como «auxiliador» o "colaborador» del bando contrario, ha recibido todo tipo de acciones vulneradoras de los derechos fundamentales.

\section{1) Las Fuerzas Armadas Revolucionarias de Colombia- Ejército del Pueblo, FARC-EP (o FARC)}

Es la principal guerrilla del país, ya que su margen de acción logra cubrir buena parte del territorio nacional (ver anexo 1). Fue resultado de la convergencia entre tendencias. Por una parte, la guerrilla campesina que no logró desmovilizar el Frente Nacional y las limitaciones sobre el Partido Comunista (PC) para encontrar su espacio en el sistema político. El proceso, en resumen, recorrió cinco momentos (PNUD, 2003, 28-29):

a) Las luchas agrarias. Los sindicatos y ligas campesinas que desde los años veinte venían actuando en regiones de Cundinamarca y Tolima se acercan al PC (creado en 1930) y se radicalizan en algunos sitios.

b) Las autodefensas. Al estallar la Violencia, aquellos movimientos campesinos crearon grupos armados que oscilan entre liberalismo y comunismo, y entre la defensa territorial estricta y ciertas incursiones de guerrilla móvil.

c) La guerrilla. En 1955 el ataque masivo del ejército en Villarica (Tolima) causó el desplazamiento de colonos armados hacia Marquetalia, Riochiquito, El Pato, Guayabero, el Duda y el Ariari, donde crean las llamadas "repúblicas independientes» bajo influencia del PC. Aunque su «comunismo» fue más una forma de organizar la vida diaria, esta palabra, en pleno auge de la guerra fría, disparó las alarmas y escaló la respuesta militar.

d) La radicalización de la guerrilla. Con la violenta ocupación militar de Marquetalia (1964) y otras «repúblicas independientes», la autodefensa acabó de convertirse en un ejército revolucionario: ese mismo año se constituye «el Bloque sur», que en 1966 
será rebautizado como FARC, bajo el anuncio de iniciar «una guerra prolongada por el poder».

e) La radicalización de la izquierda. Mientras las FARC se iban gestando en la periferia, el PC iba siendo excluido del sistema político. Tras apoyar la Revolución en Marcha y participar en los movimientos campesino y sindical de los años treinta y los cuarenta, el PC fue reprimido bajo la Violencia e ilegalizado a partir de 1954. El Frente Nacional prohibió la participación electoral y el acceso a cargos públicos de terceros partidos, de suerte que muchos cuadros urbanos del PC ingresaron a las FARC. La nueva visión política cuajó en la VII Conferencia (1982) cuando las FARC se declaran «Ejército Popular» al servicio de la revolución socialista: un proyecto de conquistar el centro del poder político que, sin embargo, actúa desde la periferia.

\section{2) Otras guerrillas}

Aunque las guerrillas distintas de las FARC son de origen más urbano, sólo han logrado mantenerse o prosperar en zonas rurales (PNUD, 2003). Más aún, el origen urbano no significa que provengan del «centro» del sistema político sino, típicamente, de fracciones de izquierda sin mayor arraigo electoral o social. El grado y modos de "campesinización» varían de una a otra organización guerrillera, de suerte que aquí nos limitaremos a una relación muy abreviada.

El Ejército de Liberación Nacional (ELN) no nace como autodefensa campesina, sino como una guerrilla decididamente revolucionaria. En 1964, inspirados en Cuba y en las teorías del Che Guevara, un grupo de activistas procedente del PC, de la izquierda liberal, de la teología de liberación y del sindicalismo crea un "foco» guerrillero en zona rural de Santander. Pese a pugnas internas y ejecuciones sumarias, el foco logra asentarse, penetrar la lucha obrera (en petróleo sobre todo) y tener un momento de brillo con el ingreso del padre Camilo Torres (1965).

Pero el ELN no prosperó en las ciudades (PNUD, 2003). En parte por doctrina, en parte por caudillismo y rencillas internas, en parte porque el Estado desbarata sus redes, en parte por reveses militares, esta guerrilla siguió siendo campesina. Y la tendencia se acentúa desde la segunda mitad de los setenta, cuando la presión militar y las necesidades de finan- 
ciación concentran al ELN en las zonas de bonanza (petróleo del Magdalena medio, norte de Santander, Arauca y Casanare; banano de Urabá; oro del oriente antioqueño y el sur de Bolívar).

El Ejército Popular de Liberación (EPL), que fue importante en su tiempo, nació cuando el pleno del Partido Comunista Marxista-Leninista ordenó el traslado de los cuadros directivos al campo. Creado en 1967 y desmovilizado en 1991, el EPL de línea china logró penetrar el movimiento campesino y tuvo presencia significativa en regiones de Córdoba y Urabá.

Tampoco, por supuesto, han logrado acceder al centro los pequeños grupos que aún operan en Colombia: el Ejército Revolucionario del Pueblo (ERP), el Ejército Revolucionario Guevarista (ERG) y el remanente del EPL.

El contraejemplo de guerrilla no marginal fue, por supuesto, el Movimiento 19 de Abril (M-19). Tanto es así que, mientras que las FARC o el ELN jamás han registrado más de 2 o 3 puntos en los sondeos de aceptación social, el M-19 llegó a tener $15 \%$ de favorabilidad en las encuestas (PNUD, 2003, 28-29). En su origen, fue más urbano que el ELN. En 1970, a raíz de la dudosa derrota electoral del general Rojas, cuadros de la izquierda tradicional se sumaron a activistas de la Anapo - el movimiento populista/nacionalista del general — para «recuperar el poder» por las armas. Más que en acciones militares, el M-19 se especializó en golpes de opinión, que le fueron ganando cierta imagen de Robin Hood. Pero la guerrilla urbana difícilmente podía prosperar en Colombia, dado el control policial sobre las ciudades. El M-19 opta entonces por la guerra rural, e inicia operaciones en el sur. El proyecto militar del M-19 no cuaja, primero por los golpes del ejército; segundo, porque choca con el poderoso cartel de Medellín; y, tercero, porque los dirigentes perciben que tienen apoyo de la opinión y una excelente oportunidad política siempre que renuncien a la violencia. Y así, el M-19 se desmoviliza en 1990. En las elecciones siguientes, para la Asamblea Constituyente, su lista obtuvo el primer lugar, con $27 \%$ de los votos; pero para entonces el movimiento ya había desaparecido como guerrilla.

\section{3) Los paramilitares}

Los irregulares en lucha contra la guerrilla prefieren llamarse «autodefensas», mientras que en el lenguaje ordinario es más común llamarlos 
«paramilitares» ("paras»). Estos dos términos difieren en que el primero apunta a un fenómeno espontáneo de autoprotección ciudadana ante la ausencia de Estado, mientras que el segundo sugiere un cuerpo de combate paralelo a la Fuerzas Militares y en algún grado de connivencia con agentes del Estado. ${ }^{18}$ En la realidad colombiana se han dado mezclas de ambos fenómenos, y en este trabajo se hace referencia a los dos términos como sinónimos.

Los antecedentes del paramilitarismo se remontan al siglo XIX y, en tiempos más recientes, a la "ley del llano», a los "chulavitas» y "pájaros» de mediados del siglo XX, o a las autodefensas que, en la estrategia contrainsurgente de la guerra fría, tuvieron existencia legal y debatida a partir de 1965. Pero a comienzos de los ochenta surge un paramilitarismo diferente, pues no es «autodefensa» ni tampoco "estatal», sino extensión de los ejércitos privados que necesariamente tienen las industrias ilegales (narcotráfico y comercio de esmeraldas). Tras comprar grandes extensiones de tierra, aquellos «empresarios de la coacción» se empeñan en «limpiar de guerrilleros» el Magdalena medio, y su ejemplo es seguido por propietarios de Córdoba, Urabá y la Orinoquia. A partir de sus orígenes locales, algunos de estos grupos confluyeron - $-\mathrm{y}$ así lo indica el nombre- en las Autodefensas Unidas de Colombia (AUC). Pero se trata, en el mejor de los casos, de un proyecto nacional en construcción, de abajo hacia arriba, y sujeto a intensas tensiones internas. En otras palabras, aunque hayan adoptado un «discurso político» de alcance nacional, las autodefensas son respuestas locales a la guerrilla y, al igual que ella, pertenecen al mundo rural y se han expandido por el territorio nacional (ver anexo 2).

18 Una de las principales polémicas en Colombia durante los últimos años tiene que ver con la relación entre el Estado y los paramilitares. Desde organismos internacionales como la UE y la ONU hasta las ONG, son muchas y diversas las instituciones que denuncian dicha vinculación. Por ejemplo, la UE «exhorta al Gobierno colombiano a relevar de sus cargos al personal militar cuando se "sospeche" de vínculos con los grupos paramilitares», El Tiempo, 12 de abril de 2005. En el caso de las ONG, son muchas las que denuncian públicamente diversos grados de vinculación entre los paramilitares y el Estado (Codhes, Nizkor, Human Rights Watch, Cascol...). Por ejemplo, en un informe de Amnistía Internacional se señala lo siguiente: «Las fuerzas armadas y sus aliados paramilitares con frecuencia consideran a los miembros de comunidades desplazadas como simpatizantes o colaboradores de la guerrilla» (Amnistía Internacional, 2001, 2). 



\section{METODOLOGÍA}

Respecto al enfoque metodológico hay que decir que no sólo consiste en el conjunto de técnicas utilizadas para recoger y analizar la información; fundamentalmente, es la perspectiva desde la que se observa el objeto de investigación.

Por tanto, la propuesta de enfoque para el análisis incluirá una perspectiva que incorpore las interrelaciones de los actores de la cooperación y su expresión operativa a través de los proyectos. En este orden de ideas, el trabajo no se limitará a las teorías de los clásicos de la dependencia como Prebisch (1962), Cardoso (1977) y Furtado (1979), sino que también asumirá la posibilidad de una interrelación híbrida (García Canclini, 1989), en la que intervienen fuerzas contra-hegemónicas (Santos, 2003) por parte de organizaciones complejas (Morin, 1988 y 1990).

Aunque no se trata de un estudio comparativo, en ocasiones se hacen referencias a las diferencias y semejanzas entre el contexto español y colombiano. Dichas comparaciones pueden servir para descubrir procedimientos distintos para realizar acciones similares, y viceversa.

Asimismo, la reflexión cualitativa ocupa más líneas que la descripción cuantitativa, especialmente en el apartado relativo al trabajo de campo. El análisis de las interrelaciones entre los actores de la cooperación, los procesos de ejecución de los proyectos o las dificultades de la cooperación en medio del conflicto pueden aportar más que la exposición de cifras, montos y datos, que tienen una vigencia más corta en el tiempo. No obstante, recurro a ellas ocasionalmente, aunque quizá menos de lo que podría esperar el lector. Desde mi perspectiva, una frase de un entrevistado puede develar el sentido latente de sus acciones o 
intenciones, y en estos casos el trabajo resalta o ahonda unos aspectos más que otros.

\subsection{Hipótesis o supuestos ${ }^{19}$ iniciales}

En la experiencia previa sobre el tema, creía en una relación de poder de dos partes claramente diferenciables. Consideraba que, a diferentes niveles geográficos, existía una relación de dominación desde el Norte hacia el Sur, de las agencias internacionales sobre las agencias y organismos nacionales de los países pobres. Y por extensión, las ONGD del Norte se imponía a las del Sur, y así sucesivamente; es decir, estas últimas ejercían poder sobre la "gente». No obstante, y con el propósito de aspirar a la honestidad investigativa, ${ }^{20}$ pongo en evidencia ante el lector que los supuestos correspondían a prejuicios fundados sobre cierta tradición sociológica; ${ }^{21}$ luego, el transcurso de la investigación, especialmente el trabajo de campo, me ha corregido.

El punto de partida se establecía en las relaciones de poder existente entre los actores implicados en la cooperación; sin embargo, las interrelaciones inmersas en este ámbito son bastante complejas. En el trabajo de campo descubrí que hay múltiples canales de influencia entre un abanico de actores, en ocasiones difusos. Las orientaciones de influencia fluctúan de tal manera que resulta inapreciable una relación de poder unidireccional, y la aparente preeminencia de posturas sumisas y obedientes se contrarrestaba con una irreverencia disimulada ante los formularios de evaluación, los cuestionarios y las auditorías. La gente, a su modo, también

19 Sandoval (1998) sugiere que los enfoques cualitativos de investigación no parten de hipótesis que deben ser verificadas o refutadas empíricamente, sino que existen supuestos previos que orientan los primeros pasos de la investigación. Taylor y Bogdan (1987, 173) también sostienen que «el investigador comienza el estudio con un mínimo de supuestos».

20 Taylor y Bogdan $(1987,174)$ sostienen que «el mejor control de las parcialidades del investigador sea la autorreflexión crítica».

21 En esta línea, seguía, por ejemplo, la teoría de Lewis Coser (teórico del conflicto), por la cual «el conflicto sobreviene cuando diversos grupos e individuos frustrados se esfuerzan por aumentar su parte de gratificación. Sus demandas encontrarán resistencia en aquellos que establecieron previamente un interés creado en una forma dada de distribución de honor, riquezas y poder» (Coser, 1970, 35). 
ejerce un tipo de presión o influencia ante las ONGD locales, y éstas, a la vez, tienen capacidad para intervenir en decisiones de las organizaciones del Norte, etc.

Por tanto, en lugar de formas simples de dominación (duales), existen formas complejas de dominación. Para el francés E. Morin (1990), diferenciar unas partes que luchan por su gratificación no tiene sentido, ya que hablar de un todo compuesto por partes es una visión simplificada; en cambio, "la visión compleja dice: no solamente la parte está en el todo; ¡el todo está en el interior de la parte que está en el interior del todo!» (Morin, 1990, 125). En este orden de ideas, no hay relaciones de causalidad entre las partes, como si se tratase de un modelo de piezas mecánicas de relaciones unidireccionales; por el contrario, predomina la múltiple influencia con diversos grados de poder. El efecto de una acción inicial puede retroactuar para estimular o incidir sobre la intencionalidad de la acción inicial (causalidad circular retroactiva), esto es, «el producto es productor de aquello que lo produce» (causalidad recursiva) (Morin, 1990, 123).

De este modo, es pertinente situar los enfoques metodológicos de algunos pensadores cercanos al postestructuralismo. Por una parte, Maffesoli reclama unas ciencias sociales dispuestas a afrontar los temas y posturas que habitualmente ha evitado, unas ciencias capaces de "comprender el crecimiento específico y la vitalidad propia de cada cosa»; demanda un saber

que esté lo más cerca posible de su objeto. Un saber capaz de integrar el caos, o al menos de concederle el lugar que le corresponde. Un saber que sepa, por muy paradójico que pueda parecer, trazar la topografía de la incertidumbre y del azar, del desorden y de la efervescencia, de lo trágico y de lo no racional, de todas las cosas incontrolables, imprevisibles pero no por ello menos humanas (Maffesoli, 1997, 13).

Esta sociología hace una lectura compleja que se libera del temor a la supremacía del desorden. Generalmente, los sociólogos hemos pensado clasificando y actuado jerarquizando; sin embargo, la línea argumental de este apartado desconoce, como sí lo hace la postura marxista, dos partes claramente identificables en una relación jerárquica. La interrelación dual del conflicto se volatiliza, de tal modo que no son fácilmente identificables. Las figuras que forman fluctúan en una serie de tensiones inesperadas e irregulares. 
Morin (1990) es consciente de la escasa atención de las ciencias sociales a modelos teóricos que adquieran una mirada compleja, y propone evitar la huida ante lo que podamos concebir como "desorganizado"; de hecho, sostiene que

el antagonismo, más allá de ciertos umbrales y procesos, se convierte en desorganización; pero incluso convertido en desorganización, puede constituir la condición para las reorganizaciones transformadoras. La anulación parcial o total de las capacidades para actuar ante el conflicto es una de sus inmediatas consecuencias. Sin embargo, todo lo importante sucede de forma inesperada: continuamos actuando como si nada inesperado debiera suceder nunca (Morin, 1990, 117).

Por lo general, los seres humanos establecemos rituales y hábitos suponiendo que las condiciones en las que debemos vivir estarán exentas de situaciones metaestables. Aun infiriendo la inevitabilidad de la omnipresencia del conflicto, diseñamos formas de vida que desconocen el advenimiento de ellos.

Una postura compleja rehúye la aceptación del orden como estado «natural» de la sociedad; dicha naturalización es una construcción social de aceptación y suficiente información de lo que podríamos llamar una fase de caos institucionalizado. Podríamos afirmar, siguiendo a Bauman (1996), que dicha naturalización del caos corresponde a las demandas propias de la claridad cognitiva. Es esa necesidad de claridad la que nos lleva a operar con modelos basados en tipos de situaciones previsibles de suficiente información (orden) como el estado propio de la condición humana. Por tanto, lo compleja que nos pueda parecer la situación social de un país como Colombia se basa en el desconocimiento que tenemos los observadores frente a esta sociedad. Casi por unanimidad, los entrevistados consultados atribuyen dicho adjetivo a este país, pues el tipo de fenómenos que se suceden se caracterizan por la dificultad para comprenderlos y explicarlos.

Siguiendo la teoría de sistemas, Morin (1990) acoge la división de las cosas en máquinas triviales y no triviales, y al respecto afirma que

nuestras sociedades son máquinas no triviales en el sentido, también, de que conocen, sin cesar, crisis políticas, económicas y sociales. Toda crisis es un incremento de las incertidumbres. La predictibilidad disminuye. Los desórdenes se vuelven amenazadores [...] es necesario, a menudo, abandonar las soluciones que solucionaban las viejas crisis y elaborar soluciones novedosas (Morin, 1990, 117). 
A pesar de que la defensa de estos planteamientos no establece acciones metodológicas concretas, permite flexibilizar la concepción clásica del objeto de estudio, como un «artefacto» susceptible y en espera de ser conocido. En este sentido, muchas de mis reacciones, percepciones y prejuicios son puestas en evidencia en aras de aceptar mi doble papel como sujeto y objeto de investigación. Por tanto, la experiencia personal también entra a jugar en tanto acervo de conocimientos subjetivos que, por supuesto, participa del diálogo y la confrontación con las fuentes de información primaria y secundaria.

\subsection{El estudio de caso}

Como metodología de esta investigación propongo el estudio de caso, específicamente el estudio exploratorio de caso. Éste consiste en «no basar el estudio en cualquier modelo o teoría anterior» (Bermejo, 1998) para realizar un acercamiento que analice o examine al objeto a través de puntos de vista diversos pero progresivos, de tal manera que se puedan descubrir nuevos elementos a partir de varias miradas posibles (ver gráfica 2.1).

GRÁFICA 2.1

REPRESENTACIÓN GRÁFICA DEL ESTUDIO DE CASO

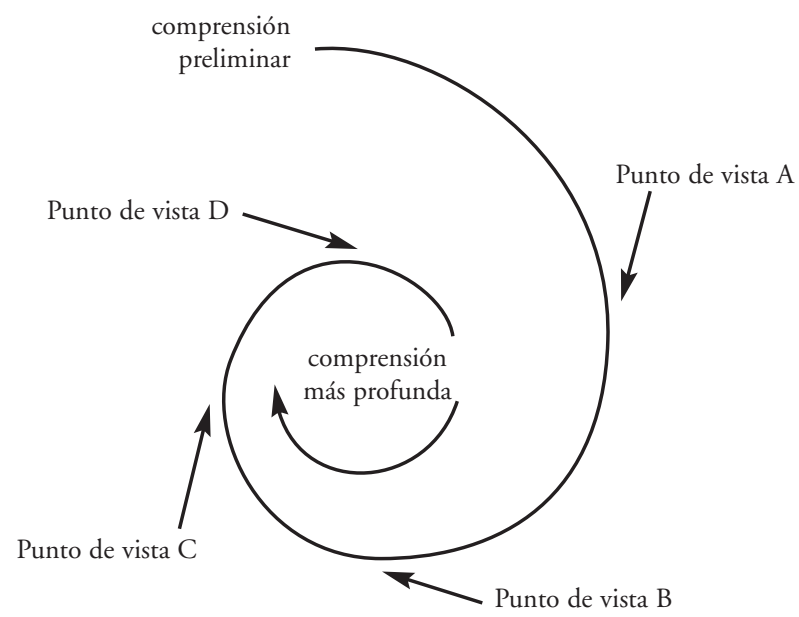


«El objetivo es documentar el objeto de forma tan completa como sea posible, y no sólo aquellos temas que fueron documentados en estudios anteriores» (Bermejo, 1998). Por tanto, el objetivo metodológico consiste en describir los rasgos singulares de la cooperación no gubernamental aragonesa en Colombia, con un énfasis en los procesos de ejecución y evaluación de los proyectos de desarrollo. En ningún caso se pretende evaluar el trabajo de las organizaciones; este último supuesto implicaría un trabajo de varios años, de muchos recursos y sería percibido por la "poblaciónobjeto» como una auditoría, en cuanto implicaría la revisión detallada de todas las fases del ciclo del proyecto.

En su lugar, el trabajo ha pretendido obtener una impresión general de la forma como se ejecutan los proyectos, más allá de los pasos propuestos, por ejemplo, por el Enfoque del Marco Lógico y la Gestión del Ciclo del Proyecto. ${ }^{22}$ En ese sentido, ha tenido como objetivos generales identificar los factores que caracterizan los procesos de ejecución de los proyectos de cooperación de las ONGD aragonesas en Colombia y el análisis de los elementos y las circunstancias que inciden en dichos procesos. De este modo, se privilegia la descripción de las percepciones de los sujetos, la reconstrucción de su experiencia concreta, así como sus expectativas previas y futuras, más que la descripción de las condiciones técnicas a través de las cuales se cumplen los pasos inherentes a la ejecución de los proyectos.

Si bien es cierto que los estudios de caso tienen la dificultad de determinar generalizaciones válidas respecto a los resultados obtenidos, también es cierto que pueden aportar los puntos de vista desde los cuales fueron obtenidos, y extrapolar a otros contextos dichas perspectivas.

\subsection{El trabajo de campo}

Identificación de las ONGD aragonesas que han realizado proyectos en Colombia entre el 2000 y el 2004

En un primer paso, a través del registro bibliográfico, la búsqueda de documentación y, en general, de la revisión de las fuentes secundarias, se

22 Para profundizar en el análisis técnico de la ejecución de los proyectos de desarrollo ver, por ejemplo, Ferrero (2003) y L. González (2002). 
elaboró una lista de las organizaciones aragonesas que tienen, o habían tenido, proyectos en el territorio colombiano. En algunos casos (como Intermón) sólo habían gestionado un proyecto en los últimos cuatro años, y la información al respecto no estaba disponible por tratarse de un proyecto esporádico o realizado conjuntamente con otra comunidad autónoma donde se encontraba la persona o delegación a cargo de él. En otro caso, una vez cerrada la muestra, surgieron entidades que estaban solicitando su acceso a la FAS y habían desarrollado proyectos en Colombia (por ejemplo, la Fundación Juan Bonal y la Asamblea de Cooperación por la Paz). En estos casos no se disponía de la información suficiente para incluir a las entidades en la muestra y pasar a la siguiente fase de identificación de las contrapartes. Por tanto, no se recogieron para el trabajo de campo, aunque sí en el registro sistemático de la cooperación no gubernamental aragonesa. Tal registro consistió en la elaboración de una plantilla para describir algunas variables que pudieran compararse y aportar información cuantitativa sobre las entidades, los proyectos, las fuente de financiación, los sectores y los lugares donde se ha intervenido (ver anexo 6).

No obstante, estas dificultades no son excepcionales; como hemos advertido, los objetos de estudio de las ciencias sociales tienen la condición de su fluctuación, movilidad y heterogeneidad, ya que se trata de sujetos, y como tales se comportan. Además, las dificultades de este primer paso fueron las propias de la mayoría de otros estudios que tienen serias dificultades para determinar su objeto, población o muestra; por ejemplo, de este modo comienza un estudio sobre las ONGD financiado por IEPALA: "los problemas que hemos encontrado al determinar el número exacto de ONGD que operan en nuestro país fueron: [...]» (Martínez Sánchez, 1998, 22). Uno de los estudios realizados en Zaragoza sobre organizaciones de voluntariado también recogía este aspecto: «el estudio pretendía abarcar todo el universo de las organizaciones de voluntariado de la ciudad. La dificultad era doble: por una parte, se carece de un censo de organizaciones de este tipo; por otra parte, las definiciones legales [...] poco ayudaban a la concreción del universo» (Ayuntamiento de Zaragoza, 2000, 9).

Considerando estas dificultades, se delimitó la muestra a 13 organizaciones aragonesas (incluidas las de ámbito nacional e internacional con delegación en Aragón), que, además de cumplir los requisitos para la selección, tenían una trayectoria en Colombia y contaban con la suficiente 
información para pasar a la fase de realización de las entrevistas, aunque no todas accedieron a participar en ellas (ver anexo 3).

\section{Entrevistas abiertas semi-estructuradas en Aragón e identificación de la contraparte local}

El uso de la técnica conocida como "entrevista abierta semi-estructurada" partía del objetivo de ahondar en las experiencias - y sus respectivas reflexiones- de informantes cualificados cuya trayectoria en el ámbito cooperante permitiera una visión general, pero no por eso superficial, de la forma de llevar a cabo la cooperación al desarrollo de Aragón en Colombia.

CUADRO 2.1

GUIÓN DE ENTREVISTA A INTEGRANTES DE ONG DE DESARROLLO. ENTIDADES ARAGONESAS Y CONTRAPARTES COLOMBIANAS

\section{OBJETIVO DEL INSTRUMENTO}

- Indagar sobre las características de los procesos de ejecución de los proyectos de cooperación de las ONGD aragonesas en Colombia.

- Analizar los diferentes elementos sociales, políticos, económicos y culturales que inciden en dichos procesos.

\section{PREGUNTAS GENERALES}

1. ¿Cuál considera que es la percepción de población beneficiaria sobre los procesos puestos en marcha en los proyectos de la cooperación aragonesa?

2. ¿De qué manera incide el conflicto armado en el proceso de ejecución de los proyectos?

3. ¿Cuáles son las características del contexto social que rodean a las entidades responsables de la ejecución de los proyectos y a sus contrapartes?

4. ¿Podría describir las dificultades y potencialidades con las que se encuentran las entidades en Colombia durante el transcurso de los proyectos?

5. ¿Existe algún factor que diferencie a Colombia de otros países en cuanto a la ejecución de los proyectos?

6. ¿Cómo considera que es el nivel de participación de los agentes implicados en los proyectos?

8. ¿Cuáles son los elementos de valoración que aplican tanto las organizaciones aragonesas como las locales en la evaluación de los proyectos?

9. ¿Podría describir y valorar los indicadores utilizados en las evaluaciones de los proyectos realizados?

10. ¿Cómo cree que es la coordinación entre ONG colombianas y aragonesas?

PREGUNTAS ESPECÍFICAS (EE-00)

1. ¿Cuál es su impresión general sobre el trabajo de las entidades colombianas?

2. ¿Qué tipo de preparación sobre Colombia tienen los cooperantes que se desplazan al país?

(EC-00)

1. ¿Cuál es su impresión general sobre la cooperación aragonesa?

2. ¿Qué tipo de relación hay entre las ONGD y las comunidades beneficiarias? 
Su carácter abierto ha permitido mayor fluidez que una entrevista cerrada, ante lo cual, como entrevistador, he podido formular preguntas a partir de las propias respuestas del entrevistado. A pesar del uso de un guión de entrevista (ver cuadro 2.1), la condición "semi-estructurada» de esta técnica ha permitido la ampliación de los horizontes temáticos, que no podían obtenerse bajo la estructura de una entrevista dirigida. El guión de entrevista ha sido similar para las dos fases del trabajo de campo, teniendo algunas preguntas específicas en razón del contexto geográfico.

La opción por el uso de una técnica implica la renuncia a otras. Por ejemplo, se desechó la encuesta porque, entre los objetivos del trabajo, pasaba a un segundo plano la distribución y frecuencia de las opiniones o de las variables respecto al tema investigado. Aunque inicialmente se había planteado en el proyecto la realización de una encuesta para estimar perfiles y opiniones de los cooperantes aragoneses que se desplazan a Colombia, el curso de la investigación fue revelando la profundidad de los aspectos que intervienen en los procesos de ejecución de los proyectos de desarrollo. En esta línea, priorizamos un enfoque microsociológico sobre otro macro, más usual en la mayoría de estudios. ${ }^{23}$ En esta dirección, y acogiendo valiosas aportaciones de la etnografía, el camino de la investigación experimentó algunos cambios respecto a la propuesta inicial. Según Hammersley y Atkinson $(1994,51)$, durante el trabajo de campo es frecuente que sean «identificados con más precisión un número de temas y [surjan] nuevas categorías de análisis».

Asimismo, la entrevista estructurada limitaba las posibilidades de profundizar en aspectos que pudieran surgir durante la realización de las entrevistas, ya que se inclina más por el uso de preguntas cerradas que proporcionan al sujeto entrevistado alternativas de respuestas que debe seleccionar, ordenar o expresar sobre el grado de acuerdo o desacuerdo con ellas. Por tanto, para la realización de un estudio de caso de carácter exploratorio, la entrevista abierta semi-estructurada era la herramienta más adecuada.

23 La mayoría de los estudios sobre cooperación en Colombia han partido de perspectivas macrosociológicas. Por ejemplo, uno de los principales estudios realizados en Colombia (Henao, 1991) recoge el análisis de la evolución de los montos de la cooperación internacional en Colombia, las políticas sectoriales, la gestión pública de los recursos. Un caso similar ocurre con el estudio de Vargas y otros (1992), que analiza la estructura de las ONG en Colombia estableciendo tipologías y relaciones institucionales. 
En total se han realizado 15 visitas a entidades en busca de información escrita (material escrito, memorias, trípticos...), información oral (contacto con personas que conocieran los proyectos en Colombia) e indicios para la selección de los informantes cualificados. Después de esta indagación inicial se realizaron 9 entrevistas a representantes de las organizaciones seleccionadas en la muestra. En el análisis y producción de la información del trabajo de campo se encontrará el código «EE-00», que identificará la entrevista en España, seguida de un número correspondiente al orden de entrevistas (ver anexo 3).

En el caso de las delegaciones aragonesas de entidades de ámbito nacional e internacional que no disponían de información ni de informantes cualificados sobre Colombia en la ciudad de Zaragoza o en la comunidad aragonesa, se recurrió a realizar contactos telefónicos y visitas a sus sedes para obtener información complementaria (anexo 3).

Después de realizar las entrevistas y las indagaciones iniciales, y, por tanto, aproximarme a conocer el trabajo de las ONGD aragonesas en Colombia, pasé a la identificación de las contrapartes locales para preparar el viaje a Colombia. Las dificultades seguían presentes. Por ejemplo, Entreculturas (Fe y Alegría) y UNICEF tienen presencia en más de cien localidades. Para subsanar esta dificultad se visitó la sede central de las organizaciones en la capital del país.

En cuanto a los departamentos para el trabajo de campo en Colombia, seleccioné los del Chocó (costa Pacífica) y Antioquia (región andina) por tener alta concentración de proyectos. El trabajo de campo en Bogotá consistió en identificar entidades públicas y privadas que tienen su sede en la capital del país; en este sentido, en lugar de identificar las necesidades propias de esta ciudad o su departamento (Cundinamarca), se empleó como espacio estratégico para la búsqueda de la información. Bogotá, como capital del país, es lugar de referencia para identificar los organismos antes mencionados y otras organizaciones (CINEP, Confederación Colombiana de $\mathrm{ONG}$ ) y entidades públicas (Ministerio de Relaciones Exteriores y la ACCI).

Asimismo, la elección de las regiones se basó en otros criterios como la viabilidad del desplazamiento: sería impensable e inviable abarcar más territorio con los recursos temporales y económicos asignados al proyecto. El transporte en Colombia es un factor condicionante para la investiga- 
ción de campo. El territorio es aproximadamente tres veces el español, cuenta con infraestructuras precarias, una orografía abrupta y un clima tropical húmedo. Asimismo, hay zonas a las que por motivos de seguridad no es recomendable viajar.

\section{Selección de informantes. Desplazamiento a las zonas y realización de las entrevistas}

En Colombia se realizaron 11 entrevistas abiertas semi-estructuradas, correspondientes a 5 unidades elegidas en la muestra como contrapartes de las organizaciones aragonesas y 6 fuentes de información complementaria, que, si bien no se habían incluido en la muestra inicial, fueron sugeridas por otros informantes gracias a su reconocida experiencia en la cooperación al desarrollo hispano-colombiana. A los entrevistados se les asignó un código «EC-00» (Entrevistas Colombia) con una numeración consecutiva en orden de visita. La totalidad de las entrevistas fueron grabadas y contaron con la autorización de los entrevistados (anexo 3).

Las entrevistas complementarias han pretendido ampliar el análisis de las categorías en torno a las cuales se redacta el informe. A pesar de tener poco o nulo contacto con las entidades aragonesas, poseían una experiencia valiosa en cuanto se trataba de personas o entidades de un liderazgo reconocido por las contrapartes aragonesas.

Otra fuente de información valiosa en Colombia fueron los diarios nacionales como El Tiempo y departamentales como El Colombiano. Las revistas periódicas como Semana y uno de los boletines más difundidos entre las ONG colombianas, Caja de Herramientas, también suministraron datos sobre el trabajo de las organizaciones sociales, su impacto en las comunidades $^{24} \mathrm{y}$, especialmente, la tensión que se vive en el país en los últimos meses entre Gobierno-ONG y ONG-grupos armados.

24 En el proyecto inicial presentado en la convocatoria para esta beca, se contemplaba la «selección y entrevista grupal con los miembros de la comunidad beneficiada». El trabajo con los miembros de las comunidades, tal como se había planificado inicialmente, no se realizó. En el caso del Chocó se trata de 120 comunidades con las que trabaja ACIA (contraparte de algunas organizaciones aragonesas); éstas se encuentran dispersas a lo largo del río Atrato, y el desplazamiento a algunas de ellas implicaba, además de un coste adicional, correr un riesgo considerable. El objetivo pudo suplirse a través del taller grupal con los líderes de las comunidades. 


\section{Taller sobre la contribución de los proyectos en el desarrollo local}

Se realizó un taller en el que se aplicó una entrevista grupal con nueve participantes de cuatro comisiones del Consejo Comunitario Mayor de la Asociación Campesina Integral del Atrato (COCOMACIA). Había representantes de varias comunidades del río Atrato y de las comisiones de Género, Desarrollo Agrícola y Medioambiental y de la Junta Directiva (anexo 3). El taller giró en torno a la percepción de los participantes respecto a las diferentes actuaciones de la cooperación aragonesa. Durante diez minutos cada miembro del taller expresaba sus opiniones y experiencias, de tal manera que el conjunto de opiniones brindó una diversidad de puntos de vista gracias a la pertenencia a diferentes zonas y comisiones. La dificultad que más persistía era que los participantes hicieran una referencia expresa a Aragón, pues la mayoría de las veces hablaban de España, cuando no de Europa. Las conclusiones de esta actividad fueron analizadas según las mismas categorías de las entrevistas, e incluidas en el trabajo de campo con el código EC-03.

\section{Elaboración del diario de campo}

Durante el trabajo de campo utilicé la técnica etnográfica de llevar un diario en el que registraba las observaciones realizadas en los territorios, los despachos y las ciudades. A pesar de ser familiares por mi experiencia en el país, el hecho de residir en España durante los últimos siete años y la búsqueda de la técnica antropológica del extrañamiento sirvieron para convertir en ajeno lo propio y en novedosa la costumbre. La idea de llevar el diario partía también del reconocimiento de que el investigador no es un observador neutral que "registra la realidad tal como es», sino que debe ser consciente de la inesperada emergencia de las subjetividades y tener un control sobre ellas para aproximarse a ciertos niveles de validez y objetividad. Asimismo, el diario permitía registrar las observaciones realizadas durante las entrevistas, las expresiones utilizadas por los sujetos, su lenguaje no verbal, los temas que preocupan o motivan al entrevistado, etc.

\subsection{El análisis de la información}

Las entrevistas fueron transcritas y posteriormente clasificadas por categorías de análisis. Dichas categorías se han construido en función de 
los objetivos de la investigación, de tal manera que en la mayoría de los casos la información se analizaba describiendo cada categoría y estableciendo relaciones con otras. La revisión de las entrevistas permitió observar nuevas categorías diferentes a las previamente especificadas; tal como sugiere el modelo propuesto por Taylor y Bogdan $(1987,167)$, he aplicado los «sistemas de codificación de categorías».

En este sistema se incluyeron las entrevistas transcritas y también las notas del diario de campo, el taller con los campesinos y algunos materiales como boletines, trípticos y folletos de las organizaciones. La codificación y separación de los datos ha permitido comparar los diferentes fragmentos relacionados con cada tema, de tal manera que se han podido refinar temas que inicialmente parecían difusos (como el del capital social) y ahondar en otros que se habían abordado con suficiente claridad (como la percepción de la evaluación). La siguiente es la construcción del esquema analítico basado en dos niveles de categorías:

\begin{tabular}{|c|c|}
\hline Categorias de primer nivel & Categorias de segundo nivel \\
\hline Relaciones con la cooperación internacional & $\begin{array}{l}\text { Relaciones instituidas entre los actores } \\
\text { Relaciones de confianza y reciprocidad } \\
\text { El papel del capital social }\end{array}$ \\
\hline Cooperación en el contexto del conflicto armado & $\begin{array}{l}\text { Implicaciones para las ONGD aragonesas } \\
\text { Implicaciones para las ONGD colombianas }\end{array}$ \\
\hline Definición, identidad y objetivos de las ONGD & $\begin{array}{l}\text { Especificidad cultural-territorial } \\
\text { Perfiles ideológicos } \\
\text { Perfiles políticos } \\
\text { Perfiles financieros }\end{array}$ \\
\hline Evaluación del proyecto & $\begin{array}{l}\text { Exigencias del donante } \\
\text { Exigencias de la comunidad }\end{array}$ \\
\hline Indicadores de evaluación & $\begin{array}{l}\text { Participación y percepciones de la comunidad } \\
\text { Valores organizativos } \\
\text { Cualitativos/endógenos } \\
\text { Contextos conflictivos }\end{array}$ \\
\hline $\begin{array}{l}\text { Coordinación entre los diferentes actores } \\
\text { de la cooperación }\end{array}$ & $\begin{array}{l}\text { Estados } \\
\text { Empresas } \\
\text { Organismos multilaterales } \\
\text { ONGD aragonesas } \\
\text { ONGD colombianas } \\
\text { Otras entidades de la sociedad civil: Iglesia } \\
\text { católica, sindicatos... }\end{array}$ \\
\hline
\end{tabular}





\section{EL PANORAMA ACTUAL DE LAS ONGD}

Uno de los fenómenos sociales más recientes en la historia de la sociedad civil ${ }^{25}$ ha sido el auge de las llamadas ONG, entre las que cabe destacar las especializadas en temas de desarrollo. En parte, han basado su auge en resultar cercanas al ciudadano común y en mostrarse como actores legitimados por la sociedad civil para actuar con las comunidades o con los beneficiarios directos. Además, han demostrado en muchos casos ser más eficientes que las burocracias estatales. De hecho, una estimación reciente sobre el conjunto del tercer sector, del que hacen parte las ONG, ha establecido las siguientes dimensiones del fenómeno en España: «más de 250000 organizaciones no lucrativas, cerca de 26 millones de cuotas, unos 11 millones de personas asociadas, un millón de voluntarios que dedican

25 El concepto de sociedad civil es extenso, tanto teórica como históricamente. Sin embargo, para no explayarnos demasiado, en esta investigación entendemos la sociedad civil según la definición elaborada por Torres Rivas $(2001,148)$ para el contexto de América Latina: «La sociedad civil existe cuando la sociedad como totalidad puede estructurarse a sí misma y coordinar sus acciones a través de un conjunto de asociaciones voluntarias. En un sentido más operacional su existencia depende de que se forme y funcione una red de organizaciones autónomas, independientes del Estado, asociaciones voluntarias que reúnen un conjunto de ciudadanos que tienen intereses comunes, y que pueden trascender el universo privado en el que surgen por la fuerza de su existencia orgánica, asociativa. De esa suerte ocupan espacios en la vida pública y desde donde influyen de manera decisiva y de las más diversas maneras en el juego político y en las estructuras estatales. [...] un conjunto de organizaciones de la más diversa naturaleza, [...] que se organizan y actúan en la vida pública de manera independiente del Estado, sus agentes y de los poderes fácticos, lo cual significa que su autonomía les permite oponerse o aproximarse a los poderes públicos, es decir, tener como referente de sus demandas y conflictos al Estado; [...] y su actuación pública tiene que hacerse conforme a las normas legales, los principios que ordenan a la sociedad y que dicta el Estado". 
más de cuatro horas semanales a colaborar en las actividades del sector, más de 475000 empleos remunerados a tiempo completo y unos gastos operativos que suponen el 4\% del PIB» (Ruiz Olabuénaga, dir., 2000, presentación).

Pese al desmonte gradual de los presupuestos para la cooperación al desarrollo de los países miembros de la OCDE (Gómez y Sanahuja, coords., 2001, 15), las ONG han gestionado, proporcionalmente, más recursos. Según la OCDE (Valderrama, 2002), entre 1970 y 1990 las ONGD quintuplicaron el dinero percibido proveniente de donaciones de agencias privadas del «Norte» y aumentaron nueve veces los subsidios otorgados por Gobiernos de esta parte del mundo. En España, los ingresos de origen público recibidos por las organizaciones que forman parte de la Coordinadora Estatal de ONGD se han multiplicado por más de 7,4 entre 1991 y 1997 (Malé, 1999).

Pero además de la evolución en sus presupuestos, se puede afirmar que «han pasado de la invisibilidad social a la presencia creciente en los medios de comunicación y en el imaginario de la sociedad. Se han consolidado como actores sociales y como actores políticos» (Ch. Marcuello y C. Marcuello, 2000).

Sin embargo, hace unos años, algunos imaginarios sociales sobre las ONGD les habían llevado a ser vistas como entidades con muy buenas intenciones, a las que, por tanto, no se les debía exigir un seguimiento riguroso. «Pareciera que la exigencia [...] a la adhesión a un cronograma o el examen de la fidelidad de la práctica con los principios y criterios, tuvieran como punto de partida una sospecha; o que al examinar las estrategias a la luz de la coyuntura política o de las tendencias financieras, se estuviera poniendo en duda la "bondad" de la propuesta que la entidad lleva a cabo» (Rodríguez, 1993).

El imaginario que hasta hace muy poco tiempo las caracterizaba las había llevado a ser «eximidas de cualquier tipo de control» (Sogge, ed., 1998), incluida la evaluación de sus proyectos. Sin embargo, muchas ONGD son cada vez más críticas consigo mismas; la reflexión de la práctica se ha valorado paulatinamente y ha permitido, en medio de su masiva proliferación, diferenciar la coherencia y responsabilidad en el trabajo de muchas de ellas. 
El segundo Foro Social Mundial de Porto Alegre (febrero de 2002) resaltó la existencia de una serie de retos que afrontan las ONGD a escala global. Son un conjunto de observaciones que «retratan una subordinación al papel que las instituciones económicas y políticas más poderosas [les] adjudican como "bomberos de la pobreza" y "ejército humanitario" destinado a sellar un hipócrita consenso moral en las sociedades del Norte» (Memorias del Foro Social de Porto Alegre, 2002). Además, hace consciente la presencia de algunas organizaciones que han perdido la autonomía y se han fundido en un sistema que perpetúa el estado actual de las cosas, desvaneciendo sus posturas críticas ante la injusticia y la desigualdad. Ante este panorama, el Foro destaca la relevancia de las ONGD con «vocación de cambio social».

Frente a la emergencia de los grupos más críticos, la «política del poder» (Malé, 1999, 23) ha intentado diluir el contenido crítico de las propuestas desviándolas hacia un activismo humanitarista, ha buscado la integración de la cooperación no gubernamental en el sistema de cooperación oficial ya establecido (Malé, 1999, 23). Uno de los principales esfuerzos de las coordinadoras y federaciones actuales de ONGD es trabajar por mantener cierto equilibrio entre las posturas críticas y la dependencia con la cooperación oficial.

Uno de los temas que plantean mayores dificultades a las ONGD es la adaptación a los cambios que conlleva el proceso de globalización. Algunas ONGD han asumido la necesidad de adaptarse a la globalización con escaso planteamiento crítico o innovador (Serrano, 2001). De hecho, la necesaria adaptación suele traducirse en la necesidad de incrementar los fondos, en lugar de plantear un cambio cualitativo que contemple la redefinición de los ámbitos de trabajo y las relaciones con el Estado y con otros agentes sociales. Desde el papel preeminente de ejecutores de proyectos, las ONGD están logrando la plena integración con la industria del desarrollo (Edwards y Hulme, 1996). La capacidad de adaptación de este tipo de ONG es tal que están asumiendo sin grandes traumas el papel de subcontratas, no sólo en las tareas relacionadas con la emergencia sino en los propios proyectos de desarrollo, con la consiguiente pérdida de autonomía real, compensada por el margen de beneficios y, sobre todo, el volumen de negocio. Hay que adaptarse a los criterios sectoriales, a las prioridades geográficas y, quizá uno de los temas que inspira más debates, a las geoestratégicas. 
La adaptación a la mundialización no puede ser la de convertir a las ONG en multinacionales de la gestión de la pobreza, mientras el poder político, económico y mediático continúa sus procesos de concentración. En todo caso, una acción alternativa debería dirigirse a contrastar la mundialización contribuyendo con información, contrainformación y movilización. Se debería apostar por organizaciones que tengan capacidad de unirse entre ellas para contrarrestar las propuestas que se presentan como inevitables, con propuestas alternativas; la información que se presenta como verdadera, con información veraz; y el monopolio de los conocimientos, con su difusión y socialización. Hay que saber dar respuestas diferentes, pero, sobre todo, hay que tener capacidad para decidir cuáles son las preguntas (Serrano, 2001, 165).

Por otro lado, empieza a apreciarse una «ofensiva de la empresa privada, que, en España, acaba de descubrir que la solidaridad vende, con lo que se empieza a observar nuevas alianzas comerciales entre ONG y empresas, no sólo en el terreno del marketing, sino probablemente en el trabajo en el terreno" (Serrano, 2001, 160-170). Esta autora sugiere que se debería fortalecer la alianza con los movimientos populares y con las gentes de las comunidades con las que se trabaja, en lugar de entrar a canalizar recursos de la «responsabilidad social corporativa».

Sin embargo, desde los últimos años de la década de los noventa, dicha presencia pública se está convirtiendo en una especie de masificación o popularización de la cooperación (Doppler, 1997), o incluso en una trivialización de la ayuda (González Parada, 2001, 78).

Por una parte, con el propósito de captar donativos, muchas entidades han logrado llegar a millones de personas a través de campañas publicitarias - este proceso se ha denominado marketing solidario (Nieto, coord., 2001; Serrano, 2001) — y para captar socios y voluntarios se han adaptado ciertos proyectos para facilitar el desplazamiento y colaboración de personas interesadas en participar de una experiencia de cooperación (este apartado se retomará más adelante). El paso de la presencia pública a la trivialización ha sido motivo de serias dificultades en el interior de las federaciones y coordinadoras. De hecho, las propias ONGD consolidadas y federadas a la CONGD han construido un código de conducta debido a que sienten la necesidad de «clarificar algunos conceptos y consensuar algunos principios». ${ }^{26}$

26 Código de conducta de las ONG de desarrollo de la CONGDE. Aprobado por la Asamblea General Ordinaria del 28 de marzo de 1998. <http://www.congde.org/codigo.htm\#1> (11 de octubre de 2005). 
Este proceso empieza a preocupar a muchas entidades que realizan un trabajo serio y comprometido. Las publicaciones internas de las organizaciones serias y comprometidas con las transformaciones han empezado a dar cuenta de ello: "la superficialidad domina en los planteamientos de algunas ONGs [sic], que no son capaces de ver los mecanismos económicos, políticos y sociales que provocan las realidades con las que se enfrentan. Esta miopía se traduce en superficialidad a la hora de definir actuaciones y soluciones, a veces eurocéntricas, a veces ineficaces. [...] las ONG pueden ser actores decisivos en el espacio socio-político, o pueden contribuir a esta falsa "solidaridad" que adormece conciencias y evita todo compromiso transformador» (Zambrana, 2002, 19).

Aunque haya indicios de un panorama difícil para estas entidades, provocado por algunas homólogas, este trabajo devela que muchas de ellas fortalecen su papel como actores legítimos, necesarios y primordiales en la cooperación y en la construcción de la paz en Colombia. 



\section{LA COOPERACIÓN INTERNACIONAL EN COLOMBIA}

\subsection{Reseña histórica}

La cooperación al desarrollo en Colombia, en su versión moderna, se inició en los años cincuenta. El primer estudio del Banco Mundial sobre un país del "Tercer Mundo" se llevó a cabo en Colombia. ${ }^{27}$ Lauchlin Currie dirigió el estudio, y de este modo describía al país: "Colombia ha sido el país predilecto de las agencias encargadas de dar préstamos y asistencia, así como escenario de numerosos ensayos y experimentos». ${ }^{28}$ Como consecuencia de la Misión Currie, se crearon en el país dos instituciones encargadas de la planificación de las políticas socio-económicas: el Consejo Económico de Política Económica y el Departamento Administrativo de Planeación y Servicios Técnicos.

A comienzos de los sesenta el Gobierno estadounidense, presidido por John F. Kennedy, ejecutó la política conocida como Alianza para el Progreso, en respuesta a la evolución de las relaciones internacionales geopolíticas y económicas del orden mundial vigente, y como una estrategia orientada a impedir el avance del comunismo en América Latina, que había logrado establecerse en el continente con la revolución cubana de 1959. Este hito se había convertido en una preocupante señal de alerta para el país del norte.

27 El estudio se realizó en 1950 y su título fue Evaluación de la asesoría económica a los paises en desarrollo. El caso colombiano.

28 Currie (1984), citado por Henao (1991, 31). 
La Alianza para el Progreso partía del supuesto de considerar el fortalecimiento de los vínculos de los Estados latinoamericanos como única alternativa para lograr el progreso, y, asesorado por la CEPAL, el Departamento Nacional de Planeación colombiano elaboró un plan de desarrollo decenal que recibió el visto bueno de organismos como el BIRF (Banco Internacional de Reconstrucción y Fomento) y la OEA (Organización de Estados Americanos).

El auge en los montos internacionales coincidió con algunos cambios de la Iglesia católica por los cuales se concibió la propagación de la fe a través del trabajo pastoral. El Concilio Vaticano II entre 1962 y 1965, las encíclicas Mater et Magistra de Juan XXIII en 1961 y Populorum Progressio de Pablo VI en 1967 fueron motores para el surgimiento de un gran número de organizaciones católicas que apoyaron la labor de promoción del desarrollo de la Iglesia latinoamericana y de organizaciones no gubernamentales laicas en la región.

Entre 1962 y 1969 el Estado colombiano firmó los primeros convenios bilaterales con seis Estados (Estados Unidos, Francia, Alemania Occidental, Reino Unido, Países Bajos y Suiza) y entre 1971 y 1978 firmó otros tres (con Italia, Canadá y Japón). El primer convenio marco firmado con España lo fue el 27 de junio de 1979 y se aprobó en el Congreso de la República a través de la Ley 13 de 1980. A pesar de que habían existido algunos convenios previos como el "Convenio Cultural» suscrito el 11 de abril de 1953, el de 1979 constituyó un primer marco general para la cooperación al desarrollo entre los dos Estados (Henao, 1991).

En cuanto a la cooperación multilateral, los principales protagonistas de la historia de la cooperación desde los años cincuenta han sido el BIRF, el FMI, la CEPAL, el BID y la OEA. En los años sesenta y setenta han sobresalido los distintos organismos de las Naciones Unidas que se iban creando y consolidando en esos años (OIT, FAO, OMS, PNUD y UNICEF). De hecho, las Naciones Unidas transfirieron el $80 \%$ de los recursos asignados durante esta década, mientras que el porcentaje restante correspondió a los organismos antes mencionados (Henao, 1991, 36).

La cooperación no gubernamental empezó a crecer considerablemente en la segunda mitad de la década de los ochenta. Hasta esos años los Estados y las agencias multilaterales contaban principalmente con las entidades gubernamentales. En el caso colombiano, la División Especial de 
Cooperación Técnica Internacional del Departamento Nacional de Planeación (DNP) era la entidad a través de la cual se canalizaban las actividades oficiales de cooperación.

Aunque el DNP no recibió con agrado el auge de los montos que gestionaban las organizaciones, no pasaron muchos años para que dicha institución empezara a transferir recursos a las entidades no gubernamentales, siempre que "éstas se apadrinen de una entidad estatal y diseñen un proyecto que se encuentre de acuerdo y en armonía con los planes de desarrollo del Gobierno» (Henao, 1991, 55).

Entre 1987 y 1990 la distribución de la ayuda al desarrollo, tanto oficial como no oficial, fue la siguiente: el 59\% provino de Gobiernos extranjeros, el $24 \%$ de organismos multilaterales, tan sólo el $9 \%$ de ONG y el $8 \%$ de otros fondos y Estados (Henao, 1991, 73). Aunque la participación porcentual de las ONG era baja entonces, al compararse con los organismos multilaterales que no se encontraban en el sistema de las Naciones Unidas, esta participación resultaba ligeramente superior y en una tendencia creciente.

En el mismo período, el monto total percibido por AOD estuvo alrededor de los 500 millones de dólares. Como dato paradójico, en esos cuatro años Colombia pagó 10280 millones de dólares por concepto de abono a su deuda pública externa (Henao, 1991, 79) y más de 4000 millones por concepto de intereses y comisiones. Por tanto, los recursos recibidos a través de la cooperación internacional representaron tan sólo el $4 \%$ de los montos pagados por la deuda externa.

En el estudio realizado por Henao (1991) en el que analiza la cooperación de 10 países (dos norteamericanos, siete europeos y uno asiático) entre 1987 y 1990 resaltaba la magnitud de la cooperación de Estados Unidos, con el $22 \%$ del total de los recursos, mientras que España fue el país, de los analizados en la investigación, que menos aportó, con el 0,6\% del total. Sin embargo, en esos fondos se incluyó la ayuda militar que provino de fondos USAID y la ayuda "antidrogas» que aportaba el Departamento de Estado de EE. UU.

Los sectores del desarrollo colombiano al que se dirigieron los recursos al final de la década de los ochenta no coincidían entre las diversas fuentes de cooperación. Para los organismos multilaterales la prioridad 
estuvo en el sector de desarrollo rural, agricultura y pesca, y, en segundo lugar, la planificación y gestión públicas. Para los Gobiernos extranjeros el principal sector fueron los recursos naturales, seguido del desarrollo rural. No obstante, las ONG dirigieron especialmente sus ayudas a la educación, el desarrollo urbano, rural, la salud y las condiciones sociales.

Esta tendencia se explica a partir de los objetivos de las agencias multilaterales y los Gobiernos extranjeros que tendían a trabajar con las entidades gubernamentales, mientras que las ONG foráneas buscaban apoyar los esfuerzos de la sociedad civil y sus organizaciones no gubernamentales. No obstante, el conflicto armado no llegaba a los niveles de agudización que alcanzó a finales de los noventa, y, por tanto, los temas como la consecución de la paz y la defensa de los derechos humanos no eran los que más llamaban la atención en la cooperación.

Durante la década de los noventa la tendencia a trabajar sobre los mismos sectores se mantuvo; sin embargo, se incrementaron de manera vertiginosa los fondos de cooperación destinados a la reducción del narcotráfico:

Por iniciativa del presidente Virgilio Barco (1986-1990) y desarrollado durante el Gobierno del presidente Gaviria (1990-1994), para mitigar los efectos de la lucha contra el narcotráfico, se presentó a la comunidad internacional el Plan Especial de Cooperación para Colombia (PEC). Este programa, conformado por alrededor de 120 proyectos elaborados por entidades públicas y privadas, distribuidos en aproximadamente 9 áreas, fue apoyado en su diseño por el PNUD y presentado a las fuentes cooperantes en el año 1989, y trajo como resultado un incremento en los niveles de cooperación cercano al $50 \%$ anual (ACCI, 2004b, 9).

Asimismo, se implementaron diversas estrategias mundiales o nacionales, entre ellas, «el Plan de Acción Forestal para Colombia, el Programa de Agua Potable y Saneamiento, el Plan Ambiental para Colombia, los desarrollos de la Cumbre de Río 92 (GEF, Global Environmental Facility, Protocolo de Montreal, Ramsar, Cumbre de Desarrollo Sostenible, etc.), el Plan Pacífico y la movilización en torno al Quinto Centenario del Descubrimiento" (ACCI, 2004b, 9).

Además, en la década de los noventa Colombia fue considerada como una nación de desarrollo humano medio, lo cual la situaba con indicadores socioeconómicos superiores a Centroamérica y el Caribe. Sin embargo, 
GRÁFICA 4.1

EVOLUCIÓN DE LA AOD BILATERAL A COLOMBIA, 1999-2003

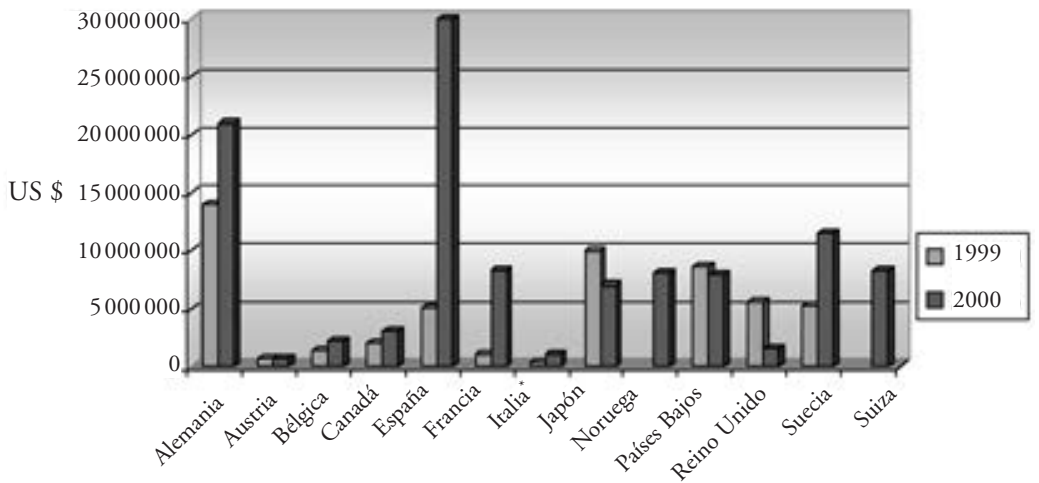

* Datos de 1998. Se ha excluido valor mínimo (Finlandia) y máximo (EE. UU.) para observar tendencias medias.

FUENTE: Elaboración propia a partir de ACCI (2004b).

el recrudecimiento del conflicto, el aumento del narcotráfico y las repercusiones de ambos en la región andina no desviaban la atención como país receptor de cooperación. De este modo, al final de la década se puso en marcha el Plan Colombia y, vinculada a éste, la participación de la comunidad internacional en el conflicto y sus repercusiones sociales.

En el cuatrienio comprendido entre 1999 y 2003 se presentaron cambios considerables en la distribución de la participación de los países donantes a Colombia: Japón, Países Bajos y Reino Unido disminuyeron sus montos; por el contrario, las evoluciones de Estados Unidos y España fueron espectaculares (ver gráfica 4.1). Durante ese período de tiempo ingresaron en el conjunto de países donantes Noruega y Suiza, a los que posteriormente se sumaron Corea del Sur y Rusia. El 10 de julio de 2003 se constituyó en Londres el G-24 durante la primera Mesa de Coordinación y Cooperación Internacional para Colombia.

Recientemente, e incorporando a los organismos multilaterales, la mayor parte de los proyectos ejecutados corresponden al sistema de las Naciones Unidas, en el que destaca el Programa de las Naciones Unidas para el Desarrollo, con una tercera parte de todos los proyectos (gráfica 
GRÁFICA 4.2

AOD BILATERAL A COLOMBIA, 2003

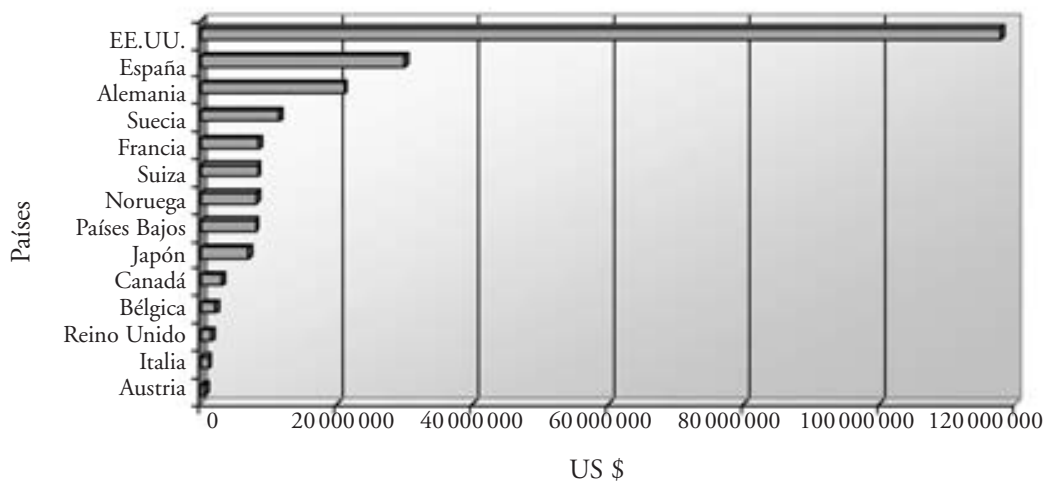

FUENTE: Elaboración propia a partir de ACCI (2004b).

4.3). Dentro del mismo sistema aparecen el Fondo de Población (UNFPA), la Oficina contra la Droga y el Delito (UNDCP) y el Fondo de Alimentos (FAO). Otros organismos multilaterales destacados son la UE, el BID y el Banco Mundial. Por Estados resaltan Alemania, Estados Unidos (USAID) y España. La participación de España es muy elevada cuando se incluye la cooperación reembolsable (créditos FAD y microcréditos), pero disminuye cuando se describe la cooperación no reembolsable (ver apartado 4.3). El caso contrario ocurre con Alemania, la cual aumenta su participación con la cooperación no reembolsable (ver gráficas 4.2 y 4.3).

\subsection{La ayuda oficial de la Unión Europea}

\subsubsection{El contexto latinoamericano}

Para explicar las relaciones de cooperación entre la UE y Colombia es necesario situar a esta última en el contexto de América Latina. Por una parte, las prioridades de las relaciones internacionales de la región han girado fundamentalmente alrededor de dos tendencias: mirar hacia el 
GRÁFICA 4.3

PROYECTOS DE COOPERACIÓN EN COLOMBIA

POR FUENTES DE FINANCIACIÓN, 2003

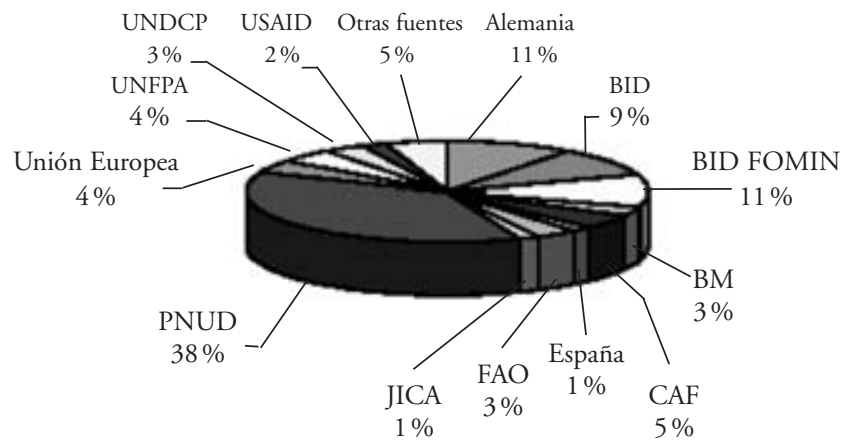

FUENTE: ACCI $(2003,29)$.

norte (respice polum) y mirar hacia los semejantes (respice similia) (Sanín, 2004). En tal sentido, Colombia, como buena parte del subcontinente latinoamericano, ha preferido mirar hacia Estados Unidos como potencia económica, y a sus vecinos latinoamericanos como socios comerciales, antes que a otras potencias mundiales como la UE. Además, «el desconocimiento e interés que tiene Colombia acerca de la dinámica del bloque europeo es innegable» (Sanín, 2004, 6).

De otro lado, América Latina no ha sido una región de especial interés para la Unión Europea (Gilhodes, 2001; Sanahuja, 2004). En los últimos años, las principales preocupaciones de la UE han sido la integración interna de los Estados miembros, especialmente a raíz de la más ambiciosa ampliación realizada en la historia de la UE en 2004, y, por tanto, el orden de relevancia para los temas de relaciones internacionales ha girado en torno a las nuevas fronteras que delimitan el espacio de la Unión. De este modo, los temas vinculados a la OTAN, a la relación con la frontera sur de Europa, de Turquía hasta Marruecos y los países del Este, en especial la región de los Balcanes, han marcado las principales líneas de actuación de la política exterior de la UE de los últimos años. Después de estas preocupaciones,

África tiene mayor prioridad aunque sea de interés relativo, y dentro de América Latina las fuerzas están volcadas hacia Mercosur. La Unión Europea hará 
todo por impedir que Mercosur se destruya. Después vendría América Central, por los acuerdos que tienen como el de San José, y después estaría el resto de América incluyendo Colombia, por el riesgo que representa este país, por su situación de narcotráfico, de conflicto interno y de debilidad de los Gobiernos (Gilhodes, 2001, 3).

Respecto a la ayuda al desarrollo, hasta 1976 la UE no había prestado ningún tipo de ayuda a Latinoamérica que no fuera en el marco de las preferencias comerciales (L. González, 2002, 163). La primera normativa que regula la cooperación entre la Unión Europea y América Latina es de 1981 (relativa a la ayuda financiera y técnica en favor de los países en vías de desarrollo no asociados) e incluía a América Latina y Asia (PVD/ALA).

Sin embargo, a principios de los noventa, y como consecuencia del surgimiento de un nuevo orden mundial como fruto de la disolución de la Unión Soviética, la UE modifica la pirámide de preferencias de sus relaciones exteriores y se da un refuerzo a las relaciones con América Latina por razones fundamentalmente de interés político y económico (IRELA, 1995).

Arenal (1997, 111-138), Gómez y Sanahuja (1999, 134) resumen las cuatro generaciones por las que han pasado las relaciones de cooperación entre la Unión Europea y América Latina:

1. Acuerdos de primera generación entre 1957-1971, en que las relaciones fueron bastante limitadas, dada la escasa atención prestada hacia AL.

2. Los acuerdos de segunda generación en la década de los ochenta tuvieron en cuenta las demandas formuladas por los países latinoamericanos y trataron de establecer relaciones más acordes con los intereses políticos, económicos, culturales y de seguridad comunes a ambas regiones. Siguen siendo acuerdos de intenciones con poca implicación operativa.

3. Los acuerdos de tercera generación se suscriben basándose en las nuevas orientaciones para la cooperación con América Latina y Asia que el Consejo aprueba en los noventa. Éstas se centran en dos grandes ejes: la ayuda hacia los países menos desarrollados y la cooperación económica y comercial con los países más avanzados. Entre estos acuerdos están los firmados con Chile y Argentina en 1990, y con Centroamérica y el grupo andino en 1993. 
4. Los acuerdos de cuarta generación ponen la atención en el diálogo político y la cooperación al desarrollo desde una concepción de socios. El más importante es el acuerdo Marco Interregional de Cooperación entre la UE y MERCOSUR de 1995.

En esta última generación se inscriben los avances logrados durante la última década, quizá la más significativa en los avances de cooperación en materia política, económica y cultural. En dicha concepción del diálogo politico entre socios, la UE ha concebido las relaciones internacionales con los Estados a través de acercamientos establecidos hacia conjuntos de países en función de las particularidades regionales: «La evolución experimentada por las relaciones entre la Unión Europea y América Latina demuestra un enfoque de asociación diferenciado en función de las regiones y de las especificidades nacionales, dada la heterogeneidad del subcontinente». ${ }^{29}$ De este modo, la política de cooperación con América Latina se desarrolla en tres niveles geográficos:

1. En el ámbito regional, donde la UE mantiene desde 1990, tras la firma de la Declaración de Roma, un diálogo político oficial con el Grupo de Río (Argentina, Bolivia Brasil, Chile, Colombia, Ecuador, México, Panamá, Uruguay y Venezuela).

2. A nivel subregional, mantiene los acuerdos alcanzados en el Diálogo de San José con los países de América Central, que se centra en el apoyo al proceso de paz y la democratización, las ayudas humanitaria y al desarrollo, y a la integración regional.

3. En el ámbito bilateral, la comisión ha firmado acuerdos con distintos países y grupos de países latinoamericanos como MERCOSUR (Argentina, Brasil, Paraguay y Uruguay) y la Comunidad Andina de las Naciones (Venezuela, ${ }^{*}$ Colombia, Ecuador, Perú y Bolivia), centrados en el régimen de preferencias comerciales y en la lucha contra la droga.

29 Delegación de la CE para Colombia y Ecuador. <http://www.delcol.cec.eu.int/es/ ue_al/introduccion.htm>. Asimismo, podemos afirmar que estos criterios regionales no han impedido el establecimiento de relaciones concretas con países de especial interés para la UE como ha ocurrido con México o Chile.

* Recientemente el Gobierno de Hugo Chávez se ha retirado de esta organización. 
En la última década, en la que las relaciones UE-AL se han intensificado respecto al pasado, ha habido dos períodos claramente diferenciados: el primero entre 1996 y 1999, y el actual, iniciado en 1999 en la Cumbre de Río.

El primer período se inició en diciembre de 1995, en el cual el Consejo Europeo de Madrid definió los criterios de relación en el documento UE y AL. Actualidad y perspectivas de fortalecimiento de asociación 19962000. En dicho documento la prioridad de la UE para la región andina resaltaba principalmente un factor: «la lucha contra las drogas y el tráfico de estupefacientes se ha convertido en uno de los aspectos principales del diálogo conjunto y se ha traducido en particular en el establecimiento de programas de apoyo en los ámbitos del desarrollo alternativo y de la armonización del marco jurídico e institucional» (Delegación de la Comisión Europea para Colombia y Ecuador, 2005).

El segundo se inicia en enero de 1999 en la Cumbre de Río de Janeiro, en la que por primera vez se reunieron los jefes de Estado y de Gobierno de ambas regiones. Las conclusiones se recogen en la Comunicación de la Comisión al Consejo, al Parlamento Europeo y al Comité Económico y Social sobre una nueva Asociación Unión EuropealAmérica Latina en los albores del siglo XXI (Delegación de la Comisión Europea para Colombia y Ecuador, 2005). Esta nueva asociación resalta el apoyo de la UE a los tres grandes desafios del sub-continente:

1. El refuerzo del Estado de derecho y la irreversibilidad de los procesos democráticos en el plano institucional

2. La lucha contra la pobreza, la desigualdad y la exclusión social

3. La consolidación de las reformas económicas y el aumento de la competitividad internacional.

Estos ejes prioritarios se articulan con tres temas transversales esenciales para la UE, como son el apoyo a la cooperación y a la integración regional, la educación y la formación, y la gestión de las interdependencias Norte/Sur. Paulatinamente, se aprecia un leve giro por el cual se enfatiza menos la lucha antidroga y adquiere mayor relevancia el apoyo al fortalecimiento democrático y la lucha contra la pobreza. 


\subsubsection{La cooperación con Colombia}

Una de las primeras experiencias significativas de la cooperación europea se llevó a cabo durante la administración del presidente Virgilio Barco (1986-1990). Esta administración diseñó un Programa Especial de Cooperación que buscaba el apoyo de otros países para luchar contra el narcotráfico. Los mecanismos utilizados fueron un tratamiento preferencial de productos colombianos en el mercado europeo, ayuda para el desarrollo agroindustrial, sustitución de cultivos ilícitos, desarrollo rural, fortalecimiento del sistema de justicia nacional y la mejora de la imagen externa del país.

TABLA 4.1

CRONOLOGÍA DE LAS RELACIONES ENTRE LA UE Y COLOMBIA

\begin{tabular}{|c|c|}
\hline Fecha & Avances en las relaciones UE-Colombia \\
\hline 29 de octubre de 1990 & $\begin{array}{l}\text { El Consejo de la UE aprueba el Sistema de Preferencias Generalizadas } \\
\text { (SPG) especiales para los países andinos en el marco de la lucha contra el } \\
\text { narcotráfico, denominado SPG-andino. }\end{array}$ \\
\hline 28 de octubre de 1992 & $\begin{array}{l}\text { El Gobierno de Colombia y la Comisión Europea firman en Bruselas un } \\
\text { acuerdo relativo al establecimiento de una representación diplomática de } \\
\text { la CE en Colombia. }\end{array}$ \\
\hline 24 de febrero de 2000 & $\begin{array}{l}\text { Los cancilleres de la Comunidad Andina y la UE, en el marco del IX } \\
\text { Encuentro ministerial UE-Grupo de Río, reunidos en Vilamoura (Portu- } \\
\text { gal), manifestaron su satisfacción por los diálogos de paz y la búsqueda de } \\
\text { una solución negociada al conflicto armado en Colombia. }\end{array}$ \\
\hline 7 de julio de 2000 & $\begin{array}{l}\text { Con el apoyo de la Unión Europea, el Gobierno colombiano y la sociedad } \\
\text { civil, se realiza la primera reunión del Grupo de Apoyo a la paz para } \\
\text { Colombia en Madrid. La Presidencia de la UE hace una declaración con } \\
\text { motivo de la conferencia. }\end{array}$ \\
\hline 17 de octubre de 2000 & $\begin{array}{l}\text { La Comisión Europea presenta el programa de soporte plurianual de } \\
\text { apoyo a la paz en Colombia y aprueba una ayuda de } 105 \text { millones de } \\
\text { euros. }\end{array}$ \\
\hline 24 de octubre de 2000 & $\begin{array}{l}\text { Se realiza en Bogotá la segunda reunión del Grupo de Apoyo a la paz para } \\
\text { definir presupuestos de ayuda para Colombia. }\end{array}$ \\
\hline 30 de abril de 2001 & $\begin{array}{l}\text { Se realiza en Bruselas la Tercera Reunión del Grupo de Apoyo al Proceso } \\
\text { de paz en Colombia. Se define la ayuda financiera para Colombia y las } \\
\text { principales líneas donde se invertirán los recursos europeos. }\end{array}$ \\
\hline
\end{tabular}

FUENTE: Elaboración propia. <http://www.delcol.cec.eu.int/es/ue_colombia/acuerdos.htm> (abril de 2005). 
La cooperación de la Unión Europea con Colombia, al igual que ocurre con los demás países andinos, está regulada por el Acuerdo Marco de Cooperación firmado en 1993 entre la Comunidad Europea y la Comunidad Andina.

En noviembre de 1998 la Comisión Europea aprobó un documento llamado Orientaciones plurianuales para la ayuda comunitaria: Colombia (OPIN) (CE, 1998), en el cual se definieron cinco temas estratégicos prioritarios que constituyen los elementos básicos en la cooperación europea con Colombia:

1. El apoyo a la modernización del sector productivo colombiano. Ayuda a las empresas colombianas para participar en la apertura de mercados más competitivos y apoyo para reforzar la posición colombiana en el marco continental.

2. El refuerzo del Estado de derecho. En este punto se destacan tres aspectos prioritarios: apoyo a la Administración de justicia, apoyo a la descentralización y a la eficacia del aparato de Estado y fortalecimiento del papel de la sociedad civil y de los mandatarios locales en el proceso de paz.

3. El apoyo al desarrollo alternativo. Una estrategia basada en la sustitución de cultivos ilícitos para reducir la producción de estupefacientes promoviendo cultivos alternativos.

4. La contribución al proceso de paz. Europa reiteraba su disponibilidad para apoyar desde el exterior el proceso de paz colombiano, en puntos como los desplazados por la violencia y la aplicación de los acuerdos de paz futuros (principalmente mediante apoyo financiero).

5. La protección del medio ambiente y la conservación de los recursos naturales. Se buscaba contribuir a la compatibilidad entre el crecimiento demográfico, la industrialización, la explotación de los recursos naturales y la conservación del medio ambiente; además, se ponía el énfasis en la problemática de la gestión de la selva amazónica.

Los mecanismos europeos de cooperación con Colombia se clasifican en tres grupos principales ${ }^{30}$ (ver gráfica 4.4):

30 Delegación de la Comisión Europea para Colombia y Ecuador (2005). $<$ http://www.delcol.cec.eu.int/es/ue_colombia/cooperacion_mecanismos.htm>. 


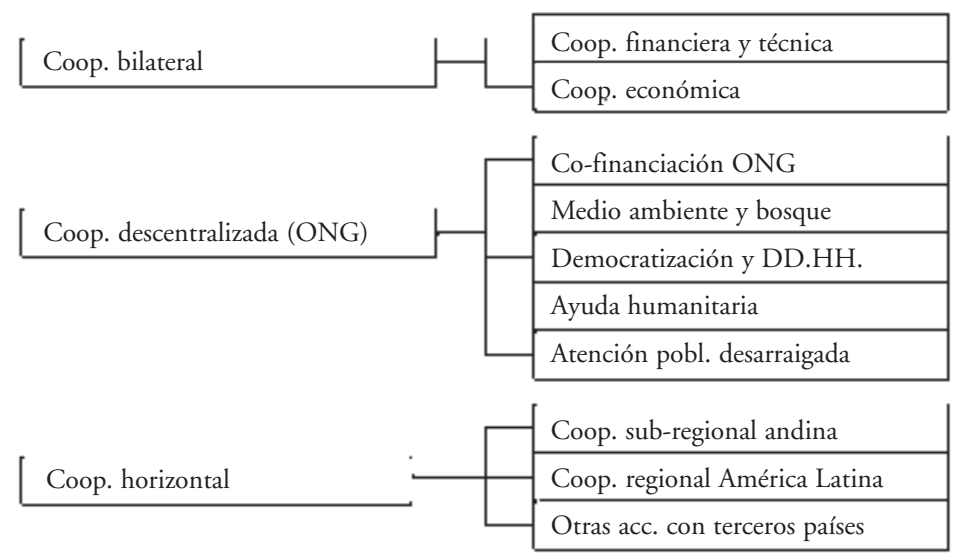

FUENTE: Elaboración propia a partir de Delegación de la Comisión Europea para Colombia y Ecuador (2004).

1) La cooperación bilateral

2) La cooperación descentralizada a través de ONG u otras instituciones

3) Los programas horizontales.

\section{1) La cooperación bilateral}

Éste es el canal de cooperación que moviliza más recursos respecto a los otros mecanismos. Los instrumentos más importantes de ayuda son la cooperación financiera y técnica y la cooperación económica. Los proyectos llevados a cabo a través de la cooperación bilateral responden a unas líneas estratégicas fijadas conjuntamente con el país receptor en el documento OPIN.

Como complemento al Acuerdo de Cooperación con la Comunidad Andina de 1993, el Gobierno de Colombia y la Comunidad Europea firmaron el 14 de diciembre de 2000 un Convenio Marco relativo a la eje- 
cución de la ayuda financiera y técnica y de la cooperación económica. Este Convenio definió el ámbito jurídico y técnico necesario para el desarrollo de la cooperación entre las partes y permitió ejecutar programas y proyectos de acuerdo con nuevas modalidades de gestión diferentes a las tradicionales. Respondía cada vez más a una ejecución directa y de mayor responsabilidad por parte del beneficiario.

Los proyectos de cooperación bilateral han sido cofinanciados por una contraparte nacional, que ha aportado, en promedio, un $30 \%$ del costo total (Delegación de la Comisión Europea para Colombia y Ecuador, 2005). Tradicionalmente han sido ejecutados en forma de «Unidad de Gestión» (compuesta por un codirector nacional y un codirector europeo). No obstante, según este Convenio Marco, la ejecución también se podía llevar a cabo directamente por el beneficiario o por una entidad tercera delegada por éste. Sin embargo, siempre se incluía como componente importante la presencia de la Asistencia Técnica Europea. Toda entidad pública colombiana que quería tener acceso a esta forma de ayuda debía tramitar los proyectos a través de la ACCI, contraparte en Colombia encargada por el Gobierno Nacional (Ley 318 de 1996) de la gestión de la cooperación internacional no reembolsable.

- Cooperación financiera y técnica. Tiene como destino las capas de población menos favorecidas y hace hincapié en la lucha contra la pobreza. Se aplica en las siguientes áreas: sector rural, seguridad alimenticia, derechos humanos, medio ambiente, apoyo a la mujer, protección de la infancia, prevención de desastres y rehabilitación. Esta línea es el mayor eje de contribución en América Latina. Para Colombia representa el $54 \%$ de toda la cooperación comunitaria. Bajo esta cooperación, la Comisión Europea definió para el período 2002-2006 proyectos por un monto de 105 millones de euros, que apoyan la estrategia de acciones dirigidas hacia la búsqueda de la paz, dentro de los que se encuentran los «Laboratorios de Paz», el proyecto de fortalecimiento del sector justicia y el apoyo a acciones contra minas antipersonales en Colombia, entre otras iniciativas.

- Cooperación económica. Se dirige a los países de mayor desarrollo relativo, con una perspectiva de interés mutuo entre la UE y los países socios, con el fin de facilitar las relaciones económicas y promover los intercambios comerciales, favorecer la integración 
regional y promover la transferencia de tecnología y de conocimientos. ${ }^{31}$

\section{2) La cooperación descentralizada a través de $O N G$}

En el marco de la cooperación descentralizada, existen líneas presupuestarias llamadas horizontales y sectoriales, dirigidas a ONG y a otras entidades sin ánimo de lucro públicas o privadas. En el marco de la cooperación descentralizada, las entidades en mención pueden presentar directamente solicitudes de proyectos a la Comisión Europea, sin pasar necesariamente por la ACCI; sin embargo, cada una de estas posibilidades de financiación tiene su propia dinámica.

Los instrumentos de cooperación más importantes de este grupo son los siguientes: ${ }^{32}$

- Cofinanciación $O N G$. Esta línea se destina a cofinanciar operaciones de desarrollo, de carácter tanto social como económico, emprendidas por ONG europeas en países en desarrollo. Los proyectos financiados en el marco de esta línea se dirigen a las capas más desfavorecidas de la población (mujeres, jóvenes en riesgo, minorías étnicas, etc.) y tienen siempre una vertiente social. Los campos de acción son: desarrollo rural, salud, microcrédito, capacitación, fortalecimiento institucional y participación comunitaria, entre otros. Los proyectos tienen la particularidad de ser presentados exclusivamente por ONG europeas, a partir de la iniciativa de una ONG local y socia en Colombia.

- Medio ambiente y bosque tropical. La primera línea se destina a apoyar procesos de desarrollo sostenible y a financiar proyectos que prevean una integración real de la dimensión medioambiental en el proceso de desarrollo. La segunda apoya actividades de protección, regeneración y gestión de las selvas tropicales.

31 Muchos proyectos de cooperación económica, tales como la difusión del SPG andino o la promoción de encuentros de negocios, son llevados a cabo en colaboración con los Eurocentros de Cooperación Empresarial de Bogotá y Medellín.

32 Existen otras líneas más, entre las cuales se destaca: lucha contra el sida, mujeres y desarrollo, droga, cooperación descentralizada, demografía y desarrollo. Con excepción de la línea «droga», los montos anuales son relativamente pequeños. 
- Democratización y derechos humanos. Creada en 1994, por impulso del Parlamento Europeo, la Iniciativa Europea para la Democracia y los Derechos Humanos (IEDDH) tiene el objetivo de promover y apoyar los procesos de democratización y la promoción de los derechos humanos en el mundo. Esta línea ha permitido crear la base para desarrollar importantes proyectos en este campo en Colombia. ${ }^{33}$

- Ayuda humanitaria (ECHO). La ayuda humanitaria y de emergencia es otorgada a través del Departamento de Ayuda Humanitaria de la Comisión Europea (ECHO). Esta agencia especializada fue creada en 1992 para responder de manera rápida y eficiente a las crisis humanitarias que se presentan en el mundo, y ha sido la institución que proporciona la mayor cantidad de ayuda humanitaria en el mundo. Aunque ECHO financia especialmente el socorro a las víctimas de las catástrofes naturales, a partir de 1997 empezó a intervenir en la crisis del desplazamiento forzado en Colombia, que ha afectado a más de dos millones de personas (ver anexo 5).

- Atención a población desarraigada. Esta línea se ha destinado en Colombia a contribuir a la rehabilitación y reintegración física y socioeconómica de los desplazados, al establecimiento de estructuras democráticas fuertes y a mitigar el impacto del conflicto interno. Más específicamente, a ayudar en la solución de necesidades de medio y largo plazo de los desplazados, complementando y superando la etapa de ayuda humanitaria y/o de emergencia. ${ }^{34}$

33 En el 2001, bajo esta línea, fue lanzado el Programa Andino de Derechos Humanos y Democracia 2002-2005, con un componente para cada país de la región. Como parte integral del Programa, se dispone de una Oficina de Coordinación Regional con sede en Bogotá, la cual presta también apoyo al resto de programas y proyectos de derechos humanos financiados por la Comisión Europea en la región. También cuenta con convocatorias anuales basadas en propuestas de cobertura mundial con focalizaciones específicas de trabajo, de las que salen proyectos por montos superiores a los 300000 euros. Y por último, los microproyectos están pensados para fortalecer la sociedad civil a escala local y apoyar su contribución al proceso democrático.

34 A partir del año 2002 la Delegación de la CE ha implementado programas para la atención integral de la población desplazada a través de ACNUR y varias intervenciones para el reestablecimiento social y económico de población desarraigada a través de ONG locales y europeas seleccionadas mediante convocatorias. Un total de 23 millones de euros han sido ejecutados durante el período 2002-2004, y otros 40 millones se prevén para el período 2005-2006. 


\section{Los programas horizontales}

Un capítulo especial de la cooperación de la UE lo representa cierto número de programas de alcance regional que se caracterizan por la ejecución de una serie de acciones que responden no sólo a un objetivo temático, sino también a una especificidad en favor de determinadas categorías de operadores.

La horizontalidad hace referencia al hecho de que son programas transversales de alcance regional y a que promueven la cooperación y el intercambio en sectores temáticos a través de la creación de redes o consorcios entre instituciones, universidades o empresas de Europa y América Latina.

- Cooperación regional andina. Los países de la Comunidad Andina reciben fondos adicionales de la Comisión Europea para cofinanciar actividades de cooperación, a través de una programación geográfica subregional andina, basada en un documento de estrategia regional que señala cinco desafíos principales: la democracia, el respeto por los derechos humanos y la estabilidad política; la integración (económica) regional; la cohesión social; el medio ambiente; y la lucha contra la droga.

- Cooperación regional América Latina. Alban: Programa de Becas de Alto Nivel para latinoamericanos en la Unión Europea. Alfa: Programa de Formación Académica entre la Unión Europea y América Latina. Urb-AL: Programa de Cooperación e intercambio entre ciudades de la Unión Europea y América Latina. @LIS: Alianza para la Sociedad de la Información. AL-Invest III: Programa de Promoción de Negocios entre la Unión Europea y América Latina. Oreal: Observatorio de las Relaciones Unión Europea/América Latina. Eurosocial: Programa Regional para la Cohesión Social en América Latina

-Otras acciones de cooperación con terceros paises. La Comisión Europea extiende ciertas acciones de algunos de sus programas internos a terceros países, dentro de los cuales Colombia se beneficia. Ejemplo de estas acciones son los proyectos adelantados a través de: Inco-Dev (Cooperación Científica y Tecnológica con los Países en Desarrollo), programa Juventud y Erasmus Mundus (cursos de máster y becas para estudiantes y académicos, así como asociaciones con universidades de terceros países). 
En cuanto a los actores principales que han desempeñado el papel de contrapartes de la UE en Colombia han sido: ACCI y las ONG. Ambos actores se han fortalecido como ejes importantes para la cooperación internacional. Han pasado de un papel administrativo y ejecutor de recursos financieros a desempeñar una función más participativa y constructiva de los procesos de resolución de las problemáticas sociales. Asimismo, en los últimos años se ha fortalecido el componente técnico de los proyectos, especialmente su formulación y evaluación, los cuales se han orientado hacia la búsqueda de una mayor sostenibilidad e impacto (L. González, 2002).

Sin embargo, en los últimos años estos actores - y otros de relevancia como organismos estatales, empresas privadas y otras entidades sin ánimo de lucro- han venido trabajando en la propuesta de crear un Sistema Nacional de Cooperación que reduzca la dispersión y descoordinación $^{35}$ de la cooperación que proviene de Europa y de otros Estados y organizaciones internacionales. «El Sistema Nacional de Cooperación busca ser un mecanismo orientado a la difusión de la política de cooperación, al manejo sostenible de la cooperación internacional, al fomento de la oferta y la demanda, y de un marco legal». ${ }^{36}$

De hecho, el mismo Gobierno reconoce la necesidad de coordinar la multiplicidad de aspectos que encierra la cooperación: «En los últimos años se ha reconocido la necesidad de integrar el Sistema Nacional de Cooperación Internacional en Colombia, como un esfuerzo de coordinación, consenso y articulación de todos los actores políticos, técnicos y reguladores de la cooperación internacional del país. Se parte de la identificación de algunas dificultades del modelo actual de trabajo de la cooperación internacional, que ameritan una atención integrada» (ACCI, $2004 a)$.

\subsubsection{La UE y el conflicto armado en Colombia}

Hasta hace muy pocos años el papel de la Unión Europea en la prevención de conflictos no había cumplido, según Cecilia Bruhn (2001),

35 En el momento de redactar este trabajo es técnicamente imposible conocer, por ejemplo, el dinero que ingresa al país por cooperación no oficial al desarrollo. No hay ningún organismo regulador de dichos flujos ni centralizador de la información.

36 Villegas (2001), citado por L. González (2002). 
GRÁFICA 4.5

EVOLUCIÓN DE LA AOD UE-COLOMBIA, 1998-2005

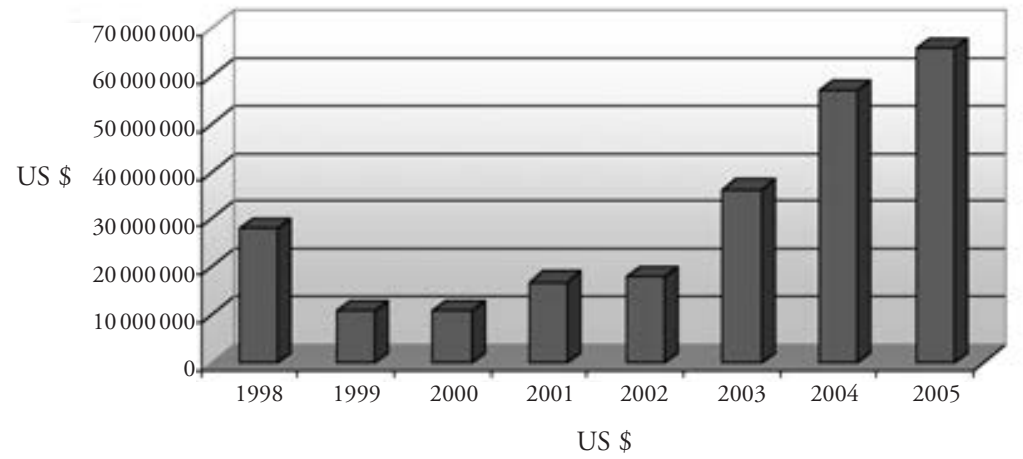

* Cifras hasta 2003 desembolsos efectivos. Cifras 2004-2005: Programación ya acordada.

FUENTE: Elaboración propia a partir de ACCI (2004b).

con las expectativas que corresponderían a su papel en el plano internacional. Tan sólo en 2001, a partir de la Comunicación de la Comisión Europea sobre prevención de conflictos y el Programa de la UE para la prevención de conflictos violentos, adoptado por el Consejo Europeo de Gotemburgo (Suecia) las acciones encaminadas a prevenir conflictos han pasado a formar parte de la agenda política de la UE. En los últimos años ha habido cambios importantes en la política exterior de la UE, cambios que han influido en la ayuda oficial al desarrollo.

La UE ha tenido bastante claro que el comercio, la ayuda y la cooperación se basan en un diálogo político que exige, como condición legitimadora de la contraparte, el respeto a los derechos humanos. Sin embargo, a partir de 2003 «la UE decidió que todos los nuevos acuerdos deberán incluir una cláusula en virtud de la cual los países socios se comprometen a respetar la no proliferación de armas de destrucción masiva» (European Commission, 2004, 6). Estos cambios, al parecer de analistas como Sanahuja, evidencian un giro de la política exterior hacia la «lucha global contra el terrorismo»:

tras los atentados del 11-S en Nueva York y Washington, y su brutal reedición el 11 de marzo de 2004 en Madrid, la nueva agenda de seguridad que ha 
impuesto la "guerra global contra el terrorismo" ha acelerado la tendencia al distanciamiento y el desinterés de la UE hacia la región [...]. Esa devaluación estratégica de Latinoamérica afecta especialmente a Centroamérica y el área andina, con la obvia excepción de Colombia, que tras el 11 de septiembre parecen estar fuera del radar (Sanahuja, 2004, 2).

En la opinión de otros analistas (Ardila, 2003; Aristizábal, 2004), los problemas internos de Colombia han pasado de ser problemas nacionales a convertirse en una desestabilización regional que demandaría la atención de actores externos relevantes como la UE. Las repercusiones internacionales de la producción y el tráfico de drogas, la expansión del conflicto armado a las zonas limítrofes ${ }^{37}$ y el desplazamiento de población civil a los países vecinos ${ }^{38}$ son claras muestras de desequilibrio en la región andina, además de las fronteras selváticas (la amazónica con Brasil y el Darién con Panamá). De tal manera,

Colombia es el único país de América Latina en el que el narcotráfico y la guerra interna son cuestiones estratégicas en las que sí puede esperarse atención política y respaldo económico por parte de la UE, y por lo tanto, pueden sustentar un diálogo sobre paz y seguridad que vaya más allá de los pronunciamientos genéricos y sin consecuencias prácticas que han dominado la agenda birregional en estas materias (Sanahuja, 2004, 8).

Sin embargo, la atención de la UE al conflicto colombiano ha tenido diversas tendencias en función de los actores y el contexto: las políticas del Gobierno colombiano frente al conflicto armado, la influencia de algunos Estados miembros sobre decisiones de la Unión, las orientaciones tomadas por Estados Unidos en materia antiterrorista y del papel ejercido por las organizaciones de la sociedad civil. Según Javier Sanín y Eduardo Pastrana (2004), las relaciones entre Colombia y la UE han sido afectadas recientemente por diferentes motivos: el apoyo incondicional de Colombia al ataque de EE. UU. a Irak y el cambio de Gobierno español, que ha

37 Algunos titulares de prensa que dan cuenta de esta influencia se encuentran por doquier: «Denuncian en Ecuador supuesta incursión de las FARC», El Tiempo, 19 de mayo de 2005. "Autoridades panameñas decomisan armas para las FARC», El Colombiano, 6 de junio de 2005. "Autoridades [sic] Colombia dicen "FARC mataron a militares venezolanos"», Puerto Rico, 20 de septiembre de 2004. <http://www.terra.com.pr/actualidad/articulo/html/act183634.htm>.

38 «Entre el 2000 y el 2002 unos 100000 colombianos habrían buscado refugio en algún momento en un país vecino huyendo de la violencia», El Tiempo, «En los confines de Colombia», 8 de agosto de 2003. 
dado leves giros a las relaciones con Colombia, como fue el caso de «los tanques». 39

Respecto a los primeros años del Gobierno de Uribe, las principales anotaciones críticas de la UE ante dicha administración podrían resumirse en las siguientes:

a) No comparte el darles facultades de policía judicial a las Fuerzas Armadas, como lo establece el «estatuto antiterrorista»; $b$ ) priorizan el respeto a los derechos humanos y al DIH; igualmente respetar el trabajo de las ONG en este campo; $c$ ) el énfasis en la búsqueda de la solución negociada del conflicto interno armado; $d$ ) su preocupación de que el proceso de desmovilización de los grupos de autodefensa o paramilitares no conlleve impunidad y que los aspectos de verdad, justicia y reparación sean considerados (Vargas Velásquez, 2004).

A estas razones, Sanín y Pastrana $(2004,2)$ añaden la crisis de los desplazados y el apoyo de la UE a las declaraciones de las diversas agencias de la ONU que trabajan en Colombia, ya que para la UE las Naciones Unidas son una expresión valorada del multilateralismo que incorpora en su política exterior y de seguridad.

El papel de la UE ha sido objeto de expectativas y debates similares desde finales de la década de los noventa, al empezar a suministrar ayuda al desarrollo y ayuda humanitaria a este país. Ambos han evolucionado como contrapunto a EE. UU. que, desde el año 1998, ha favorecido o bien una solución militar o bien el uso de la fuerza como medio para llevar a las facciones armadas a la mesa negociadora (Welna y López, 2004, 1).

Las expectativas que se tienen en Colombia sobre el papel de la UE en el conflicto armado son diversas, y en muchos casos, contrapuestas. Por una parte, un segmento considerable de la población cree que «Europa no entiende lo que ocurre en Colombia», ya que, en su opinión, es bastante permisiva con los grupos guerrilleros y demasiado exigente con el Estado

39 «Uribe destacó la donación de España de dos aviones [...] y la venta "en condiciones bastante equitativas" de tanques destinados a la "disuasión terrorista en controles de carretera”. Posteriormente se conoció que eran entre 32 y 46 tanques adquiridos por seis millones de dólares, cuyo origen de fabricación era francés. Sin embargo, el análisis de los expertos [...] mostró que los tanques difícilmente tendrían utilización en el territorio colombiano, a no ser en la Guajira, lo que desató la reacción venezolana en búsqueda de una escalada armamentista para reequilibrar su tradicional supremacía militar en la frontera [...] al poco tiempo, el nuevo Gobierno español de Rodríguez Zapatero [...] anunció que cumpliría las promesas electorales revesando la operación» (Sanín y Pastrana, 2004, 5). 
y sus instituciones. En esta dirección, el segundo periódico de mayor difusión en el país dedicaba un editorial al respecto:

Los europeos poco saben de Colombia y de los colombianos. Y lo que saben no les permite tener una imagen equilibrada de nuestro país. Allá sólo llegan las malas noticias. Aunque se han hecho esfuerzos, la gestión diplomática para dar a conocer la real realidad [sic] colombiana es muy débil e inconsistente. En cambio, los grupos guerrilleros sí han tenido una diplomacia alternativa constante que pinta un país que no es, y promueve otro que no debe ser. [...] Europa sigue siendo romántica y cree en las legiones liberadoras de Robin Hood. ${ }^{40}$

Esta postura suele ser compartida por algunos representantes de los partidos políticos mayoritarios, por empresarios, así como por la reducida clase media y alta colombiana. En general, atribuyen esta visión a un supuesto triunfo diplomático de las guerrillas, que, en alianza con algunas ONG europeas, han logrado convencer a eurodiputados y representantes políticos de diferentes instancias de la UE a endurecer sus críticas ante los Gobiernos colombianos, especialmente el de Uribe Vélez.

En el país causó incomprensión, y cierta indignación, que al presidente Uribe no le escuchara el pleno del Parlamento Europeo en una intervención en Estrasburgo en febrero de 2004, «ya que algunos legisladores europeos de izquierda boicotearon la asamblea y usaron pañuelos blancos con la inscripción "Paz y Justicia en Colombia" ". ${ }^{41}$ Además, muchos de ellos abandonaron el recinto en el momento de su intervención. ${ }^{42} \mathrm{Al}$ igual que ocurre con las organizaciones no gubernamentales internacionales (como Human Rights Watch o Amnistía Internacional) y con organismos multilaterales como la ONU, a «los europeos se les atribuye cierta tendencia izquierdista», fundada tanto en el supuesto silencio ante los atropellos de la guerrilla como en su aparente dureza ante los actos del Estado y el paramilitarismo. Para estos sectores de la población, el principal pro-

40 El Colombiano, editorial del 15 de julio de 2004.

41 "Uribe pide ayuda militar a la UE», BBC mundo.com, 12 de febrero de 2004. $<$ http://news.bbc.co.uk/hi/spanish/latin_america/newsid_3480000/3480951.stmen>.

42 «Según Paul Dupret, asesor de Izquierda Unitaria Europea, al menos 150 parlamentarios utilizaron una bufanda blanca en señal de protesta y por lo menos 100 abandonaron el recinto. Sin embargo, otras fuentes señalan que la protesta fue menor y que sólo dejaron el lugar unos 20 diputados». "Uribe critica a eurodiputados», BBC mundo.com, 10 de febrero de 2004. 
blema del país es la guerrilla, y los paramilitares corresponden a una defensa, en ocasiones considerada legítima, de grupos de terratenientes, ganaderos y comerciantes.

En este contexto, las altas esferas del Gobierno se han pronunciado en contra de las críticas emitidas por el Parlamento Europeo: «El presidente de Colombia, Álvaro Uribe, enfrentó a sus críticos en el Parlamento Europeo por los cuestionamientos a su política de seguridad». ${ }^{43}$ Por su parte, el vicepresidente de la República, Francisco Santos, se pronunció en contra del apoyo de una ONG danesa a las FARC en estos términos:

Exigimos a la Unión Europea y a Dinamarca que actúe contra los grupos de extrema izquierda de la misma forma que hace contra los grupos de extrema derecha, pues apoyar a estos últimos sí es considerado un delito. Esa es una hipocresía y una doble moral que tenemos que acabar. ${ }^{44}$

Por otra parte, uno de los pasos en el ámbito diplomático del anterior Gobierno colombiano encabezado por Andrés Pastrana (1998-2002) fue la transmisión de la corresponsabilidad internacional en el tráfico y especialmente en el consumo de narcóticos como supuesta financiación indirecta para los grupos armados. El éxito de la idea de responsabilidad compartida en cuanto a los narcóticos ha servido para que tanto políticos como medios periodísticos miren a Europa de otro modo, aunque no siempre en el tono diplomático convencional. En estos términos se refería el editorial citado anteriormente del segundo diario más leído en Colombia: «Y apenas ahora asume su corresponsabilidad [la UE], no sólo por ser consumidora de alucinógenos sino lavadora del dinero maldito de la droga». De forma similar, aunque con mayor discreción, el actual Gobierno ha concebido el papel de la UE en esta vía:

Respecto a la discusión pública sobre el rol de la UE para aportar de forma más coherente en Colombia, Gaviria [José Obdulio Gaviria, asesor presidencial de Uribe] recordó el tema de la corresponsabilidad en la lucha contra las drogas y evocó las últimas cifras crecientes de consumo, en un mercado que «según los últimos reportes se dirige de forma creciente hacia Europa». ${ }^{45}$

43 BBC mundo.com, 12 de febrero de 2004.

44 "Exigimos a la UE que actúe contra grupos de extrema izquierda": Francisco Santos», El Tiempo, 12 de enero de 2005, sección «Derechos Humanos».

45 "UE analiza su papel en crisis colombiana», El Colombiano, jueves, 26 de mayo de 2005 . 
Por parte de los movimientos sociales, entre los que destacan las ONG colombianas y europeas, hay una solicitud expresa de mayor acompañamiento y compromiso por parte de la UE ante la situación colombiana. La ven como un gran apoyo político en cuanto a la influencia que han ejercido para mejorar el comportamiento gubernamental en materia de derechos humanos, la protección de los defensores de éstos, la incorporación de «temas sociales» en el Plan Colombia, la exigencia de leyes que eviten la impunidad, etc. Además, muchas de éstas sugieren «un nuevo liderazgo europeo en un proceso de paz colombiano» (Welna y López, 2004, 1). En los últimos años, Europa se ha fortalecido como escenario del enfrentamiento cívico-político para mostrar la «verdadera cara del conflicto». Las OSC y el Gobierno rivalizan en alcanzar plataformas de divulgación europeas para exponer lo que cada cual considera como «la realidad de la situación colombiana».

En la historia política colombiana, la sociedad civil ha sido un actor débil y disperso; por tanto, la UE entiende que este actor debe participar para fortalecer la democracia colombiana. El organismo europeo, al igual que otros actores multilaterales, dirige sus esfuerzos a la resolución negociada del conflicto y resalta el papel del las OSC: «La ONU, la UE y Mercosur deben estimular los esfuerzos de la sociedad civil de los cinco países andino-amazónicos en la búsqueda de la paz» (Aristizábal, 2004, 9). Además, en la mesa de donantes de Londres la participación de la sociedad civil fue un paso importante para su inclusión en las orientaciones de la cooperación internacional, específicamente en los temas vinculados al conflicto. La UE ha sido uno de los principales actores que ha presionado al Gobierno colombiano para promover actitudes de diálogo y apertura ante las consideraciones de las OSC.

No obstante, la UE y sus miembros tienen diferentes concepciones sobre el conflicto en Colombia, aunque éstas divergen en función de los organismos y, como hemos afirmado, de la «calidez» o «enfriamiento" de las relaciones bilaterales. Esta variedad de opiniones se puede congregar en las siguientes tendencias:

\section{1) Presión directa de partidos politicos y parlamentos de los Estados miembros de la Unión Europea hacia el Gobierno colombiano}

Algunos países miembros de la Unión han ejercido una presión directa sobre el Gobierno colombiano respecto a la denuncia sobre la violación 
de los derechos humanos, a la poca atención a la población desplazada, al reconocimiento de la existencia de un conflicto armado y a otros temas que preocupan a los políticos europeos. ${ }^{46}$ Por lo general, se trata de una acción emprendida por parte de grupos de presión de la sociedad civil que logran el apoyo de partidos políticos, casi siempre de izquierda, ${ }^{47}$ aunque también de otras tendencias (ambientalistas ${ }^{48}$ y partidos de centro derecha... ${ }^{49}$ ) para aprobar condenas, manifiestos o cartas dirigidas al Gobierno colombiano o al Gobierno del propio país con el propósito de influir sobre las relaciones exteriores con el país andino. Muchos de estos grupos (entre los que destacan más de cien ONG, asociaciones y sindicatos que integran la Red Europea de Hermandad y Solidaridad con Colombia) están asociados con organizaciones colombianas o cuentan con una presencia consolidada en el país. Asimismo, presentan informes y denuncias ante organismos como las Naciones Unidas.

\section{2) El Parlamento europeo como escenario de debate cívico-político} en torno al conflicto colombiano

El Parlamento europeo ha sido escenario para la exposición de la situación colombiana en la versión de las OSC, que han contado, en algunas ocasiones, con más respaldo que las propias exposiciones del Gobierno colombiano. Una de las presencias más recientes y difundidas de la sociedad civil fue a través de la Plataforma Colombiana de Derechos Humanos, Democracia y Desarrollo. El portavoz ante el Parlamento fue el padre Javier Giraldo (director del CINEP), que el 1. ${ }^{\circ}$ de diciembre 2004 presentó al Parlamento europeo en Estrasburgo el informe El embrujo con-

46 Un ejemplo de titulares de prensa bastante frecuentes en esta dirección: «Diputadas belgas piden solución pacífica a conflicto colombiano», Efe. El Colombiano, 23 de febrero de 2005.

47 En este sentido ha sido considerable el papel ejercido por el bloque de la Izquierda Unitaria Europea GUE.

48 Ante la masacre de San José de Apartadó, «El pasado jueves 17 de marzo [2005], los Senadores del partido VERDES de Italia, [...] han organizado una conferencia de prensa en Roma-Palacio Madama (sede del Senado de la República), para denunciar la masacre [...]» (Morsolin, 2005).

49 Algunos políticos franceses de centro-derecha han presionado al Gobierno colombiano para facilitar el intercambio humanitario que culmine con la liberación de la senadora colombiana de origen francés Ingrid Betancourt, secuestrada por las FARC hace más de cuatro años. 
tinúa, que daba continuidad al título del informe del primer año de Gobierno de Uribe titulado El embrujo autoritario: «Pedimos a la Unión Europea y a los europarlamentarios solidaridad, apoyo político y reconocimiento de los Derechos Humanos». ${ }^{50}$

\section{3) Pronunciamientos oficiales de la Comisión Europea (CE) frente a la salida negociada al conflicto}

Como voz oficial de la Unión Europea, el tono de los pronunciamientos de la CE es, obviamente, más diplomático y conciliador. No obstante, leyendo determinadas afirmaciones es probable evidenciar reiteradas contradicciones, no sólo con los mensajes emitidos por el Parlamento europeo, sino por la tensión implícita en el apoyo a la política del presidente Uribe bajo unas condiciones que, según un buen número de informes, no se están cumpliendo. ${ }^{51}$ Para los analistas expuestos en este estudio, la solución del conflicto armado del Gobierno de Uribe no pasa por vías de negociación pacífica; sin embargo, la Comisión declara el «apoyo de la UE a Uribe y a la solución pacífica del conflicto» (Euronotas, 2004, 1).

Por una parte, la Comisión no siempre se pronuncia desde Bruselas; frecuentemente las comunicaciones de la Comisión se hacen a través del delegado de la CE para Ecuador y Colombia en Bogotá, lo cual influye en el tono de las recomendaciones o sugerencias al Gobierno colombiano. Asimismo, la CE es la encargada de administrar las políticas de cooperación entre la UE y Colombia, de tal manera que debe procurar coordina-

50 «Graves denuncias del Gobierno de Uribe en el Parlamento Europeo», CM\& Europa Press, 2 diciembre 2004. <http://www.educweb.org/webnews/ColNews-Dec04/ Spanish/Articles/UnionEuropeaanalizaelconf.html>.

51 Algunas de las condiciones de la UE sobre el Gobierno colombiano son: «la importancia de actuar pronta y efectivamente contra la impunidad y la connivencia, en particular en lo que se refiere a los grupos paramilitares. [...] y de modo tal que se respete el derecho de las víctimas del conflicto a la verdad, la justicia y la reparación. [...] El Consejo [...] ha instado al Gobierno a hacer frente urgentemente a esta situación, en particular aplicando inmediatamente las recomendaciones específicas del Alto Comisionado de las Naciones Unidas para los Derechos Humanos, incluida la recomendación de publicar un plan de acción sobre los derechos humanos con un calendario para su aplicación. [...] El Consejo, tomando nota con honda preocupación del sufrimiento de los desplazados internos y de los habitantes de las comunidades cercadas, ha confirmado la disposición de la UE a colaborar con el Gobierno colombiano y la ONU para realizar una labor específica y coordinada con objeto de resolver esta crisis» (Euronotas, 2004). 
ción y coherencia con las instituciones colombianas. Además, hace unos años inició el apoyo a importantes proyectos que se han constituido como acciones significativas hacia la pacificación de determinadas regiones:

Esto explica el papel desempeñado por Europa en acompañar el esfuerzo de paz negociada en el pasado reciente — con seguridad lo hará en el futuro- - y la importante participación en la financiación a los Laboratorios de Paz en nuestro país; el primero de ellos, el Programa de Desarrollo y Paz del Magdalena Medio, ha cumplido una extraordinaria labor consolidando ambientes de paz regionales y ahora el del Oriente Antioqueño; lo anterior porque la Unión Europea y sus Estados miembros son el mayor donante de asistencia oficial del mundo [...] esto desvirtúa la opinión, bastante generalizada, de que los europeos hablan mucho y hacen poco (Vargas Velásquez, 2004).

Uno de los aspectos que más preocupa a la CE en sus sutiles llamados de atención ante el Gobierno colombiano es la situación de las ONG en Colombia. Muchos de sus mensajes hablan de la necesidad de respaldo al «papel de la sociedad civil, en particular de las ONG, en la búsqueda de la paz en Colombia» (Euronotas, 2005, 4), ya que es uno de los sectores que más ha sido afectado por sus denuncias ante los actores armados y el Estado. Asimismo, la $\mathrm{CE}$ «ha puesto de relieve las peligrosas condiciones de seguridad en las cuales se ven obligadas a actuar en Colombia las ONG nacionales e internacionales y las organizaciones de la sociedad civil, entre ellas los sindicatos y los defensores de los derechos humanos, e insta al Gobierno a cooperar estrechamente con todos esos grupos con objeto de garantizar su protección» (Euronotas, 2004).

Por otra parte, el papel de la UE como mediador en los procesos de paz se ha visto limitado a partir de la inclusión de la guerrilla de las FARC en la lista de grupos terroristas de la UE elaborada en 2001.

EE. UU. presionó a la ONU y a otros gobiernos para que incluyeran a las milicias paramilitares colombianas (AUC) y a dos grupos guerrilleros - primero las FARC y luego, tras largas negociaciones, el ELN- en la lista de organizaciones terroristas. La incorporación del FARC a la lista europea de organizaciones terroristas en mayo de 2002, y del ELN en abril de 2004, podría limitar la capacidad de los gobiernos europeos para influenciar la toma de decisiones en ambos grupos armados (Welna y López, 2004, 5).

Uno de los temas que ha despertado más discrepancias entre la UE y Colombia es la propia naturaleza del conflicto y, por tanto, la forma de orientar las vías de su resolución. El Gobierno colombiano considera que el tráfico de drogas es la causa de buena parte de los problemas del país, ya 
que los traficantes, en una alianza estratégica con grupos armados, cometen actos «terroristas»; en consecuencia, debe haber una estrategia militar para detener a los «narcoterroristas». Por su parte, la UE enfatiza el origen social del conflicto y advierte sobre la necesidad de responder a las grandes desigualdades sociales para dirigir una resolución negociada.

\section{De Londres a Cartagena: un giro que preocupa a las organizaciones}

Desde hace unos años se consolidó el G-24, integrado en su mayoría por países de la Unión Europea, EE. UU., Japón, Corea del Sur y Rusia, que asumieron un compromiso conjunto para cooperar con Colombia durante la Administración del presidente Andrés Pastrana bajo la figura de una «Mesa de Donantes», y continuó con la presidencia del Gobierno de Uribe Vélez. En la reciente reunión de la Mesa de Donantes de Cartagena (febrero de 2005) se dieron importantes pasos que, en la opinión de algunos observadores (Pérez Guzmán, 2005), determinan un giro en las relaciones UE-Colombia respecto a los acuerdos logrados en la reunión de Londres de 2003. Uno de los principales avances de la Mesa de Donantes de Londres había sido el compromiso del Gobierno colombiano por acoger las recomendaciones de la ONU sobre el respeto de los derechos humanos y el DIH.

Las organizaciones de la sociedad civil, teniendo en cuenta la Declaración de Londres, crearon la «Alianza de organizaciones sociales y afines por una cooperación internacional para la paz y la democracia en Colombia», conformada por más de 122 organizaciones nacionales y regionales, sociales, ambientales, sindicales, de derechos humanos, iniciativas de paz, democracia y desarrollo. "Durante este tiempo la Alianza animó, impulso y coordinó las discusiones, el seguimiento a Londres, la elaboración de documentos y la participación en los espacios que hubo con el Gobierno» (Pérez Guzmán, 2005).

El Gobierno logró congregar otras organizaciones de la sociedad civil que, según Pérez Guzmán (2005), eran afines a sus políticas y pudieran hacer contrapeso a la postura de la Alianza:

El Gobierno nacional, para contrarrestar el peso de las críticas de las ONG y organizaciones sociales, impone un escenario de sociedad civil en el que participarán también, además de las organizaciones de la Alianza y de las ONG internacionales de Cooperación, la Confederación de Municipios de 
Colombia, la Confederación de ONG, el Consejo Gremial [empresarios], las fundaciones privadas [de los gremios]; [...] En todo caso, salta a la vista la desventaja en la que se encuentra la Alianza y la cooperación internacional no gubernamental frente a los demás delegados, afines a las políticas del presidente Uribe. Resulta claro, una vez más, que, con la presencia de algunos sectores de la sociedad civil en la reunión, el Gobierno legitima y gana el aval necesario para el proceso (Pérez Guzmán, 2005).

A pesar del compromiso adquirido por el Gobierno de Colombia en Londres, "éste consideró que la "declaración de Londres" constituía una camisa de fuerza y obstaculizaba el desarrollo de sus estrategias y políticas» (Pérez Guzmán, 2005). Por la presión de las organizaciones sociales colombianas, las agencias de cooperación internacional, la Comisión de Derechos Humanos de Naciones Unidas y el G-24 que estuvieron en Londres, «el Gobierno aceptó algunos espacios de discusión sobre su estrategia de cooperación internacional, y en ese marco el seguimiento a la declaración de Londres y al cumplimiento de las recomendaciones de la alta comisionada de Naciones Unidas para los derechos humanos» (Pérez Guzmán, 2005).

Según Pérez Guzmán (2005), en la Cumbre de Cartagena se evidenció una tendencia de la Unión Europea y los Gobiernos participantes en la cumbre a "compartir la reinterpretación del conflicto en clave antiterrorista». En la declaración de Londres los principios conductores (casi como condiciones) fueron varios: el cumplimiento de las recomendaciones de Naciones Unidas en materia de derechos humanos por parte del Gobierno de Colombia; la necesidad de la salida política negociada al conflicto armado y una política estatal de paz; la concertación con las organizaciones de la sociedad civil y de derechos humanos, así como plenas garantías para el desarrollo de sus labores; la necesidad de tomar medidas eficaces contra la impunidad y el diseño de una estrategia coordinada y coherente de cooperación, entre otros. Mientras que en la declaración de Cartagena los representantes gubernamentales respaldaron al presidente Uribe en su política de seguridad democrática, en sus esfuerzos por fortalecer la lucha contra el terrorismo y las drogas ilícitas; manifestaron el apoyo al proceso de desmovilización y reinserción con los grupos paramilitares, recomendando la importancia de que exista un marco jurídico que considere los principios de verdad, justicia y reparación.

La Unión Europea mantiene su posición ambigua en cuanto a la cooperación en Colombia, pero cada vez se acerca más a los postulados uribistas y que el pueblo colombiano no obtendrá ninguna mejoría sustancial de la situa- 
ción, con este evento, pues al parecer entre Londres y Cartagena se han «embolatado» [perdido], más aún, sus derechos (Pérez Guzmán, 2005).

De cara a los próximos años, otro investigador del papel de la UE en el conflicto colombiano afirma que es necesario trabajar por la democratización del país mientras llega la negociación política:

Es positivo y necesario que la ONU y la UE continúen con la búsqueda de una salida política negociada al conflicto [...]. Pero también es necesario que, mientras se inicia la negociación, se amplíe el apoyo a los esfuerzos que muchas comunidades, movimientos sociales y gobiernos municipales o departamentales están realizando por la democratización de la sociedad, de sus instituciones públicas y de los sistemas productivos. Este trabajo es indispensable para presionar hacia la negociación y para que, cuando ésta llegue, sea más incluyente, tenga mayor margen de independencia frente a EE.UU. y, con todo ello, no se quede sólo en un nuevo giro pendular del dilema «o guerra total o negociación» (Aristizábal, 2004, 10).

\subsection{La cooperación española ${ }^{52}$}

España ha sido, en los últimos 10 años, el país que más ha incrementado proporcionalmente su AOD bilateral a Colombia (gráfica 4.6). Pasó de ser uno de los países donantes que menos aportaba, con el 0,6\% de la ayuda total entre 1987-1990 (Henao, 1991), a ser el segundo país que más contribuye, con el $13 \%$ de la AOD bilateral en 2003 (ACCI, $2004 a$ ). No obstante, hay que resaltar que más del $70 \%$ de los presupuesto de los últimos años (1999-2003) ha correspondido a ayuda financiera reembolsable, concretamente créditos FAD (82\%) y microcréditos $(18 \%)$.

52 Además de la cooperación bilateral, descentralizada y no gubernamental, la cooperación española también ha participado a través de otros mecanismos que, a pesar de su relevancia, no se recogen en el presente estudio en aras de la brevedad y de la descripción de la contextualización general. Estas otras expresiones de cooperación son las derivadas de las cumbres iberoamericanas de jefes de Estado y de Gobierno, en la que tiene especial interés para Colombia el Programa Iberoamericano de Ciencia y Tecnología para el desarrollo (CYTED) y el Programa del Fondo Indígena. Asimismo, España contribuye con organismos multilaterales que tienen una gran trayectoria en Colombia: ACNUR, FAO, OEA, UNICEF, UE, OIT, OPS, PNUD y FODEPAL. 


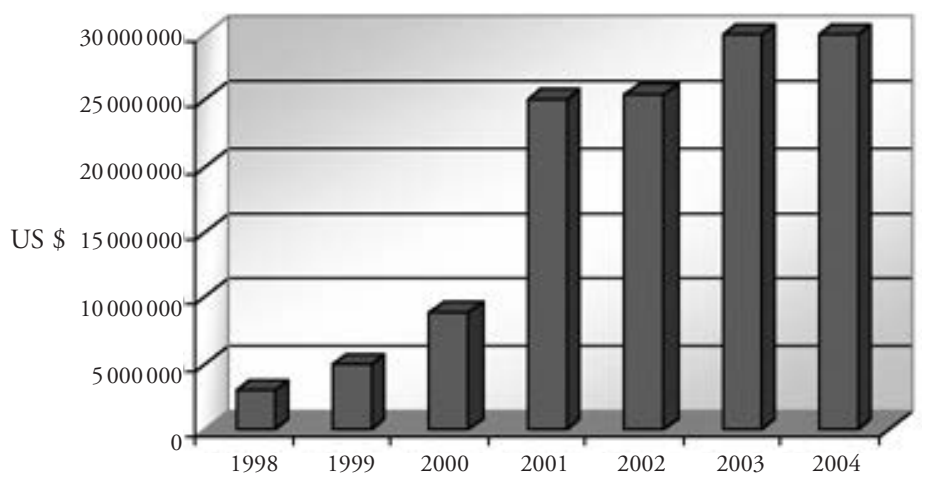

FUENTE: Elaboración propia a partir de ACCI (2004b).

La inversión de la cooperación española en Colombia en los últimos 5 años (1999-2003) supera los 228 millones de euros, con un $26 \%$ correspondiente a la cooperación no reembolsable y un $74 \%$ a la cooperación financiera reembolsable, entre la que se incluyen el Fondo de Microcréditos financiado por la AECI y el Fondo de Ayuda al Desarrollo financiado por el Ministerio de Economía español. Desglosada por el carácter público o privado de operadores, se constata que un $94 \%$ es cooperación bilateral y un $6 \%$ cooperación a través de ONG españolas. Este dato supone que más de un tercio de la cooperación no reembolsable estaría canalizada a través de estos importantes operadores (OTC, 2004, 5-6).

Asimismo, en cuanto a la cooperación no gubernamental internacional, es el país que tiene mayor presencia de ONGD en Colombia (OTC, $2004,3)$. Tan sólo la observación de estos indicadores demuestra la creciente participación de España en la configuración de la cooperación internacional percibida por el país andino.

La cooperación bilateral ha tenido, como principal mecanismo de coordinación, la realización de comisiones mixtas entre representantes de los dos Gobiernos. Entre 1999 y 2002 estuvo en vigencia la V Comisión Mixta y hasta hace poco rigieron los acuerdos de la VI Comisión, que tuvo vigencia hasta 2006. Durante la celebración de la reunión de la VI Comisión Mixta se señaló: 
El Plan Director de la Cooperación Española prioriza a Colombia como país preferente de la cooperación para el desarrollo, por su especial situación derivada del conflicto interno, y por el especial interés que reviste el contenido del nuevo programa, orientado fundamentalmente a acompañar los esfuerzos de Colombia por superar aquél. De esta forma, España hace suyo el principio de «desarrollo como mejor contribución a la paz» (AECI y ACCI, 2003, 4).

Los tratados o convenios vigentes entre España y Colombia en materia de cooperación han sido los siguientes:

TABLA 4.2

TRATADOS Y CONVENIOS VIGENTES ENTRE ESPAÑA Y COLOMBIA EN MATERIA DE COOPERACIÓN

\begin{tabular}{|l|l|}
\hline Convenio, acuerdo o tratado & Fecha \\
\hline Convenio Cultural & 11 de abril de 1953 \\
Convenio Básico de Cooperación Científica y Técnica entre el & \\
Gobierno de la República de Colombia y el Gobierno de España & 20 de junio de 1979 \\
Acuerdo Complementario General de Cooperación & 31 de mayo de 1988 \\
Tratado General de Cooperación y Amistad & 29 de octubre de 1992 \\
La VI Comisión Mixta Hispano-Colombiana que definió el & 19 de junio de 2003 \\
Programa de Cooperación Bilateral 2003-2006 & \\
\hline
\end{tabular}

FUENTE: ACCI (2004a).

El Plan Director de la Cooperación Española (2001-2004) recogía seis sectores prioritarios de actuación (ver tabla 4.3).

Además, la Comisión estableció tres enfoques horizontales que debían estar presentes en todos los proyectos de la cooperación española: lucha contra la pobreza, la promoción de la igualdad entre hombres y mujeres, y la sostenibilidad medio ambiental.

En las actas de la VI Comisión Mixta, la delegación española fijó los criterios para lograr una mejor eficacia:

Al efecto de alcanzar una mayor eficacia de la cooperación española, se fijan como criterios de actuación: la concentración geográfica y sectorial, la coordinación entre los diversos actores (incluidas las ONGD, las comunidades autónomas y las entidades locales), y la complementariedad entre los distintos instrumentos de la cooperación española, así como la coordinación con las actuaciones de otros países donantes y organismos internacionales, especialmente de la Unión Europea y del Sistema de Naciones Unidas (AECI y ACCI, 2003, 4). 
TABLA 4.3

SECTORES PRIORITARIOS DE ACTUACIÓN SEGÚN EL PLAN DIRECTOR DE ESPAÑA

\begin{tabular}{|c|c|}
\hline $\begin{array}{l}\text { Sectores } \\
\text { comisión mixta }\end{array}$ & Principales proyectos en Colombia \\
\hline $\begin{array}{l}\text { 1. Necesidades } \\
\text { sociales básicas }\end{array}$ & $\begin{array}{l}\text { 1. Fortalecimiento del tejido social y productivo de indígenas y negros de Chocó } \\
\text { 2. Ayuda Humanitaria de Emergencia } \\
\text { 3. Dotación de centros polifuncionales para población desplazada en el departamento del } \\
\text { Meta colombiano } \\
\text { 4. Fortalecimiento de la democracia desde una perspectiva de inclusión de las mujeres en } \\
\text { igualdad de oportunidades con los hombres } \\
\text { 5. Fortalecimiento de los servicios sociales en Bogotá }\end{array}$ \\
\hline $\begin{array}{l}\text { 2. Inversión en el } \\
\text { ser humano }\end{array}$ & $\begin{array}{l}\text { 1. Red de voces e imágenes para un nuevo país } \\
\text { 2. Fortalecimiento de las emisoras indígenas del Cauca } \\
\text { 3. La acción cultural española en Colombia } \\
\text { 4. Centro de formación de Cartagena de Indias } \\
\text { 5. Programa de preservación del patrimonio histórico } \\
\text { 6. Becas, capacitación y cooperación interuniversitaria }\end{array}$ \\
\hline $\begin{array}{l}\text { 3. Infraestructuras } \\
\text { y promoción del } \\
\text { tejido económico }\end{array}$ & $\begin{array}{l}\text { 1. El programa de microcréditos } \\
\text { 2. Desarrollo integral de dos comunidades en situación de marginalidad de la costa atlán- } \\
\text { tica colombiana } \\
\text { 3. Programa de desarrollo comunitario en el barrio Las Américas (Valle del Cauca) } \\
\text { 4. Desarrollo de la autogestión y las capacidades productivas en comunidades desplazadas } \\
\text { por la violencia en Santa Marta } \\
\text { 5. Planificación y gestión del hábitat en barrios receptores de desplazados/as en el Caribe } \\
\text { colombiano }\end{array}$ \\
\hline $\begin{array}{l}\text { 4. Defensa del } \\
\text { medio ambiente }\end{array}$ & $\begin{array}{l}\text { 1. Fortalecimiento de la gestión y el manejo del Sistema de Parques Nacionales Naturales } \\
\text { de Colombia } \\
\text { 2. Contribución a la autosostenibilidad y el manejo común con las comunidades del Par- } \\
\text { que Nacional Tayrona } \\
\text { 3. Formulación y puesta en marcha de los Programas Nacionales de capacitación e infor- } \\
\text { mación pública en prevención y mitigación de incendios forestales en Colombia } \\
\text { 4. Ordenamiento y protección ambiental para el desarrollo comunitario en la selva de } \\
\text { Matavén, Vichada, y su área de influencia } \\
\text { 5. Creación de una base social de apoyo al Plan Nacional de Conservación del Caimán } \\
\text { Llanero }\end{array}$ \\
\hline $\begin{array}{l}\text { 5. Participación } \\
\text { social, desarrollo } \\
\text { institucional } \\
\text { y buen gobierno }\end{array}$ & $\begin{array}{l}\text { 1. Fortalecimiento institucional de la gobernación del departamento del Cauca } \\
\text { 2. Comunicación integral, adecuación, potenciación y racionalización de la Federación } \\
\text { Colombiana de Municipios } \\
\text { 3. Asistencias técnicas para el desarrollo institucional y el desarrollo productivo } \\
\text { 4. Programa de desarrollo institucional y apoyo a la Agencia Colombiana de Cooperación } \\
\text { Internacional (ACCI) } \\
\text { 5. Fortalecimiento municipal en la costa Pacífica del departamento del Cauca }\end{array}$ \\
\hline $\begin{array}{l}\text { 6. Prevención } \\
\text { de conflictos } \\
\text { y construcción } \\
\text { de la paz }\end{array}$ & $\begin{array}{l}\text { 1. Apoyo al diseño de un Plan Social Integral en los barrios marginales de Medellín } \\
\text { 2. Pedagogía y cultura en regiones y sectores desde la Asamblea Permanente de la Socie- } \\
\text { dad Civil por la Paz } \\
\text { 3. Ampliación del Marco de Acción de una pedagogía integral para la Paz y el respeto a } \\
\text { los DD. HH. } \\
\text { 4. Red Social de Promotores de Derechos Humanos } \\
\text { 5. Construcción ciudadana de la paz } \\
\text { 6. Fortalecimiento del tejido social en Antioquia hacia un plan congruente de paz }\end{array}$ \\
\hline
\end{tabular}

FUENTE: Elaboración propia a partir de AECI y ACCI (2003). 
En tal sentido, las áreas de concentración geográfica definidas se dividieron en dos grupos según la prioridad de la cooperación española: por una parte, "Cartagena (donde se concentrarán las actividades a medida que concluyan los proyectos en ejecución en el Caribe colombiano), área urbana de Bogotá y los departamentos de Antioquia, Cauca y Chocó» (AECI y ACCI, 2003, 7). En segundo orden se definió la región del Magdalena Medio, los departamentos de Valle del Cauca, Nariño y Córdoba.

En cuanto a los tipos de cooperación, la bilateral centralizada es la que predomina, con el $80 \%$ de los recursos (ver gráfica 4.7). Sin embargo, al desagregar la cooperación no reembolsable, la participación de las ONG se incrementa al punto de gestionar el $30 \%$ de los recursos.

La cooperación descentralizada, aquella que ha provenido de las comunidades autónomas, diputaciones provinciales y ayuntamientos españoles, ha contado con recursos propios para apoyar programas y proyectos de desarrollo. Las convocatorias se han dirigido a ONGD españolas y, en algunos casos, a entidades territoriales del país receptor. Sin embargo, tanto la Agencia Colombiana como la Española, insistieron en señalar las dificultades de conocer las cantidades, sectores, proyectos y actores de este tipo de cooperación. La OTC de la Embajada española en Colombia calculó en 6 millones de dólares anuales la cooperación descentralizada entre 1999 y 2003 (OTC, 2004, 4).

\section{GRÁFICA 4.7}

APORTES A LA COOPERACIÓN COLOMBIANA POR TIPO DE COOPERANTE (Proyectos vigentes en 2004)

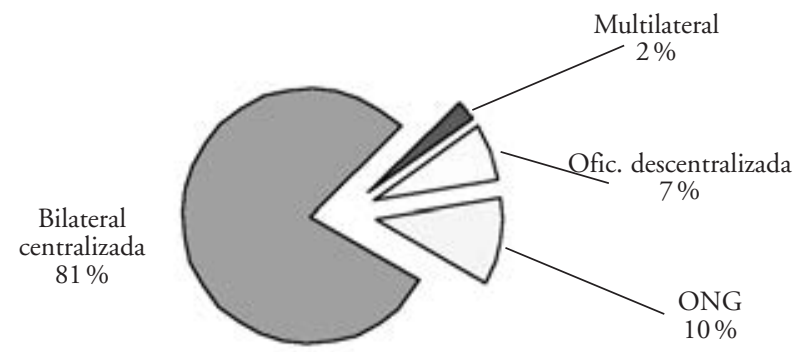

FUENTE: Elaboración propia a partir de Embajada española en Colombia y AECI (2004). 
Las 10 comunidades autónomas que más recursos aportaron a este tipo de cooperación en 2004 fueron, en orden, Valencia, Madrid, Navarra y Cataluña, con más de 700000 euros. En segundo lugar aparecen Asturias, País Vasco, La Rioja, Baleares, Castilla-León y Aragón con aportaciones entre 150000 y 400000 euros. Sin embargo, la cantidad aportada por la Comunidad Valenciana fue superior a la suma de las nueve comunidades restantes, con más de 6 millones de euros. Por diputaciones destaca la de Barcelona y por ayuntamientos el de Madrid.

Las principales entidades públicas que destinan recursos a la cooperación colombiana o contribuyen con una ONGD que tiene presencia en el territorio colombiano son las siguientes. En los últimos años (2004-2006) han estado a la cabeza de los principales organismos, según el volumen de sus aportaciones, la Agencia Española de Cooperación Internacional y el Ministerio de Industria, Turismo y Comercio, con más del $80 \%$ del monto total. El 20\% restante de las aportaciones se reparte entre 89 organismos públicos, entre los que se encuentran ministerios, comunidades autónomas, diputaciones provinciales y ayuntamientos (ver mapa 4.1).

AOD ESPAÑOLA. PROYECTOS EN EJECUCIÓN, 2006

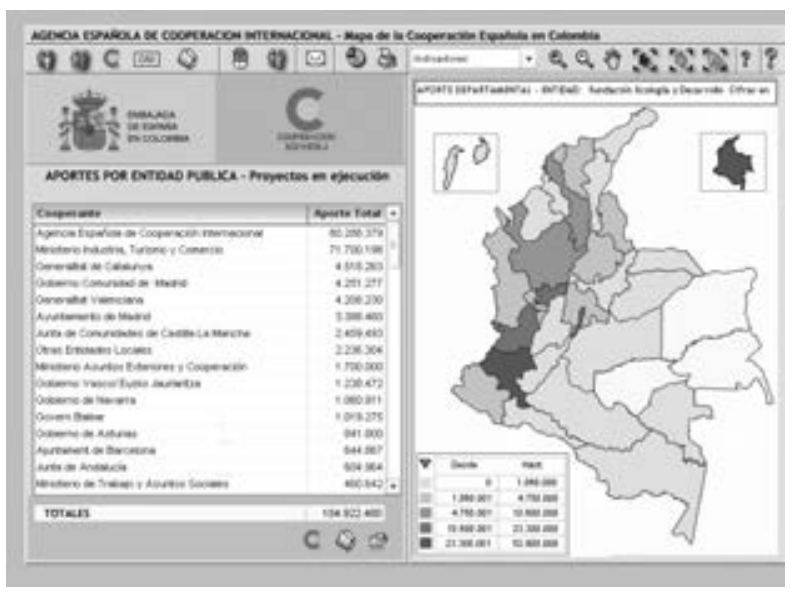

FUENTE: AECI (2006). 
Por ejemplo, en 2004 los departamentos colombianos que más fondos recibieron de la cooperación española fueron Nariño (casi 34 millones de euros), Cauca (20 millones) y Bolívar (15 millones). Estas distribuciones coinciden, en parte, con las prioridades geográficas establecidas en la VI Comisión Mixta, ya que aparecen como mayores receptores los departamentos de Cauca y Bolívar (cuya capital es Cartagena). No obstante, los otros departamentos no corresponden a dicha prioridad. En 2006 disminuyó considerablemente la aportación recibida por Nariño (que pasó a 2 millones de euros), mientras que se mantuvieron estables el Cauca y Bolívar. En este último año se han seguido de forma más coherente los criterios de la Comisión Mixta, y, efectivamente, aumentaron las asignaciones para Caldas (16 millones), la zona urbana de Bogotá (15 millones), Valle del Cauca (12 millones), Antioquia (9 millones) y Bolívar (9 millones). Otras zonas, históricamente marginales para el Estado colombiano como los Llanos Orientales y la región amazónica, al parecer de las actuales tendencias, lo seguirán siendo para la cooperación hispano-colombiana, debido a factores sociodemográficos (poca población, dispersa y presencia de comunidades indígenas), políticos (bajo potencial electoral, baja organización cívica) y socio-culturales (escasas redes sociales con organizaciones nacionales y españolas que promuevan su visibilidad y la dotación de recursos a través del capital social).

En 2004 los departamentos más beneficiados con los recursos económicos han tenido como principal fuente al Ministerio de Industria, Turismo y Comercio español, que concentró en dos de los 32 departamentos colombianos el 70,6\% de las cantidades asignadas para Colombia (Embajada española en Colombia y AECI, 2004). Una de las obras que más ha comprometido estos recursos, correspondientes a créditos FAD, ha sido la construcción de una central hidroeléctrica de Guapi en el Cauca y la interconexión eléctrica con su vecino Nariño (mapa 4.1). Según el Gobierno colombiano, «los recursos serán invertidos dentro del componente social del Plan Colombia, teniendo en cuenta que el proyecto de la Central Hidroeléctrica de Guapi está incluido dentro de las obras de infraestructura con las cuales se busca redimir esa región del país» (Casa de Nariño, 2004).

El peso relativo de estos recursos congregó, tanto en 2004 como en 2006, en un solo sector CAD, el de "Generación y Suministro de Ener- 
GRÁFICA 4.8

PRINCIPALES SECTORES CAD DE LA AYUDA ESPAÑOLA

EN COLOMBIA POR APORTACIONES, 2004

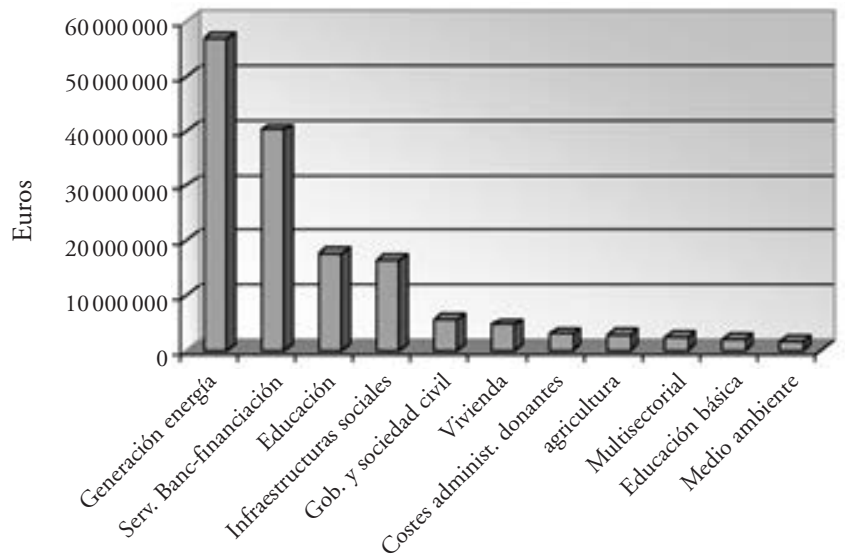

FUENTE: Elaboración propia a partir de Embajada de España en Colombia y AECI (2004).

gía», el $33 \%$ de los recursos reembolsables y no reembolsables que provienen de España (ACCI, 2004b; AECI, 2006). En ambos años el segundo sector al que más se destinó la ayuda oficial, con el $20 \%$ del total, fue el de «Servicios Bancarios y Financieros». Llama la atención que el séptimo sector que empleó más recursos en 2004 fue el de los "costes administrativos de los donantes» (ver gráfica 4.8), aunque este sector bajó al decimoquinto lugar en 2006 (AECI, 2006).

\subsubsection{Las ONGD españolas en Colombia}

La cooperación no gubernamental incorpora un abanico de actores bastante diverso que no siempre corresponde a la denominación de «organización no gubernamental», y cuya acción implica un tipo de trabajo que prescinde, en muchos casos, de los proyectos de desarrollo. Dentro de los actores de este tipo de cooperación están las ONGD, las universidades, los sindicatos y las empresas. No obstante, en este apartado comentaremos sólo el primer tipo de actores. 
A pesar de que la explicación de la presencia de las ONGD debería incluir una tipología exhaustiva y pormenorizada, en este apartado haremos referencia a tres tipos diferentes de organizaciones no gubernamentales de desarrollo españolas con presencia en Colombia.

En primer lugar, las ONGD que ejecutan proyectos de desarrollo, un segundo grupo que se mueve en el espectro de la solidaridad política y la defensa de los derechos fundamentales (mas cercanas a los movimientos sociales), y un tercer grupo, de reciente aparición, vinculado a la responsabilidad corporativa de grandes empresas privadas españolas que canalizan sus ayudas a través de fundaciones u ONGD convencionales. En algunos casos las fronteras de los tres grupos pueden observarse con claridad; en otros, sus acciones y discursos pueden incorporar elementos de diversos grupos.

El primer grupo, las ONGD «convencionales», son los actores más reconocidos por las agencias estatales de ambos países y hacen el papel de interlocutores y gestores de sus recursos. Debido a este papel, suelen estar recogidos en los informes y memorias de las agencias estatales y de los organismos públicos.

En la evaluación de los resultados de la V Comisión Mixta, se detectaron dificultades en el «seguimiento de los proyectos e información mutua» (AECI y ACCI, 2003, 5), además de algunos vacíos de información en cuanto al conocimiento de la Agencia Colombiana de los recursos de la AECI gestionados por las ONGD; de hecho, "la Delegación española se comprometió a comunicar a la Agencia Colombiana de Cooperación Internacional, como viene haciendo habitualmente, todas las subvenciones que conceda la AECI a actividades de ONGD en Colombia» (AECI y ACCI, 2003, 7).

Asimismo, en cuanto a la coordinación de las ONGD españolas con los diferentes niveles de las unidades administrativas colombianas, la OTC de la Embajada española en Bogotá sugirió al Gobierno colombiano que, debido a su creciente papel, estos operadores se han hecho "merecedores, en lo posible», de la creación de "un marco especial de relación con las autoridades nacionales que mejorara el actual y que se estableciese sobre la base de un intercambio de información operativo y fluido" (OTC, 2004, 3). Por su parte, la delegación colombiana

reiteró su interés en seguir contando con estos importantes agentes de desarrollo y se comprometió a adoptar las medidas necesarias para facilitar la entrada, permanencia y circulación de los cooperantes no gubernamentales, previo 
cumplimiento de los procedimientos establecidos e información por parte de la Oficina Técnica de Cooperación (OTC) de la Embajada de España (AECI y ACCI, 2003, 40-41).

En este sentido, se plantearon varias propuestas en torno a la identificación de los cooperantes españoles que tengan presencia en Colombia y acordaron «la comunicación por parte de la OTC a la Agencia Colombiana de Cooperación Internacional y al Ministerio de Relaciones Exteriores, caso por caso, de los carnés de cooperantes españoles expedidos por la OTC-Embajada de España, y que van sujetos al registro consular de los beneficiarios». La expedición de dichos carnés corresponde a la identificación de los proyectos que estarán «sujetos a seguimiento y, en el caso de las misiones de identificación o de visitas cortas, se requerirá que exista información sobre las acciones previstas con suficiente detalle y/o con informes técnicos previos» (AECI y ACCI, 2003, 42).

En cuanto al seguimiento de los proyectos, la VI Comisión Mixta implantó una Tabla de control para la gestión del ciclo de proyectos (o de IIICCCS), para valorar cada proyecto o programa de cooperación, y también el conjunto de un programa bilateral o el contenido de una comisión mixta (AECI y ACCI, 2003, anexo V, 5).

Los principales sectores de la Comisión Mixta en los que estas organizaciones desarrollaron su actuación durante 2004 fueron: cobertura de necesidades sociales básicas, inversión en el ser humano, e infraestructura y promoción del tejido económico. Las entidades que más recursos de la AECI administraron durante el 2004 fueron: la Fundación para el Análisis y los Estudios Sociales (FAES), que gestionó una cantidad superior a la suma de las siguientes 10 ONGD que recibieron subvenciones de la Agencia Española, seguida a mucha distancia del Centro de Investigación y Desarrollo de América Latina (CIDEAL), Cruz Roja, Fe y Alegría, Cáritas Española, Instituto Sindical de Cooperación al Desarrollo (ISCOD), Nuevo Futuro, Mundo Cooperante, etc. En 2006, la principal ONGD receptora de recursos públicos para su gestión en Colombia fue la fundación Humanismo y Democracia, ${ }^{53}$

53 Podría suponerse que el cambio de Gobierno en España en 2004 significó un drástico giro en la canalización de los recursos por parte de las ONGD. Precisamente en 2004 la ONG que más recursos recibió fue la fundación FAES, presidida por el ex presidente del Gobierno español José María Aznar. No obstante, la fundación que más recursos recibió en 2006 también está fundada y dirigida por miembros del Partido Popular (Concepción Dancausa Treviño, Gonzalo Robles Orozco). 
en segundo lugar aparece Solidaridad Internacional y, a continuación, CIDEAL, Cáritas Española, Fe y Alegría. A diferencia del período anterior, en 2006 ninguna ONGD gestionó más del 14\% del total de recursos recibidos por estas organizaciones.

Por otra parte, existe un peso considerable de organizaciones que trabajan desde la solidaridad política a través del seguimiento, análisis ${ }^{54}$ y/o denuncia de situaciones vinculadas al conflicto armado. En muchas ocasiones renuncian a trabajar con determinadas instituciones en aras de mantener la coherencia entre su discurso crítico ante las posibles fuentes de financiación. También reciben fondos públicos de la cooperación, pero menos cuantiosos que las ONGD convencionales. Su presencia abarca menos territorio que las entidades del primer grupo, si bien tienden a mantener su continuidad por períodos prolongados de tiempo y a pesar de los enfrentamientos de los actores armados..$^{55}$

De igual modo, en este grupo se pueden ubicar asociaciones, $\mathrm{ONG}$, plataformas y coordinadoras dedicadas a la sensibilización de la población española sobre el conflicto colombiano, pero enfatizan especialmente la denuncia pública de la situación de colectivos específicos (campesinos, sindicalistas, indígenas o defensores de derechos humanos), de hechos bélicos y de presión política a los Estados. A este grupo pertenecen también organizaciones de exiliados políticos, periodistas amenazados e inmigrantes colombianos con un discurso crítico y reivindicativo ante el Gobierno colombiano y el español. Suelen organizarse en coordinadoras como CASCOL en el caso de Aragón, de ámbito autonómico con incidencia estatal. En este sentido destacan las coordinadoras y comités en Valencia, Cataluña, País Vasco y Madrid.

Por último, como resultado del incremento de las inversiones españolas en Colombia, las principales empresas han venido creando o apoyando a fundaciones y asociaciones que gestionan proyectos y programas

54 Aparte existe un conjunto de personas y entidades españolas que dedican recursos en cuanto espacios de análisis, publicaciones, investigadores y foros de debate sobre el conflicto armado en Colombia (CIP, IECAH, SIP, CIDOB, CIDEAL..., y universidades como la Complutense de Madrid, la Autónoma de Barcelona, Deusto, Comillas, País Vasco...).

55 Por ejemplo, Paz y Tercer Mundo gestionó más de 500000 euros en el Chocó, las Brigadas Internacionales de Paz más de 600000 euros en Antioquia, Bogotá y Santander. 
solidarios en el marco de la responsabilidad social corporativa. ${ }^{56}$ En el presente estudio no se hace referencia a este tipo de cooperación no gubernamental, aunque algunas de las entidades que forman parte del estudio como Entreculturas reciben apoyo de empresas como Unión Fenosa. En los próximos años, los actores de la cooperación deberán prestar una atención especial al tipo de alianzas que se establezcan entre las ONG y las empresas, ya que muchas de ellas «intentan un lavado de imagen, más que incorporar las preocupaciones sociales y medioambientales como funciones básicas de su trabajo» (Henderson, 2004, 155). Sin embargo, hay otros que defienden la necesidad de estas alianzas como un tipo de «asociación para el desarrollo» que incorpora la constitución de redes con grandes y pequeñas empresas, y permite un impacto positivo en los contextos geográficos en las cuales desempeñan su actividad productiva (Husselbee, 2004, 159-180). ${ }^{57}$

Además, entre las diferentes tipologías de organizaciones hay discrepancias políticas e ideológicas en cuanto a los mismos temas en los que disienten los partidos políticos y los Gobiernos, es decir, la naturaleza del conflicto armado y las vías de resolución de éste. De hecho, hay organizaciones del primer y segundo tipo que denuncian abiertamente el comportamiento de algunas empresas españolas, como recientemente lo hizo el sacerdote jesuita Javier Giraldo, director de la ONG colombiana CINEP, ante el Parlamento europeo:

El patrimonio natural colombiano se distribuye según los intereses políticos de empresas europeas y estrategias económicas estadounidenses. Entre las sociedades a las que consideró «culpables» del incremento de la pobreza, destacó a la española Unión Fenosa, "quien se hizo cargo de las infraestructuras eléctricas del país y cuyos servicios ahora son insuficientes porque alumbrar Colombia no le es rentable» (CM\& Europa Press, 2 de diciembre de 2004).

El aumento y complejidad de las interrelaciones entre viejos y nuevos actores de la cooperación puede poner en evidencia las contradicciones

56 Empresas como Unión Fenosa han decidido dedicar sus proyectos solidarios en 2005 a Colombia. Por otra parte, «ENDESA en Colombia y sus filiales BETANIA, CODENSA y EMGESA se suscriben al pacto global de las Naciones Unidas». <http://www.codensa.com.co>, comunicado n. ${ }^{\circ}$ 40, 23 de septiembre de 2004 .

57 Para profundizar en el debate de la alianza ONGD-empresa en el contexto español, ver Nieto (2002). 
entre los valores organizativos, las fuentes de financiación y la denuncia política de las ONG. ¿Se pueden recibir fondos para proyectos solidarios de una empresa que es denunciada porque sus políticas afectan a grupos desfavorecidos? En este caso, una ONG de jesuitas (CINEP) denuncia la poca sensibilidad social de una empresa española (Unión Fenosa) que a su vez financia proyectos de otra ONG jesuita (Fe y Alegría) para la construcción de un centro educativo que benefició a 120 niños en Villa Guadalupe (Bolivia)..$^{58}$ Por coherencia, ¿deberían las ONG renunciar a recibir recursos que provienen de entidades privadas que pueden vulnerar derechos sociales, económicos o ambientales? ¿De qué forma afectaría a las poblaciones beneficiadas la renuncia a la financiación de proyectos como el descrito anteriormente?

\subsubsection{Las relaciones exteriores hispano-colombianas \\ El Plan Colombia}

El sociólogo Alfredo Molano (2000, 1-8) afirma que «El Plan Colombia se presentó a la comunidad internacional antes de divulgarse en nuestro país y, naturalmente, sin haberse puesto a consideración del Congreso de la República ni de la sociedad civil». Según este investigador, dicho Plan tiene tres grandes objetivos: 1) Forzar un acuerdo de paz conveniente para el «establecimiento» por medio del apoyo militar al ejército colombiano. Este "conveniente» significa una negociación basada en la entrega de armas y reinserción del movimiento guerrillero en las instituciones vigentes. 2) Aumentar la injerencia militar de Estados Unidos en la convulsionada región andino-amazónica con miras a controlar las reacciones sociales desencadenadas por las políticas neoliberales. 3) El Plan Colombia tiene un objetivo interno en Estados Unidos: disminuir las presiones del puritanismo norteamericano, que considera la droga el sustituto del comunismo.

El Plan tiene un costo de 7558 millones de dólares, y el principal programa es la "defensa nacional: seguridad y justicia», que concentra el 64\% de los recursos. El Plan Colombia parte de un supuesto discutible: establecer las causas de la crisis de gobernabilidad y legitimidad del Estado

$58<$ http://www.unionfenosa.es/ShowContent.do?contenido=RSC_04_02_ 01_03_03> (24 de agosto de 2005). 
colombiano en el narcotráfico y el conflicto armado. Otra afirmación discutible del Plan Colombia es que sostiene que los recursos financieros orientados hacia las fuerzas armadas y la justicia vienen siendo decrecientes; de allí su debilidad para enfrentar los diversos conflictos y controlar el territorio. Además del escalamiento de la guerra interna, la otra estrategia de paz del Plan Colombia corresponde a una militarización de la vida civil con ideas de seguridad, orden y fortalecimiento del Estado.

Además, algunos años después de su puesta en práctica se han encontrado muchas promesas incumplidas por parte de los países que inicialmente se habían comprometido en su cofinanciación; así lo reveló un informe del CEPEI $(2004,4)$ :

El Sistema Nacional de Evaluación de Resultados de la Gestión Publica del DNP, sin embargo, menciona en su balance del Plan Colombia (19992003) que este aparente éxito de las Mesas de Aportantes [para promocionar el Plan] es a su vez uno de los principales fracasos del Plan, toda vez que, aparte de la ayuda de Estados Unidos de América, que materializó un $91 \%$ de los recursos ofrecidos, sólo un $44 \%$ de los recursos de cooperación no reembolsable ofrecidos por el resto del mundo fue respaldado con compromisos.

Sin embargo, España ha sido uno de los países que más se ha acercado al apoyo prometido en la financiación del Plan Colombia. De hecho, la explicación del elevado incremento en los fondos de AOD de España hacia Colombia puede encontrar su explicación en el apoyo del Gobierno español al Plan Colombia en el año 2000.59

El respaldo de España al Plan Colombia no se redujo al plano de las declaraciones. El Gobierno se comprometió a dotarlo con 124 millones de dólares en el período 2000-2003 (casi un tercio del total comprometido por la Comisión y los Estados miembros) destinados a proyectos sociales, económicos, humanitarios, de reforzamiento institucional y de sustitución de cultivos ilícitos (Sanz, 2004, 4).

59 En cuanto a la política exterior del Gobierno español, ésta no había sufrido grandes cambios entre las diferentes legislaturas de los últimos años; sin embargo, el Plan Colombia presentado por el Gobierno de Andrés Pastrana (1998-2002) supuso una ruptura importante «La política exterior de los gobiernos del Partido Popular hacia Colombia prácticamente mantuvo a lo largo de la primera legislatura un alto grado de continuidad respecto de las anteriores administraciones socialistas (apoyo al proceso de paz y al diálogo entre las partes como única vía para la superación del conflicto armado). Esta continuidad empezó a resquebrajarse a partir del Plan Colombia» (Sanz, 2004, 1-2). 
La posición enfrentada entre el Gobierno del Partido Popular, que apoyó dicho Plan, y la postura oficial de la UE, y de muchas organizaciones sociales españolas y europeas, fue el escenario de constantes declaraciones, manifestaciones y comunicados que evidenciaban las enormes discrepancias entre las posibles salidas al conflicto: la victoria militar del Estado o el proceso de paz.

Algunos analistas (Mansilla Blanco, 2005) sostienen que el Plan Colombia es una estrategia apoyada por el Gobierno de Estados Unidos para ejercer un control en la zona CAN debido a los «brotes» en la región especialmente en Venezuela, Ecuador y Bolivia.

\section{El apoyo a la política de seguridad democrática}

Las ONG españolas, especialmente las identificadas en los ámbitos de solidaridad política, han ejercido presión ante el Gobierno socialista de José Luis Rodríguez Zapatero para que rechace la política de seguridad democrática del presidente Uribe Vélez, y en las leyes acordadas en Cartagena 2005 se cree un marco jurídico que garantice el derecho de las víctimas a la verdad, la justicia y la reparación:

Esperamos que el Gobierno español ni financie ni apoye políticamente el proceso de desmovilización de los grupos paramilitares mientras no se garantice que los responsables de crímenes de guerra comparecerán ante la justicia y mientras no haya un marco de normas que haga que esto no parezca lo que es: un proceso de impunidad [...] hay una petición expresa del Congreso de los Diputados, de julio del año pasado, en la que la mayor parte de los grupos políticos, incluido el grupo socialista, pide que las relaciones con Colombia se analicen y se manejen desde la perspectiva del cumplimiento o no de las recomendaciones de Naciones Unidas en materia de derechos humanos. ${ }^{60}$

De forma similar, ante hechos ocurridos en el conflicto armado, el Congreso de los Diputados de España se ha pronunciado en diversas ocasiones para exigir ante el Gobierno colombiano investigaciones y sanciones a los responsables de aquéllos. Una de las más recientes fue la masacre

60 Declaraciones de Esteban Beltrán, director de Amnistía Internacional España. El Tiempo, 12 de febrero 2005, «Amnistía Internacional pide a la Unión Europea que condicione ayuda económica a Colombia». "Federación Internacional de Derechos Humanos lamenta apoyo de España a política de Uribe», El Tiempo, 7 de abril de 2005. 
de San José de Apartadó (Antioquia): «Diputados españoles piden que se investigue masacre de San José de Apartadó». ${ }^{61}$

Desde el apoyo de España al Plan Colombia, este país se ha convertido en un aliado importante para Colombia en su trabajo diplomático ante la Unión Europea. De hecho, el Gobierno colombiano logró recientemente que España influyese ante Europa para evitar el apoyo directo de ONG europeas a las guerrillas colombianas:

España y Alemania trabajarán para evitar que se repitan hechos como el de la ONG danesa que le entregó 8500 dólares al grupo subversivo colombiano. En una manifestación frente al Senado, el ministro de Justicia español, Juan Fernando López, lo calificó como un hecho "gravísimo" e indicó que el asunto ya fue tratado con Alemania durante la reciente Cumbre hispano-germana en León (8 de noviembre). Según su versión, ambos Gobiernos se comprometieron a "promover ante la Comisión Europea el establecimiento de un grupo de trabajo para asegurar la plena efectividad de las resoluciones adoptadas en las instituciones europeas" y para que sea "imposible, en lo sucesivo, que una organización no gubernamental -o cualquier institución reconocida por la Unión Europea-, pueda vehicular ningún tipo de financiación o de colaboración» hacia "una organización terrorista como las FARC». ${ }^{62}$

Entre los hechos más recientes de la relación hispano-colombiana, destaca la última visita oficial de tres días que el presidente colombiano Álvaro Uribe Vélez realizó en julio de 2005 a España. En ésta, visitó por primera vez al presidente de Gobierno español José Luis Rodríguez Zapatero para solicitar apoyo en materia de cooperación y conocer su opinión sobre la Ley de desmovilización de los grupos armados ilegales. El triunfo diplomático de Uribe Vélez fue evidente al recibir el apoyo español y, por tanto, la influencia positiva de España ante los países miembros de la UE. Dicho apoyo incomodó a las ONG que presionaban para que España rechazara la ley. Partidos políticos como IU se negaron a estar presentes en la reunión que las fuerzas políticas tuvieron con el mandatario colombia-

61 El Tiempo, 14 de abril de 2005, «En carta al Vicepresidente, [los diputados] piden garantizar a la comunidad su derecho a permanecer fuera del conflicto sin sufrir ataques o señalamientos por ello. Los diputados, de los grupos parlamentarios Socialista, Popular, Izquierda Verde-Izquierda Unida-Iniciativa por Cataluña Verdes (IV-IU-ICV), Vasco y Coalición Canaria, pidieron también al vicepresidente Francisco Santos una "investigación exhaustiva e imparcial", sancionar a los responsables y reparar a los familiares y a la comunidad".

62 El Tiempo, 17 de noviembre de 2004, «Promoverán revisión a mecanismos de la Unión Europea para frenar nuevas donaciones a las FARC». 
no. Respecto a dicha ley, diarios de prestigio internacional como el New York Times se pronunciaron calificándola como «una la ley de impunidad para asesinos, terroristas y traficantes de cocaína». ${ }^{63}$

\subsection{La estrategia de cooperación internacional del Gobierno colombiano}

La estrategia de cooperación internacional del Gobierno del presidente Álvaro Uribe Vélez se fundamenta en el Plan Nacional de Desarrollo denominado Hacia un Estado Comunitario, cuyos principales objetivos son:

Brindar seguridad democrática, renovar la Administración pública e impulsar la reactivación económica y la equidad social; además de invitar a la comunidad internacional a fortalecer la coalición internacional que viene trabajando por la paz de Colombia, a través del apoyo decidido y concreto de la propuesta de cooperación que se detalla en este documento (ACCI, 2004b, 3).

La estrategia de cooperación internacional del Gobierno pretende «fortalecer la coalición internacional que viene trabajando por la paz de Colombia, permitiendo un mejor entendimiento y participación de la comunidad internacional en los procesos de cambio de la realidad colombiana» (ACCI, 2004c, 14).

Para llevar a cabo los objetivos, según el Gobierno, las prioridades de los programas y proyectos en materia de cooperación deben girar en torno a los siguientes ejes:

1) Ayuda humanitaria

2) Familias guardabosques

3) Microcréditos y minicadenas productivas

4) Plan nacional de lectura y bibliotecas

5) Plan nacional de música para la convivencia.

Llama la atención que en un país que vive un conflicto armado con una de las tasas de homicidios más altas del mundo tenga dentro de sus ejes principales de cooperación «las familias guardabosques, la lectura y las

63 El Tiempo, 9 de julio de 2005. 
bibliotecas». De hecho, cuando dicho documento fue presentado al G-24, el Gobierno colombiano se dio cuenta de que «estas iniciativas no colmaron las expectativas de los países donantes, y en tal sentido el Gobierno inició un amplio proceso de concertación a efectos de lograr la consolidación de una estrategia que, además de responder a las necesidades nacionales, encontrase una respuesta favorable de la comunidad internacional (ACCI, 2004c, 15).

En la Reunión Preparatoria de la Mesa de Coordinación y Cooperación Internacional para Colombia, celebrada en Londres el 10 de julio de 2003, el Gobierno colombiano presentó el documento Una coalición internacional por la paz de Colombia. Después de dichas reuniones preparatorias, en las que también hubo espacio para la sociedad civil se definieron los siguientes ejes:

- Bosques

- Paz y reincorporación

- Desarrollo productivo y alternativo

- Fortalecimiento del Estado de derecho

- Programas regionales de desarrollo y paz

- Desplazamiento forzoso y asistencia humanitaria.

En la mesa de Londres las organizaciones sociales presentaron un documento en el cual afirmaron que "Existen diferencias centrales entre nuestras organizaciones y los planteamientos del Gobierno en materia de cooperación. Dicho disenso proviene tanto de la valoración diferente de las causas de la grave crisis que vive Colombia como de las soluciones planteadas frente a dicha crisis». Además, critican la base de la seguridad democrática como pilar de la estrategia de cooperación, ya que

Se fundamenta en la corresponsabilidad del Estado y la ciudadanía en materia de seguridad, atenta contra la Constitución de Colombia y contraviene principios reconocidos en el derecho internacional de los derechos humanos. En esa política la población no se concibe esencialmente como acreedora de derechos, ni como destinataria de protección estatal y es vista ante todo como un instrumento de la guerra. La militarización del Estado ha tenido como consecuencia la persecución de miembros de diversos sectores sociales, tales como sindicalistas, líderes sociales, organizaciones de mujeres, defensores de derechos humanos y población humilde de zonas con presencia guerrillera (Organizaciones colombianas de sectores sociales populares, de iniciativas de paz y de derechos humanos, 2003, 3). 
Además, para ampliar las diferencias entre las organizaciones sociales y el Gobierno nacional, en junio de 2005 el Alto Comisionado para la Paz de la Presidencia de la República elaboró un documento titulado Lineamientos para el enfoque de los proyectos de cooperación internacional, en el que se definían una serie de criterios que debían tener en cuenta los proyectos de cooperación internacional. El documento hacía una prohibición expresa a contactar, dialogar, apoyar o incorporar a grupos armados ilegales entre los proyectos de cooperación. Asimismo, se destacaban los siguientes lineamientos:

- Las expresiones "actores armados» o "actores del conflicto", en las cuales se pretende incluir a los miembros de la Fuerza Pública, los equipara con los grupos armados al margen de la ley. [...] situación [...] inaceptable para el Gobierno Nacional [...].

- Los conceptos que se incorporen dentro de los proyectos tales como "comunidad de paz», "territorio de paz», "región o campo humanitaria» [sic] son generalmente ambiguos [...] en ningún momento deben suponer la imposición de límites a la acción territorial de la Fuerza Pública ni a la acción de la justicia [...].

- Se debe tener presente que Colombia es una democracia pluralista y garantista, donde se cuenta con los cauces apropiados para dirimir las diferencias. El aceptar la existencia de un conflicto armado interno implica la negación de dichos canales, lo cual es utilizado por los grupos armados ilegales para polarizar y capitalizar su estrategia de poder [...].

- En los proyectos se debe hacer énfasis no sólo en los derechos, sino en los deberes que los ciudadanos tienen para con su comunidad (Alto Comisionado para la Paz, 2005, 1-3).

Dichos lineamientos han producido respuestas importantes por parte de la opinión pública ${ }^{64}$ y de las organizaciones sociales, entre las que destaca la Alianza de Organizaciones Sociales y Afines por una Cooperación Internacional para la Paz y la Democracia en Colombia. En una carta dirigida a la ACCI por parte de esta red de organizaciones se preguntaban:

¿Qué lugar ocupa el documento mencionado en relación con la Declaración de Londres, de la Declaración de Cartagena, de la Declaración de Consenso de las Organizaciones de la Sociedad Civil, del Documento de Política de Cooperación del Gobierno Colombiano, del Documento de las Agencias Internacionales de Cooperación y del Documento de Observaciones a la política de Cooperación presentado por las Organizaciones de la Sociedad Civil? Estos documentos sobre cooperación internacional, incluyen lineamientos y

64 Editorial de El Tiempo del 14 de junio de 2005, "Una iniciativa desafortunada». 
compromisos gubernamentales; y son los referentes básicos acordados con el Gobierno, Naciones Unidas y el G-24. ${ }^{65}$

Las principales críticas al documento se basan en la intención de "pretender imponer, además del lenguaje, condiciones que, de hecho, excluyen automáticamente docenas de valiosas iniciativas que a nivel local y regional enfrentan el conflicto armado" (editorial de El Tiempo, 14 de junio de 2005). Asimismo, se duda de la legitimidad y legalidad de iniciativas concretas, precisamente muy apoyadas desde Aragón, como ha sido el caso de las Comunidades de Paz, que han representado para entidades como ASA «un paradigma de lo que una organización como la nuestra puede hacer [y reconocen] la necesidad de extender este proyecto y darlo a conocer en nuestra propia sociedad» (ASA, 1999, 10).

Asimismo, cabe preguntarse, si el Gobierno nacional desconoce la existencia del conflicto armado, ¿qué validez, por tanto, tendrían los convenios de cooperación con otros Estados y los cientos de proyectos realizados por ONGD que promueven la paz y la convivencia en Colombia?

Por otra parte, el desarrollo institucional de la cooperación en Colombia es aún precario, a pesar de los avances realizados por las entidades que tienen competencia en la materia. Las siguientes son las principales dificultades que Colombia tendría que afrontar en los próximo años en materia de cooperación internacional, según el análisis presentado en 2004 por el CEPEI (2004, 4-5):

1) Contar con la información necesaria para estimar la magnitud, los resultados e impactos de la cooperación que recibe Colombia.

2) Articular los programas de cooperación a los lineamientos de política exterior y a las prioridades de la planeación sectorial del desarrollo.

3) Coordinar la red de oficinas de cooperación internacional del sector público y de las organizaciones no públicas para evitar la dispersión de esfuerzos y el envío de señales equivocadas a los donantes.

4) Establecer canales de comunicación fluida entre el Gobierno nacional, las ONG y los Gobiernos regionales o locales, incorporando incentivos para que se involucren de manera más activa en los procesos de retroalimentación, seguimiento y evaluación. [...]

65 Carta dirigida al doctor Luis Alfonso Hoyos Aristizábal, director (e) Agencia Colombiana de Cooperación Internacional (ACCI), Bogotá, 15 de junio de 2005. Por parte de las «Organizaciones colombianas de sectores sociales populares, de iniciativas de paz y de derechos humanos», 2003. 
6) Contar con alternativas de administración de los proyectos de cooperación que faciliten al Estado y a las organizaciones no públicas el manejo y control de los recursos.

\subsubsection{La Agencia Presidencial para la Acción Social y la Cooperación Internacional, $\mathrm{ACCI}^{66}$}

La ACCI es un establecimiento público de carácter nacional con autonomía administrativa y financiera. Se creó en septiembre de 1996 e inició sus actividades en diciembre de 1997 como resultado de un "proceso de negociación interna que pretendía aprovechar el potencial de los recursos de cooperación y optimizarlos según las políticas nacionales» (ACCI, 2004a).

En 1999 cambió su adscripción del Departamento Nacional de Planeación (DNP) al Ministerio de Relaciones Exteriores, y en junio de 2003 fue adscrita al Departamento Administrativo de la Presidencia de la República. Entre sus objetivos está buscar una posición integrada del país en materia de cooperación técnica y financiera no reembolsable, ${ }^{67}$ a través de una interlocución única que evita duplicidad de acciones y facilita la coordinación con los cooperantes. La ACCI no coordina la cooperación que llega a las ONG, debido a que la naturaleza de esta cooperación es privada y en ella, según la Ley 318 de 1996, no interviene el Gobierno nacional.

Uno de los instrumentos más importantes para orientar la cooperación internacional de Colombia es el Plan Nacional de Desarrollo. Se trata de un plan cuatrienal que cada Gobierno está obligado constitucionalmente a presentar para iniciar su período de gobierno. Dicho Plan tiene el rango de Ley de la República y la Agencia busca que la cooperación internacional se adapte a los programas contenidos en el Plan.

66 Antes del cierre del informe final de este estudio, la Agencia Colombiana de Cooperación Internacional ha tenido una reestructuración por la cual ha pasado a llamarse Agencia Presidencial para la Acción Social y la Cooperación Internacional. Para este estudio ambas agencias se identificarán con las siglas ACCI.

67 La ACCI define la cooperación financiera no reembolsable como la cooperación ofrecida por algunas fuentes mediante asignación de recursos en efectivo, con el objeto de apoyar proyectos o actividades de desarrollo. 
En 2005 la ACCI ha tenido una reestructuración por la cual ha pasado a llamarse Agencia Presidencial para la Acción Social y la Cooperación Internacional, creada mediante el Decreto 2467 de 2005. Básicamente, esta reforma es la fusión de la Red de Solidaridad Social ${ }^{68}$ y la ACCI.

CUADRO 4.1

ESTRUCTURA DE LA AGENCIA PRESIDENCIAL PARA

LA ACCIÓN SOCIAL Y LA COOPERACIÓN INTERNACIONAL

\section{CONSEJO DIRECTIVO}

Integrado por: 1. El director del Departamento Administrativo de la Presidencia de la República o su delegado, quien lo presidirá. 2. El ministro de Relaciones Exteriores o el viceministro de Asuntos Multilaterales. 3. Tres (3) delegados designados por el presidente de la República

1. DESPACHO DEL DIRECTOR GENERAL

1.1. Oficina Asesora de Planeación

1.2. Oficina Asesora Jurídica

1.3. Oficina de Control Interno

1.4. Oficina de Control Interno Disciplinario

2. DIRECCIÓN RED DE SOLIDARIDAD SOCIAL

2.1. Subdirección de Atención a Víctimas de la Violencia

2.2. Subdirección de Atención a Población Desplazada

3. DIRECCIÓN DE COOPERACIÓN INTERNACIONAL

3.1. Subdirección de Nuevas Fuentes de Cooperación Internacional

3.2. Subdirección de Ayuda Oficial al Desarrollo

4. SECRETARÍA GENERAL

5. ÓRGANOS DE ASESORÍA Y COORDINACIÓN

5.1. Comité de Coordinación del Sistema de Control Interno

5.2. Comité de Defensa Judicial y Conciliación

5.3. Comisión de Personal

FUENTE: <http://www.acci.gov.co/La_Entidad/Estructura.htm> (6 de septiembre de 2005).

68 La Red de Solidaridad Social es «una iniciativa presidencial que convoca a la solidaridad nacional para atender las necesidades apremiantes de los grupos de población más pobres y vulnerables del país y facilitar su participación en los grandes programas sociales. Bajo esta orientación, la Red ejecuta un conjunto de acciones que, articuladas entre sí, buscan mejorar la calidad de vida de estos grupos y consolidar el ejercicio de sus derechos ciudadanos». <http://www.acci.gov.co/La_Entidad/Historia.htm> (6 de septiembre de 2005). 
Los objetivos de la ACCI son generar capacidad instalada en las entidades que reciban la asistencia; lograr un nivel adecuado de intercambio informativo entre la Agencia y las entidades territoriales, garantizando una constante retroalimentación; aumentar la capacidad de una entidad para lograr la sostenibilidad de los resultados alcanzados y transferir e incrementar capacidad y conocimiento a las entidades.

Con la más reciente reestructuración, la Agencia asume los objetivos de coordinar, administrar y ejecutar los programas de acción social y los proyectos de desarrollo dirigidos a la población pobre y vulnerable. Además, se propone coordinar el desarrollo de la política que en materia de acción social fije el Gobierno nacional. En el tema específico de formulación de proyectos, la ACCI ejecuta un programa de capacitación dirigido a instituciones públicas, del orden nacional, regional y local, orientado a mejorar los conocimientos y destrezas para diseñar proyectos de alta calidad. La Agencia también hace el seguimiento y la coordinación con otras oficinas de cooperación internacional que están adscritas a los ministerios y algunos establecimientos públicos del orden nacional. Algunas de ellas cumplen el papel de "punto focal» de ciertos organismos internacionales con misión sectorial. Esto significa que ellas coordinan y manejan algunas de las líneas o programas de cooperación, como es el caso de los Ministerios de Protección Social (con enlace con la OIT para los temas de empleo y con OPS/OMS para los temas de salud), de Educación (UNESCO y SECAB), o Ambiente, Vivienda y Desarrollo Territorial (punto focal de algunos programas de medio ambiente). También en algunos departamentos y municipios, como Medellín (Agencia de Cooperación Internacional de Medellín), se han establecido unidades con funciones relacionadas con la cooperación internacional, que apoyan a las entidades y comunidades en la gestión de ayuda externa.

En cuanto a la evaluación, la ACCI ha diseñado e implementado el Sistema de Seguimiento y Monitoreo a Proyectos (SIMEP):

Para facilitar el flujo de información referente a la ejecución de los proyectos y responder a las necesidades de seguimiento de la cooperación internacional. Son potenciales usuarios del SIMEP: las fuentes cooperantes; las entidades ejecutoras; la ACCI y público en general. [...] En este sentido, se reconoce que este sistema necesita el respaldo de las fuentes cooperantes y el suministro de información por parte de las entidades ejecutoras, para lo cual 
la ACCI ha buscado su apoyo, que permita implementar efectivamente el programa. No ha sido una labor fácil, ya que cada una de las fuentes tiene una dinámica específica y poseen sus propios mecanismos de seguimiento, y sin el apoyo de éstas es imposible avanzar en el desarrollo del sistema, pues en últimas son los proyectos los que suministran la información que alimenta el SIMEP (ACCI, 2003, 18).

\section{La cooperación técnica entre paises en desarrollo (CTPD)}

Ésta es una modalidad de cooperación realizada entre países de similar nivel de desarrollo económico relativo; por esto se la conoce igualmente como "cooperación horizontal» o "cooperación Sur-Sur», y también puede ser ofrecida a través de fuentes bilaterales o multilaterales. Este tipo de cooperación es de doble vía, pues un país recibe y ofrece cooperación en las áreas en las que tiene un mayor desarrollo, una experiencia exitosa para compartir, un conocimiento o una tecnología específica apropiada que amerite ser compartida con otros países (Embajada española en Colombia y AECI, 2004).

Estas acciones de cooperación son ejecutadas dentro del marco de la política exterior, para lo cual la ACCI trabaja en estrecha coordinación con la Cancillería (Ministerio de Relaciones Exteriores). La financiación de la CTPD se puede dar a través de fuentes multilaterales, así como con recursos nacionales del Fondo de Cooperación y Asistencia Internacional, FOCAI, ${ }^{69}$ que es una cuenta especial de la ACCI. El objetivo de este fondo es apoyar las acciones de cooperación técnica y financiera no reembolsable y de asistencia internacional que Colombia destine a otros países en desarrollo. Las acciones que se financian con este fondo son las ofertas de cooperación de entidades colombianas.

Dentro de las modalidades de la CTPD se pueden encontrar las mismas que en la cooperación internacional convencional; las principales diferencias se encuentran en su costo y duración. Las actividades de la CTPD consisten en pasantías (estancias), envío o recepción de expertos,

69 Este Fondo, creado por la Ley 318 de 1996, tiene por objeto financiar acciones de cooperación técnica y financiera no reembolsable y de asistencia internacional que Colombia destine a otros países en desarrollo. Las acciones de cooperación internacional que financia el Fondo se adelantan de acuerdo con las prioridades de la política exterior, con énfasis en Latinoamérica y el Caribe, aunque se podrían ejecutar en Colombia. 
seminarios, cursos y talleres de corta duración. Para la financiación de la CTPD se emplea la figura de costos compartidos. El país que envía los profesionales asume la financiación de los costos de su desplazamiento, mientras que el país que los recibe paga los viáticos y gastos operativos. También existe la cooperación triangular, la cual se basa en un proyecto que se apoya en una tercera fuente bilateral o multilateral.

\subsection{Las ONGD y la sociedad civil en Colombia}

Como hemos afirmado en otros apartados, en Colombia ha habido pocos estudios que profundicen en el análisis de las ONG como expresión institucional de un conjunto de organizaciones no lucrativas que integran el denominado tercer sector. Para estudios como el de Salamon (dir., 1999) y entidades como la CCONG (2002a), las ONG son parte de un conjunto más amplio y variado que corresponde al sector no lucrativo. ${ }^{70}$ Las diferencias entre las ESAL y las ONG resultan evidentes cuando, por ejemplo, a las instituciones privadas que se dedican a la educación superior se les exige jurídicamente que adopten la forma de entidad sin ánimo de lucro. ${ }^{71}$

A pesar de los pocos datos que hemos podido ofrecer sobre la trayectoria específica de las ONG en Colombia (Henao, 1991; Vargas y otros, 1992), el estudio comparativo realizado por Salamon (dir., 1999) de las entidades sin ánimo de lucro ha permitido acercarnos a las dimensiones actuales del fenómeno en Colombia.

Dicho estudio revela cinco hallazgos principales sobre el ámbito, estructura, financiación y papel del sector no lucrativo en Colombia, dentro de los cuales destacamos los siguientes:

En primer lugar, aparte de su importancia social y política, el sector no lucrativo resulta ser una fuerza económica en Colombia, representando importantes cuotas del empleo y los gastos nacionales. En 1995 el sector no lucrativo colombiano movía unos gastos operativos de más de

70 En Colombia se les denomina entidades sin ánimo de lucro, ESAL, y en España organizaciones no lucrativas, ONL.

71 Inciso 2 del artículo 203 de la Ley General de Educación, Ley 115 de 1994. 
1700 millones de dólares ( 1,57 billones de pesos colombianos, 1400 millones de euros), o el equivalente al 2,1\% del producto interior bruto del país, una cantidad bastante considerable (Salamon, dir., 1999, 498499). Además constituye una importante fuente de empleo. Detrás de estos gastos se encuentra una importante fuerza laboral que incluye a cerca de 287000 empleados asalariados equivalentes a jornada completa. Esta cifra constituye el 2,4\% del total de trabajadores no agrícolas del país, el 14,9\% del empleo en el sector servicios y el equivalente a casi una tercera parte del personal empleado por el Estado en todos los ámbitos: nacional, departamental y municipal (Salamon, dir., 1999, 498-499). Aunque el sector no lucrativo colombiano es moderado en relación con su economía, «está por encima del promedio de los países latinoamericanos, aunque todavía no llegue al nivel de los países desarrollados» (Salamon, dir., 1999, 500).

La mayoría de los ingresos de las ESAL proceden de las cuotas y los pagos por servicios, no de la filantropía o del sector público (Salamon, dir., 1999, 506). La principal fuente de ingresos, con diferencia, de las organizaciones no lucrativas en Colombia la constituyen las cuotas y los pagos por servicios prestados: sólo esta fuente de ingresos aporta el 70,2\%, del total de ingresos del sector no lucrativo en el país. Por el contrario, la financiación procedente de la filantropía privada y el sector público constituye unas cuotas mucho menores de los ingresos totales. Por tanto, «la filantropía privada - procedente de personas físicas, empresas y fundaciones, en conjunto-y los pagos procedentes del sector público constituyen cada uno el $14,9 \%$ de los ingresos del sector no lucrativo en Colombia» (Salamon, dir., 1999, 508).

Si la composición, financiación y estructura de las ONG les permite ser consideradas como parte del sector no lucrativo, sus características cívicas, ideológicas y políticas, además de su papel en el espacio público e influencia en las estructuras del Estado, les lleva a «trascender el universo privado en el que surgen por la fuerza de su existencia orgánica, asociativa» (Torres Rivas, 2001, 148) y a constituirse como parte relevante de la sociedad civil.

En Colombia hay grandes esfuerzos por diferenciar y clarificar la heterogeneidad de las organizaciones de la sociedad civil (OSC). Entre otras razones, está la dificultad para identificar y erigir a representantes de 
la sociedad civil que puedan ser interlocutores ante el Gobierno y los grupos armados en los pasos que se den para avanzar en la búsqueda de la paz. $^{72}$

Aunque no nos resuelva los problemas de la precisión en las definiciones, la siguiente es una aproximación al esfuerzo por dilucidar las aspiraciones de unos actores y la delimitación de su campo de actuación.

La sociedad civil es el espacio de la diversidad, de la originalidad, de la innovación social porque se puede hacer todo lo que no está prohibido. Esto explica la múltiple diversidad que existe en el mundo empresarial lucrativo (segundo sector) y la diversidad del tercer sector no lucrativo y solidario (ONG, fundaciones, cooperativas, clubes, asociaciones, JAL, etc.). La diversidad es lo característico de la sociedad civil. Es esta diversidad la que permite encontrar nuevas respuestas y soluciones a los problemas de la sociedad (CCONG, 2002a, 3). ${ }^{73}$

A pesar de insistir en la diversidad como aspecto característico de la sociedad civil, la amplitud de este adjetivo arroja pocos elementos conceptuales, pero puede constituir un punto de partida para admitir no sólo la pluralidad de actores, sino de posturas ideológicas.

Es importante mantener presente el contexto socio-político colombiano, especialmente marcado por una extrema polarización de las ideas respecto a varios aspectos cruciales del conflicto: los mecanismos de resolución del conflicto (diálogo o enfrentamiento armado), el carácter político de ciertos delitos de la insurgencia (rebelión o terrorismo), el papel de los grupos paramilitares (insurgencia político-opositora o estrategia ilegal del Estado).

72 Una de las preguntas que se hizo la Confederación Colombiana de ONG (CCONG) dentro de su proceso de fortalecimiento institucional fue «¿Cómo construir colectivamente un pensamiento orientador común y una actuación convergente a partir de la diversidad de actores de la sociedad civil?» (CCONG, 2002a, 3).

73 En el año 2000, la CCONG optó por suscribir colectivamente un Acuerdo Programático por la Paz, como el medio para construir la unidad a partir de la diversidad de actores de la sociedad civil. Este acuerdo, que fue definido como «una postura política frente a una realidad social [basada en unos] criterios y conceptos desde los cuales una organización mira la realidad y ordena sus múltiples acciones», buscaba "orientar las acciones que fortalezcan el Estado Social de Derecho, promuevan la democracia, defienda los Derechos Humanos, coordinen la construcción de bienes públicos, el trabajo en red y fomenten la alianza con distintos actores de desarrollo»(CCONG, 2002a, 4). 
Si el punto de partida es la diversidad, el objetivo establecido por consenso es la construcción de la nación y la consecución de la paz:

Las organizaciones de la sociedad civil (OSC), ya sean empresas lucrativas o entidades sin ánimo de lucro, deben tener como proyecto político hacer posible y fortalecer el proyecto de nación expresado en la Constitución. Para la CCONG y las organizaciones que federa, el proyecto de nación resumido en el artículo $1 .^{\circ}$ de la Constitución política de Colombia es la fuente de inspiración y de propuesta del Acuerdo Programático. La construcción de una sociedad en paz, es decir, de una sociedad que es capaz de solucionar todos sus conflictos (desde los domésticos hasta los nacionales) sin violencia, sin eliminar al otro, con criterios de inclusión, equidad y participación, requiere que las organizaciones de la sociedad civil dirijan todos sus múltiples y diversos propósitos para hacer posible un Estado social de derecho en donde la ética de todas las actuaciones esté orientada por los derechos humanos. Es el proyecto de nación el que crea la unidad en la diversidad de la sociedad (CCONG, 2002a, 4).

Sin embargo, a pesar del anhelo de unidad entre las OSC, las tendencias opuestas frente a las políticas gubernamentales han generado en los últimos años distancias considerables. Por una parte, el sector lucrativo mantiene un apoyo incondicional a la Administración del actual Gobierno; de hecho, uno de los ministerios más vinculados a los temas de paz (Interior y Justicia) ha estado encabezado por un ex dirigente de la Federación Nacional de Comerciantes.

Asimismo, entre los actores del sector no lucrativo colombiano también hay importantes diferencias en estos niveles. Dos ejemplos constatan esta afirmación. Por una parte, un sector de las ESAL da la bienvenida al Plan de Desarrollo del Gobierno de Uribe, que propone la creación de un Estado comunitario en el que el sector solidario resulta fundamental para «ampliar los servicios y estar más cerca de la comunidad», y propone que el mecanismo para llevarlo acabo se base en «un modelo de contratación en el que las ONG administran recursos públicos, [bajo] la corriente moderna de reducir el tamaño del Estado» (Codesarrollo, 2002, presentación). ${ }^{74}$ De hecho, el estudio de Salamon (dir., 1999) advertía hace unos años sobre la falta de autonomía de las ESAL respecto al Estado y los partidos políticos:

La relación entre el sector no lucrativo y el Gobierno ha sido desde hace mucho tiempo complicada en Colombia. Muchas instituciones no lucrativas

74 Estas posturas se reflejan en el directorio colombiano de ESAL, que registra información de 2936 organizaciones de todo el país. 
se han creado gracias a programas iniciados por el Gobierno, y algunas de ellas se han convertido en vehículos para el clientelismo, en el que la financiación o el apoyo se intercambia por favores o votos. Las recientes reglamentaciones introducidas con la nueva Constitución (1991) han remodelado las relaciones entre el Gobierno y las organizaciones no lucrativas. El reto ahora consiste en garantizar que estos cambios no afecten negativamente la viabilidad financiera del sector no lucrativo a largo plazo ni su capacidad para mantener un grado razonable de autonomía (Salamon, dir., 1999, 514).

Por otra parte, ejemplificadas en la CCONG, el planteamiento de las ONG en sus relaciones con el Estado busca "Contribuir e influir en la construcción de lo público y en política pública, [...] generar una actitud de predominio del interés colectivo frente al particular» (CCONG, 2003d, 4). La perspectiva de la CCONG se distancia de determinadas políticas de "privatización de los servicios», aunque realiza contratos con el Estado como los originados en los programas Empleo en Acción, dentro del componente social del Plan Colombia. Además, reconocen que su especificidad frente a otras OSC encuentra su "norte ético» en los derechos humanos (Querubín, 2003, 6). Asimismo, su planteamiento crítico y reivindicativo ante la Administración de Uribe se ha dejado notar en las mesas de Londres 2003 y Cartagena 2005.

De otro lado, pero siguiendo en el marco de las delimitaciones conceptuales, hay que resaltar que en Colombia no es muy clara la diferencia entre ONG y ONGD. «Hoy se cobija bajo esa denominación un amplio espectro que incluye grupos de personas que se asocian para una obra benéfica, para ejecutar un contrato que, una vez acabado, desaparecen, organizaciones que llevan décadas prestando servicios sociales de muy diverso tipo, grupos de voluntarios de ayuda, más un amplísimo etcétera» (Fernández, 2004, 3).

Fernández (2004) propone unos elementos mínimos que deben constituir la base común de las entidades que se definen como ONG, por lo menos desde la perspectiva de la Confederación Colombiana de ONG: ${ }^{75}$

75 La CCONG como organización de cuarto nivel confedera 12 federaciones regionales de ONG de orden nacional, 8 redes y 10 asociaciones nacionales (de segundo y tercer nivel). En conjunto agrupa más de 1000 entidades, diversas en tamaño (ONG con menos de 20 y más de 4000 colaboradores), en cobertura, origen, antigüedad y discurso ideológico. 


\title{
CUADRO 4.2
}

\section{LA CONSTITUCIÓN COLOMBIANA Y EL ASOCIACIONISMO}

\begin{abstract}
En el artículo 38 de la Constitución colombiana «se consagra el derecho de libre asociación de las personas para el desarrollo de las actividades que realicen en sociedad». Ejerciendo este derecho fundamental, la sociedad civil puede constituir organizaciones desprovistas del objetivo de lucro, que busquen el bien común.

En el artículo 103, sobre los mecanismos de participación popular, la Constitución reconoce que las organizaciones sociales pueden actuar a través del control y vigilancia de la gestión pública: «El Estado contribuirá a la organización, promoción, y capacitación de las asociaciones profesionales, cívicas, comunitarias, juveniles, benéficas, o de utilidad común no gubernamentales, sin detrimento de su autonomía, con el objeto de que constituyan mecanismos democráticos de representación en las diferentes instancias de participación, concertación, control y vigilancia de la gestión pública que se establezcan».
\end{abstract}

FUENTE: Ministerio del Interior de la República de Colombia (1991).

La primera característica es que las ONG no son grupos informales, sino que están dotados de estructuras formales de decisión y funcionamiento que gozan de cierta estabilidad. Este nivel de estructuración les permite presentar balances sociales públicos o posibilita contraer compromisos legales con el Estado, con empleados, con los destinatarios de la acción y, en muchos casos, con clientes. Por lo general, esta característica se soporta sobre una estructura administrativa con algún nivel de especialización en la tarea. Este punto nada tiene que ver con el tamaño. Hay entidades grandes y pequeñas, simples o complejas. Un cierto grado de formalización de la estructura y el funcionamiento son los rasgos característicos.

Asimismo, las ONG, bajo otras formas de naturaleza jurídica con reconocimiento formal del Estado, ${ }^{76}$ están implícitamente recogidas en la Constitución política de 1991.

Las ONG son parte del espectro de organizaciones de la sociedad civil. El carácter «civil» en Colombia contiene dos características centrales: la primera es que no son ni estatales, ni gubernamentales, en el sentido de

76 Aunque la legislación colombiana no las regula específicamente, sí considera su existencia: la Ley 850 del 1 de noviembre de 2003, por la cual se reglamentan las veedurías ciudadanas, prohíbe que los candidatos a veedor tengan vinculaciones contractuales o participen en la gestión de las ONG. 
que no están creadas por ellos, ni hacen parte orgánica de su aparato institucional. Pero también significa que no están armados, ni ejercen actividades que tengan que ver con el ejercicio violento de la fuerza.

A diferencia de los grupos que utilizan la figura jurídica de las ONG para ejecutar un contrato, y que, una vez concluido, se desmovilizan, las organizaciones no gubernamentales tienen usualmente acciones, planes, programas o políticas de mediano y largo plazo, cuando no, como es el caso de la mayoría, su vocación es de permanencia indefinida, dado que sus propósitos están atados a problemáticas de hondas raíces estructurales, por lo que no es esperable que sus razones de existir desaparezcan en el corto plazo.

Las ONG prestan servicios que van dirigidos a un tercero que no son los propios empleados, ni los socios o fundadores. Éste es un punto que las diferencia de otras organizaciones sin ánimo de lucro de la sociedad civil. Esos servicios, como antes quedó evidenciado, pueden consistir en muy diversas cosas, pero tienen en común el ser bienes públicos, que, por lo mismo, pueden ser auditados y evaluados públicamente. No obstante, las ONG colombianas se diferencian de las españolas en la adscripción a las corrientes administrativas provenientes del ámbito empresarial para gestionar las ONG. Un contexto marcado por la escasez de recursos financieros y elevados niveles de desempleo profesional son una mezcla para optar por el uso de hábiles técnicas empresariales para la captación de fondos que permitan no sólo la financiación de los proyectos, sino de sus trabajadores. Las grandes universidades colombianas en Bogotá, Medellín y Cali no suelen tener grandes dificultades para llenar sus cursos y másteres en gestión de las ESAL. Por ejemplo, uno de los trabajos de grado de un máster de la Universidad de Antioquia de Medellín se titulaba El espiritu humano y empresarial de las ONG federadas en Antioquia para acceder a la cooperación internacional (Barrero y otros, 2003, 13).

Un último punto específico de las ONG tiene que ver con lo que éstas declaran como su principal motivación, es decir, hay una referencia explícita a su vocación de servicio y solidaridad, a su idea de «mejorar la calidad de la vida» de algún sector de la población o de la sociedad en su conjunto, independiente de cuál sea la idea que se tenga de la «calidad de vida». Es claro que en este punto pueden existir ideas contrapuestas. Se reivindica el hecho de un espíritu solidario, de ayuda a otros, más allá del 
beneficio personal o grupal. Esto, en opinión de la CCONG, debe verse claramente reflejado en la visión y la misión de cada identidad y en la congruencia de sus acciones respecto a estos parámetros.

A pesar de la clarificación de los puntos establecidos por Rubén Fernández, la trayectoria de las ONG en Colombia ha sido breve si se compara con España; de hecho, como lo afirma Urán (2000), el fenómeno de las ONG es relativamente nuevo en Colombia. La «mayoría de las que han existido se han dado en el campo de lo denominado "instituciones de beneficencia social", muchas de las cuales se originaron a partir de acciones filantrópicas de algunos industriales y sus cónyuges, de la acción social de la Iglesia católica, y muy pocas como asociaciones cívicas de amoblamiento e higiene urbana» (Urán, 2000, 268).

El estudio comparativo que analiza el sector no lucrativo en 22 países de cuatro continentes describe los aspectos más sobresalientes de esta historia en Colombia:

El amplio abanico de organizaciones benéficas —escuelas, hospitales, orfanatos y hospicios - administradas por la Iglesia católica bajo el dominio de la Corona española durante el período colonial, y financiadas con fondos procedentes del Estado, donaciones privadas y obras pías; es decir, donaciones de particulares a la Iglesia. Las escuelas y asociaciones en defensa de la educación católica organizadas por la Iglesia católica, que florecieron especialmente durante períodos de reformas secularistas liberales e intentaron ejercer el control gubernamental sobre la educación. Las Juntas de Beneficencia establecidas a mediados del siglo XIX como un mecanismo del Gobierno para secularizar y ejercer un mayor control sobre las organizaciones benéficas, gestionadas normalmente por entidades privadas, principalmente religiosas, y financiadas extensamente por fondos procedentes del sector público. [...] Otros ejemplos de organizaciones benéficas incluyen el Círculo de Obreros y la Caja Social de Ahorros, fundadas a principios del siglo XX por el padre Campoamor para servir a las necesidades de la clase trabajadora (Salamon, dir., 1999, 502-503).

Otras manifestaciones relevantes en el florecimiento de las organizaciones no lucrativas fueron las Cajas de Compensación Familiar, un tipo de sistema de seguridad social establecido originalmente por la Asociación Nacional de Industriales en 1954 para distribuir subsidios a las familias de los trabajadores. A partir de 1957, el Gobierno nacional decretó que los pagos de los patronos a estas organizaciones debían ser obligatorios.

Las fundaciones empresariales, fundadas muchas de ellas en los años sesenta y setenta para impulsar el desarrollo económico, a menudo median- 
te el fomento de microempresas, y cubrir otras necesidades medioambientales, educativas y sociales. Algunos de los ejemplos más destacados de este tipo de fundaciones incluyen la Fundación Social y la Fundación para la Educación Superior, que establecieron empresas separadas con el fin de generar recursos para lograr sus objetivos sociales (Salamon, dir., 1999).

Organizaciones tales como las Juntas de Acción Comunal, los Consejos Verdes y los Hogares Infantiles de Bienestar Familiar, concebidas durante las últimas décadas mediante programas del Gobierno «diseñados para sacar el máximo fruto de la escasa financiación estatal por medio de la utilización de la contribución voluntaria de los miembros de la comunidad» (Salamon, 1999, 503). En la actualidad, las Juntas son las organizaciones no lucrativas más extendidas en Colombia (incluyen a más de 42000 organizaciones) y se calcula que un $15 \%$ de la población adulta está afiliada a ellas (Salamon, dir., 1999).

Es sobre todo a mediados de los setenta cuando surgen ONG con alto componente de trabajo voluntario y se orientan a la construcción y mejoramiento del tejido social y a la democratización de las relaciones políticas entre el Estado y los sectores populares y comunitarios de las ciudades. Como sostiene Urán $(2000,268)$, «muchas se conforman por ex miembros de organizaciones de izquierda, debido al agotamiento de modelos tradicionales de acción política, así como debido al quiebre de los proyectos utópicos alternativos en el ámbito global».

Por tanto, la presencia de líderes de izquierda se explica principalmente por la nula cabida ideológica en los espacios de participación política y el refugio, casi obligado entre los márgenes de la legalidad estatal, en la sociedad civil. Durante muchos años (1958-1972) se vivió en el país el Frente Nacional, una alternancia pactada de los partidos liberal y conservador que ha sido calificada por algunos como una "dictadura hegemónica bipartidista en el manejo del Estado» (Segovia, 1999).

Algunas entidades y escritores presentan a Colombia como «la democracia más antigua y estable de América Latina»; ${ }^{77}$ no obstante, este califi-

77 Embajada de Colombia en España, <http://www.embacol.com/positiva>, 20 de junio de 2005. Además de ONG como YMCA (<http://www.ymcacolombia.org/sintonia/nota42.htm>) y revistas universitarias de América Latina: Julio Sergio Ramírez (2000), «El liderazgo moral: El reto de este siglo», Revista Lila (Asunción), n. ${ }^{\circ} 27$, mayo-junio. 
cativo se enuncia en términos de ausencia de dictaduras militares prolongadas como las ocurridas en el sur del continente. En Colombia hubo una dictadura militar del general Gustavo Rojas Pinilla que duró de 1953 a 1957, pero las condiciones de representatividad de los partidos políticos, su vinculación con elites económicas de fuerte arraigo familiar, la escasa consolidación de las instituciones democráticas y la poca garantía de los derechos no caracterizan precisamente una democracia antigua y estable en un sentido amplio del término.

Las profundas contradicciones generadas por el modelo económico, la exclusión política y la dependencia de los Estados Unidos, junto con la ruptura provocada por la Revolución cubana, crearon las condiciones para el surgimiento o radicalización de fuerzas insurgentes. Inicialmente se trataba de miles de campesinos pobres que reivindicaban la distribución de la tierra que se encontraba (y aún se encuentra) en manos de la aristocracia colombiana.

Fue en ese contexto, durante el último cuarto de siglo, en el que «sobreponiéndose a la represión, los obstáculos jurídicos, las limitaciones económicas y dificultades de todo tipo, nacieron, crecieron y maduraron decenas de organismos no gubernamentales que han contribuido a la formación y organización popular, la promoción y defensa de los derechos humanos, económicos y sociales, y a confrontar el sistema dominante de violencia, exclusión y pobreza» (Segovia, 1999).

Existen muchos tipos de divagaciones teóricas sobre el papel de las organizaciones no gubernamentales en Colombia. Por ejemplo, Segovia (1999) sostiene que es tal la diversidad de este tipo de entidades, que

Para algunos son una expresión de reformismo, de institucionalización de la acción social, de populismo. De otro lado, no sin fundamento, se afirma que son vivideros disfrazados, oficinas de relaciones públicas de los grandes conglomerados, artificios politiqueros de izquierda y derecha o canales oportunistas de recursos.

Lo que sí es un síntoma claro del compromiso cívico y político de buena parte de éstas es la cantidad de dirigentes y miembros de ONG, especialmente las que trabajan en el ámbito de la paz y los derechos humanos, que han sido asesinados, que han desaparecido o han tenido que exiliarse por llevar a cabo su trabajo. 
Un denominador común en la historia de las ONG colombianas es el trabajo en medio de un complejo conflicto armado que ha sacrificado a muchos integrantes. En ese contexto de violencia política y social, la mayoría de fuentes consultadas en este estudio coinciden con Segovia (1999) al afirmar que la mayoría de las ONG se identifican con un «esfuerzo ciudadano por mejorar las condiciones de vida de la mayoría de la población, consolidar una democracia participativa con justicia social y equidad de géneros; y por garantizar el respeto y realización de los derechos humanos, económicos y sociales: de los niños, la juventud, la mujer y los mayores adultos; y de los derechos de los pueblos indígenas, afrocolombianos y de las minorías étnicas existentes en el país».

\subsubsection{Diferencias entre «las colombianas»y «las españolas»}

Como la mayoría de los autores latinoamericanos que investigan el fenómeno de las ONG, Eloy Anello (1989) centra su interés en el estudio de las ONGD, y define este tipo de organización como

Entidades autónomas, legalmente establecidas que poseen estatus de no beneficio y organizadas por ciudadanos comunes (profesionales, técnicos y trabajadores de campo —-sociales-) cuya motivación primaria es mejorar el nivel de vida de su pueblo. Ellas orientan sus servicios y su misión en términos de guiar (orientar, acompañar)... Sirven a la población en diversas y complejas actividades relacionadas con procesos de desarrollo, tales como la generación de conocimiento, la prestación de servicios que respondan a la satisfacción de las necesidades humanas fundamentales, y la investigación y aplicación de estrategias alternativas de desarrollo que promuevan la transformación social. Ellas reflejan una pluralidad de perspectivas ideológicas y aprecian su independencia y autonomía institucional. Su modo primario de acción son los proyectos y programas que son auspiciados por las agencias internacionales de ayuda. Perciben el desarrollo en términos de un proceso de aprendizaje participativo que facilite la construcción de capacidades y de autorreforzamiento. Tienden a ser organizaciones de tamaño intermedio dotadas de un alto grado de flexibilidad para responder a cambios en el entorno socieconómico. Aunque [operan] en la sociedad a niveles nacional, regional y local, la mayoría funciona en los niveles regional y local en unión con las organizaciones populares. Aunque su trabajo puede tener implicaciones políticas, no son partidos políticos y tienden a mantener una posición política independiente. ${ }^{78}$

78 Anello (1989), citado por Vargas y otros (1992). 
Hay varios aspectos que cuesta dejar pasar de forma inadvertida si se compara con la definición de las ONGD españolas según la perspectiva de la CONGDE. ${ }^{79}$

En común, se destaca la relevancia del carácter voluntario, no lucrativo, independiente y transformador de ambas concepciones. No obstante, en la definición «española» aparece el requisito del "grado mínimo de estructura» de la organización, mientras que en la "colombiana» no aparece este elemento. Se hace referencia a que son organizadas por "ciudadanos "comunes"” (profesionales, técnicos y trabajadores sociales). Llama la atención la elevada preocupación del asociacionismo español por la estructura o, según se mire, el latente desinterés de las colombianas por las estructuras organizativas.

Los organigramas, el establecimiento de juntas directivas y la necesaria distribución del trabajo en comisiones son aspectos recurrentes en las entidades españolas. Éstos suelen ser los primeros aspectos que asume una entidad en sus orígenes; no obstante, a la mayoría de las entidades colombianas les preocupa sobremanera la realización de actividades. El activismo es el criterio por el cual se descubren las necesidades de estructuración, y, por tanto, la estructura organizativa es una consecuencia ligada a la preparación y realización de las actividades. ${ }^{80}$

Otra diferencia apreciable es la consideración de la interrelación con entidades similares. Las ONGD españolas relatan su condición de entidades que «trabajan activamente en el campo de la cooperación y la solida-

79 Dicha definición queda recogida en el Código de conducta de las ONG de desarrollo de la CONGDE y en otros documentos: «Es una organización estable que dispone de un grado mínimo de estructura, sin ánimo de lucro, que trabaja activamente en el campo de la cooperación para el desarrollo y la solidaridad internacional. Tiene voluntad de cambio o de transformación social. Que posee respaldo y presencia social (apoyo económico mediante donaciones o cuotas; capacidad para movilizar trabajo voluntario, participación activa en redes con presencia social, contacto con otras organizaciones sociales). Es independiente, posee recursos, tanto humanos como económicos, que provienen de la solidaridad, de donaciones privadas, de trabajo voluntario o semejantes. Actúa con mecanismos transparentes y participativos de elección y nombramiento de sus cargos, promoviendo la igualdad de oportunidades entre hombres y mujeres. Y es transparente en su política, en sus prácticas y en sus presupuestos" (Nieto, coord., 2001).

80 Este comportamiento puede entenderse desde varias hipótesis. Podría explicarse a partir del esquema weberiano por el cual hay un tipo de organización de autoridad legalracional, que podríamos asociar al europeo y otro más intuitivo-tradicional, más afín al «latino», pero con una relativa influencia del pragmatismo anglosajón. 
ridad», mientras que las colombianas «sirven a la población en diversas actividades». La condición de "servicio» también puede tener diferencias culturales (incluso religiosas). Por su parte, las ONG españolas, aunque tienen un fuerte matiz religioso en su origen, han pasado por un intenso proceso de secularización en los últimos 25 años. En Colombia el sincretismo religioso con otras pautas socio-culturales está más expuesto.

La definición de las entidades colombianas afirma trabajar en unión con «las organizaciones populares», mientras que el objeto de intervención de las entidades españolas no es tan explícito; en su lugar valoran la base social que las apoya y sustenta. En cuanto a la financiación, las españolas hacen referencia a las cuotas de socios, donaciones, y reconocen la posesión de recursos económicos propios. En las colombianas sólo se menciona el «auspicio de los programas y proyectos por parte de agencias internacionales de ayuda»; aunque la definición no lo recoja, estas entidades también reciben cuotas de socios y donaciones particulares. Además, como se menciona en otros apartados del trabajo, para algunas organizaciones colombianas, la búsqueda de fondos privados, ante la escasez y reticencia del Estado colombiano, pasa por una serie de actividades que imprimen un matiz más «empresarial» que las españolas. De hecho, se afirma que «las ONG reinvierten las ganancias en la propia actividad» (Fernández, 2004). Esta característica las diferencia de otro tipo de estructuras, «en particular de los negocios que buscan producir rendimientos a sus dueños». Las ONG buscan realizar una actividad que sea también productiva y sostenible en lo económico; normalmente, estos rendimientos se utilizan para proyectos especiales, para reforzar líneas débiles de la actividad o para crear fondos que garanticen la sostenibilidad de largo plazo de la organización.

Por último, uno de los rangos de diferenciación más claro es el ámbito geográfico de intervención. En las entidades españolas hay una evidente tendencia hacia la esfera internacional, y en las organizaciones del país suramericano destaca el nivel regional y local. Incluso, no aparece enunciado el carácter nacional, ya que es una reducida proporción de organizaciones la que tiene presencia en la mayoría de los departamentos colombianos.

\subsubsection{Los primeros pasos y sus huellas}

Para los países latinoamericanos, el sociólogo chileno Manuel Baquedano (1990) estableció tres generaciones de ONG comunes a la mayor 
parte de los países del subcontinente. ${ }^{81}$ La primera generación de ONG corresponde aproximadamente a los inicios del siglo XX hasta la década de los cincuenta y abarca una época en la cual las organizaciones no cuestionaban el modelo de desarrollo vigente, sino que buscaban mitigar y limitar los daños derivados de la situación socioeconómica predominante. Se trataba de entidades caritativas u organizaciones promovidas por empresarios abiertos al cambio que apoyaban programas para mejorar las condiciones de los sectores más oprimidos. Los valores que inspiraban la acción de entidades y empresarios encontraban su fundamento en la religión católica.

La segunda generación de ONG no comparte el modelo de desarrollo imperante y busca sustituirlo dentro de un marco de cambios de estructuras. Sostiene un modelo de desarrollo nacional basado en la redistribución del ingreso y los procesos de democratización de los Estados. Esta generación surge a mediados de los sesenta, cuando se hacen más patentes los estragos ocasionados por los modelos desarrollistas.

La tercera - y actual— generación también se opone al modelo de desarrollo vigente, pero trabaja por un modelo alternativo que replantea la concepción misma del desarrollo. Muchas surgieron a finales de los setenta en medio de un contexto político autoritario, tienen vínculos con la Iglesia católica, las universidades y los partidos políticos de oposición. Aún se mantienen vigentes y trabajan por el fortalecimiento de una sociedad civil que interpele al Estado. En esta generación se circunscribe la aparición de las ONGD impulsadas por la vertiente popular de la Iglesia católica, caracterizándose por mantener una actitud contestataria hacia la ineficacia del Estado (Baquedano, 1990). No obstante, las entidades de más reciente creación han dado un giro en la relación con el Estado, cambio que ha sido acompañado (e influenciado) por los procesos de descentralización y promoción de la autonomía regional, que ha llevado a algunas organizaciones a contribuir a la implementación y ejecución de la política social del Estado.

Al comparar algunas clasificaciones de generaciones realizadas en España (Nieto, coord., 2001) con otras que han surgido en contexto latinoamericano (Baquedano, 1990; Vargas y otros, 1992) se aprecia una

81 Para profundizar en las generaciones de ONG, ver Korten (1994). 
coincidencia general en algunos aspectos como la consecución de la autonomía por parte de las poblaciones, el endurecimiento de las críticas y reivindicaciones ante el Estado, el paso de la aceptación al cuestionamiento de los modelos económicos, etc. Sin embargo, existen algunas diferencias importantes, que sólo serán enunciadas por no tratarse de un tema prioritario. En las entidades españolas ha cobrado un papel importante, en las últimas generaciones, la sensibilización de la población general ante los problemas que padece el «Tercer Mundo", pero para sus contrapartes del «Sur» esto no parece representar una prioridad. En sus objetivos, propósitos y líneas de trabajo, la concienciación de las reducidas poblaciones que pertenecen a niveles socioeconómicos medios y de los minúsculos pero poderosos grupos centralizadores de la riqueza no suele destacar.

Por otro lado, como parte de las ONGD del «Norte», las españolas han ampliado la perspectiva mundial (universalista), pasando de regiones preferentes por lazos históricos, culturales y religiosos a unificar su mirada en una gran parte del mundo con problemáticas similares de pobreza. Las organizaciones del «Sur» han mantenido una perspectiva local y algunas han ampliado su actuación al plano regional. ${ }^{82}$

El desarrollo institucional de las ONG en Colombia ha experimentado cambios significativos de creciente complejidad en la forma de concebir su papel como agente de cambio social, en sus acciones, en la manera de operar y de influir en las comunidades hacia las cuales proyectan su trabajo. Han pasado de cierto grado de asistencialismo que las unificaba a una variedad de enfoques que incluye la prestación de servicios, la reivindicación ante el Estado y la construcción del tejido social como parte del fortalecimiento de la sociedad civil.

En Colombia se crearon 21 ONG desde 1839 hasta 1900 (0,35 ONG por año). Más que organizaciones, tal como se conocen actualmente, se trataba especialmente de casas de hospicio y refugio para albergar a desempleados y mendigos. Entre 1901 y 1950 se fundaron 221 (4,42 por año), en la década de 1950 se conformaron 106 (10,6 entidades por año), en los sesenta 232 (23,2 por año) y de los setenta hasta los noventa 833 (41,6

82 En esta afirmación se exceptúan aproximadamente el centenar de instituciones, congregaciones y comunidades misioneras que realizan su trabajo pastoral en Centroamérica, Sudamérica, África y Asia. 
entidades por año). El ritmo de crecimiento anual se ha duplicado en las sucesivas décadas desde los cincuenta (Vargas y otros, 1992, 232-233).

Es a partir de la década de los ochenta cuando empieza el auge de las ONG especializadas en el desarrollo. Se trata de un período de crisis institucional generalizada. En el ámbito político el país no se reponía de la pérdida de legitimidad del sistema bipartidista (agudizado por casi veinte años del Frente Nacional), a nivel económico había recesión externa e interna, y los intereses de la deuda externa ahogaban las finanzas del Estado, el conflicto armado se hacía más extenso y cruento ante la escasa presencia estatal en muchas regiones.

Había un ambiente generalizado de descontento y desesperanza después de muchos años de confianza en los modelos convencionales de desarrollo: no es casualidad que la CEPAL la haya denominado, para el conjunto de América Latina, la "década perdida». Dicho descontento produjo, al interior de la débil y fragmentada sociedad civil, la "génesis de una visión autorreflexiva que, además de haber intensificado la propuesta popular (pacífica en unos casos, violenta en otros, reprimida en ambos), ha generado nuevas formas de pensar y actuar para lograr estilos de desarrollo alternativo más acorde con el espíritu de la modernidad» (Vargas y otros, 1992, 40). De hecho, mucho del inconformismo fue expresado por vías extrainstitucionales promoviendo formas de lucha que fortalecían a los grupos subversivos.

No obstante, las ONGD empezaron a ser admitidas por el Estado colombiano, pese al tono contestatario de muchas de ellas. A través de la Ley 11 de 1986, se autorizó a los municipios a realizar contratos, convenios y acuerdos con organismos no gubernamentales (aunque no recibieran esa denominación en la ley) ${ }^{83}$ que tuvieran sede en el distrito respectivo y que promovieran el desarrollo.

83 «Artículo 22. Las Juntas de Acción Comunal, las Sociedades de Mejora y Ornato, las Juntas y Asociaciones de Recreación, Defensa Civil y Usuarios, constituidas con arreglo a la ley, y sin ánimo de lucro, que tengan sede en el respectivo distrito, podrán vincularse al desarrollo y mejoramiento de los municipios mediante su participación en el ejercicio de las funciones y la prestación de los servicios que se hallen a cargo de éstos. Con tal fin, dichas juntas y organizaciones celebrarán con los municipios y sus entidades descentralizadas los convenios, acuerdos o contratos a que hubiere lugar para el cumplimiento o la ejecución de determinadas funciones u obras». Congreso de la República de Colombia. Ley 11 de 1986 (16 enero). Diario Oficial, n. ${ }^{\circ}$ 37310, de 17 de enero de 1986. 
La forma de financiación más habitual por parte de este tipo de entidades ha sido la autofinanciación (venta de productos o servicios, realización de eventos de carácter cívico, cuotas a socios), la recepción de donaciones de empresas y particulares, y la firma de convenios con entes gubernamentales. En el estudio realizado por la Fundación Social (Vargas y otros, 1992) el 61,2\% de las organizaciones se financiaba a través de operaciones propias de cada institución y de las donaciones hechas por el sector privado nacional. El 33\% recibió financiación pública y sólo el 5,5\% de ONG recibió ayuda internacional. La escasa participación de la ayuda internacional se debe al reducido tamaño de la mayor parte de ONGD; sólo las más grandes tienen posibilidad de acceder a estos recursos, y, en comparación con el total de organizaciones, son muy pocas. Además, hay un gran desconocimiento de los procedimientos técnicos para solicitar recursos internacionales.

Sin importar tanto el tamaño y los recursos, gran parte de las entidades ha priorizado por ámbitos de actuación similares. El enfoque inicial de las ONGD fue la satisfacción de las necesidades humanas materiales (supervivencia física) e inmateriales (autorrealización personal, derechos humanos...), pero poco a poco se fue avanzando en el apoyo a las comunidades populares, ya que empezaron a concebirse como elementos dinamizadores que conformaban un tejido asociativo fuerte y permanente que vinculaba los procesos locales con los nacionales. Las ONGD han actuado siempre en esferas en las que el Estado no ha respondido a las necesidades de las grandes mayorías; por ello se han concentrado en aquellos sectores de la población que se encuentran en condiciones de marginación social y política. A continuación se describen las principales organizaciones que se han conformado en Colombia por ámbito de actuación, según la síntesis elaborada por Segovia (1999).

\section{Derechos humanos}

Frente a la tendencia oficial de desconocer el estatus de prisioneros políticos y tratar a los rebeldes como delincuentes comunes, un grupo de activistas y simpatizantes con grupos rebeldes crearon a finales de los años sesenta el Comité de Solidaridad con los Presos Políticos (CSPP). Esta organización años después, ante la agudización del conflicto y la represión con la imposición del Estatuto de Seguridad en el Gobierno de Julio 
César Turbay (1978-1982), extendió su acción solidaria, de asesoramiento legal a los detenidos y de protección, «más allá de quienes se reclamaban insurgentes, a líderes y luchadores populares víctimas de una generalizada represión» (Segovia, 1999). Treinta años después, el Comité continúa su acción legal, de denuncia, de defensa de los dirigentes populares y de apoyo a los defensores de los derechos humanos, en medio de los asesinatos a defensores.

La represión desatada a comienzos de los ochenta, bajo la Doctrina de la Seguridad Nacional, justificada por el Gobierno en las acciones de la guerrilla urbana del M-19 y otros grupos (que significó detenciones y torturas), motivó una reacción amplia y pluralista en exigencia del respeto a los derechos humanos y de buscar una salida pacífica al conflicto. En ese contexto se convocó al Primer Foro Nacional por los Derechos Humanos, del que surgió el Comité Permanente por la Defensa de los Derechos Humanos $(\mathrm{CPDH})$, que se convirtió en una instancia permanente de seguimiento y denuncia al respecto. En ese contexto se introdujo en el país la modalidad contrainsurgente de la desaparición, importada de las dictaduras del sur del subcontinente. Para presionar por la responsabilidad de los agentes del Estado en esos casos, la posible aparición de las víctimas y el castigo a los culpables, surgió la Asociación de Familiares de Detenidos Desaparecidos (ASFADDES), cuya lucha de años ha buscado materializarse con la aprobación y aplicación de las leyes correspondientes.

En el trabajo de apoyo legal a personas vinculadas a procesos por «delitos contra la seguridad del Estado», en defensa de las garantías procesales y los derechos humanos, pero también en la batalla política y jurídica por confrontar los marcos cada vez más restringidos de interpretación del delito político y la criminalización de la protesta social, fue conformado el Colectivo de Abogados José Alvear Restrepo, dos de cuyos impulsores pagaron con la vida su lucha por una justicia transparente: Eduardo Umaña Mendoza (asesinado en mayo de 1998) y Alirio Pedraza (desaparecido a finales de los ochenta). El trabajo del Colectivo tuvo un elocuente reconocimiento al serle otorgado el Premio de Derechos Humanos del Gobierno de Francia en 1997. En esa senda también se crearon Minga, la Fundación Manuel Cepeda y Reiniciar (Segovia, 1999, 20-21).

Surgida inicialmente como un esfuerzo de seguimiento, interpretación y denuncia sobre la situación de los derechos humanos en Colombia, 
la Comisión Colombiana de Juristas se convirtió en un referente obligatorio para la comprensión del tema, la búsqueda de alternativas y la recomendación de acciones y medidas al Estado en la tarea de superar las irregularidades que rescaten la legitimidad de su función. Los objetivos de la Comisión se han ampliado con el estudio, divulgación y análisis de la situación de derechos económicos y sociales en el marco de los postulados de un Estado social de derecho, consagrado en la Constitución de 1991. La Comisión es hasta ahora el único organismo no gubernamental colombiano que ha logrado estatus consultivo frente a la Comisión de Derechos Humanos de la Organización de Naciones Unidas.

La degradación e intensificación del conflicto interno y la generalización de la acción del paramilitarismo y la guerrilla en todo el país, unidos a otros fenómenos como el narcotráfico, trajeron consigo nuevas formas de imposición, terror y despojo como el desplazamiento que hoy afecta a más dos millones de colombianos pobres (ver anexo 5). Los trabajos de la Corporación Regional para la Defensa de los Derechos Humanos (CREDHOS) en Santander (ver mapa 4.2) se dedica a investigar y denunciar estas situaciones y apoyar a sus víctimas. Con esta población también trabaja la Consultoría para los Derechos Humanos y el Desplazamiento (CODHES) y el Grupo de Apoyo a Organizaciones de Desplazados (GAD). Otras entidades como la Corporación AVRE y la Fundación Cedavida prestan asistencia a las víctimas de la violencia en la búsqueda de superar los traumas generados, especialmente en los niños.

\section{Trabajo por la paz}

A la par con el recrudecimiento del conflicto armado, hay varias entidades que trabajan en la promoción de una solución política entre el Estado y la insurgencia. Destaca a mediados de los ochenta el Movimiento por la Vida, que daría lugar a la creación de la Red de Iniciativas por la Paz y contra la Guerra (Redepaz), que aglutina más de un centenar de experiencias a nivel nacional. Utilizando medios lúdicos y artísticos, Redepaz ha logrado convocar un número importante de activistas de la paz, institucionalizó la Semana Nacional por la Paz y es parte activa de los actuales esfuerzos en ese sentido.

Alrededor de este empeño se impulsaron el Mandato de los Niños por la Paz (1996) y el Mandato Ciudadano por la Paz (1997), ejercicios sim- 
bólicos en los que dos millones de niños y 10 millones de adultos manifestaron su anhelo de paz. En ese mismo sentido algunas personalidades convocadas por la Iglesia católica convergieron en la Comisión Nacional de Conciliación, una instancia de promoción y asesoría en el tema. Experiencias como éstas motivaron un espectro más amplio de sectores, para que se fundara la Asamblea de la Sociedad Civil por la Paz, que ha realizado dos grandes plenarias nacionales cuyas conclusiones y recomendaciones constituyen insumos para el trabajo en esta materia. La demostración más contundente de cómo estos esfuerzos han calado en la conciencia de los colombianos fueron las movilizaciones masivas del «iNo más!» realizadas el 24 de octubre de 1999.

La crisis vivida por el país en todas sus manifestaciones y la incapacidad del Estado para imponer el monopolio de la fuerza, la justicia y ganar legitimidad, han generado también una explosión de criminalidad, violencia común e intolerancia, con cifras dramáticas. A impulsar mecanismos de resolución pacífica de los conflictos cotidianos y procesos de convivencia se han dirigido los esfuerzos de varias ONG como Justapaz. En 1987, la Compañía de Jesús creó el Programa por la Paz, que adelanta y apoya procesos en todo el país en favor de la participación ciudadana en la construcción de la paz, el desarme, la inserción de jóvenes delincuentes, y actividades de reflexión sobre la paz, la ética y la democracia. ${ }^{84}$

\section{Comunicación, educación y cultura popular}

A finales de los años setenta, impulsados por la carencia de órganos de expresión alternativos a los medios masivos ligados políticamente a los sectores más privilegiados, algunos colectivos asumieron iniciativas modestas pero de gran compromiso. La necesidad de una información no oficial y una visión crítica la había corroborado la gran acogida que dieron organizaciones populares y lectores independientes a la revista Alternativa, desaparecida ante el retorno de la mayoría de sus realizadores a su casa matriz periodística (El Tiempo) y a su replanteamiento ideológico. En la investigación y formación en el campo de la comunicación se creó el Servicio Colombiano de Comunicación Social (SCCS). Ligada a cristianos

84 Es uno de los ejes de mayor concentración. En el año 2000 más de mil ONG firmaron un acuerdo programático por la paz. 
comprometidos y al trabajo de las Comunidades Eclesiales de Base, surgió la Corporación para la Promoción Popular (CPP) y su publicación Solidaridad. Aportes Cristianos para la Liberación, que se editó durante una década y tiene continuidad en Utopías. Un grupo de profesores e investigadores de la educación fundan el Centro de Promoción Ecuménica y Social (CEPECS), que da vida a Colombia Hoy Informa, editada hasta 1995, cuando desapareció para integrarse al esfuerzo de la nueva revista Alternativa.

Por esa misma época, para contribuir con una lectura crítica de los medios, capacitar a las organizaciones populares en su uso y promover su creación, surge el Centro Popular para América Latina de Comunicación (CEPALC), que desde entonces publica la revista de comunicación popular Encuentro y realiza festivales populares de comunicación para compartir los resultados del trabajo en esa área. Con el fin de ofrecer a organizaciones solidarias o comprometidas con la situación colombiana en el exterior un panorama integral de la situación nacional con énfasis en los derechos humanos y el conflicto interno, desde 1988 CEPECS y CINEP publican el boletín quincenal Actualidad Colombiana.

\section{Investigación para desarrollo social}

En 1972 con el apoyo de la comunidad jesuita se creó el Centro de Investigación y Educación Popular (CINEP) con la participación de investigadores sociales, pedagogos, teólogos, sacerdotes y laicos, que iniciaron un trabajo crítico de investigaciones, divulgación sobre la realidad nacional y formación para el trabajo popular y pastoral. El CINEP abrió un espacio casi inédito de interpretación de la realidad que le valió un reconocimiento nacional e internacional por su trabajo en materia de derechos humanos, violencia y paz, desarrollo regional, de formación bíblica y pastoral para el cambio social.

Sus publicaciones Controversia y Documentos Ocasionales se convirtieron en materiales de consulta. En 1989 emprendió la ambiciosa e innovadora investigación Colombia: conflicto social y violencia, que aportó luces a una interpretación de la realidad a partir de la constatación de las carencias en la construcción democrática del país. Su publicación trimestral Cien Días es otro aporte permanente a una comprensión más profunda de los asuntos nacionales. Tanto como ha sido reconocido el trabajo del 
MAPA 4.2

DISTRIBUCIÓN DE LAS ONG PIONERAS EN COLOMBIA POR DEPARTAMENTOS

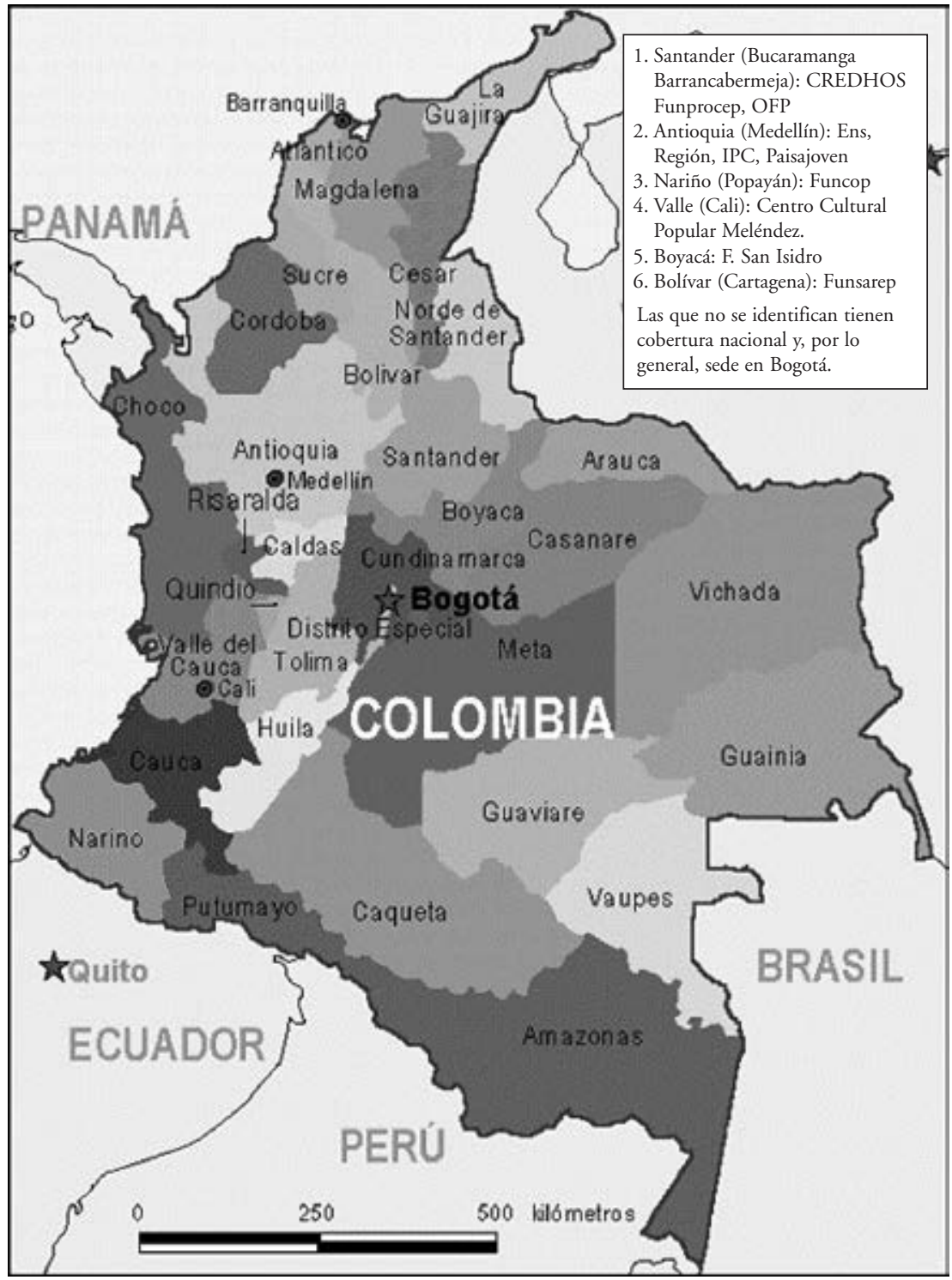

FUENTE: Elaboración propia a partir de Segovia (1999). 
CINEP, ha sido permanentemente hostigado, situación que dejó su huella con el asesinato de Elsa Alvarado y Mario Calderón.

En lo relacionado con el tema de los derechos humanos, el CINEP creó una oficina permanente de sistematización y seguimiento a sus violaciones, acompañamiento a las víctimas y promoción de acciones para la superación de esta situación. A su vez, la Conferencia de Religiosos de Colombia (CRC) dio pie a la Comisión Intercongregacional de Justicia y Paz, cuyo equipo de trabajo publica desde hace 12 años Justicia y Paz. En un esfuerzo conjunto con el CINEP crearon el Banco de Datos sobre Derechos Humanos, que constituye el servicio más documentado en esta materia en el país y publica trimestralmente un informe de seguimiento sobre violaciones con el nombre de Noche y Niebla.

\section{El otro derecho}

En toda América Latina han surgido grupos de abogados interesados en prestar sus servicios a los sectores populares, a través de consultorios jurídicos y asesoramiento legal. De la necesidad de articular esos esfuerzos y sistematizar sus experiencias, en 1978 se creó el Instituto Latinoamericano de Servicios Legales Alternativos (ILSA). Los procesos sociales y populares en el continente y las luchas cotidianas de los sectores populares por sus reivindicaciones han generado experiencias inéditas en el campo jurídico que llevan a esta red a fijar un nuevo referente conceptual, como es el del derecho alternativo, cuyo objetivo, más allá de buscar acceso a la justicia, consiste en reclamar garantías procesales y el cumplimiento de los fines del Estado en ese aspecto. El trabajo de ILSA halló una perspectiva más amplia durante la última década en su replanteamiento frente al tema de los derechos humanos, del reclamo individual hacia la materialización colectiva en los derechos económicos, sociales y culturales, en cuya realización centra ahora su trabajo teórico, investigativo y práctico.

En el campo de la investigación y capacitación sobre el mundo del trabajo, la legislación laboral y la acción sindical, junto a la labor del Centro de Estudios e Investigaciones Sociales (CEIS) y del Centro de Estudios del Trabajo (Cedetrabajo), hace veinte años abogados laboralistas dieron vida al Instituto Sindical María Cano (ISMAC), que inició su labor a través de cursos, talleres y publicaciones relacionadas con estos temas desde los intereses de los trabajadores. En la coyuntura de 1991 (cuando se con- 
vocó la Asamblea Nacional Constituyente) el ISMAC adelantó un importante trabajo de divulgación, sistematización y promoción de propuestas en temas relacionados con el derecho al trabajo, los derechos fundamentales y la organización y movilización social. En un nuevo eje de su acción se ha vinculado a la reflexión y movilización por la paz, la solución pacífica del conflicto y las reivindicaciones sociales. En esa misma vertiente se ubica el trabajo realizado por la Escuela Nacional Sindical (ENS) y el Instituto Popular de Capacitación (IPC), creados en Medellín, cuya actividad ha recibido constantes amenazas y presiones.

\section{Redes y plataformas}

Con propósitos de investigación similares a los del CINEP, pero centrados en la realidad del departamento de Antioquia (ver mapa 4.2), surgió la Corporación Región. Sus trabajos investigativos y de recuperación de la historia oral del conflicto permitieron una nueva comprensión sobre la realidad social de Medellín, como el pionero de Alonso Salazar No nacimos $p a$ semilla. Centrada en la investigación sobre procesos políticos y sociales hacia la modernización y el fortalecimiento de la democracia, en 1984 un grupo de investigadores y docentes crean la Fundación Foro Nacional por Colombia. En esta área también se destaca la creación de varios centros e institutos de investigaciones sociales y políticas en las universidades, como es el caso del Instituto de Estudios Políticos y Relaciones Internacionales de la Universidad Nacional (IEPRI) y su publicación Análisis Politico.

Dicha Fundación publica la revista trimestral Foro, que constituye un importante aporte analítico sobre temas como la paz y la guerra, la ideología, la sociedad, el ordenamiento territorial, los partidos políticos, la educación y los problemas nacionales. Foro extendió su acción a la formación de liderazgos populares en espacios locales, como una forma de contribuir a la construcción de la democracia. En la coyuntura constituyente de 1991, Foro por Colombia, unida a otras ONG regionales (Podion, Casa de la Mujer, Fundación Social, CORFAS, Corporación Región, Escuela Nacional Sindical, Conciudadanía), puso en marcha la campaña de educación para la democracia Viva la Ciudadanía, un empeño sin precedentes de capacitación ciudadana en torno a los contenidos de la nueva Constitución, su divulgación y la presión social para hacer efectivos sus 
desarrollos legislativos. De esa iniciativa surgió la Corporación S.O.S. Colombia, que viene apoyando distintas iniciativas en este campo y publica el periódico Caja de Herramientas, órgano de análisis y formación distribuido a todos los rincones de Colombia.

\section{Mujeres, juventud y niñez}

Durante las últimas dos décadas surgió un sinnúmero de organizaciones locales y regionales de mujeres con objetivos propios por sus derechos, la equidad de géneros y reivindicaciones más amplias de los sectores sociales. En Barrancabermeja (ver mapa 4.2) la Organización Femenina Popular (OFP), creada en 1972, hizo de la capacitación, la denuncia, la movilización y la solidaridad principios fundamentales de su acción, sensibilizando, concienciando y formando mujeres como líderes y actoras de la realidad local tan golpeada por la injusticia y la violencia ${ }^{85}$ (Segovia, 1999, 37).

En el trabajo de educación y prevención contra la violencia intrafamiliar y en defensa y promoción de los derechos de los niños trabajan Save the Children (capítulo colombiano), Defensa de los Niños Internacional (DNI), la Fundación Afecto y la Fundación Dos Mundos. En lo atinente a la juventud, experiencias como Benposta, Nación de los Muchachos (que acaba de cumplir 25 años de labores), la Juventud Trabajadora de Colombia (JTC) y Paisajoven en Medellín (con la ayuda de la Gesellschaft für Technische Zusammenarbeit, GTZ, alemana).

Uno de los principales pasos de los últimos 10 años ha sido la formación de federaciones departamentales, lo que ha permitido mejorar la coordinación, la comunicación y fortalecimiento de las ONG colombianas (ver tabla 4.4).

85 Otras expresiones importantes del trabajo con mujeres son el Centro de Documentación Meira del Mar de Barranquilla, la Fundación Sí Mujer de Cali, Funcop de Popayán, Vamos Mujer de Medellín y Diálogo Mujer, el Grupo Mujer y Sociedad de la Universidad Nacional, la Corporación Casa de la Mujer — con veinte años de trabajo y notoria incidencia pública - y la Fundación Promujer en Bogotá. Desde 1996, las cuatro últimas publican la revista especializada de género En Otras Palabras... 
TABLA 4.4

FEDERACIONES DE ONG COLOMBIANAS

\begin{tabular}{|c|c|}
\hline Federaciones & Descripción \\
\hline Federación de ONG de Santander & $\begin{array}{l}\text { La Federación Santandereana de ONG-FESANONG es una asociación } \\
\text { gremial, de carácter privado sin ánimo de lucro, de beneficio social, que } \\
\text { tiene como propósito fundamental ejercer la representación de las entida- } \\
\text { des federadas, impulsar el fortalecimiento institucional y facilitar el traba- } \\
\text { jo de las organizaciones de esta naturaleza que tengan domicilio en cual- } \\
\text { quier municipio del departamento de Santander. }\end{array}$ \\
\hline Federación Risaraldense de ONG & $\begin{array}{l}\text { Es una organización no gubernamental de carácter pluralista, que agremia } \\
\text { a la sociedad civil organizada bajo el esquema de entidades sin ánimo de } \\
\text { lucro en el departamento de Risaralda. Creada por resolución n. }{ }^{\circ} 2582 \text { el } \\
28 \text { agosto de } 1989 \text {. }\end{array}$ \\
\hline $\begin{array}{l}\text { Asociación de ONG } \\
\text { de Cali PROCALI-PROVALLE }\end{array}$ & $\begin{array}{l}\text { PROCALI-PROVALLE es una corporación mixta, de carácter civil y sin } \\
\text { ánimo de lucro, que agremia a las organizaciones sociales (ONG) de Cali } \\
\text { y el Valle del Cauca. PROCALI nace en } 1980 \text { como resultado de un pro- } \\
\text { ceso de concertación entre la alcaldía de Cali, el sector fundacional, las } \\
\text { organizaciones de la sociedad civil (ONG, cooperativas, gremios, etc.) y la } \\
\text { empresa privada. }\end{array}$ \\
\hline $\begin{array}{l}\text { Corporación para el Desarrollo } \\
\text { del Meta-CORPOMETA }\end{array}$ & $\begin{array}{l}\text { CORPOMETA es una organización de tercer nivel, de carácter mixto, sin } \\
\text { ánimo de lucro, cuyo objeto social es promover el desarrollo del departa- } \\
\text { mento del Meta bajo los principios de equidad, solidaridad, igualdad, } \\
\text { humanidad, neutralidad, imparcialidad y desarrollo sostenible, sin discri- } \\
\text { minación de ninguna clase por aspectos políticos, religiosos, étnicos o de } \\
\text { género, de acuerdo con la Constitución política de Colombia. }\end{array}$ \\
\hline $\begin{array}{l}\text { Federación de ONG } \\
\text { de Cartagena y Bolívar }\end{array}$ & $\begin{array}{l}\text { FONGCAB es una entidad civil de carácter privado, de beneficio social y } \\
\text { comunitario y sin ánimo de lucro, constituida en el año } 2000 \text {, con reco- } \\
\text { nocimiento jurídico n. }{ }^{\circ} 2238 \text { de septiembre del mismo año. Es una orga- } \\
\text { nización de segundo nivel, coordinadora de las ONG de Cartagena y Bolí- } \\
\text { var en torno a objetivos de solidaridad, mutua cooperación y defensa de } \\
\text { valores que conduzcan al desarrollo de una sociedad civil participativa y } \\
\text { democrática. }\end{array}$ \\
\hline FEDECARIBE-ONG EN LÍNEA & $\begin{array}{l}\text { FEDECARIBE es una entidad que brinda apoyo permanente a las organi- } \\
\text { zaciones de la sociedad civil y tiene como propósito fundamental la cons- } \\
\text { trucción de un tejido social generado por el robustecimiento en la gestión } \\
\text { de las OSC. El objetivo principal es brindar un servicio de fortalecimien- } \\
\text { to institucional con calidad que ofrezca herramientas importantes para la } \\
\text { consolidación del sector. }\end{array}$ \\
\hline Federación Antioqueña de ONG & $\begin{array}{l}\text { Cuenta con más de un centenar de organizaciones del departamento, tra- } \\
\text { baja por el fortalecimiento institucional y gremial de las ONG. }\end{array}$ \\
\hline Federación Chocoana de ONG & $\begin{array}{l}\text { Creada en 1988, busca fortalecer el asociacionismo en el departamento y } \\
\text { apoyar a las organizaciones para que puedan aprovechar las oportunidades } \\
\text { internas y externas en materia de cooperación. }\end{array}$ \\
\hline Federación Quindiana de ONG & $\begin{array}{l}\text { Fue creada en } 1988 \text { y también trabaja en el norte del departamento del } \\
\text { Valle. Creció y se fortaleció durante las tareas de reconstrucción del terre- } \\
\text { moto de Armenia de } 1999 \text {. }\end{array}$ \\
\hline
\end{tabular}

FUENTE: Elaboración propia con datos de CCONG. <http://www.ccong.org.co/generales/ federaciones.htm> (25 de agosto de 2005). 


\subsubsection{Los próximos años}

En la Mesa de Donantes de Londres ${ }^{86}$ se definieron los temas y líneas de actuación para la cooperación no gubernamental al desarrollo de los siguientes años. Las organizaciones miembros de las Confederación Colombiana de ONG presentaron una serie de propuestas que puede resumir, de forma precisa, los criterios que deben orientar las acciones que se establezcan en adelante respecto a la cooperación internacional al desarrollo.

\section{CUADRO 4.3 \\ PROPUESTAS DE LA CCONG SOBRE COOPERACIÓN INTERNACIONAL EN COLOMBIA}

Proponemos a la comunidad internacional, en su acercamiento a Colombia, que tenga en cuenta los siguientes criterios:

1. Fortalecimiento de la estructura institucional del Estado social de derecho en Colombia como garante de los derechos y libertades de todas las personas que habitan en todo su territorio y la separación y autonomía de los poderes públicos. [...]

2. Fortalecimiento de las OSC que actúen dentro de los marcos de la Constitución política, como representantes de distintos sectores de la población colombiana y como defensores legítimos de sus derechos e intereses.

3. Respeto a la normatividad internacional y nacional existente para la protección de los derechos humanos y el derecho internacional humanitario.

5. Erradicación de la pobreza crítica, la reducción de las desigualdades y la gradual eliminación de los motivos de exclusión social, económica, política y cultural de todos los sectores de la población.

6. Atención prioritaria a la crisis humanitaria en el país y relevancia de un campo humanitario que permita construir soluciones adecuadas y sostenibles para las diferentes poblaciones.

7. Programas y proyectos con estrictos compromisos de transparencia y rendición de cuentas.

8. Sistematización y transferencia de conocimientos y experiencias de otros países y construcción de alianzas en el mundo internacional.

FUENTE: CCONG $(2003 a, 2)$.

86 El día 10 de julio de 2003 se reunieron en Londres altos representantes de los Gobiernos de Argentina, Brasil, Canadá, Chile, Colombia, la Unión Europea, Japón, México, Noruega, Suiza y los Estados Unidos de América y de la Comisión Europea, la ONU y sus instituciones, la Corporación Andina de Fomento, el Banco Interamericano de Desarrollo, FMI y Banco Mundial para examinar la situación en Colombia. 
Estas propuestas dejan entrever la preocupación de las ONG en unas direcciones muy concretas. Por una parte, ponen el acento en la demanda de una cooperación que ayude al fortalecimiento de la democracia en dos sentidos fundamentales: lograr la realización efectiva del Estado social de derecho, proclamado en la Constitución colombiana, y la inclusión de sectores social y políticamente excluidos a través de la participación de los representantes de la sociedad civil y la participación en la vida económica (reducción de las desigualdades). Es interesante apreciar que la reducción de la pobreza no es la principal demanda ni la más reiterada; aparece como un elemento vinculado a otros objetivos como la democratización y la paz. En los aspectos técnicos de la cooperación se resalta la transparencia, la rendición de cuentas y el intercambio de los conocimientos en el ámbito internacional.

Además de los criterios que sugieren a los donantes para orientar la cooperación de los próximos años, efectuaron propuestas concretas en torno a tres grandes campos: «Respeto y Protección de los DD.HH. y del DIH, Construcción de la Paz y Desarrollo Humano Integral y Sostenible» (CCONG, 2003a, 3-5). Piden financiación y apoyo a «Programas de Desarrollo y Paz en Regiones especialmente afectadas por el conflicto armado», teniendo en cuenta que «el apoyo a estos programas no se debe restringir a la operación de proyectos concretos sino que debe extenderse a la creación de condiciones básicas, prerrequisito para que los proyectos sean exitosos».

Sin embargo, los problemas de representación de la sociedad civil hicieron de nuevo su aparición. En ese sentido, los empresarios y otras organizaciones $^{87}$ redactaron una declaración al margen de las ONG. Hacían énfasis sobre su carácter de miembros de la sociedad civil, pero reconociendo su identidad empresarial y exigiendo la defensa de sus intereses: «La Sociedad Civil Colombiana, también por nuestras organizaciones representada, propugna por la promoción, generación de empleo y defensa de la producción nacional»(CCONG, 2003c, 1).

A pesar de muchos desacuerdos y dificultades para llegar a puntos de consenso, finalmente salió adelante un manifiesto que, en el apartado correspondiente a la cooperación internacional, establecía lo siguiente:

87 Asociación Colombiana de Medianas y Pequeñas Industrias-ACOPI, Consejo Nacional de la Economía Solidaria, Federación Colombiana de Municipios, Consejo Nacional de Planeación. 
La cooperación internacional es de alta importancia para Colombia y hacemos un llamado a toda la comunidad internacional, en este caso en particular a Europa, a profundizar su ayuda en temas tan importantes para la solución política del conflicto como los derechos humanos, el desarrollo rural integral y la economía campesina, apoyo a desplazados (as), sustitución de cultivos ilícitos con desarrollo alternativo sustentable, laboratorios, planes de vida e iniciativas de paz y pedagogía para la convivencia, acuerdos especiales de aplicación del derecho internacional humanitario, acciones humanitarias de atención a víctimas y prevención de violencia, fortalecimiento de las organizaciones de la sociedad civil y de la participación de la mujer, del desarrollo desde lo regional y la multiculturalidad, entre muchos (CCONG, 2003b, 2).

La generalidad y variedad de las demandas expuestas en el manifiesto restaba fuerza a determinados puntos como la presión de algunas ONG por el respeto a los derechos humanos, y disminuía el tono crítico ante el Gobierno colombiano. Ante la preocupación de que la reunión del G-24 en Cartagena 2005 disolviera los consensos logrados en Londres y desviara la atención de la salida negociada al conflicto y la consideración a la situación de los derechos humanos, las OSC redactaron un documento de consensos que redundaba en los criterios y propuestas anteriores, y recordaba a los Estados y organismos multilaterales presentes la vigencia de Londres 2003. Como elementos novedosos, sugerían que los próximos marcos normativos, de cara a la desmovilización de los grupos armados, específicamente de los paramilitares, evitaran la impunidad y la excesiva flexibilidad con los delitos más atroces: «Todo proceso de paz se debe regir por un marco legal que observe los principios de verdad, justicia y reparación congruentes con las exigencias del derecho internacional y válidos para situaciones de conflictos armados internos» (Organizaciones de la Sociedad Colombiana, 2005, 2).

Estas orientaciones para los próximos años coinciden con algunas reflexiones teóricas que se vienen llevando a cabo por organismos dedicados a la investigación de la cooperación al desarrollo, ${ }^{88}$ y que sugieren fortalecer determinados aspectos que constituyen la base de las ONG. Desde principios de los noventa, entidades como el PNUD (1993) y autores como Sogge (1998) y John Clark (1991) han insistido 
en que la incidencia política de las $\mathrm{ONG}$ es «la estrategia con más probabilidades de contribuir con la reducción significativa de los niveles de pobreza». ${ }^{89}$

Éste es, pues, el reto para los programas de incidencia política de las ONG: evaluar la eficacia de su activismo, su capacidad de presión y la educación para el desarrollo para que puedan demostrar con seguridad sus logros en este terreno. Al hacerlo, las ONG se verían liberadas de las limitaciones impuestas por las creencias de los donantes privados y oficiales de que los fondos no deberían desviarse de proyectos tangibles, y actualmente más comercializables, como los de ayuda humanitaria y desarrollo (Anderson, 2004, 287).

89 Clark (1991), citado por Anderson (2004, 280). 



\section{EL CONTEXTO ARAGONÉS}

La década de los ochenta representó un avance importante en la extensión y complejidad de las formas de llevar a cabo la cooperación al desarrollo en esta comunidad autónoma. La historia de la cooperación oficial fue respuesta o, en todo caso, consecuencia de las expresiones ciudadanas que exigían actuaciones oficiales en materia de cooperación y solidaridad. El avance de ambas, gubernamental y no gubernamental, está marcado por hitos que presentan una gran coincidencia cronológica. Un paso importante de la actual cooperación oficial aragonesa puede situarse en 1994, con la aprobación del primer decreto que regula la cooperación autonómica y el de la nogubernamental, con el reconocimiento legal de la Federación Aragonesa de Solidaridad en 1995.

\subsection{La cooperación oficial al desarrollo}

Antes de la conformación de las comunidades autónomas, los ayuntamientos y las diputaciones provinciales tenían una incipiente trayectoria en materia de cooperación al desarrollo.

A mediados de la década de los 80 ya se realizaban proyectos cofinanciados por el Gobierno de Aragón, Ayuntamiento de Zaragoza, diputaciones provinciales y otros ayuntamientos. Los requisitos exigibles se establecían en el momento de aprobar las actuaciones, que principalmente trataban de dar respuesta a necesidades que podrían considerarse más próximas a la ayuda humanitaria que al desarrollo (FAS, 2003, 2).

La Comunidad Autónoma de Aragón inició su política de cooperación al desarrollo a principios de los años noventa. En 1994 se aprobó el primer decreto (n. ${ }^{\circ} 180$ ) que «regulaba la ayuda a los países del Tercer 
Mundo». De este modo, se atendía parte de las reivindicaciones sociales que reclamaban el $1 \%$ del PIB para la cooperación internacional. «Estos años de inicio y consolidación, [...] fueron unos años de aprendizaje y de conocimiento mutuo entre los actores implicados, y en los que se configuraron unas líneas de trabajo y zonas de actuación preferente de la cooperación aragonesa para el desarrollo» (Obis, 2004).

El siguiente párrafo resume la dedicación de los montos globales de la cooperación del Gobierno de Aragón entre 1998 y 2002:

El Gobierno de Aragón disminuye sus aportaciones en 1998 y 1999 hasta el $0,13 \%$ y $0,04 \%$ del presupuesto respectivamente, alcanzando este año su cota más baja. [...] En 2000 se produce un cambio de tendencia en el Gobierno de Aragón, la aportación supone un $0,16 \%$ del presupuesto total, lo que supone cuatro veces la del año anterior. En 2001 continúa el incremento hasta el 0,21\%. Y desciende ligeramente en 2002 hasta el 0,19\%. La responsabilidad de gobierno la tiene el Partido Socialista Obrero Español en coalición con el Partido Aragonés y con el apoyo necesario de Izquierda Unida (FAS, 2003, 7).

En cuanto a los proyectos de cooperación, desde 1994 la cantidad de entidades con proyectos aprobados por el Gobierno de Aragón se ha duplicado. En esa fecha financió a 30 proyectos, en el 2001 subió hasta 76 y en 2003 descendió a 63 proyectos. Asimismo, cabe destacar que los presupuestos prácticamente se han cuadruplicado, pasando de 1186293 euros a 4462514 en el mismo período (1994-2003).

Los criterios que actualmente rigen la política aragonesa de cooperación para el desarrollo son cuatro (Obis, 2004):

1) El desarrollo humano, como un criterio cada vez más valorado por organismos internacionales como el PNUD, propone la ampliación de las opciones que los pueblos tienen para vivir de acuerdo con sus valores. En este sentido se acoge una perspectiva que implica un crecimiento económico sostenible y equitativo, la promoción de la justicia social, la lucha contra la pobreza, la defensa de los derechos humanos, estructuras democráticas y la participación social. Asimismo, adquiere relevancia otro elemento que en los primeros años de la cooperación oficial aragonesa no había sido considerado: la multiculturalidad.

2) Adopción de la "estrategia de asociación» o trabajo en red diseñada por el Comité de Ayuda al Desarrollo, CAD. Parte de la idea 
de asociación basada en la confianza, en la mutua responsabilidad $\mathrm{y}$ en un compromiso compartido con respecto a objetivos y metas. La relación de "asociación" rompe con la costumbre de la unilateralidad y promueve la multilateralidad al incluir a las contrapartes locales y a los distintos actores, públicos y privados, de la cooperación aragonesa.

3) Planificación orientada a la consecución de resultados. La cooperación aragonesa, acogiendo los postulados del desarrollo humano, pretende desarrollar una metodología participativa, que cuente con la intervención de los socios de la cooperación que desempeñan su labor desde Aragón.

4) La política aragonesa señala la importancia de «aprovechar la experiencia de la Comunidad Autónoma y sus ventajas comparativas» (Obis, 2004). Esto es, su situación geoestratégica y la convivencia con territorios pertenecientes a otro Estado, que puede ayudar a gestionar y a prevenir los conflictos de carácter fronterizo. La existencia de una metrópoli regional que puede servir de modelo a otras metrópolis regionales para configurarse como motor de desarrollo de su región de pertenencia. La experiencia en la gestión de los desequilibrios territoriales y de los problemas de articulación del territorio. La experiencia en procesos de descentralización y acercamiento a los ciudadanos (ej., comarcalización). El desarrollo del sector primario, especialmente en las reformas para acceder a un nuevo mercado de alimentos en el que el consumidor demanda seguridad y calidad. La experiencia en la puesta en marcha de estrategias de desarrollo rural sostenible. Un tejido asociativo fuerte que puede ayudar, mediante el traslado de experiencias participativas, al arraigo de las estructuras democráticas en muchos de estos países. Un turismo interior creciente que puede contribuir a generar alternativas turísticas en países sin costas o en territorios interiores que hasta ahora no contemplaban ese tipo de turismo como fuente de ingresos y empleo. El abastecimiento y saneamiento del agua es parte integrante de la política de medio ambiente. Complementariedad entre las políticas dirigidas a las personas inmigrantes en Aragón y la política de cooperación para el desarrollo en los países de origen. Experiencia de la Universidad en materia de cooperación, tanto en la ejecución 
directa de proyectos sobre el terreno como en la formación en esta materia.

En el aspecto legislativo, la Ley 10/2000, de 27 de diciembre, dio un paso más por incorporar la cooperación a la política de la comunidad aragonesa y asumir nuevas líneas de actuación:

En ella se contempla la planificación de la cooperación aragonesa para el desarrollo [...] y se prevé la constitución de dos órganos destinados a tener una especial relevancia en la definición de esta política: la Comisión Autonómica de Cooperación para el Desarrollo, órgano de coordinación y colaboración entre las Administraciones Públicas de la Comunidad Autónoma de Aragón que ejecuten gastos computables como cooperación para el desarrollo; el Consejo Aragonés de Cooperación para el Desarrollo, órgano de consulta y asesoramiento en materia de solidaridad internacional y cooperación para el desarrollo. ${ }^{90}$

Asimismo, dicha ley creó el Fondo Aragonés de Cooperación para el Desarrollo, con el objetivo de dotar de instrumentos financieros a la cooperación aragonesa; no obstante, cinco años después dicho fondo no está operativo.

El Plan Director de la Cooperación Aragonesa para el Desarrollo es un mecanismo planificador de carácter cuatrienal que ha sido aprobado por las Cortes (BOCA, n. ${ }^{\circ}$ 56, de mayo de 2004). Este Plan establece una serie de criterios y prioridades para la adjudicación de los recursos.

Instaura algunas prioridades a las que denomina «horizontales, geográficas y sectoriales». La primera línea de prioridades se refiere a aspectos transversales que deben estar integrados en todas las actuaciones; son éstos: la lucha contra la pobreza, la promoción de la igualdad entre mujeres y hombres, el medio ambiente, la defensa de los derechos humanos. Las prioridades geográficas implicarán la atención a países con menor índice de desarrollo humano, ${ }^{91} \mathrm{y}$ en especial a las siguientes áreas:

90 La composición y el funcionamiento de ambos órganos se regulan en sendos reglamentos, aprobados por los Decretos 11/2002 y 12/2002, de 22 enero, del Gobierno de Aragón. <http://portal.aragob.es/servlet/page>.

91 El plan hace referencia a las siguientes áreas. En Iberoamérica: Bolivia, Cuba, Ecuador, El Salvador, Guatemala, Honduras, Nicaragua, Perú y República Dominicana. Toda el África subsahariana, en el Magreb: Marruecos y Argelia, y menciona otras regiones como los campamentos de refugiados palestinos y saharauis. 
Prioridades sectoriales: a) El fortalecimiento de las estructuras democráticas y de la participación de los pueblos y de sus organizaciones, así como el fomento del respeto y protección a los derechos humanos. b) Los servicios sociales básicos (vivienda, salud, alimentación y educación). c) La dotación y mejora de las infraestructuras económicas, prestando especial atención al desarrollo de proyectos de economía social que permitan el desarrollo de los pueblos. d) La educación y sensibilización de la sociedad aragonesa en materia de cooperación para el desarrollo.

Los tipos de ayuda han sido clasificados en cuatro grupos: proyectos que contribuyen a satisfacer necesidades básicas, programas de desarrollo específico, acciones de sensibilización y educación, y ayuda humanitaria. Sin embargo, recientemente (convocatoria de julio de 2004) se han incluido dos nuevos tipos de subvención: iniciativas y redes de comercio justo y formación de cooperantes y voluntarios aragoneses. Por tanto, los dos últimos apartados no se incluyen en el siguiente resumen de la distribución de las ayudas por tipo de subvención.

Cabe destacar que los proyectos y programas de desarrollo han recibido más dinero que los otros tipos: a los dos primeros se han dedicado aproximadamente unos 500000 euros anuales desde 1994 hasta 1999, mientras que los últimos han estado por debajo de los 250000 euros en este período de tiempo (IAEST, 2004). En el 2000 y 2001, los programas de desarrollo específico han superado notablemente a los proyectos que atienden necesidades básicas (2400000 euros, frente a 1400000), y las acciones de formación y ayuda humanitaria han llegado a los 400000 euros (IAEST, 2004).

En cuanto a la distribución de los tipos de ayuda que han predominado entre 1994 y 2000, han sido, en primer lugar, los proyectos que contribuyen a satisfacer necesidades básicas (43\%), programas de desarrollo específico $(30 \%)$, acciones de sensibilización, información y educación para el desarrollo (15\%) y ayuda humanitaria (11\%).

Entre 2001 y 2003 la tendencia de los dos principales tipos de ayuda se invirtió, pasando a predominar los programas de desarrollo (38\%) por encima de los proyectos de satisfacción de necesidades básicas (28\%). Además, se incrementaron considerablemente las ayudas para acciones de sensibilización y educación (25\%), y prácticamente se ha mantenido la proporción dedicada a ayuda humanitaria (9\%) (IAEST, 2004). 
La Comunidad Autónoma de Aragón ha tenido presencia a través de la cooperación al desarrollo en 43 países de cuatro continentes entre 1994 y 2003. Sin embargo, la principal zona geográfica de destino ha sido América Latina. El 61 \% de los proyectos se han dirigido a esa región (273 proyectos financiados de un total de 444), aunque, si se divide el destino de los recursos entre Centroamérica y Sudamérica, se puede observar que la primera recibe el $70 \%$ (por países se aprecia una concentración destacable en dos: Nicaragua y Guatemala reciben el $45 \%$ de la ayuda destinada a Centroamérica). En Sudamérica ha habido ocho países receptores, de los cuales dos, Bolivia y Perú, concentran el $62 \%$ de los proyectos dirigidos al subcontinente (IAEST, 2004).

El segundo lugar de respaldo a proyectos ha permanecido dentro de España, con el 19,5\% del total de proyectos (sensibilización y formación). Antes del año 2000 la cantidad de proyectos que tenían como territorio de ejecución a España era mínimo: en los años 1994 y 1995 no se apoyó ningún proyecto, entre 1996 y 1999 se apoyó el 23\% de todos los proyectos respaldados durante el período analizado, y en los últimos cuatro años se ha apoyado el $73 \%$ (IAEST, 2004). Esta tendencia se explica a partir de la disminución gradual en los importes destinados a proyectos que contribuyen a satisfacer necesidades básicas en los países del llamado "Tercer Mundo" y por el aumento de las sumas dedicadas a acciones de sensibilización, información y educación para el desarrollo en países del Norte como España.

Continuando con la distribución geográfica de la cooperación aragonesa, se encuentran, con porcentajes inferiores a la décima parte de los proyectos, el África subsahariana (9,6\% de los proyectos), Asia, con el $3 \%$, la zona del Magreb, con el 2,9\%, y «varios países», con el 2,7\% (IAEST, 2004).

África subsahariana es la región en la que participa un mayor número de países receptores (17 Estados), pero, a diferencia de otras regiones, no hay un solo país que reciba más del $25 \%$ de proyectos. Se podría mencionar a Mozambique, que ha recibido una cuarta parte de los proyectos de la región entre 1994 y 2003; sin embargo, buena parte de los recursos (aproximadamente 200000 euros) se destinaron a ayuda humanitaria durante las inundaciones ocurridas en febrero del 2000.

En el caso de Asia cabe destacar que ha habido un cambio considerable en la segunda parte del período analizado. Del total de proyectos que 
se han apoyado en este continente entre 1994 y 2003 tan sólo el 22\% corresponde a los primeros años (1994-1999), mientras que la mayor parte de éstos (78\%) se han financiado entre los años 2000 y 2003 (IAEST, 2004). Esta tendencia puede explicarse cuando se identifican los países en los que se han llevado a cabo dichos proyectos. El principal país receptor del continente ha sido la India, con el $50 \%$ de los proyectos; este país ha recibido ayuda desde 1996, y, como es sabido, es uno de los países con mayor número de habitantes en situación de extrema pobreza, por lo cual se puede identificar como un receptor convencional. ${ }^{92}$ No obstante, el $50 \%$ restante se divide en cuatro países que, además de las condiciones estructurales de pobreza, han participado o han sido escenarios de recientes intervenciones militares por parte de otros países (Estados Unidos, Inglaterra, España, Israel, etc.). Por ejemplo, en Afganistán no hay constancia de que se haya apoyado algún proyecto hasta los años 2001 y 2002, en los que se financió un proyecto por año; en Irak se apoyaron dos proyectos en 2003 relacionados con ayuda humanitaria; y en Pakistán se financió un proyecto en 2002. En las convocatorias de los años 2002 y 2003 el Gobierno de Aragón financió sendos proyectos dirigidos a Palestina por un total de 226000 euros.

En total, el Gobierno de Aragón ha dedicado entre 1994 y 2003 alrededor de 25 millones de euros (24767 864) a la financiación de proyectos de cooperación al desarrollo. El 50,5\% ha sido destinado a Centroamérica, el 21,6\% a Sudamérica, a África subsahariana el 9,1\%, a «varios países» el 4,1\%, a Asia el 3,4\% y al Magreb el 2,2\% (IAEST, 2004).

Aquí se pueden apreciar varios aspectos interesantes: aunque en España, por acciones de sensibilización y formación, se hayan apoyado más proyectos que en África subsahariana (87 frente a 43), la cantidad financiada a proyectos en esta parte de África es ligeramente superior a los realizados en España (2 277134 euros frente a 2 167431). Asimismo, aunque el número de proyectos aprobados en "varios países» es inferior a regiones como Asia y el Magreb, la cantidad de dinero destinada a un conjunto de Estados y regiones es superior a los montos que se dirigieron a dichas

92 Esta tendencia de la cooperación aragonesa en Asia no ha incluido las ayudas dirigidas a las zonas devastadas por un tsunami en las costas de Indonesia, India, Sri Lanka y otros países del sureste asiático en diciembre de 2004. 
zonas (10161 153 euros frente a 858651 y 561542 , respectivamente) (IAEST, 2004).

Colombia ha sido el lugar de destino de siete proyectos financiados por el Gobierno de Aragón entre 2000 y 2005 por un total de 342124 euros. En el ámbito de la región andina se encuentra detrás de países como Bolivia, Perú y Ecuador. No obstante, si ampliamos el análisis comparando la financiación a proyectos entre 1994 y 1999, podemos afirmar que en los últimos cinco años (excepto 2004) la cooperación financiada por el Gobierno de Aragón en Colombia ha sido más significativa.

En cuanto a otras formas de cooperación descentralizada, las diputaciones provinciales aragonesas destinaron 640433 euros durante el año 2002 para proyectos y programas de cooperación en los países del «Sur». La Diputación Provincial de Zaragoza dedica el 0,48 \% de su presupuesto

\section{GRÁFICA 5.1}

EVOLUCIÓN DE LOS PRESUPUESTOS DE LOS PROYECTOS FINANCIADOS POR EL GOBIERNO DE ARAGÓN EN COLOMBIA, 2000-2005

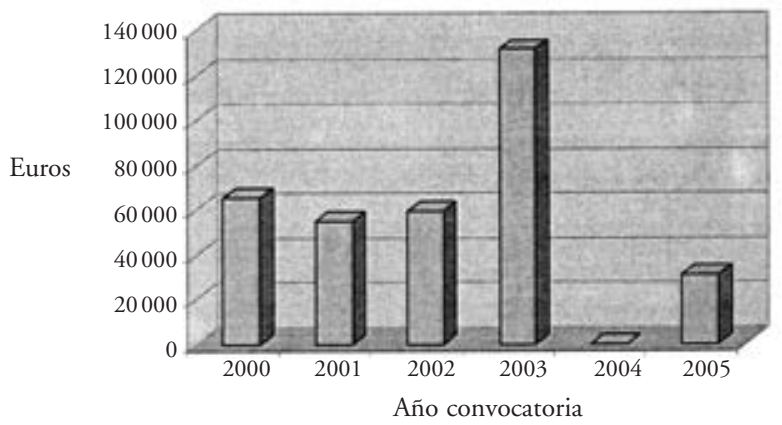

\begin{tabular}{|l|c|c|}
\hline Año convocatoria & Importe concedido (euros) & $N .^{\circ}$ proyectos concedidos \\
\hline 2000 & 65665 & 1 \\
2001 & 54712 & 1 \\
2002 & 59350 & 2 \\
2003 & 131397 & 2 \\
2004 & 0 & 0 \\
2005 & 31000 & 1 \\
TOTAL & 342124 & 7 \\
\hline
\end{tabular}

FUENTE: Elaboración propia a partir de IAEST (2004). 
a cooperación al desarrollo, y la de Teruel ha pasado del 0,05\% hasta el 0,09\% (IAEST, 2004).

Respecto a los ayuntamientos, éstos dedicaron en 2002 un total de 2586084 euros para cooperación al desarrollo con los países del «Sur». De los 730 municipios aragoneses, hay 78 que declaran destinar recursos a la cooperación para el desarrollo. Se trata, especialmente, de municipios grandes o intermedios, ya que, aunque representan tan sólo el 10,6\% del total de municipios aragoneses, agrupan el 75,2\% de la población de la comunidad autónoma. Por otro lado, de estos 78 municipios, 39 cuentan con partida presupuestaria específica dedicada a la cooperación para el desarrollo, y 11 de ellos tienen personal técnico dedicado a la cooperación. Estos municipios se distribuyen por provincias de la siguiente manera: el $31 \%$ en Huesca, el $23 \%$ en Teruel y el $46 \%$ en Zaragoza (IAEST, 2004). En el caso de Colombia, entre 2003 y 2004 los municipios y comarcas aragonesas apoyaron siete proyectos de satisfacción de necesidades básicas y cuatro programas de desarrollo económico y social (IAEST, 2004).

La trayectoria del Ayuntamiento de Zaragoza ha sido más amplia que en las otras unidades administrativas; "efectivamente, en 1995 el Ayuntamiento de Zaragoza destina a cooperación el 0,55\% de su presupuesto (338 millones de pesetas) frente al 0,07\% del año anterior (30 millones), si bien este porcentaje no se mantuvo y ha ido disminuyendo año tras año» (FAS, 2003, 2). Durante 1998 y 1999 el Ayuntamiento disminuye levemente sus aportaciones al 0,47\% y 0,46\% del presupuesto, respectivamente. En 2003 destinó 1950000 euros en la convocatoria pública para la concesión de subvenciones a proyectos de desarrollo y solidaridad en el «Tercer Mundo». En cuanto a Colombia, en 2006 apoyó tres proyectos (educativo, laboral y de necesidades básicas), con un total de 80000 euros (AECI, 2006).

\subsection{La presencia aragonesa en Colombia}

La presencia aragonesa en Colombia no se circunscribe exclusivamente a la cooperación al desarrollo, aunque la razón de ser del estudio centra la mirada en este tipo de expresión.

Los antecedentes de la presencia de Aragón en Colombia están vinculados a los lazos históricos de la colonización española en América. En este sentido, hicieron parte las instituciones católicas de la época, y desde 
entonces hasta la actualidad unos vínculos se han extinguido y otros se han mantenido, la mayoría sustentados en la matriz de la religión católica. Es así como en el último cuarto de siglo han destacado misioneros, comunidades religiosas, instituciones de educación (por ejemplo, San José de Calasanz, escolapios, religiosas calasancias...).

Incluso, uno de los personajes más conocidos en la historia del conflicto armado colombiano fue un sacerdote aragonés: Manuel Pérez Martínez, conocido en Colombia como «el cura Pérez», que, inspirado en los curas obreros franceses y en la decisión del cura colombiano Camilo Torres de tomar las armas, viajó a Colombia con otro sacerdote aragonés, Domingo Laín, y estuvo al frente de la segunda guerrilla más importante del país, el ELN. Desde esta relación, en su pueblo natal, Alfamén, y también en Zaragoza, se siguen con especial interés los hechos relacionados con el conflicto armado y las acciones del ELN. De hecho, la Diputación Provincial de Zaragoza ha publicado libros sobre su vida. ${ }^{93}$

En los medios aragoneses de comunicación, además de las noticias enviadas por las agencias internacionales y cubiertas en la sección correspondiente, la visita de líderes de organizaciones sociales colombianas, en su trabajo de difusión y sensibilización a la población aragonesa sobre el conflicto colombiano, ha sido recogida por diarios como Heraldo de Aragón, El Periódico de Aragón, o Diario del Alto Aragón. En ocasiones son entrevistas de contraportada que explican la labor de las ONG, sindicatos o asociaciones. Como informes especiales, Heraldo de Aragón recoge, una vez al año o cada dos años, informes sucesivos de periodistas como Gervasio Sánchez. El seguimiento en los medios radiofónicos y audiovisuales ha sido minoritario.

Después del cese de los conflictos centroamericanos y la agudización del conflicto colombiano, muchas ONGD aragonesas (como otras tantas españolas) dirigieron su mirada al conflicto colombiano. Su sensibilidad respecto a los conflictos armados había sido significativa y, por tanto, había elementos de conocimiento y acercamiento ante estas situaciones. Ése ha sido uno de los mecanismos de difusión en los medios aragonesas entre los que también se identifican coyunturas como la de los brigadistas que se describe en otro apar-

93 María López Vigil (2001), Manuel, el Cura Pérez. Camilo camina en Colombia, 4. ${ }^{a}$ ed., Zaragoza, Comité de Solidaridad Internacionalista de Zaragoza, Diputación Provincial de Zaragoza. 
tado. No obstante, "Colombia es en muchos aspectos un "conflicto olvidado" para los medios, y no existe ni el interés ni la corriente de solidaridad que pudo haber, hace veinte años, con Centroamérica» (Sanahuja, 2004, 9).

\subsubsection{ONGD aragonesas federadas con presencia en Colombia}

Son varias las organizaciones aragonesas no federadas que tienen presencia en Colombia y han recibido subvenciones públicas. En los últimos años, por ejemplo, la Asociación para el Desarrollo Nuevos Caminos (Nous Camins) ha realizado proyectos para la mejora de la educación infantil en la vereda Aurora Alta en el municipio La Calera (Cundinamarca). Asimismo, Global Humanitaria adelanta proyectos nutricionales en Tumaco (Nariño); la Asociación de Familias Adoptantes de Aragón, AFADA, ha apoyado proyectos en el Chocó; el grupo de educación intercultural Almaciga ha trabajado en la recuperación colectiva de la cultura e historia muisca en Bosa (Cundinamarca); la Fundación Internacional de Solidaridad de la Compañía de María ha apoyado un centro comunitario en la Rosa (Pasto). La ONG Madreselva ha trabajado en la construcción de la Casa de los Niños en el Centro Laura Vicuña de Armenia (Quindío) durante el año 2001 con la financiación del Gobierno de Aragón.

No se ha pretendido destacar o favorecer la labor específica de una ONGD; en muchos casos durante el trabajo de campo se omiten sus nombres, pues la renuncia al reconocimiento particular redunda en la exaltación colectiva de un conjunto de organizaciones comprometidas con la gente de Colombia.

De las 40 entidades agrupadas en la FAS, las siguientes son las organizaciones que tienen, o han tenido, relaciones de cooperación con Colombia entre 2000 y 2004 (para un mayor detalle de la relación de entidades y proyectos ver anexo 6). Asimismo, existe una coordinadora ${ }^{94}$ que no pertenece a la FAS, pero sí algunos de sus miembros.

94 Coordinadora Aragonesa de Solidaridad con Colombia (CASCOL). Está compuesta por las siguientes organizaciones: Asociación Marianista de Ayuda al Tercer Mundo, Asociación Solidaria Aragonesa, Chunta Aragonesista, Comité Cristiano de Solidaridad Óscar Romero, Comité de Solidaridad Internacionalista de Zaragoza. Colectivo Universitario Iquique, Colectivo Napoti-Miru, Entrepueblos Aragón, Izquierda Unida Aragón, Unión de Agricultores y Ganaderos de Aragón, Médicos del Mundo, y es parte de la Red Europea de Hermandad y Solidaridad con Colombia, compuesta por más de cien organizaciones de toda Europa. 
1. Acción Solidaria Aragonesa (ASA)

2. Asamblea de Cooperación por la Paz (ACPP)

3. Asociación Marianista de Ayuda al Tercer Mundo (AMAT)

4. Comité Cristiano de Solidaridad Óscar Romero

5. Comité de Solidaridad Internacionalista de Zaragoza

6. Entreculturas Aragón (Fe y Alegría)

7. Fundación Juan Bonal

8. InteRed Aragón

9. Manos Unidas Zaragoza

10. Médicos del Mundo Aragón

11. Organización de Solidaridad de los Pueblos de África, Asia y América Latina (OSPAAL)

12. PROCLADE Aragón (Misioneros Claretianos)

13. UNICEF Aragón.

\section{1) Acción Solidaria Aragonesa (ASA)}

Organización no gubernamental de cooperación internacional para el desarrollo que desde 1985 trabaja en Aragón por el desarrollo de los pueblos del Sur desde la perspectiva de la dependencia Norte-Sur. La entidad está organizada en cuatro delegaciones: Bajo Aragón, Huesca, Teruel y Zaragoza, y se definen como «una asamblea de personas que nos unimos desde distintas creencias y organizaciones con una idea común: la pobreza y el subdesarrollo económico del llamado Tercer Mundo es consecuencia de nuestra riqueza y desarrollo». ${ }^{95}$

Algunos de los proyectos que ha gestionado en Colombia antes del 2000 son los siguientes: entre 1996 y 1999 apoyaron la capacitación de personal de talleres de carpintería en el medio Atrato (Chocó), el mejoramiento integrado del hábitat de la comunidad indígena chamí en el municipio de Obando (valle del Cauca) y la organización de huertas caseras y compra de material para microempresas de modistería y tejidos en el municipio de Popayán (Cauca).

$95<$ http://asa.solidaragon.org/> (21 de junio de 2005). 


\section{2) Asamblea de Cooperación por la Paz (ACPP)}

Asamblea de Cooperación por la Paz es una ONGD nacional que surgió en 1990 con el propósito de apostar por el pacifismo, la tolerancia y el diálogo. "Apoyamos a la sociedad civil, democrática y progresista de los países en vías de desarrollo generando organización local, fomentando la participación ciudadana y la búsqueda de alternativas para conseguir sociedades más justas y más democráticas, donde los beneficios del desarrollo se redistribuyan más equitativamente, dando el protagonismo a los agentes locales». ${ }^{96}$ Afirma que la base de su trabajo se sustenta en dos valores básicos: cooperación y paz.

Por un lado, la cooperación con los países en vías de desarrollo desde la equidad de género y el desarrollo sostenible, fomentando el fortalecimiento del tejido asociativo de sus propias sociedades para que ellas mismas tomen las riendas del desarrollo. Por otro lado, la paz. Desde su nacimiento, a raíz de las manifestaciones pacifistas contra la primera guerra del Golfo, las actuaciones de ACPP están marcadas por los deseos de paz y la consideración de que el uso de la violencia sólo puede ser considerado como último recurso para evitar genocidios y violaciones colectivas de los derechos humanos. En Colombia apoyaron la construcción de 15 viviendas en una comunidad indígena de Urabá (Antioquia).

\section{3) Asociación Marianista de Ayuda al Tercer Mundo (AMAT)}

Esta asociación ha centrado su labor principalmente en Colombia "por ser la provincia marianista del Tercer Mundo hermanada con la de Zaragoza». Entre sus objetivos está «favorecer la relación entre miembros de la familia marianista presentes en el Tercer Mundo y en España, denunciar la situación injusta de los países del Tercer Mundo y concienciar en nuestro entorno» (FAS, 2000, 29).

La delegación aragonesa ha tenido presencia en Chocó y Antioquia. Ha apoyado el fortalecimiento institucional de un centro para la orientación de la economía solidaria y la ampliación de la cobertura educativa a niños sin oportunidades de escolarización en Medellín. De

96 <http://www.acpp.com> (5 de noviembre de 2005). 
igual manera, la entidad concede becas para estudios universitarios de jóvenes vinculados a los marianistas en diferentes municipios. En Chocó apoyó la creación de talleres de confección y bordado para mujeres de Lloró (Chocó).

\section{4) Comité Cristiano de Solidaridad Óscar Romero}

El Comité Óscar Romero es «un grupo de inspiración cristiana que desarrolla un trabajo de concienciación solidaria en la sociedad, para abrir la visión, habitualmente eurocéntrica, a otras realidades procedentes del llamado Tercer Mundo, en concreto de América Latina». ${ }^{97}$

El Comité Óscar Romero de Aragón fue fundado en 1984 a petición de las comunidades cristianas de base de Centroamérica; en 1989 el Comité se constituyó en asociación legalmente reconocida. Está coordinado con otros treinta grupos homónimos de otras ciudades españolas, así como, a través de un Secretariado Internacional, con varios centenares de Comités Cristianos de Solidaridad con América Latina constituidos por todo el mundo. Entre sus objetivos permanentes están:

Promover actitudes solidarias en la sociedad tanto hacia Centroamérica y América Latina como hacia las realidades de marginación que se dan en nuestro mismo entorno. Desarrollar además este trabajo específicamente entre los cristianos. Convocar y aglutinar a las personas y grupos de nuestro entorno en la solidaridad con el proyecto liberador de los pueblos y de las comunidades de América Latina. Crear un sistema de comunicación, como red de información, que potencie el conocimiento correcto de los procesos populares en América Latina para ayudar a la formación de la conciencia de nuestra sociedad en torno a los mismos $\left[\ldots . .{ }^{98}\right.$

En Colombia ha apoyado la construcción de un centro de formación para líderes sociales del Chocó. En Aragón ha realizado campañas de sensibilización y denuncia respecto a la situación de algunos grupos humanos que padecen las consecuencias del conflicto armado en ese país.

97 <http://csor.solidaragon.org/objets.html> (21 de junio de 2005). ASA y CSOR publicaron en 2006 una sistematización de los 20 años de presencia en Colombia que recogía su experiencia de economía solidaria.

98 Página web del Comité Óscar Romero: <http://csor.solidaragon.org> (julio de 2004). 


\section{5) Comité de Solidaridad Internacionalista de Zaragoza}

El Comité de Solidaridad Internacionalista «nace de la profunda reorganización de lo que constituyó uno de los primeros grupos de solidaridad con Centroamérica, el Comité de Solidaridad con Nicaragua de Zaragoza. Éste surge en 1977 como apoyo a la lucha del pueblo nicaragüense contra la dictadura somocista y toma fuerza en la solidaridad a una revolución triunfante, la sandinista, agredida por toda la fuerza del gigante norteamericano». ${ }^{99}$

Su metodología de trabajo no implica en todos los casos la realización de proyectos de cooperación al desarrollo: el Comité considera que esta metodología de trabajo no discute las bases de la desigualdad e injusticia internacional y por el contrario se inscribe dentro del sistema perpetuándolo. Trabaja a partir del envío de brigadistas a Colombia; allí sus miembros entran en contacto con organizaciones campesinas, sindicales, de mujeres y defensores de derechos humanos, que demandan presencia internacional. Asimismo, destaca por la realización de actividades de sensibilización y denuncia en ámbitos locales e internacionales.

\section{6) Entreculturas (Fe y Alegría)}

Es una organización no gubernamental, promovida por la Compañía de Jesús, que «defiende el acceso a la educación de los más desfavorecidos, como medio de cambio social, justicia y diálogo entre culturas. Actuamos a favor del desarrollo cultural y humano a través de la Federación Internacional de Fe y Alegría». En Aragón su trabajo se fundamenta en la sensibilización y en la presentación de proyectos a instancias públicas y privadas. Colombia es, después de Perú, el país que más fondos recibe de esta organización. Su contraparte es Fe y Alegría Colombia, que cuenta con más de 200000 beneficiarios, entre alumnos en educación formal, ${ }^{100}$ niños en hogares infantiles, beneficiarios/as de programas de educación informal y servicios asistenciales y formativos (centros de salud, programas de nutrición o de economía solidaria). «Entreculturas nace en España en

99 Página web del Comité Internacionalista: <http://internacionalistas.solidaragon. org/> (julio de 2004).

100 Entre 1992 y 1998 se han construido a través de programas de cooperación internacional 132 aulas y 10000 nuevas plazas. 
1986, como Fe y Alegría España. 1999 es un año clave para nuestra organización que apuesta por una nueva imagen y un nuevo nombre. Entreculturas se adapta mejor a nuestra misión en el campo de la cooperación internacional, enfocada en la búsqueda de nuevos caminos de justicia en un mundo global de mezcla de culturas y de convivencia». ${ }^{101}$

\section{7) Fundación Juan Bonal}

La Fundación fue inscrita en la FAS en el año 2000 y pertenece a la Congregación Hermanas de la Caridad de Santa Ana. La Congregación se creó en 1804 en la ciudad de Zaragoza con la finalidad de prestar sus servicios al Hospital de Nuestra Señora de Gracia. Esta fundación actualmente trabaja en 30 países de los cinco continentes y presta servicios en áreas tan variadas como la salud, la educación, la atención a niños y ancianos, la promoción de la mujer y el desarrollo agrícola. Una de sus principales campañas permanentes es el apadrinamiento de niños: «En la actualidad, se encuentran apadrinados mas de 7300 niños y existe un potencial de otros 6000 niños pendientes de apadrinamiento. Éste es un dato que crece exponencialmente en el tiempo, dado que atendemos las solicitudes de apadrinamiento desde más de ochenta centros en el mundo». ${ }^{102}$ En Colombia han trabajado en diferentes proyectos, desde el apoyo a comedores escolares, pasando por la implementación de sala informática de un colegio hasta la dotación de planta eléctrica para un centro de salud.

\section{8) InteRed Aragón}

Es una ONGD promovida por la Institución Teresiana para «impulsar una Red de Intercambio y Solidaridad entre grupos sociales, pueblos y culturas en el Norte y en el Sur». Su finalidad es colaborar en la «transformación de la realidad actual generadora de injusticia, y lograr una vida justa, digna y más humana para todos y todas». ${ }^{103}$

101 Página web de la entidad: <http://www.entreculturas.org/somos2.asp> (21 de junio de 2005).

102 <http://www.padrinos.org/secciones/somos/fundacion.asp> (5 de noviembre de 2005)

103 <http://www.intered.net/> (5 de noviembre de 2005). 
Su forma de trabajo se basa en procesos educativos y la promoción y defensa de los derechos humanos. Las principales líneas de acción son: Cooperación Internacional (apoyando acciones de formación, educación y capacitación en países del Sur) y Educación para el Desarrollo (a través de trabajo en educación formal y no formal, promoción y formación de voluntariado, comunicación e investigación). En Colombia han apoyado la mejora de la educación para niños y adolescentes trabajadores de un barrio de Bogotá. En Aragón han llevado a cabo la campaña «educar a una mujer es educar a un pueblo", en la que se han sensibilizado sobre la situación de las mujeres colombianas.

\section{9) Manos Unidas Zaragoza}

Es una organización no gubernamental para el desarrollo (ONGD) católica, de voluntarios, que desde 1960 «lucha contra la pobreza, el hambre, la malnutrición, la enfermedad, la falta de instrucción, el subdesarrollo y contra sus causas». ${ }^{104}$ Nació como una campaña puntual contra el hambre, y a partir de 1978 adquirió personalidad jurídica, canónica y civil, como organización, pasando a denominarse Manos Unidas. Para cumplir su objetivo financia proyectos de desarrollo en los países del Sur y realiza campañas de sensibilización en España.

En Colombia han apoyado la construcción de un salón multifuncional para ampliar la cobertura de los cursos en un colegio del departamento del Cesar, han promovido una granja experimental de un colegio indígena en el Amazonas y han ayudado al fortalecimiento de la organización de las comunidades afrocolombianas en el Chocó.

\section{0) Médicos del Mundo Aragón}

Es una asociación de «solidaridad internacional, independiente, regida por el derecho fundamental a la salud y a una vida digna para cualquier persona». Sus objetivos son: ayudar en el ámbito de la salud, a las poblaciones más vulnerables en situaciones de crisis humanitarias provocadas por guerras o catástrofes naturales y en situaciones de pobreza en aquellas zonas de más bajo desarrollo humano del planeta. Sus intervenciones se

104 <http://www.manosunidas.org/> (5 de noviembre de 2005). 
«acompañan de la denuncia, mediante acciones testimoniales, de los atentados contra los derechos humanos, tanto de mujeres como hombres, en especial enfocándonos más concretamente en las trabas al acceso a la asistencia sanitaria». ${ }^{105}$

En Colombia han realizado el proyecto Dotación de botiquines, microscopios y formación de promotores de salud en el alto Atrato (el Chocó), dirigido a 56 comunidades (15000 personas) pertenecientes a los municipios de Bagadó, Atrato (Yuto) y Lloró. Dicho proyecto busca «fortalecer las estructuras de salud mediante el diagnóstico del paludismo, enfermedad endémica en la zona, y favorecer el desarrollo comunitario a través del apoyo a la ONG local, y la participación de la mujer proporcionando conocimientos sobre higiene para la salud».

\section{1) Organización de Solidaridad de los Pueblos de África, Asia y América Latina (OSPAAL)}

Es una organización constituida legalmente el 22 de octubre de 1990, trabaja en el ámbito nacional y su misión es «la realización de proyectos de cooperación al desarrollo económico y social de los pueblos subdesarrollados y en vías de desarrollo. Coordinar organizaciones, grupos e individualidades que trabajen en pro de la solidaridad con los pueblos de América Latina, África y Asia; y, en general, con todos los pueblos del mundo. La promoción de la paz y de los derechos humanos entre los pueblos. Promover y alentar actos destinados al desarrollo de la solidaridad entre los pueblos». ${ }^{106}$

En Colombia apoyaron recientemente el surgimiento de una empresa comunitaria para el reciclaje, comercialización, transformación de productos y prestación de servicios varios en Bogotá.

\section{2) PROCLADE (Misioneros Claretianos)}

Es una organización «con vocación de servicio al Tercer Mundo, que sentimos los problemas de los pueblos del Sur como nuestros» (PROCLADE, $2004,1)$. Admiten que exigir y esperar las soluciones de los Gobiernos y

\footnotetext{
$105<$ http://www.medicosdelmundo.org> (julio de 2004).

106 <http://directorio-guia.congde.org/inc_ong/ong.php?di_id=89> (2 de noviembre de 2005).
} 
organismos internacionales no es suficiente, y que, mientras transcurre ese proceso, no sólo pueden, sino que deben «hacer algo más». Pretenden ser un cauce operativo que facilite la solidaridad por parte de personas y entidades cercanas a la filosofía de la entidad. Realizan tareas de sensibilización a los ciudadanos de los países del Norte para crear una cultura de la solidaridad, promueven y financian proyectos de desarrollo (con donaciones de los colaboradores y con actividades propias de la fundación).

En Colombia han apoyado la construcción de centros de formación afrochocoanos para desarrollar actividades de promoción social y cultural entre sectores populares de la población en el departamento del Chocó.

\section{3) UNICEF Aragón}

Pertenece al Comité Español y, como todos los comités, se dedica a apoyar las políticas y programas de UNICEF mediante la promoción y defensa de los derechos de la infancia, la educación para el desarrollo y la recaudación de fondos. ${ }^{107}$ Asimismo, ayuda a través del Programa PROANDES, por el cual recaudan donaciones y ayudas públicas y privadas que se envían a varios comités, entre los que se encuentran los países de la región andina.

Las principales actividades de UNICEF en Colombia incluyen el apoyo a las poblaciones desplazadas por medio del Plan de Acción Humanitario; reducción de la mortalidad derivada de la maternidad; promoción del desarrollo integrado de la primera infancia y de escuelas acogedoras para la niñez. Asimismo, trabaja en otros frentes que, como consecuencia del conflicto, afectan a la infancia: niños soldados, minas terrestres (casi un $20 \%$ de las víctimas son menores de 18 años) y secuestro de niños y niñas. ${ }^{108}$

\subsubsection{Análisis cuantitativo de la presencia de las ONGD aragonesas en Colombia}

Los datos expuestos a continuación corresponden al análisis de la información suministrada por 13 entidades que entre el año 2000 y el

$107<$ http://www.unicef.es> (21 de junio de 2005).

108 <http://www.unicef.org/spanish/infobycountry/colombia.html> (21 de junio de 2005). 
2004 realizaron proyectos en Colombia. ${ }^{109}$ Esta información se obtuvo a partir de la cumplimentación de la ficha «Registro sistemático de las ONGD aragonesas en Colombia» (ver anexo 6) para describir algunas variables cuantitativas que aportaran en el logro del objetivo del presente estudio, es decir, el análisis de los procesos de ejecución de los proyectos de las ONGD aragonesas en Colombia. Los principales resultados que se extraen de este análisis son los siguientes:

El 56\% de los fondos gestionados por las ONGD aragonesas con presencia en Colombia procede de distintos entes de la Administración Pública aragonesa. El organismo oficial aragonés que más fondos destinó a proyectos en Colombia fue la Diputación General de Aragón, con el $63 \%$ de los fondos públicos, seguido, a mucha distancia, por el Ayuntamiento de Zaragoza (16\%) y el Ayuntamiento de Huesca (14\%). La organización que más subvenciones públicas recibió para Colombia fue InteRed, con 145597 euros, seguida, a una distancia considerable, por ASA, con 70400 euros.
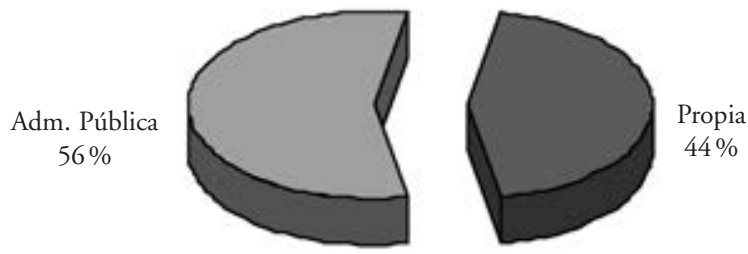

FUENTE: Elaboración propia.

109 UNICEF Aragón y Entreculturas Aragón no desagregaban la ayuda a nivel autonómico, sino que se gestionaba en el ámbito estatal. Asimismo, en todos los casos la ayuda no se dirigía concretamente a Colombia, sino a la región andina, como sucede con UNICEF. 
El 44\% restante corresponde a fondos que las propias entidades han recaudado por diferentes vías. Se da el caso de entidades que han recaudado el $100 \%$ de sus fondos sin recurrir a subvenciones públicas, como fue la Fundación Juan Bonal, AMAT, Manos Unidas Zaragoza y el Comité Óscar Romero. Estas entidades obtuvieron sus fondos a partir de las cuotas de asociados y donativos. Por ejemplo, la Fundación Juan Bonal se financia principalmente a través del apadrinamiento de niños, AMAT recibe cuotas de socios y realiza campañas de recaudación en los colegios marianistas, y Manos Unidas distribuye los proyectos a las diferentes parroquias de la diócesis o, cuando se trata de grandes proyectos, los asume el conjunto de la delegación diocesana. En años previos a los del estudio otras delegaciones de Manos Unidas en Aragón (Manos Unidas Teruel) ejecutaron proyectos en Colombia, pero, para el período comprendido en el análisis, sólo la diócesis de Zaragoza había apoyado tres proyectos. Las cajas de aho-

TABLA 5.1

FUENTES DE FINANCIACIÓN

DE LA COOPERACIÓN ARAGONESA EN COLOMBIA, 2000-2004

\begin{tabular}{|l|l|c|c|}
\hline Origen & \multicolumn{1}{|c|}{ Entidad } & Cantidad & $\%$ \\
\hline Adm. Pública & DGA & 252196,95 & 35,4 \\
& Ayto. Zaragoza & 63000 & 8,8 \\
& Ayto. Huesca & 56920 & 8,0 \\
& DPZ & 20327,29 & 2,9 \\
& Ayto. Ejea & 4000 & 0,6 \\
\hline Propia & Manos Unidas & 164831 & 23,1 \\
& F. Juan Bonal & 33461 & 4,7 \\
& C. Óscar Romero & 22243,65 & 3,1 \\
& ASA & 21713,01 & 3,0 \\
& AMAT & 18385 & 2,6 \\
& C. Solidar. Intern. & 16825 & 2,4 \\
& CAI & 13441 & 1,9 \\
& Médicos del Mundo & 7852 & 1,1 \\
& PROCLADE & 7000 & 1,0 \\
& Ibercaja & 6000 & 0,8 \\
& OSPAAL & 4273 & 0,6 \\
\hline \multirow{2}{*}{ Total } & & 712468,9 & 100,0 \\
\hline
\end{tabular}




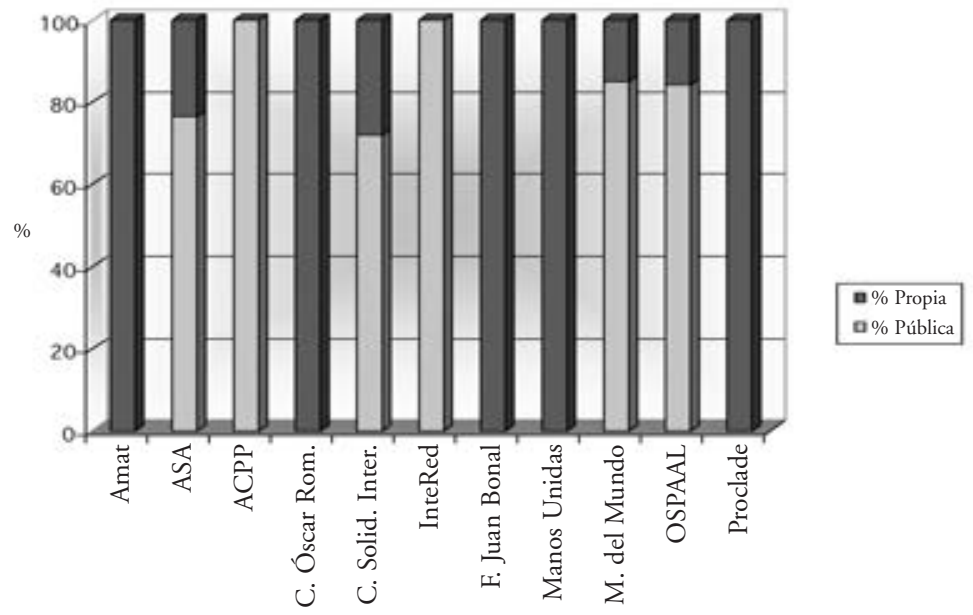

FUENTE: Elaboración propia.

rro aragonesas participan tímidamente de este apartado de la financiación, debido a que tan sólo el $6 \%$ de la financiación propia procede de estas fuentes de financiación (Caja Inmaculada 4\%; Ibercaja, 2\%). También se da un caso por el cual una ONG financia a otra, como fue el Comité Óscar Romero, que apoyó un proyecto gestionado por ASA.

Casi la mitad de las entidades combina la financiación propia con la que procede de las administraciones públicas. Entre las entidades que usan esta financiación mixta, la media de aportación propia frente a la pública es de un $20 \%$, destacando como aportación máxima el Comité de Solidaridad Internacionalista con un $27 \%$ de fondos propios.

La ONG que más proyectos ejecutó en Colombia dentro del período analizado en el estudio fue ASA, con 8 proyectos (ASA Zaragoza y ASA Huesca), seguida de la Fundación Juan Bonal (5) y AMAT (4). Sin embargo, este orden no corresponde con la envergadura de los proyectos, ya que el orden de las entidades que gestionaron los proyectos más costosos la encabeza Manos Unidas Zaragoza, con un total de 165000 euros distribuidos en 3 proyectos, seguida de InteRed, con 145000 euros en un solo proyecto. 
GRÁFICA 5.4

DISTRIBUCIÓN DE LAS ENTIDADES ARAGONESAS

POR PROYECTOS EN COLOMBIA, 2000-2004

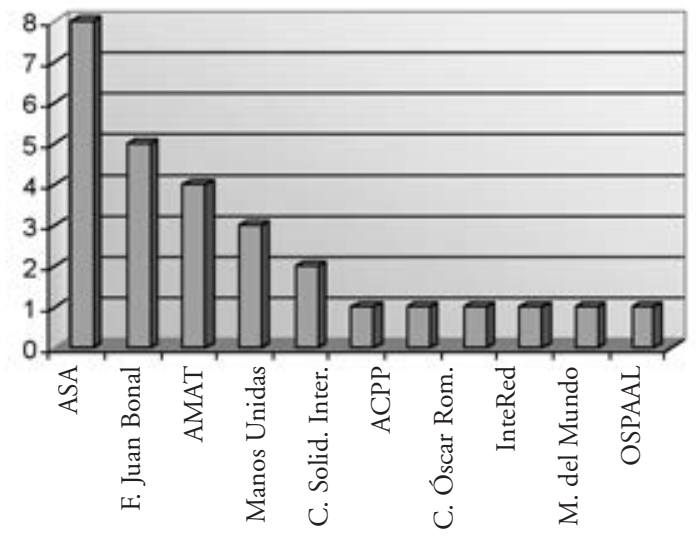

FUENTE: Elaboración propia.

Los departamentos colombianos que más ayuda recibieron de Aragón, usando como criterio los fondos destinados a proyectos, fueron: Chocó, con el 33\%, Bogotá D.C., 27\%, y Antioquia, 17\%. Por tanto, estas tres regiones agruparon el $78 \%$ de los fondos, mientras que otros 7 departamentos se repartieron el $22 \%$ restante.

La observación de la distribución de las inversiones de la cooperación aragonesa por regiones, en lugar de ceñirse a las divisiones administrativas de los departamentos, permite extraer algunos matices. Por ejemplo, Antioquia y Chocó se reparten buena parte de los proyectos de cooperación; sin embargo, las regiones de Urabá y alto Atrato, compartidas por ambos departamentos en la zona noroccidental, agrupan una presencia relevante de proyectos que no puede generalizarse al conjunto. Además, los otros proyectos que también se realizan en el Chocó tienen como contrapartes organizaciones como ACIA y Pastoral Social de la Diócesis de Quibdó, cuya sede se encuentra en la capital del departamento, lo cual convierte a Quibdó en un receptor de recursos provenientes de Aragón que luego se distribuye entre las comunidades con las cuales trabaja la 
MAPA 5.1

UBICACIÓN DE LOS PROYECTOS EJECUTADOS

EN COLOMBIA POR ONGD ARAGONESAS, 2000-2004

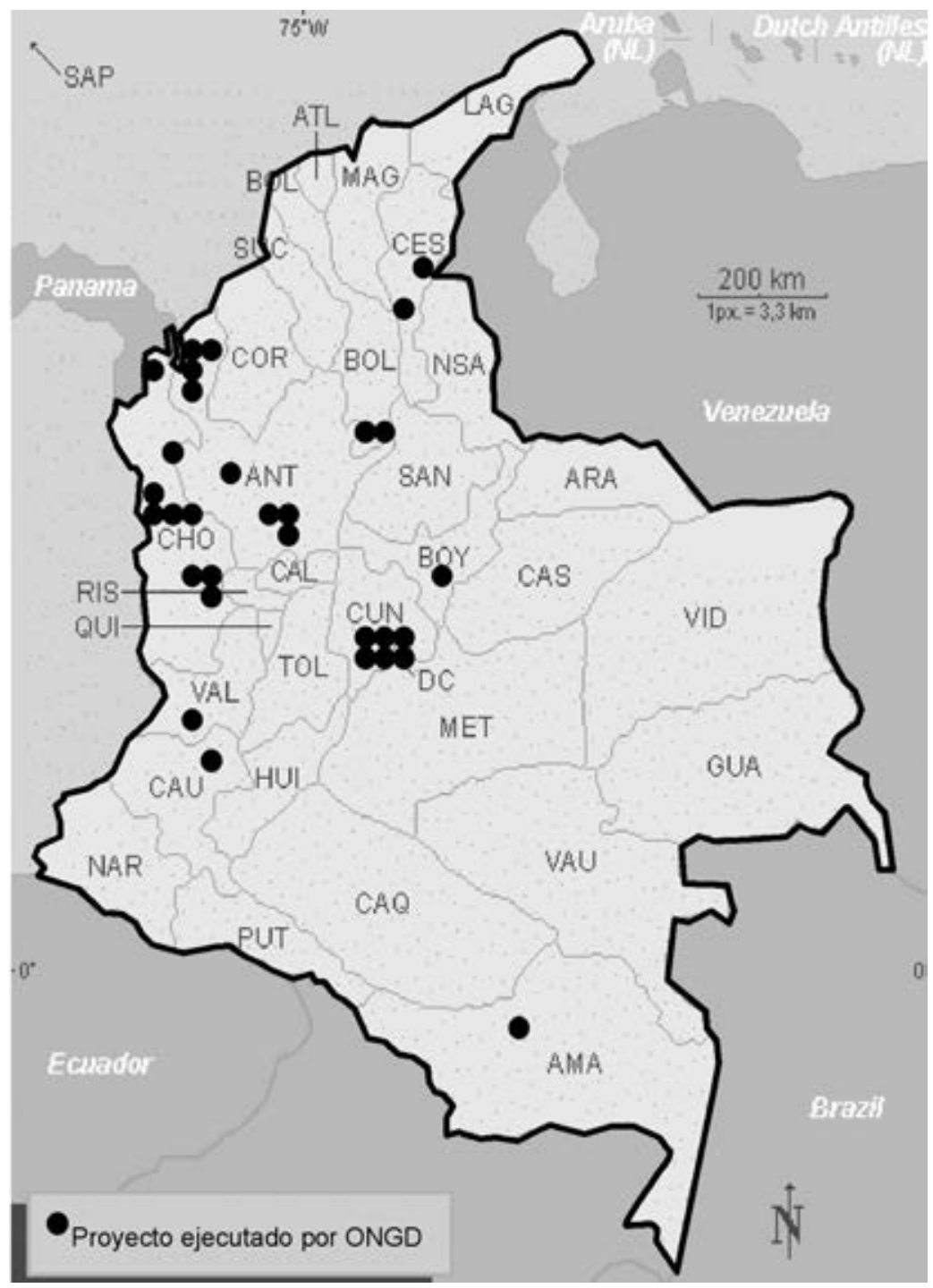

FUENTE: Elaboración propia. 
GRÁFICA 5.5

PRESUPUESTOS DE LA COOPERACIÓN ARAGONESA

POR DEPARTAMENTOS COLOMBIANOS, 2000-2004

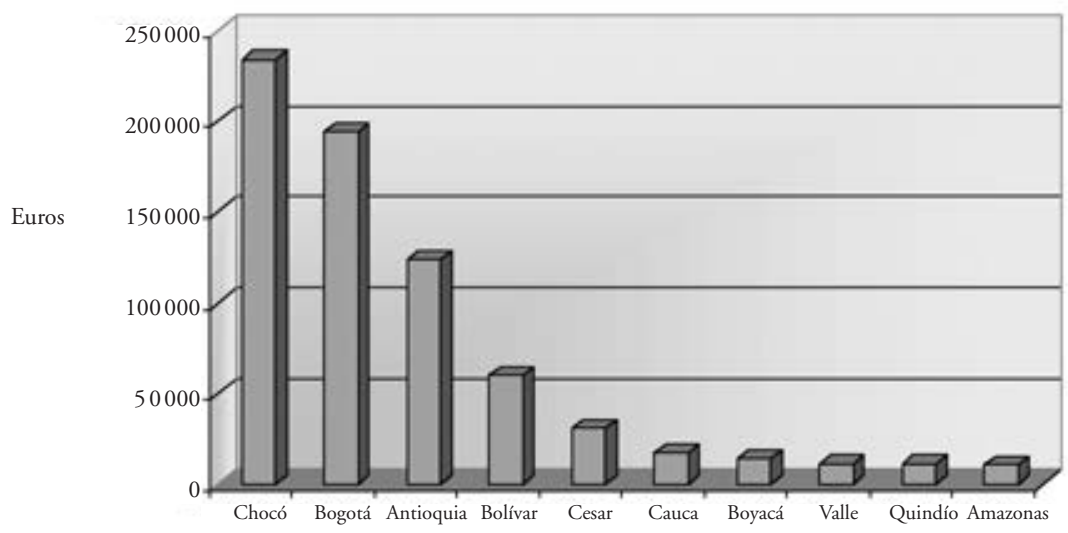

FUENTE: Elaboración propia.

organización campesina y la institución católica. Por su parte, las intervenciones en Antioquia se encuentran concentradas en las zonas descritas anteriormente y en la capital de este departamento, Medellín.

Algunas situaciones similares ocurren en otros departamentos y ciudades colombianas, es decir, una tendencia progresiva a la concentración de los proyectos en zonas específicas de un departamento o barrios de una gran ciudad. Esta tendencia puede ser explicada a partir de la existencia de una red duradera de relaciones de conocimiento (Bourdieu, 2001) que lleva a mantener y fortalecer los vínculos que proveen recursos económicos, sociales o políticos.

En cuanto a los sectores a los que se dirigen los proyectos, la mayor parte de éstos están dirigidos a la educación (44\%). Por una parte, se trata de apoyar el sistema de educación formal $(25 \%)$ a través del apoyo de los comedores escolares, la ampliación de la cobertura educativa y la dotación de recursos para mejorar la formación de los alumnos. ${ }^{110}$ En segundo

110 Si hubiese sido posible recoger la información desagregada de UNICEF y Entreculturas, el apartado de proyectos destinados al sector educativo hubiese destacado aún más. 
MAPA 5.2

INVERSIONES DE LA COOPERACIÓN ARAGONESA EN COLOMBIA POR REGIONES, 2000-2004 (Euros)

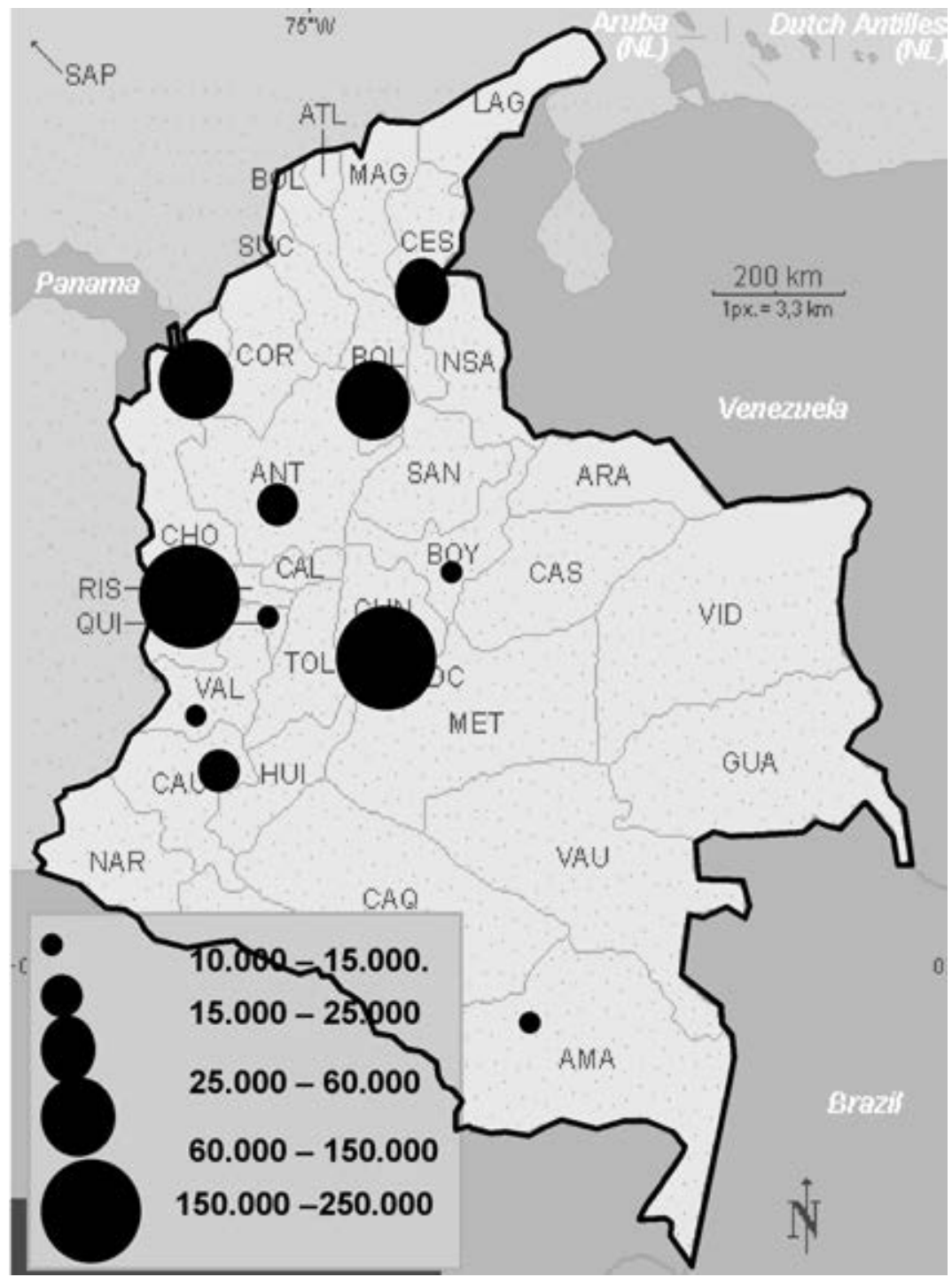

FUENTE: Elaboración propia. 
lugar, la educación postsecundaria (19\%) está dirigida principalmente a líderes de comunidades campesinas, indígenas o negras y promueve tanto la organización social como el aprendizaje de técnicas y oficios para la autonomía productiva de los grupos beneficiarios. En tercer lugar aparece el «Apoyo a las ONG» (15\%), que consiste básicamente en fortalecer las organizaciones sociales de base; por tanto, aunque la definición del sector según el Comité de Ayuda al Desarrollo habla de ONG, aquí se incluyen otras organizaciones comunitarias y movimientos populares que no asumen directamente la denominación de ONG. En consecuencia, este sector estaría vinculado al de "Gobierno y sociedad civil» (4\%). En cuarto lugar, destacan proyectos de salud, llevados a cabo por entidades como Médicos del Mundo y la Fundación Juan Bonal. Con menos de un 10\% de los proyectos aparecen otros sectores como la ayuda alimenticia, los sectores productivos, la mujer, la vivienda y las comunicaciones.

GRÁFICA 5.6

DISTRIBUCIÓN DE LA COOPERACIÓN ARAGONESA

EN COLOMBIA POR SECTORES CAD

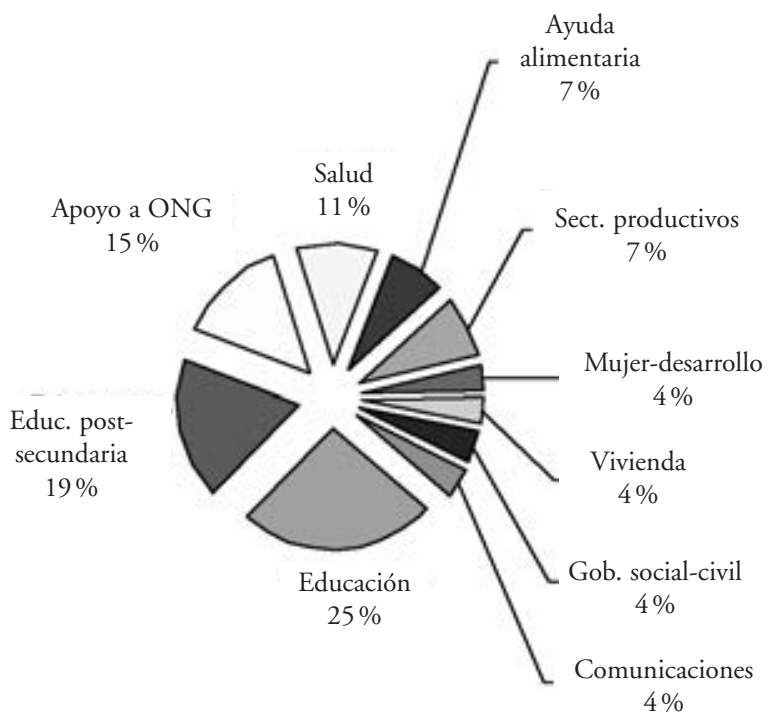

FUENTE: Elaboración propia. 



\section{EL TRABAJO DE CAMPO: FACTORES QUE CARACTERIZAN LOS PROCESOS DE EJECUCIÓN DE LOS PROYECTOS}

La terquedad de vivir... Y aun así prosigue su terco peregrinar por la defensa de una vida digna y de un país democrático, equitativo y en paz.

Guillermo Segovia (1999, 38)

\subsection{El punto de partida}

Entre las hipótesis previas que orientaban el curso de la investigación, ocupaba un papel relevante el análisis de la percepción de las organizaciones comunitarias en Colombia respecto a las entidades aragonesas. Como se ha señalado en la presentación, la influencia de las teorías de la dependencia, ${ }^{111}$ que advierten relaciones unidireccionales de dominación de los países ricos sobre los pobres, determinaron la elaboración de las hipótesis

111 Fue una corriente económica que surgió entre 1957 y 1969. Según esta teoría, la explicación del subdesarrollo se fundamenta en el intercambio comercial entre los países desarrollados (centro) y los países en vías de desarrollo (periferia). Los primeros son exportadores de bienes industriales y los segundos de materias primas y productos agrícolas. «Los países del tercer mundo — decía Prebisch (1962) — han caído en un estado de "dependencia" del primer mundo, convirtiéndose en productores de materias primas en una relación de "centro-periferia" con sus metrópolis". 
previas desde el enfoque de dicha interrelación pero aplicada a la establecida por las ONGD ${ }^{112}$ del «Norte» respecto a las del «Sur». Por tanto, una de las tareas iniciales consistía en corroborar dicha relación, aparentemente clara y evidente, a través del acercamiento a las ONG locales. Era de esperar, como no podía ser de otra manera, cierta unanimidad de las asociaciones y organizaciones respecto a la verticalidad de las relaciones y a la supuesta «injerencia de elementos exógenos» del propio desarrollo.

Las primeras luces arrojadas por las indagaciones iniciales han dejado entrever, de manera latente, un sesgo en el trasfondo de la hipótesis. Ésta estaba viciada al diferenciar sólo dos actores posibles - costumbre muy arraigada en las teorías dialécticas del marxismo convencional- de la compleja relación que hay entre las diversas partes que intervienen en la cooperación internacional.

Por un lado, se omitían las ONGD colombianas, a las que inicialmente equiparaba con las organizaciones comunitarias; no obstante, se constataba una premisa bastante evidente pero contradictoria con las teorías convencionales: la nacionalidad de la entidad no garantizaba la adscripción a unos perfiles ideológicos, políticos y metodológicos. En la observación de muchas de ellas afloraban determinadas características que no se diferenciaban considerablemente de sus homólogas españolas.

Por otra parte, la pertenencia a un ámbito geográfico, aparentemente unificado por unas condiciones materiales y espirituales de vida, en ese caso el «Norte» — rico, próspero, racionalista y desarrollado-, no garantizaba la unidad de pensamiento y acción entre sus integrantes. Había que separar las organizaciones no gubernamentales de desarrollo españolas de las agencias oficiales y multilaterales de cooperación. ${ }^{113}$

112 Este apartado contiene referencias que equiparan las ONG a las ONGD. Para el trabajo de campo se han considerado como sinónimas, ya que en Colombia la diferencia entre una y otras no es tan explícita como en España. Por ejemplo, en España hay una coordinadora para las entidades especializadas en desarrollo, mientras que la Confederación Colombiana de ONG las agrupa sin discriminar su actividad.

113 Esta confusión también es frecuente en el discurso de algunos líderes de ONGD colombianas que unifican, como si se tratase de un mismo actor, a las agencias y a las ONG extranjeras. Bajo la denominación «el Norte», la aglomeración de partículas padece la uniformización de las etiquetas simples que facilitan la comprensión de la alteridad. En una situación similar incurren los cooperantes que hablan de «el Sur». Al respecto ver Gómez, y Martínez (2002). 
Buena parte de la bibliografía sobre las particularidades del sector resaltaba este tipo de aspectos, es decir, la pluralidad de las organizaciones del «Norte». Sin embargo, estas afirmaciones suelen decir poco cuando no se constatan en el terreno.

Una gran parte de las observaciones «viciadas» se fundamentaban en el supuesto de mirar la realidad como una simple interacción de dominación entre unos actores del mundo rico y otros del mundo pobre. Pero el sesgo estaba en el ámbito espacial en el que se han situado unos y otros. La división de países ricos y desarrollados ha sido una clasificación bastante simplista y reduccionista, y puede provocar errores evidentes en la percepción. En su lugar, algunos destacados sociólogos ${ }^{114}$ han propuesto una serie de categorías que sugieren la idea de ámbitos o campos de interacción que explican la existencia de espacios en los que los sujetos establecen relaciones bajo una lógica específica ${ }^{115}$ que les permite interactuar bajo la creencia en determinados aspectos prioritarios del campo. La utilidad de este concepto, $u$ otros conceptos similares, ${ }^{116}$ se basa en la superación del paradigma de los Estados-nación, ${ }^{117}$ el cual nos puede limitar el análisis bajo rígidos criterios geográficos y político-administrativos.

Estos ámbitos de interacción se pueden diferenciar con criterios más cercanos a las formas de relacionarse por parte de los sujetos que intervienen: las poblaciones, sus organizaciones sociales, las ONGD nacionales, las internacionales, las entidades oficiales del Estado y las agencias de cooperación internacionales. Por tanto, desde esta perspectiva resulta más

114 Husserl y posteriormente Schutz y Habermas han trabajado el concepto de «Mundo de la Vida» como "el mundo intersubjetivo en el que la gente crea la realidad social, a la vez que está sujeta a las constricciones que ejercen las estructuras sociales y culturas previamente creadas por sus antecesores» (Ritzer, 1993, 85). Bourdieu lo denomina "Campo» y es «la red de relaciones entre las posiciones objetivas que hay en él [...] Los ocupantes de las posiciones pueden ser agentes o instituciones, y están constreñidos por la estructura del campo [...] todos [los campos] tienen su lógica específica y generan entre los actores una creencia sobre las cosas que son importantes en el campo" (Ritzer, 1993, 503).

115 Bourdieu, citado por Ritzer (1993).

116 Hanna Arendt utiliza el concepto de «esfera». Al respecto ver Arendt (1993), cap. 2, «La esfera pública y la privada», pp. 37-97.

117 Beck $(1996,258)$ sugiere que la modernidad nos ha llevado a pensar el mundo en términos de naciones, que nuestras ansias de universalismo se basaron en conjuntos de naciones (excluyendo la idea un vínculo humano), y considera que «la sociedad burguesa habla de "humanidad", pero — a lo sumo— se refiere a la nación". 
relevante situar las coincidencias/discrepancias ideológicas y políticas, las concepciones de la solidaridad y el desarrollo, y la forma de llevar a cabo el trabajo en los aspectos metodológicos. En esta línea, la nacionalidad, el ámbito geográfico o el estatus jurídico de la entidad puede resultar menos relevante que sus posturas frente a los grandes temas como el desarrollo o la globalización y la forma de trabajar con la población. De igual manera, esta idea nos abre el camino para encontrar afinidades entre organizaciones de diferentes continentes o países pero pertenecientes a un mismo campo. Por ejemplo, durante el trabajo de campo, pude hallar más afinidad ideológica entre ONGD aragonesas y antioqueñas que entre las segundas y las oficinas gubernamentales de cooperación en la capital del departamento o del país.

Los campos se encuentran delimitados por distancias sociales verticales (Bogardus, 1947), culturales o ideológicas (Marcuello, 1996); estas distancias hacen referencia a las posiciones que ocupan los sujetos en un sistema jerárquico. Un caso bastante claro se aprecia en la distancia que hay entre las organizaciones campesinas del Chocó y las elevadas oficinas gubernamentales ubicadas en los últimos pisos de los rascacielos bogotanos, la cual no se aleja mucho de la que puede existir entre las primeras y una agencia estatal de cooperación en Europa.

Hay organizaciones que por su magnitud y origen evidencian una solidaridad elitista (altruismo como "distinción», en la línea de Bourdieu, 1998). Después de la visita a los despachos de una de estas entidades en Bogotá, pude constatar que la población marginada que conocían les llegaba principalmente a través de informes escritos y gráficos de sus socios en los territorios. Nada hacía pensar que los despachos de esta entidad tenían que ver con un sector de la población marginado y en extrema pobreza. El lujo presente en sus oficinas, empleados y decorados, así como el trato clasista — que se aprecia — en la forma de atender a los empleados no cualificados (quien no es «doctor", ni usa traje y corbata), hacían suponer que se trataba de la alta gerencia de una gran multinacional norteamericana. Estas distancias, las culturales e ideológicas, por lo general no se miden ni se calculan, pero son precisamente una de las miradas que interesan en este estudio.

Refiriéndose a la cercanía del barrio El Cartucho de Bogotá (un barrio deprimido de indigentes y recicladores) a la sede de la presidencia 
del país y la alcaldía de la ciudad, un observador español afirmaba lo siguiente: «Tan cerca de las oficinas donde se anuncia la modernización y tan lejos de los supuestos beneficios de la globalización» (Martín Medem, 1999, 77)..$^{118}$

La distancia del elitismo frente a lo popular o lo propio de «los pobres» es una de las principales patologías sociales normalizadas que aqueja a Colombia, ya que la solidaridad no es vista como un tema de justicia o responsabilidad estatal, sino como un efecto residual atribuido a la capacidad individual y, por tanto, al mérito personal. No hay un acuerdo implícito en identificar unas condiciones estructurales como elementos determinantes para estar en la pobreza. Este liberalismo económico es un factor latente en la conciencia colectiva, aunque las evidencias demuestren que ese «efecto residual» afecta a aproximadamente al $70 \%$ de la población. ${ }^{119}$ En medio de una pobreza tan extrema y arraigada en la sociedad, hay que hacer lo posible por dejar claro a los demás que no se es pobre. Bajo esta concepción, el pobre no tiene identidad (Carrasquilla, 1999); en eso también se basa su pobreza.

Tuve la oportunidad de conocer la visión y el trabajo de entidades como ACARPIN. Ésta es una organización dedicada a proteger a niños, niñas y jóvenes de la ciudad de Medellín y su área metropolitana, huérfanos, abandonados o en peligro físico, moral, social y psicológico, ofreciéndoles acogida en sus hogares y atención en sus necesidades básicas. La entidad ha recibido ayuda aragonesa a través de la Asociación de Familias Adoptantes de Aragón ${ }^{120}$ (AFADA) y se aprecian similitudes en cuanto a las motivaciones de sus socios, la identidad con un tipo de compromiso

118 En el momento de escribir este apartado he conocido que se ha solucionado el problema: sus habitantes han sido trasladados a varios kilómetros del centro político y administrativo del país. "Indigentes que salieron de El Cartucho han colonizado otras zonas de Bogotá», El Tiempo, 11 de agosto de 2005.

119 Un estudio de Libardo Sarmiento de la Universidad Nacional estima que la incidencia de la pobreza fue en 2004 del 77,3\%. Estudios de la Contraloría general de la Nación y el Informe del PNUD de 2003 tienen estimaciones superiores al 65\%. Corporación Viva la Ciudadanía (2004).

120 Esta entidad no hizo parte de la muestra del estudio, ya que no cumplía el requisito de estar federada en la FAS. Tuve la oportunidad de conocer su trabajo y el de su contraparte a través de una gestión particular para el apoyo de un proyecto de niños y adolescentes en situación de desprotección en la ciudad de Medellín. 
voluntario, el papel del Estado ante la situación de desprotección infantil y cierto aroma de precariedad llevada con bastante dignidad.

Muchas ONGD colombianas están constituyéndose como una alternativa laboral ante el elevado desempleo profesional. Están surgiendo entidades fruto del «rebusque», ${ }^{121}$ más que de la concienciación; sin embargo, su profesionalidad les permite competir, en condiciones aventajadas, con las entidades experimentadas pero de poca cualificación, por los escasos recursos que brinda el medio. El resultado es que «ganan» los proyectos, los redactan mejor, tienen expertos contables, abogados, trabajadores sociales, pero evidencian escasa sensibilidad social y nula reivindicación cívica (especialmente los egresados de las universidades privadas) y mucha eficiencia en la gestión. Sin embargo, no las sustenta un movimiento popular, una convicción de cambio o la creencia en unos determinados valores religiosos o cívicos; son, básicamente, una opción viable de autoempleo en el tercer sector.

Otra de las hipótesis previas consistía en suponer que la mayoría de los proyectos de cooperación era fruto de la existencia de vínculos formales entre donante y receptor a través de la oferta/demanda de ayuda, la presentación de proyectos en convocatorias públicas o concesiones acordadas entre diferentes organismos de una misma esfera o campo, etc. No obstante, el trabajo de campo ha demostrado que muchas de las relaciones de cooperación han surgido como resultado de los vínculos personales, familiares o religiosos de aragoneses que han viajado o vivido en Colombia. Se aprecia que en los próximos años, y como fruto del asentamiento migratorio, se crearán nuevos lazos de cooperación por parte de colombianos que, residiendo en Aragón, empiezan a considerar el establecimiento de lazos solidarios con sus regiones de origen.

\subsection{Identidad de las ONG: ¿Gestionar recursos o procesos?}

Como ya han sostenido algunos (Sogge, ed., 1998; Hailey, 2004), la identidad y los valores de la organización confieren las características sustanciales que diferencian a las ONG. Por tanto, en sus principios y valo-

$121 \mathrm{Al}$ respecto ver unas breves reflexiones en J. D. Gómez (2004). 
res está implícito el tipo de trabajo que realizan y la capacidad de afrontar los nuevos retos que plantean otros actores de la cooperación.

Rubén Fernández ${ }^{122}$ desarrolla y amplía las condiciones de la diversidad de las ONG colombianas. Identifica una serie de dimensiones que han sido planteadas en la Confederación Colombiana de ONG y constituyen un valioso punto de partida.

CUADRO 6.1

TIPOLOGÍA DE LAS ONG COLOMBIANAS

En cuanto a la naturaleza jurídica:

En Colombia predominan dos figuras jurídicas:

1. Corporaciones: asociaciones de personas basadas en una asamblea que definen los criterios programáticos y financieros.

2. Fundaciones: creaciones de empresas o personas que donan un capital inicial, colocan una impronta particular a la organización y cuidan de la fidelidad de la misma a su marca fundacional.

En cuanto a los promotores:

— fundadas por iglesias o sus fieles

— individuos altruistas

— grupos de familiares y amigos de un personaje fallecido

- creadas por movimientos populares

- partidos políticos

- por empresas privadas

- por grupos de profesionales

- comunidades de base, de interés o de creencia.

Modalidades para llevar a cabo su acción:

— ejecutoras de proyectos elaborados por sí mismas

- contratistas con sectores gubernamentales

- ejecutoras de recursos nacionales o internacionales

- realizadoras de una acción solidaria puntual y concreta

- diseñadoras y ejecutoras de complejos planes plurianuales

- entidades que surgen para ejecutar un solo proyecto

- entidades que gestionan una "obra» social (jardín infantil, escuela, hospital, orfanato) y dedican sus energías a mantenerlo abierto y en servicio.

FUENTE: Elaboración propia a partir de Fernández (2004).

122 Vicepresidente de la Confederación Colombiana de ONG y presidente de la Corporación REGIÓN Medellín. 
En este campo, dentro del mundo de las ONG «hay tanta diversidad como diversa es la sociedad colombiana» (EC-01). Están las que poseen carácter confesional, como también las de carácter laico y agnóstico. «Lo primero que habría que decir es que el abanico de las ONG [...] es infinito. Las hay que defienden la vida y la dignidad de los soldados. Otras, como País Libre, defienden a los secuestrados. Otras son financiadas por la Iglesia católica. Otras por los evangélicos» (Semana, 2002). A pesar de que podríamos señalar que en todos los países las ONG abarcan campos variados, el caso de las ONG colombianas destaca por esta característica respecto a otras naciones del subcontinente: «En cada una de estas áreas [salud, desarrollo, servicios profesionales y servicios sociales] la cuota de empleo no lucrativo en Colombia es más elevada que la cuota media de los cinco países latinoamericanos incluidos en este estudio. Estos datos demuestran claramente que el sector no lucrativo colombiano es más diverso que el del resto de los países de Latinoamérica» (Salamon, dir., 1999, 506).

El concepto de desarrollo con que se trabaja es otra fuente de diversidad ideológica. Desde el «llano asistencialismo, hasta nociones de desarrollo humano como realización de derechos y libertades, son todas concepciones presentes en el mundo organizativo no gubernamental colombiano» (EC-01). También estas concepciones condicionan el tipo de problemas que atienden. En este terreno puede decirse que, en general, las ONG están presentes en la mayoría de los campos de actividad de la sociedad: el desarrollo comunitario, la cultura y las artes, los derechos humanos, la educación formal y no formal, la generación y capacitación para el empleo, el medio ambiente, la infancia, la juventud y la tercera edad, la vivienda, la atención de emergencias, la mujer, las opciones sexuales diferentes, entre muchas otras.

Una de las grandes amenazas que hay sobre el sector es que existe un cierto "des-dibujamiento del papel de las ONG» (EC-01). Son tantas y tan variadas que pueden perderse en los linderos por los que deberían moverse, y en esto influye considerablemente la proliferación de ONG.

Según un entrevistado, "hay una sobre-utilización de la figura jurídica», muchas veces por formas organizativas que no son propiamente ONG en el sentido convencional. Tal como se ha descrito en el apartado «Las 
ONG y la sociedad civil en Colombia», la denominación ONG no aparece recogida en el ordenamiento jurídico colombiano; en general, opera como una categoría que agrupa formas jurídicas reconocidas como corporaciones, fundaciones, asociaciones, cajas de compensación, acciones comunales... (Codesarrollo, 2002). En estos casos surgen entidades que, como hemos afirmado, buscan una alternativa laboral o una finalidad asociativa asumiendo el nombre de ONG pero sin principios o fines que acojan los establecidos por las federaciones departamentales. En algunos casos, «su existencia es efímera, ejecutan un proyecto y una vez finalizado se acaban o se desmovilizan. Hay un reto pendiente para dotarnos de mecanismos de identificación, de acreditación de quiénes sí y quiénes no son ONG. Hubo un intento de legislarnos, pero no prosperó, afortunadamente, porque esos esfuerzos no deben venir de afuera, sino especialmente de nosotros mismos» (EC-01). ${ }^{123}$

No todas nacen, ni tienen por qué, de movimientos populares. Hay una buena parte de las ONG que provienen de movimientos sociales cuyas reivindicaciones provienen del reconocimiento a la diversidad cultural o del respeto a los derechos colectivos (ambientales), sin que su origen tenga una asentamiento en las clases populares. Por ejemplo, señala el entrevistado, «los movimientos de mujeres han tenido segmentos de clases medias, no populares» (EC-01).

A pesar de los múltiples perfiles y la enorme distancia ideológica, política y económica, muchas organizaciones coinciden en la necesidad y posibilidad de elevar el nivel de federación sobre la base de algunos criterios fundamentales. El primero es que las propias entidades, y los agentes externos, acepten que son un sector muy heterogéneo, y que las generalizaciones perjudican al conjunto de las organizaciones del país. Uno de los retos más difíciles es evitar la extensión de la polarización social respecto a las posturas frente a los actores de la guerra. Por tanto, dicha diversidad puede ocasionar serias dificultades para la agrupación sectorial, o, por el contrario, encontrar en ella su fortaleza.

123 «La CCONG y las federaciones están trabajando en un Registro cualificado de ONG que brinde confianza a los ejecutores de políticas públicas. Este registro es un paso necesario para pensar en la acreditación y certificación de estas organizaciones en Colombia» (CCONG, 2002b, 1). 
Por ejemplo, «en Antioquia hay ONG furibundamente uribistas ${ }^{124} \mathrm{y}$ antiuribistas, y, a pesar de esto, hay una Federación que funciona y cuenta actualmente con más de 100 entidades federadas» (EC-01). ${ }^{125}$

En el caso del Chocó también existe unidad en la heterogeneidad. La Federación de ONG del Chocó (Fedechocó) cuenta con 30 organizaciones. Los proyectos más recientes gestionados por la Federación han pretendido fortalecer la capacidad organizativa y administrativa de los socios. Han detectado que éste es uno de los aspectos más débiles de su trabajo. A diferencia de otras federaciones, en ésta persiste el trabajo voluntario no profesionalizado, algunas personas que ejercen cargos administrativos (secretario o tesorero) no tienen los niveles de estudios adecuados para desempeñar dichas funciones. Esta Federación ha podido emplear recursos para la formación del personal de las entidades miembros de manera que se dominen algunas tareas administrativas básicas (manejo del archivo, elaboración de actas, contabilidad de la entidad, etc.). Por lo general, las actividades realizadas son cursos y talleres para los líderes y voluntarios financiadas por entidades gubernamentales sectoriales como el Servicio Nacional de Aprendizaje (SENA) —el equivalente al INEM en España - o Empleo en Acción, una de las líneas sociales del controvertido Plan Colombia, iniciado durante el Gobierno de Andrés Pastrana (1998-2002) y continuado por el de Álvaro Uribe (2002-2006).

La vida de las ONG en regiones como el Chocó es muy efímera; para algunas, la tarea diaria consiste en subsistir. Uno de los informantes entrevistados señalaba que en el departamento del Chocó la subsistencia de las organizaciones resultaba más difícil que en otros departamentos colombianos por la inexistencia de empresas privadas, ya que esto reducía considerablemente las posibilidades de buscar fuentes de financiación: «dependemos sólo de las administraciones públicas, pero sólo les dan dinero a las organizaciones cercanas al partido o grupo político elegido. Las demás tienen que salir a buscar los recursos que aquí no encuentran» (EC-02).

124 Las posturas del actual presidente de la República, Álvaro Uribe, han llevado a enfrentar a sus defensores y detractores, básicamente por un tipo de autoridad que los primeros demandan como «necesaria, para poner orden» y los segundos critican como «autoritarismo antidemocrático».

125 Un ejemplo de ello lo refleja el siguiente titular: "Noventa ONG critican a Uribe por violar los derechos humanos. Noventa ONG de Colombia critican al presidente Uribe por un aumento en las violaciones de los derechos humanos». Ibarz (2004). 
De igual forma, las vías de financiación pasan por muchas alternativas, entre las que se incluyen la autofinanciación. La Red de Mujeres del Chocó tiene un restaurante "típico» en el centro de Quibdó (capital del Chocó) para financiar el pago del local y otros gastos corrientes. Es muy común en Colombia que las organizaciones recurran a este tipo de iniciativas para obtener unos ingresos mínimos, especialmente cuando se encuentran ante la escasa sensibilidad de la empresa privada y la dificultad burocrática y política de los entes públicos.

Siguiendo en este departamento, a pesar de la escasa financiación, la cohesión grupal e identitaria de las ONG étnico-territoriales es más fuerte que otras entidades que basan su trabajo en ejes sectoriales (mujer, infancia, ambiente...). La trayectoria de lucha y reivindicación de los movimientos afrocolombiano e indígena ha fortalecido la unidad de la acción. De hecho, constituyen una referencia para las entidades sectoriales, pues el consenso logrado por parte de las organizaciones étnicas, basado en la identificación de focos de reivindicación común (la lucha por la titulación colectiva de la tierra, pluralidad lingüística, la etno-educación...), ha sido un paso muy importante para la redacción y difusión de principios básicos de los cuales se desprenden líneas de acción coherentes y perdurables en el tiempo.

Este aspecto ha sido otro punto de debilidad entre las organizaciones sectoriales. Muchas de ellas no han elaborado planes o declaraciones de principios, lo cual crea una especie de identidad difusa que varía según la junta directiva de turno o las prioridades establecidas por las agencias de cooperación o el Estado. Por otra parte, persiste un elemento común de división entre las entidades nacionales (incluso internacionales), esto es, divagar en la postura de considerar que deben ejercer resistencia a ciertas formas de poder empresarial o estatal, o bien establecer alianzas y convenios con este tipo de organismos reduciendo o eliminando la intensidad de sus críticas y reivindicaciones. "Hay ONGD que quieren evitar la discusión sobre las relaciones con el Estado, [...] y la cuestión nos parece de tal importancia por la coyuntura y la falta de perspectiva que vive Colombia» ${ }^{126}$ (Casas Buenas, 1988).

126 Es de resaltar que el artículo es de 1988, año en que las ONG tenían escasa participación en el ámbito nacional; aun así, ya había voces que evidenciaban cierta institucionalización de ellas. 
La falta de organización y unificación de criterios ideológicos y metodológicos ha redundado en división y fragmentación de las coordinadoras o federaciones ante las ofertas de empresas cuya actividad puede ser considerada por algunos miembros como "poco ética» o «injusta», o cuando surge la posibilidad de un convenio o contrato con una Administración Pública gestionada por dirigentes con investigaciones judiciales pendientes o cuyas políticas perjudican a un colectivo específico. Un ejemplo claro que identifican en el territorio chocoano es la llegada de empresas multinacionales extranjeras, en alianza con empresas nacionales, que quieren explotar recursos naturales convencionales (minerales) y emergentes (palma africana o aceitera). Dentro del conjunto de organizaciones sectoriales hay posturas que consideran que la llegada de estas empresas puede representar oportunidades de empleo e inversión en infraestructuras; por otra parte, hay quienes piensan que la forma de llevar a cabo la explotación de dichos recursos traerá desastres ambientales, económicos y sociales para la región del Atrato. ${ }^{127}$ En medio de esta disputa están los campesinos que deciden vender o alquilar sus tierras para la explotación minera o vegetal, y quienes consideran que la comunidad debe resistir suscribiendo un plan colectivo de desarrollo humano y sostenible. «Tenemos que saber generar unas formas de resistencia que permitan nuestra supervivencia. Si estuviéramos organizados, por lo menos dificultaríamos la explotación indiscriminada de las empresas multinacionales, podríamos al menos pronunciarnos. Si hay unidad, puede haber voz» (EC-02). Hasta aquí sólo se señala lo correspondiente al apartado de identidad y agrupación de las ONG; no obstante, más adelante se profundizará sobre este apartado.

Buena parte de la identidad de una organización se fundamenta en sus orígenes, y la importancia de vincularlos con las iniciativas y aspiraciones de los nuevos integrantes resulta prioritaria. La Asociación Campesina Integral del Atrato (ACIA) resaltaba sus objetivos en función de sus orígenes. La organización no surge como consecuencia de la expansión o agudización del conflicto armado; sus raíces se encuentran en la insatisfacción generalizada de la población ante tantas necesidades no cubiertas por parte del

127 El Atrato es el río que cruza de sur a norte el departamento del Chocó; además, es criterio territorial de organización campesina (bajo, medio y alto Atrato) que, para determinados efectos de organización social, altera la organización administrativa departamental que atraviesa: Chocó y Antioquia. 
Estado y por la defensa del territorio: «tenemos muy claro que el conflicto es una parte importante del problema que tenemos, pero no es lo fundamental; lo importante es la desigualdad social que existe» ${ }^{128}$ (EC-03).

Esta misma entidad considera que la capacidad de negociar con otras organizaciones o agencias de carácter internacional depende del grado de identificación de la organización con una razón de ser y unos objetivos claros y compartidos. Si una entidad no sabe lo que quiere, y, más importante aún, si no sabe lo que es, se convierte en un instrumento de gestión al servicio de otras instituciones. Por eso creen que lo conveniente es establecer una serie de principios que orienten a sus integrantes y a las entidades con las que puedan y quieran trabajar. Es un ejercicio de unidad interna y esclarecimiento externo. Muchas entidades, especialmente las de mayor trayectoria, están trabajando con planes plurianuales, de manera que los proyectos que soliciten o la oferta que les llegue por vías de financiación internacional se acojan a objetivos estables y plazos más largos que los empleados hasta hace muy poco.

«Las ONG deben ganar en conciencia política» (EC-07), y uno de esos puntos de fortaleza se ha encontrado en los derechos humanos, económicos, sociales y culturales (DHESC). Éstos se han convertido en un eje que atraviesa todos los ámbitos de la sociedad. En opinión de una investigadora del CINEP, el discurso reivindicativo de las organizaciones de izquierda dio un giro importante a finales de los años ochenta. Muchas personas y organizaciones sustituyeron la máxima de la «revolución contra el Estado» como propósito colectivo y fundamental por el de la denuncia y exigibilidad ante el Estado de los DHESC. En definitiva, encontraban en éstos los requisitos básicos para la construcción de la democracia, la reducción de las desigualdades, el fomento de la participación ciudadana, la aplicación de la justicia y la vía para la resolución pacífica de los conflictos. Este importante cambio en la dirección de las ONG colombianas se fortaleció con el proceso de elaboración de una nueva Constitución política de Colombia en 1991.

128 Esta advertencia suele ser empleada como consigna explícita para los sectores gubernamentales, empresariales, institucionales o mediáticos que, según algunas organizaciones, ubican el conflicto armado en Colombia como la raíz de todos los males que aquejan el país. La propia organización afirma que la posible firma de un acuerdo de paz entre los actores armados no es suficiente para atacar las causas de sus reivindicaciones. 
Con la participación de integrantes de grupos guerrilleros desmovilizados en la Asamblea Nacional Constituyente quedó patente la transición del modelo bipolar («la sociedad contra el Estado») hacia un modelo multipolar, en el que se asumía la variedad de actores sociales y la especificidad de sus exigencias y problemáticas.

Muchas entidades han encontrado en los derechos humanos y concretamente en las demandas específicas de los derechos fundamentales (derecho a la vida, libertad de opinión...), sociales (familia, paz, asociación...), económicos (trabajo digno, remuneración justa, seguridad social...) y culturales (acceso a la educación, a la cultura...) unas aspiraciones legítimas que paulatinamente perfilaban su identidad. De este modo, la acción colectiva ha tenido una coherencia interna que en mayor o menor grado orientaba el trabajo.

Sin embargo, no todas las organizaciones han sido plenamente «fieles» a estos principios o a los establecidos por sus fundadores, socios o bases. Aunque muchas han definido una visión y misión que clarifica su identidad y sus objetivos, el trabajo basado en la ejecución de proyectos de desarrollo financiados a través de concursos públicos nacionales e internacionales ha supuesto, en algunos casos, una fractura respecto a la coherencia pragmática. Las organizaciones más sólidas, en cuanto a estructura organizativa y solvencia financiera, han participado en convocatorias afines a su trayectoria ideológica y metodológica; incluso, han podido negociar determinas condiciones con la agencia o institución respectiva. Hay organizaciones que se atreven a plantearle a una agencia u ONGD del «Norte»: «Nosotros les contamos qué es lo que vemos oportuno y, si ustedes quieren, nos financian» (EE-03). Por su parte, las entidades carentes de dicha solidez han flexibilizado sus propósitos, en aras de garantizar su supervivencia, y han apuntado hacia los ámbitos o colectivos propuestos por «las financieras» independientemente de la afinidad con su origen, visión, misión y experiencia.

De esta forma, la posibilidad de crear una capacidad local que genere procesos de cambio perdurables en el tiempo se reduce, y convierte a la entidad en un instrumento ejecutor de proyectos inconexos y puntuales. La pregunta por resolver en los próximos años tendrá que ver con la paradoja a la que se enfrentan muchas organizaciones: ¿pueden conciliarse los procesos políticos de transformación con la gestión de recursos para la ejecución de proyectos solidarios? 
A la luz de las opiniones expuestas por algunas personas, es prioritario que las ONG «deban apostar a un plan, y no aceptarlo todo, hay que tener una capacidad de gestión ante las demandas de las agencias internacionales» (EC-07). En esa compleja situación se encuentran muchas entidades, ya que se debaten entre liderar procesos de transformación, con todas sus implicaciones (vinculación estable con un territorio determinado, trabajo a medio y largo plazo, concienciación política en términos de la relación Estado-ciudadano) o convertirse en una gestora de recursos (intermediaria que canaliza recursos, ejecuta proyectos a corto plazo, desvinculación del territorio priorizando por sectores sociales). La fórmula planteada por la persona indagada la resume según la paradoja «igestionar recursos o gestionar procesos?» ${ }^{129}$ (EC-07).

\subsection{Relaciones con la cooperación internacional}

Este apartado pretendía abordar los vínculos formales a través de los cuales se construían los lazos entre las organizaciones aragonesas y las colombianas. Inicialmente, se presuponía una relación formal entre contrapartes basadas en oferta/demanda de ayuda, presentación/recepción de proyectos, afinidad ideológico-política, etc. Sin embargo, a través del trabajo de campo se reflejaba que, en muchos casos, transcurría latente un tipo de relación no pautada fundada en el vínculo personal, familiar o fraternal. Este tipo de vínculo no regulado, basado en la confianza y la reciprocidad, ${ }^{130}$ era el origen y permanencia de varios acuerdos para trabajar conjuntamente. Por tal motivo, expondremos unas primeras reflexiones del primer tipo de relación (más previsible y documentado) ${ }^{131}$ y posteriormente, una segunda parte que aborda el tipo de relaciones que se enmarcan dentro de la categoría de capital social.

129 Ésta es una pregunta que cada vez más aparece en diversos medios académicos vinculados a la ONG. Una reciente tesis doctoral de la Universidad Politécnica de Valencia ahonda en los aspectos técnicos que encierra este dilema. Al respecto ver Ferrero (2003).

130 Para Coleman (1990) el capital social tiene que ver con el grado de integración social de un individuo, su red de contactos sociales, que implican relaciones, expectativas de reciprocidad y comportamientos confiables.

131 Buena parte de las publicaciones que analizan las relaciones entre actores de la cooperación consideran fundamentalmente las relaciones formales o institucionalizadas. En esta línea trabajan, por ejemplo, Gómez y Sanahuja (1999), Borren (2004), Alonso (2004) y Storey (2004). 


\subsubsection{Relaciones instituidas entre los actores de la cooperación}

Hay un número considerable de organizaciones colombianas que aspiran a obtener recursos en el exterior. Podría ser fácil pensar que el auge de las ONG en los últimos años en Colombia se debe al interés por concursar en la adjudicación de los recursos. No obstante, para acceder a estos recursos se requiere una estructura sólida, una capacidad técnica y una profesionalización importante que impide a las entidades emergentes poder competir con éxito en dicha búsqueda.

No cualquier organización logra tener éxito. Los procesos son muy exigentes y no cualquiera puede obtenerlos. En este momento el primer lugar al que acuden las entidades son los países de la Unión Europea (Italia, Alemania, Francia, Holanda) y en segundo lugar a Norteamérica. A una distancia considerable se encuentran países asiáticos (Japón y Corea). En los últimos años los recursos no han aumentado, en algunos casos disminuyen y en otros se mantienen (EC-01).

La agenda de los donantes o de las entidades intermediarias no siempre coincide con la de las ONG colombianas. En ocasiones muchas incorporan los ejes a su propia agenda modificando algunas áreas de trabajo y diversificando sus intervenciones: «Muchas han respondido a la demanda de las agencias internacionales que periódicamente indican los ejes sobre los cuales hay que trabajar, hay algunas que pueden mantenerse a pesar de esa demanda. CINEP ha logrado mantenerse por tratarse de una entidad grande y que pertenece a la Compañía de Jesús» (EC-07).

Esta entrevistada apunta, a partir de la expresión «mantenerse», en la dirección de la fidelidad o coherencia con la identidad de la organización. Deja constancia de que hay algunas entidades que, desconociendo la trayectoria y el seguimiento de unos criterios ideológicos o políticos, adaptan sus objetivos y formas de organización a las exigencias realizadas por las agencias internacionales. En este sentido, también advierte la necesidad de reflexionar sobre el papel de éstas y propone una serie de preguntas que giran alrededor de la siguiente cuestión:

¿Qué papel están jugando las agencias internacionales en América Latina? ¿Están entrando a mediar y a fortalecer o a suplantar y colonizar? ¿Son conscientes de la incidencia social, política y cultural de sus acciones? Por una parte hay un gran voluntarismo, otras se mueven con macroproyectos sociales 
que desconocen lo político, que es fundamental. Se preguntan por el impacto económico y social, pero no se cuestionan lo político, que es la base de los proyectos que estamos acompañando (EC-07). ${ }^{132}$

En este sentido, otras ONG colombianas (Redepaz, Región, IPC...) coinciden en el papel fundamental de «lo político». Parten de un diagnóstico social fundado en la escasa vinculación de la población en procesos participativos de construcción y consolidación de la sociedad civil. Creen que la gente no debe pedir caridad, están en la obligación de exigir derechos, y la exigibilidad de éstos es un proceso político lento de construcción de ciudadanía, pues opinan que en el país no hay conciencia plena del papel que cumplen los ciudadanos y del que debería cumplir el Estado que se define como «social de derecho».

Este tipo de ONGD afirma que muchas agencias no desean involucrarse en «lo político» por evitar conflictos de intereses con el Estado, pero estas organizaciones son tajantes en afirmar que nunca habrá procesos de transformación si no se resuelve el conflicto social por el cual una parte considerable (quizá mayoritaria) de la población está excluida de la vida económica, social, política y cultural del país.

No obstante, el papel de los donantes externos en los proyectos es muy diverso. Los entes que hacen donaciones no intervienen directamente para indicar actuaciones concretas o prohibiciones explícitas. Sin embargo, las políticas generales que establecen los grandes organismos multilaterales y los estados del «Norte» sí tienen una influencia considerable sobre las organizaciones locales. Por ejemplo, «la cooperación de los Países Bajos o de la UE ha llegado a afirmar tajantemente: "Proyecto que no tenga contemplado el tema de género es un proyecto que tiene menos opciones"» (EC-01).

En una de las entrevistas realizadas a una líder de mujeres del Chocó, se dialogaba sobre las agencias y los Estados que contribuían con recursos para apoyar a ciertos colectivos, y se evidenció que, en algunos casos, en el

132 En el plano teórico merece la pena plantear, a la luz de la antropología del desarrollo, y concretamente de las posturas de Foster (1969) y Kottak (2000), las siguientes preguntas: ¿las agencias de desarrollo, como expresiones institucionales de una sociedad determinada, tienen una cultura propia? En caso de ser afirmativa la respuesta, ¿en qué consiste esa cultura? 
proceso de identificación de los problemas tienen mayor implicación las organizaciones sociales que las propias comunidades locales:

A la Red de Mujeres del Chocó le ayuda el Fondo de Género del Canadá, porque ellos quieren establecer la cultura de la igualdad de género en todas las relaciones que se tienen acá y fortalecer la participación de la mujer en la parte política y también cualificarla para que ellas puedan estar en los procesos de fortalecimiento civil (EC-02).

Cuando se refiere a que «ellos quieren establecer la igualdad» posiblemente está dando a entender que no es un objetivo implícito de las mujeres de la zona, porque quizá no hay una identificación plena con la problemática de la desigualdad de género en el territorio, ya que ubica en terceras personas o entidades la preocupación por la inequidad y su necesidad de reducirla. Esta situación tampoco representa una imposición o un desacuerdo fundamental entre las comunidades y las organizaciones, pero sí discute los argumentos que defienden que los procesos de cambio deben provenir desde «adentro» y desde «abajo».

En otro proyecto en el departamento de Bolívar unos voluntarios aragoneses llevaron a cabo acciones de formación en derechos humanos y percibían desequilibrios en las relaciones de género. En ese contexto, durante los cursos «se introdujo perspectiva de género y respeto del medio ambiente» debido a que "esa cultura campesina y minera es muy machista, como en toda Colombia, pero en un sitio tan cerrado, más» (EE-05).

En los casos anteriores podemos hacer la siguiente reflexión: de la forma de plantear la identificación del problema se puede inferir que el valor de la igualdad jurídica y social entre los sexos está mucho más arraigado entre los integrantes de la entidad canadiense y aragonesa que entre los ciudadanos de base. Precisamente en el Chocó, como en otras regiones del pacífico colombiano y de la costa atlántica (Bolívar), están presentes prácticas poligámicas muy arraigadas ${ }^{133}$ que no siempre son objeto de consideración por parte de los organismos que intervienen en el territorio. ${ }^{134}$

133 Virginia Gutiérrez de Pineda (1996) clasifica la poligamia de las comunidades del Chocó como poliginia dispersa, a través de la cual un varón soltero tiene una constelación de co-esposas que viven en diferentes unidades habitacionales.

134 Ante este tipo de situaciones cabría preguntarse: ¿para llevar a cabo la perspectiva de género, como elemento transversal, debe una ONG oponerse a las prácticas poligámicas de determinadas comunidades étnicas? 
Además, puede resultar paradójico la expresión «establecer la igualdad»o «introducir la perspectiva de género», puesto que la igualdad es un procesos de "cambio de normas, valores, actitudes y percepciones necesarias para alcanzar un estatus» determinado, ${ }^{135} \mathrm{y}$ dicho proceso pasa por el empoderamiento de los propios sujetos, "cambiando las relaciones de poder en favor de aquellos que con anterioridad tenían escasa autoridad sobre sus propias vidas» (Sen, 1995). Precisamente, el establecimiento de esta pauta de interacción manifiesta una relación desigual, donde una entidad establece una serie de valoraciones culturales por la vía de la financiación económica y el apoyo técnico. De esta manera se socializan valores por parte de una influencia educativa externa.

Hay un caso contrario, a través del cual también se pueden generar cambios en las relaciones de género, por medio de vías endógenas que los mismos sujetos han ido descubriendo y, por tanto, haciendo suyas. Cuando asesinan a un hombre de una región como el Chocó, son varias las mujeres que quedan viudas. Por tanto, el número de viudas es muy superior al de maridos asesinados. Aunque inicialmente muchas de estas mujeres decían «no ser nada, con muchos hijos y sin maridos» (EC-03), poco a poco se han ido organizando para compartir experiencias, acompañarse mutuamente y emprender acciones de supervivencia económica. Actualmente existe una Red de Mujeres del Chocó que trabaja para constituir "una mujer apropiada de los problemas de su comunidad, ayudando a otras mujeres, en permanente transformación, posicionada, con alto valor moral, capacitada, crítica, participativa, autodirigida...». ${ }^{136}$

Asimismo, en una de las más grandes organizaciones del Chocó (COCOMACIA) se creó hace unos años la Comisión de Género. Ésta pretendía promover la participación de las mujeres en las asambleas de la organización, y, para tal fin, fomentaba la concienciación de los hombres para que reconocieran el derecho de éstas a intervenir en las decisiones de la organización y respetaran el "uso cívico de los tiempos de su esposa» (EC-03), una idea compleja en el contexto. Actualmente los avances de la

135 Conceptos de género del PNUD para El Salvador: <http://www.genero-pnud.org. sv> (enero de 2005).

136 Visión de la Red Departamental de Mujeres del Chocoanas. Portafolio de Servicios. Quibdó, septiembre de 1992. 
Comisión se evidencian en la afluencia de mujeres en las asambleas y en la posibilidad de hablar por sí mismas. La exposición de estos casos quiere dejar en evidencia la posibilidad de avanzar en la igualdad de género, pero esos avances dejan un sedimento de fortalecimiento grupal e identitario cuando la necesidad es identificada y sentida por los protagonistas de los procesos sociales y cuando la liberación de las mujeres no implica la imitación fidedigna de procesos y actitudes externas a su cultura. ${ }^{137}$

De otro lado, las entidades colombianas valoran los procesos de identificación y formulación de los proyectos cuando son fruto del consenso y el diálogo: "Con los médicos [Médicos del Mundo Aragón] estamos concertando una propuesta sobre cómo se quería un proyecto y qué era lo que la gente esperaba con esa financiación» (EC-03).

Durante la visita a las ONG colombianas se ha apreciado claramente una diferencia en cuanto a la percepción que tienen éstas respecto a «las entidades extranjeras». Las ONG colombianas más sólidas y con una trayectoria superior a una década conocían los procesos históricos y sociales de fortalecimiento de la sociedad civil en Europa y Estados Unidos. Sabían que habían sido luchas, conflictos y manifestaciones entre asociaciones, sindicatos, ONG y otros grupos frente a los Estados y organismos multilaterales. Por tanto, conocían las reivindicaciones de los primeros y las condiciones de los segundos; en ese plano de conocimiento, la comprensión frente a la razón de ser de determinadas orientaciones, propuestas y prioridades partía de una identidad como actores sociales motivados por causas con cierto grado de afinidad. Comprendían los procesos históricos europeos que habían llevado al reconocimiento de los derechos de la mujer, la infancia y el respeto del medio ambiente, por ejemplo. En tal sentido, esta comprensión e identidad corporativa entre ONG colombianas y aragonesas caracterizan su pertenencia a la sociedad civil global (Mary Kaldor, 2003). En este contexto, destaca la importancia creciente de las alianzas entre las entidades locales e internacionales, ya que han demostrado que el vínculo local-nacional-global suele ser efectivo, tal como se evidenció en la campaña mundial para evitar la perforación de yacimientos petrolíferos en el territorio de los U'wa. Tal como sostiene Arenas (2004, 326), «la exis-

137 Para profundizar en la relación entre género y desarrollo desde perspectivas teóricas críticas ante el eurocentrismo, ver Shiva (1989) y Escobar (1996). 
tencia de ONG internacionales facilita el proceso de transnacionalización de las luchas sociales, [aunque] el éxito y potencial emancipatorio [de éstas] depende en buena parte de las organizaciones locales, que tejen y recrean día a día el "polo a tierra" de una lucha social concreta».

No obstante, el tipo de vínculo internacional y el acercamiento a las contrapartes del «Norte» ha estado, hasta hace unos años, más disponible en las organizaciones grandes y urbanas, integradas por personas con formación en ciencias jurídicas, económicas o sociales. Quienes han conocido en Colombia la historia de las ONG del «Norte», la trayectoria de su acción social, denuncia y reivindicación, han tendido a comprender e identificarse con las luchas o causas concretas que se habían desarrollado en el continente europeo o en EE. UU.

Por su parte, las ONG más pequeñas, recientes y rurales, con personal menos cualificado, han estado, hasta hace muy poco, al margen de los procesos y luchas sociales de carácter global. Por tanto, algunas causas específicas (género, medio ambiente...) les han llegado como "caídas del cielo». Para una de las entrevistadas, las preocupaciones que han traído las organizaciones extranjeras ha dependido del «auge» o del «boom del momento», ya que han desconocido la matriz socio-histórica que ha llegado a convertir ciertas causas en metas legítimas para la humanidad, y de repente ven como son una prioridad insoslayable: «En la última década están apoyando proyectos que tienen que ver con mujeres, derechos humanos, [...], según el auge que haya $[. .$.$] . Hay unas que son el boom del momento» (EC-02).$

En contra, uno de los entrevistados colombianos de una organización grande expresa su afinidad con los procesos sociales vividos en Europa:

Allá también ha habido conquistas de movimientos sociales europeos con los que yo soy totalmente solidario, me parece fantástico que hayan logrado que la cooperación tenga planteamientos de ese tipo [género], pero uno se tiene que plantear frente a eso con estatura, puede ir a la casa de la agencia y hablarlo, o hacer, como han hecho muchas, de asumir los temas de género como su agenda propia, con muchas discusiones y problemas, pero ahí van. Con esto quiero decirte que hay una interrelación que no es blanco y negro» (EC-01).

Además, el enunciado "plantarse con estatura» significa la posibilidad de una ONG colombiana de ir, en condiciones de igualdad, a hablar con la entidad que financia o gestiona los recursos para los proyectos de desarrollo. (Un ejemplo de este tipo puede verse en el anexo 4.) De hecho, el mismo 
entrevistado sugiere que también ha habido ejemplos claros que ilustran la influencia desde el «Sur» hacia el «Norte». Cita como ejemplo uno de los temas que se ha incorporado a la agenda de los donantes y que ha sido propuesto por las organizaciones colombianas:

También hay una influencia de aquí para allá; hay un ejemplo muy claro: el tema del desplazamiento forzoso. Si por el Estado colombiano hubiera sido, ese tema aún estaría oculto; han sido las ONG las que lo han puesto en la agenda pública internacional, de tal manera que hoy ese tema es una prioridad en varias de las convocatorias a proyectos. En este caso tenemos una acción positiva de aquí hacia allá que ha afectado la agenda de los donantes (EC-01).

El caso del desplazamiento forzado ${ }^{138}$ (ver anexo 5) fue planteado por varias entidades como un paso importante en la consecución de relaciones más equitativas por parte de los diferentes actores de la cooperación. Es una relación que empieza desde las propias comunidades afectadas. Muchas de ellas, ante el silencio inicial de los instituciones públicas y los escasos esfuerzos de las privadas, empezaron a tomar, pacíficamente, iglesias y despachos de la Administración Pública (fue reiterativa la toma de oficinas de la Defensoría del Pueblo y sedes de Pastoral Social de varias diócesis colombianas). De este modo, se alertaron las organizaciones cercanas a la población desplazada y con capacidad de hacer oír su voz, ${ }^{139}$ que a su vez transmitieron y denunciaron, a nivel nacional e internacional, las dimensiones reales del problema.

Otro factor común, casi unánime, en la distinción de la cooperación internacional fue la presencia de dos modelos de cooperación, no sólo diferentes, sino en algunos casos contrapuestos: el europeo y el norteamericano. La noción de "modelo» no sólo hace referencia a los procedimientos para materializar la cooperación, sino que parte fundamentalmente de la concepción del conflicto armado en Colombia. Un integrante de una ONGD aragonesa, con gran experiencia en la cooperación, aceptaba el

138 «El problema de los desplazados internos en Colombia es una de las situaciones más graves del mundo. Hay más de dos millones de desplazados internos y día a día esta cifra aumenta producto de la violencia política asociada al conflicto armado interno", Alto Comisionado de las Naciones Unidas para los Refugiados. ACNUR. Oficina para Colombia (2004).

139 UNICEF-Colombia reivindica, junto con el Comité de Derechos Humanos CODHES, ser la primera entidad que hizo público el problema del desplazamiento interno en Colombia. 
ejercicio de la presión internacional sobre Colombia, pero a partir de dos concepciones claramente diferenciables: «Estados Unidos cree en la solución de muchos problemas a través de la opción militar; sin embargo, Europa presiona a través de la exigencia del respeto a los derechos humanos» (EE-01). Un caso concreto y bastante reciente fue el Plan Colombia. Muchas ONG españolas y europeas presionaron a los países de la UE para rechazar la vía militar expuesta en el Plan, y promovían el fortalecimiento de la sociedad civil como paso fundamental para la convivencia.

Otra entrevistada también coincide en diferenciar las formas de hacer cooperación desde las dos visiones opuestas; se adhiere a la visión norteamericana la forma de trabajar del Banco Mundial a las que denomina «sudor y lágrimas», en la medida que conciben el desarrollo como una meta, fruto de un sacrificio fiscal y social previo. Desde esta visión, «hay que amarrarnos ahora para que el desarrollo nos llegue después» (EC-07).

Desde Europa el modelo se basa en el desarrollo centrado en las capacidades. No obstante, deja claro que el marco de las políticas europeas de cooperación tiene la valoración del papel de las capacidades específicas, pero una vez en el terreno algunos aspectos, como la participación comunitaria, no se llevan a cabo plenamente. En este sentido, hay una flexibilidad en el modelo, pero bastante rigidez en la aplicación y seguimiento de las fases más técnicas del proyecto.

Uno de los aspectos que más resaltaron algunas organizaciones sociales fue la importancia del apoyo en la divulgación y la denuncia que realizaron ONGD aragonesas respecto a las condiciones de vida de muchos habitantes en determinadas regiones como el Chocó y Bolívar. Muchas organizaciones colombianas se quejan de no ser escuchadas y atendidas por instituciones oficiales y multilaterales, pero han encontrado una vía para hacerse oír. Ante la queja de las organizaciones colombianas del silencio e indiferencia sistemática de las instituciones del Estado, las entidades de base han creado y fortalecido canales de comunicación ${ }^{140}$ con sus

140 Por ejemplo, las más difundidas en el contexto aragonés son las realizadas por el Comité Óscar Romero con el boletín OCOTE Encendido, ASA, a través de la revista $Y$ el Sur y el Comité de Solidaridad Internacionalista, a través de Gallopinto. Además casi todas organizan jornadas con invitados de las comunidades a las que apoyan. A través de la página web de CASCOL se difunden manifiestos, denuncias o declaraciones de sus contrapartes en Colombia. 
homólogas aragonesas para que éstas reproduzcan quejas, denuncias o propuestas ante las instancias gubernamentales del país. De esta forma lo expresaba un integrante de COCOMACIA:

Frente a lo político, para nosotros es muy difícil acceder a las instancias de decisión política, pero es más fácil a un organismo internacional llegar a ese tipo de espacios. La propuesta de acuerdo humanitario lo publicó el Comité Óscar Romero y otras ONG de la zona, lo repartieron a diferentes partes del mundo, y mucha gente leyó eso y le escribió al Gobierno, y queda muy feo, pero funciona, que una entidad de España le diga al Gobierno central o departamental las necesidades y propuestas que tiene la gente de aquí. Muchas veces es más importante el apoyo político en las propuestas locales que el económico (EC-03).

Esta trayectoria de búsqueda del eco internacional para hacer llegar la información a la Administración del Estado y ejercer presión para la solución de necesidades o respeto a ciertos derechos es un tema bastante amplio en la historia de la cooperación internacional con Colombia. Por ejemplo, nueve cooperantes aragoneses que integran la Coordinadora Aragonesa de Solidaridad con Colombia (CASCOL) participaron en agosto de 2001 en una caravana por el sur de Bolívar; ${ }^{141}$ esta caravana constituyó un hecho de presión política y mediática sobre la situación de aislamiento de los pobladores de la zona que tenían limitadas posibilidades de abastecerse de recursos básicos debido a un bloqueo de los paramilitares. ${ }^{142}$

Sin embargo, no todas las organizaciones se ven obligadas a recurrir al apoyo internacional para ejercer presión política. Grandes organizaciones como la delegación de la UNICEF en Colombia tienen la posibilidad de exponer las condiciones de vida del grupo poblacional al que atiende: "UNICEF hace una pequeña abogacía ante el Gobierno, después de visitar varias poblaciones, regresamos a Bogotá y, como tenemos acceso al Gobierno, puedo llamar a la ministra de Educación y decirle que en determinado pueblo de Cauca todavía los profesores castigan físicamente a los

141 La delegación aragonesa fue la más numerosa entre 67 representantes de varios países de Europa y Norteamérica.

142 La estrategia de bloqueo, también utilizada en el Atrato, es un conjunto de acciones militares por las cuales se «le quita el agua al pez» para que éste muera. Tanto la guerrilla como los «paras» impiden, a través del cierre de vías de transporte, el suministro de alimentos o víveres a ciertas zonas de difícil acceso para que los supuestos «auxiliadores» en logística del bando opuesto, es decir, la población civil, carezca de los recursos más básicos que les lleve a su debilitamiento o aniquilamiento. 
niños» (EC-04). Contar con una representación en la capital del país es una fortaleza que no todas las ONGD pueden tener, especialmente en un país tan dependiente del poder central como es éste.

No obstante, la ubicación en una capital de departamento o en la capital del país no es el elemento más importante para ser escuchado por las instituciones oficiales; tienen un papel más relevante el peso político de ciertos grupos de presión pertenecientes a la sociedad civil y, de manera menos evidente, la pertenencia a una elite política y económica con influencia personal, incluso familiar, sobre funcionarios que desempeñan cargos políticos distinguidos. El caso de algunas organizaciones de origen religioso, asociaciones asistencialistas fundadas por esposas de presidentes, ${ }^{143}$ gobernadores y alcaldes, fundaciones de grandes empresas que dedican recursos para realizar obras sociales, son un tipo de organizaciones que, puntualmente, ejercen influencia para atender, de manera específica y sin comprometer política y judicialmente a una institución oficial, problemáticas concretas de algunas poblaciones en riesgo.

En los casos de AMAT y Entreculturas la operatividad de las ONG está en una estrecha relación con las estructuras previas existentes a niveles de redes compuestas por comunidades religiosas, entidades educativas y parroquias que poseen una presencia territorial que en la mayoría de los casos se pone a disposición de la ONGD. Estas estructuras facilitan la instalación de la entidad, se convierten en un factor de protección y garantía en la ejecución y seguimiento de los proyectos.

Respecto al origen de AMAT, uno de sus representantes comentó que surgió de una persona que, con un grupo de laicos que integraban la familia marianista, decidió «echar una mano» a la labor de los marianistas en Colombia:

él lo coordinó siempre con el apoyo de los religiosos, que tenían ya sus estructuras, por ejemplo para el envío del dinero, de una forma fácil, rápida y segura... Además ellos te hacen de filtro, hay gente que te pide ayuda, ellos están allá, y tienen una visión un poco más objetiva (EE-06).

143 Por ejemplo, una de las más conocidas en el país es Solidaridad por Colombia, fundación creada por la ex esposa del presidente de Colombia Julio César Turbay (1978-

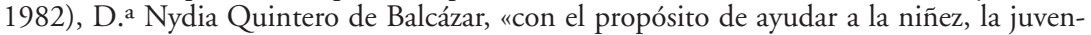
tud y a las familias más necesitadas del país», <http://www.conexion-colombia.com/ content/page.jsp?ID=3749> (junio de 2005). 
Por otra parte, para otros Estados, organismos multilaterales y agencias de cooperación, Colombia no es un país prioritario en la cooperación internacional, ya que su índice de desarrollo humano (IDH) lo ubica en una valoración media. ${ }^{144}$ Sin embargo, algunas ONGD españolas, como las aragonesas en las que hemos centrado el estudio, conocen las grandes desigualdades internas de países tan heterogéneos como Colombia. Por ejemplo, según el índice de desarrollo humano (IDH) Colombia se sitúa dentro del desarrollo humano medio en el puesto 73, con un IDH de 0,773 (PNUD, 2003); sin embargo, si se analizara este indicador por departamentos, el Chocó, con un IDH de 0,669, estaría situado en el lugar 117 (entre Mongolia y Nicaragua). Por su parte, Bogotá subiría al lugar 51, con un desarrollo humano alto, por encima de Cuba y México. Desde la mirada internacional, regiones empobrecidas como el Chocó se hacen invisibles al ser incorporadas en un listado de cifras globales que desconoce y oculta las particularidades regionales.

En las siguientes líneas se describirán las condiciones en las que se lleva a cabo la cooperación en este departamento, ya que es muy representativo en cuanto al olvido y desconocimiento por parte de las políticas gubernamentales para el desarrollo. Un grupo reducido de ONGD, entre las que se encuentran algunas entidades aragonesas (Comité Óscar Romero, ASA, Manos Unidas, Médicos del Mundo, AMAT), está contribuyendo a denunciar las difíciles condiciones de vida de quienes habitan esta parte de la costa Pacífica de Colombia.

Para una líder de mujeres del Chocó el «sistema de concesión de proyectos y ayudas está diseñado para favorecer a las entidades grandes» (EC02) de la región andina ${ }^{145} y$, por tanto, para perpetuar la situación de las organizaciones nuevas y pequeñas. Siente que las entidades adscritas a

144 La cooperación oficial aragonesa es uno de ellos: «dos son los criterios que van a determinar las prioridades geográficas de la política de cooperación aragonesa y que, por tanto, se reflejarán separadamente en la valoración técnica de los proyectos: el menor índice de desarrollo humano (IDH), publicado anualmente por el PNUD, y la ubicación dentro de Latinoamérica, África subsahariana y Magreb», Gobierno de Aragón (2004, 17).

145 En Colombia existen cinco regiones naturales y culturales diferenciadas: en la Andina están las grandes ciudades como Bogotá, Medellín y Cali y viven la mayor parte de los habitantes. Las otras cuatro regiones son la Costa Pacífica (donde está el Chocó), la Costa Caribe, los Llanos Orientales y la Amazonía. 
Fedechocó no son consideradas como entidades sólidas para servir de interlocutores ante sus contrapartes internacionales. ${ }^{146}$

Las organizaciones del Chocó somos consideradas como menores de edad, ${ }^{147}$ dicen que tenemos poca capacidad administrativa, baja capacidad organizativa, o sea, hay una crítica negativa al proceso organizativo que venimos haciendo desde hace años, y eso es lógico, porque como no hemos tenido contratación directa, eso nos resta puntos. Para mí eso es un círculo vicioso: si nadie te da recursos para administrar, nunca vas a coger experiencia en ello, y las ONG internacionales siempre piden ese tipo de experiencia (EC-02).

Hay algunas excepciones a esta tendencia. Por una parte, hay ONG sectoriales que responden a una moda, según la entrevistada, «el boom del momento». En el Chocó existe cierta preferencia por las ONG y las agencias internacionales especializadas en medio ambiente. ${ }^{148}$ Según la Federación Chocoana de ONG (Fedechocó), en este momento son las que más están recibiendo ayuda. Esta situación se explica por el valor de la selva del Darién (Chocó tiene la mayor parte), que es una reserva ecológica mundial, y hay muchas agencias y ONG que están interesadas en contribuir a la preservación de la selva tropical húmeda. Lo que preocupa a Fedechocó es que sea un interés coyuntural que se traslade en unos años a otro sector o problema de mayor relevancia internacional.

La visión que tienen en Fedechocó de la cooperación española pasa por relacionarse con proyectos que «tienen que ver con el clero; a la Iglesia cató-

146 Ella sólo identifica a las organizaciones internacionales, pero las entidades del país también tienen la misma consideración.

147 Los prejuicios frente a los chocoanos son innumerables, la mayoría basada en su color de piel. Mucha gente en Colombia, especialmente las clases medias de los grandes centros urbanos, justifica la pobreza del departamento del Chocó por «motivos culturales» o "porque son vagos o corruptos». "Son pobres porque son negros», me decían algunas personas en Medellín antes de viajar a Quibdó para hacer las entrevistas. Es una tendencia a naturalizar las consecuencias de acciones humanas para que resulten obvias, legítimas y naturales. Este tipo de percepciones coincide con la que tienen en diferentes planos las alteridades geográficas y económicas. En Colombia, los estereotipos más extremos se encuentran entre los cachacos (región andina: Bogotá, Medellín...) frente a los costeños (mar Caribe). De esta forma Gabriel García Márquez (2002, 54-55) se refiere a los cachacos: «Esa noche le escuché a mi abuela la explicación de siempre: "una cosa tan horrible sólo pudo hacerla un cachaco". Los cachacos eran los nativos del altiplano, y no sólo los distinguíamos del resto de la humanidad por sus maneras lánguidas y su dicción viciosa, sino por sus ínfulas de emisores de la Divina Providencia».

148 Para el análisis de las ONG ambientalistas en el Pacífico colombiano, ver Escobar (1996 y 1999). 
lica le apoyan mucho proyecto» (EC-02). ${ }^{149}$ Para varias ONGD aragonesas, las diócesis de Quibdó y Apartadó son contrapartes relevantes con las que han trabajado desde hace varios años. De hecho, un informe de la Oficina en Colombia del Alto Comisionado de las Naciones Unidas para los Derechos Humanos $(2002,25)$ resalta el papel de una de ellas: en cuanto a la protección y atención a al población desplazada, "La oficina reconoce los esfuerzos realizados por [...] la diócesis de Quibdó». Aunque la relación no se ha fundamentado exclusivamente en entidades confesionales, ha tenido sus orígenes en la presencia de los seglares claretianos por más de veinte años en el departamento del Chocó. En Aragón las ONGD que han trabajado con dicha diócesis han incluido entidades con vinculaciones religiosas (Comité Óscar Romero, Seglares Claretianos) y otras sin afinidad religiosa (Acción Solidaria Aragonesa y Médicos del Mundo Aragón).

Uno de los aspectos que más se valora por parte de esta Federación es la actitud de diálogo y negociación con el que se acercan algunas agencias y ONGD del «Norte». Se sienten escuchados y valorados, en sus palabras, "cuando hay un nivel de interlocución y horizontalidad con la entidad con la que van a trabajar, se logran negociar algunos aspectos del proyecto, lo cual redunda en una mejor ejecución de los proyectos y obtener un impacto real en la comunidad» (EC-02). No obstante, desde esta zona se percibe que "hay entidades que vienen con los esquemas muy rígidos, y aplican el proyecto tal como lo han diseñado desde Europa y Estados Unidos»; en estos casos, "la cooperación no logra hacerse amiga» de la gente, trae sus acciones demasiado cerradas. Según esta líder, ese tipo de cooperación "nos hace daño, porque cuando las cosas son tan acartonadas no dejamos establecida en la región una capacidad humana para cuando el proyecto salga o la agencia se vaya, esa gente que quedó capacitada quede independiente y pueda proseguir con el programa, o pueda cooperar con otros que vienen surgiendo. No queda establecido un capital social cuando esa cooperación es tan vertical; ahí hay un problema en eso» (EC-02).

En este sentido, algunos líderes de asociaciones de mujeres, campesinos o de los grupos étnico-territoriales del Chocó coinciden en la importancia de instalar una capacidad local permanente que supere la tempora-

149 A pesar de que la pregunta hacía referencia a Aragón, su respuesta, como la de otros entrevistados, iba dirigida a hablar de España. 
lidad de los proyectos. Temen que, cuando los proyectos terminen y las ONGD se vayan, no haya autonomía en las organizaciones para continuar con los procesos. Son conscientes de que los cambios ocurren con mucha lentitud, pero son optimistas frente a la posibilidad de transformación. En el caso del sur de Bolívar ocurre una situación similar en cuanto a la valoración de las actuaciones que tengan un impacto perdurable en las comunidades:

Si nos dedicáramos a hacer puestos de salud o escuelas en el sur de Bolívar, en cualquiera de las incursiones se hubieran arrasado, si formamos a 14 líderes y nos matan a 4, quedan 12, y seguirán [...], creemos que esto es más sostenible, más estable en el tiempo y transforma más la realidad de la gente (EE-05).

En el taller realizado con los integrantes de la Asociación Campesina Integral del Atrato (ACIA), se insistió en el fortalecimiento de las capacidades locales a partir de las condiciones específicas de las comunidades y su territorio. Creen que, en algunas ocasiones, los proyectos se plantean desde "arriba» y desde "afuera», esto es, la ONGD extranjera consigue un donante y le plantea a la organización de base que proponga un proyecto ajustado a los parámetros del donante. En ese sentido, el proyecto es una respuesta metodológica y operativa que obedece a una oferta de recursos y no a un plan de acción colectivo legitimado desde la base y prolongado en el tiempo.

Cuando se hace la intermediación, vienen las condiciones, te dicen «presente una propuesta, pero en esto y esto", y en algunas ocasiones nos quedamos cortos con cosas que necesitamos y obtenemos otras que no necesitamos... Hay algunas ONG que vienen a imponer sus criterios, incluso nos ha tocado enfrentarnos a algunas de ellas que han pretendido imponer unas pautas y hemos tenido que negociar cosas antes de aceptar la ayuda. No aceptamos el dinero si no hay concertación previa (EC-03).

Esta organización campesina sugiere que los donantes podrían establecer contactos directos con las organizaciones de base; de esta forma se fortalecería el diálogo alrededor de las expectativas presentes en ambas partes, y podrían crear consensos en cuanto a los objetivos de las actuaciones: "si tuviéramos una interlocución directa con las agencias, éstas conocerían de primera mano las necesidades de la gente» (EC-03).

También trabajan, junto a un Foro Interétnico en el que hay varias ONG del medio Atrato, en la elaboración del Plan de Etnodesarrollo que 
establezca unas líneas generales de intervención en la zona que sean definidas por los actores sociales y a las que se deben ajustar los donantes y las ONGD nacionales e internacionales (ver anexo 4). "Buscamos que primero nos conozcan antes de que nos ayuden, que conozcan el Foro de Solidaridad; son políticas de sobrevivencia, primero buscamos preservar la vida y luego promoverla» (EC-03).

En el apartado anterior uno de los entrevistados solicita ser conocido antes de aceptar ayuda. En esa línea, una de las entrevistas en la ciudad de Bogotá planteaba un ejemplo concreto frente a lo que ella considera como parte del desconocimiento mutuo, y tiene que ver con la percepción de la sociedad colombiana desde las formas de mirar la realidad en un contexto cultural diferente:

Cada país viene con su bagaje cultural y nos mira desde su cultura. España llega con la percepción que tienen a partir de la polarización que viven allá entre izquierda y derecha. Ellos no se ubican aquí por los términos de la comprensión de su mundo. Creen que aquí en el país se vive lo mismo, y toman posición en una percepción que no corresponde a la realidad. ¿¿Hasta dónde sus percepciones del mundo se asumen y se trasladan a ese otro mundo que es distinto? (EC-07).

A pesar de que la persona entrevistada no desarrolla la idea que afirma la inadecuación de la percepción de la sociedad colombiana por parte de observadores españoles, es posible suponer que se refiera a la dificultad para encuadrar el modelo político bipolar izquierda-derecha en los partidos políticos colombianos. En caso de ser así, existirían argumentos sólidos para sustentar dicha afirmación. Por ejemplo, el Partido Liberal Colombiano, del que hizo parte hasta hace pocos años el actual presidente Álvaro Uribe Vélez y los ex presidentes César Gaviria (1990-1994) y Ernesto Samper (1994-1998), es miembro de la Internacional Socialista, que entre sus principios consagra la «lucha tradicional por la libertad, la justicia y la solidaridad con un profundo compromiso por la paz». ${ }^{150} \mathrm{Sin}$ embargo, sus posturas frente al diálogo con los grupos guerrilleros han sido más inflexibles que las del último presidente del Partido Conservador, Andrés Pastrana (1998-2002), que se entrevistó con el máximo líder de las FARC, Manuel Marulanda Vélez, para iniciar un proceso de paz al inicio

150 <http://www.socialistinternational.org/4Principles/dofpspa2.html\#valor> (24 de agosto de 2005). 
de su mandato. Asimismo, algunos historiadores revelan el modo artificial como algunos partidos de izquierda en Colombia firmaban su adscripción al ideario socialista:

Mientras en el viejo continente el desarrollo del capitalismo y sus estragos sociales habían originado la «utopía» socialista como posibilidad de responder adecuadamente a las necesidades colectivas, en la Nueva Granada apenas empezaba a prefigurarse una burguesía con ansias de desembarazarse de una herencia colonial y encontrar caminos para emprender la liberalización de la economía. El contrasentido de la nueva generación de dirigentes fue tener un discurso impregnado de socialismo utópico y pugnar al mismo tiempo por alcanzar el socialismo. Con tamaña contradicción, [...] tenía razón el periodista francés Charles Mazade cuando en 1852 criticaba la tendencia a la imitación superficial «sin elección, sin medida, sin discernimiento» de todas las influencias provenientes de Europa (Aguilera y Vega, 1998, 107).

Además de las diferencias del contexto político, los últimos entrevistados citados hablan de "bagajes culturales" y "conocimiento" previo de la cultura. Las diferencias culturales en el ámbito de la cooperación internacional al desarrollo son otro ámbito poco investigado en España; sin embargo, los últimos congresos nacionales de antropología están empezando a interesarse por esta temática, ${ }^{151}$ al igual que los recientes trabajos de Gimeno y Monreal (eds., 1999), Viola (2000) y Bretón (2001).

Hay algunas acciones cooperantes, la mayoría de las veces complementarias o inconscientes, que podrían denominarse como "conservacionistas culturales». Son acciones que tienden a estar encaminadas para que los pueblos no "pierdan su cultura». El problema es que, en ocasiones, lo que el «extranjero» (bogotano, madrileño o "gringo») supone es «rasgo cultural» no siempre coincide con las pautas nativas. Un ejemplo de este conservacionismo artificial lo conocí durante el trabajo de campo en el Chocó. Las comunidades afro-descendientes celebran el día de la africanidad, hacen fiestas que establecen determinados vínculos con algunas tradiciones africanas. Sin embargo, estos vínculos tienen ingredientes que han ido incorporando gradualmente en su interacción histórica con otras pautas culturales del contexto (caribeña, católica, castellana, indígena o anglosajona). Es, en esta relación, como surgen los sincretismos religiosos (donde

151 Los últimos congresos (IX Congreso de Antropología en Barcelona, 2003, y X Congreso de Antropología en Sevilla, 2005) han dedicado grupos de trabajo y simposios sobre la antropología del desarrollo y sobre el papel del antropólogo en las ONGD. 
el vudú y el catolicismo son compatibles) y las hibridaciones culturales (García Canclini, 1989). A pesar de estas mezclas, algunos extranjeros se esfuerzan, a veces con más pasión que los propios chocoanos, para que ellos «recuperen»su africanidad. El ejemplo en cuestión radicaba en los intentos de una voluntaria extranjera en convencer a una familia chocoana para que bautizara a su hijo recién nacido con un nombre africano, y desistieran del empeño en ponerle un nombre más común en la región, aunque no por ello más «autóctono». ${ }^{152} \mathrm{El}$ niño finalmente fue bautizado con el nombre africano, pero los familiares y amigos le llamaban, como si fuese un apodo, por el nombre anglosajón. Cuando se decide, conscientemente, preservar una práctica o costumbre, es porque quizá ésta ha muerto. Ante el esfuerzo de recuperación de la memoria colectiva y el anhelo comunitario por fortalecer la identidad cultural, determinados ritos se reinventan a través de una reproducción artificial objetivada como folclore. Precisamente, una de las características de la cultura es que actúa a través de nosotros sin darnos cuenta.

\subsubsection{Confianza y reciprocidad: la relevancia del capital social}

La presencia de algunas organizaciones aragonesas en Colombia tiene su origen en la relación personal o familiar de sujetos que, por motivos diversos, se desplazaron al país o conocieron en España alguna región o persona que despertó en ellos el interés por apoyar a un grupo o causa concreta. En la década de los setenta y ochenta se trataba de vinculaciones con personas cercanas a la Iglesia católica, especialmente misioneros, seglares, sacerdotes jóvenes en formación pertenecientes a congregaciones de trayectoria en América Latina (jesuitas en la enseñanza, misioneros franciscanos, claretianos, salesianos, agustinos recoletos, carmelitas, hermanas de la caridad...). «Aquí hay una relación, un conjunto de relaciones de más de treinta y cuarenta años, una relación que vino a través de la Iglesia, aunque después se ha diversificado en pequeñas y grandes organizaciones laicas» (EE-03).

152 Muchos de los nombres más comunes en la región son de origen anglosajón: John, Richard, Fredy, Esteward, Steven..., que se funden con apellidos de mayor trayectoria en la región (Mosquera, Perea, Mena...). Es un tipo de modernización simbólica que huye de la tradición africana, combatida hasta la saciedad como obstáculo al desarrollo cultural. Esta hibridación onomástica expresa el anhelo por ascender en el estatus a través del prestigio social que proporciona un nombre propio. 
En los últimos años las relaciones se han secularizado, pero siguen teniendo un fuerte componente primario. En otros términos podemos referirnos al papel del capital social ${ }^{153}$ en la cooperación. Algunas entrevistas dejaban entrever el peso del conocimiento mutuo, la confianza y la amistad entre los integrantes de las entidades aragonesas y colombianas: «la relación de afecto ha sido el origen de muchos proyectos, son relaciones de muchos años» (EE-03). La historia de la presencia de ASA en Colombia se explica desde esta perspectiva:

Es una relación que empezó desde hace muchos años: fue un cura que fue allí y se casó y luego lo mataron y la viuda vino aquí. En Aragón hay mucho de esto, relaciones personales que duran mucho tiempo, [...]. En la zona de los caños de Riosucio, la comunidad de Cañoseco, que retornó después de un desplazamiento [...], esa comunidad recordaba que hacía quince años iban unas enfermeras de Zaragoza a bañarse al río y tomar el sol en traje de baño. Eran enfermeras del Hospital Miguel Servet, probablemente llegaron allá por la relación de un claretiano que había en Riosucio, esto hay que rastrearlo (EE-03).

La llegada de ASA y del Comité Óscar Romero al Chocó tuvo que ver con las relaciones previas entre voluntarios de estas ONG y los claretianos. Diez años antes de la llegada de estas organizaciones, los claretianos empezaron a trabajar en el Chocó, y con el tiempo, las visitas a los proyectos en los territorios, el conocimiento personal, la venida a Zaragoza de colombianos, se fueron «institucionalizando» las relaciones de cooperación a través de convenios entre las organizaciones y los colegios, las diócesis o las organizaciones sociales:

En 1975 se hizo un convenio entre los claretianos de Aragón y los de Colombia occidental, por lo cual iba gente al Chocó, íbamos a colaborar con los claretianos de Colombia occidental que tenían misión en el Chocó. Eso llevó por primera vez a personas de aquí de Aragón a trabajar por el Chocó en diferentes sitios, ahí se fue generando una relación de cercanía (EE-04).

153 Según Bourdieu (2001), «el capital social es el conjunto de los recursos actuales o potenciales vinculados a la posesión de una red duradera de relaciones más o menos institucionalizadas de interconocimiento e interreconocimiento; o dicho de otro modo, a la pertenencia a un grupo en tanto en cuanto que conjunto de agentes que poseen no sólo propiedades comunes (capaces de ser percibidas por el observador, por los demás o por ellos mismos) sino que están también unidos por vínculos permanentes y útiles [...] el volumen de capital social que posee un agente social depende de la extensión de la red de vínculos que puede movilizar efectivamente, así como del volumen del capital (económico, cultural o simbólico) que cada uno de aquellos a los que está vinculado posee en propiedad». 
Había - y hay - cooperantes y misioneros que pedían dinero o ayuda para enviar cosas a Colombia; el entorno de esas personas era la base o el complemento para apoyar determinados proyectos. La confianza ha sido uno de los aspectos más importantes para establecer y fortalecer dichos canales de cooperación, y en las relaciones familiares o fraternales este componente suele estar presente.

En el caso del Comité de Solidaridad Internacionalista la relación con las organizaciones y comunidades colombianas, concretamente en el sur de Bolívar, no surgió por vínculos personales o religiosos; reconocen que «fue algo ocasional» y que su búsqueda se ha basado en que las comunidades «sean capaces de recibir brigadas, delegaciones o acompañamientos, [...] surgía de nuestra preocupación por la violación de los derechos humanos» (EE-05).

En ese sentido, la zona geográfica no era criterio o requisito para la llegada de la entidad; lo importante era ayudar «no a los que más lo necesitan, sino a los que intentan transformar la realidad; nuestra contraparte es un grupo, una comunidad que intenta transformar su realidad» (EE05).

Como otras entidades, también invitan a representantes de organizaciones o a líderes comunitarios que, a través de jornadas, charlas o encuentros, promueven la sensibilización y la denuncia. Además de los objetivos explícitos de las visitas mutuas, este hecho reviste fortalecimiento de la confianza mutua:

algunos líderes han estado aquí, vienen a contarnos directamente su proyecto de vida, hemos organizado unas dos o tres giras, nosotros vamos allí, nos metemos en sus comunidades, vivimos con ellos, entonces es una relación de igual a igual, y muy de hermanamiento (EE-05).

Y aunque otras entidades como AMAT hayan surgido y trabajado a través de relaciones institucionales previas, el valor que conceden al conocimiento personal con los integrantes de la contraparte es muy similar a entidades que fueron construyendo gradualmente una mínima estructura de relación: «Estamos coordinados con los religiosos de allá; hay una gran ventaja y es que algunos hemos estado allá, nos conocemos personalmente, hay una amistad real, eso ayuda muchísimo: la confianza que te dan, la seguridad en todo momento» (EE-06). 
Actualmente, las vías para el surgimiento de nuevos canales no institucionales de cooperación están cambiando. Son otros los vínculos que, basados en la presencia de extranjeros en Aragón, se empiezan a perfilar como nuevas matrices creadoras de relaciones de cooperación internacional.

Con la inmigración colombiana en Aragón está ocurriendo un proceso de creación de canales de cooperación que abren los inmigrantes que tienen un fervor solidario y establecen redes con españoles para, conjuntamente, redactar proyectos, solicitar subvenciones, visitar bancos o hacer de intermediario entre entidades aragonesas y grupos de población que viven en condiciones precarias en Colombia. La asociación de inmigrantes colombianos en Aragón, Colombia Unida-ACULCO, tiene entre sus «fines prioritarios: colaborar con entidades sin ánimo de lucro que persigan la mejora de la situación social de la población en Colombia», y en sus actividades, la "canalización de recursos o donaciones destinadas como cooperación al desarrollo para zonas marginales en Colombia». ${ }^{154}$ Además, hay personas de origen colombiano que han empezado a vincularse como voluntarios a organizaciones no gubernamentales, asociaciones de vecinos, sindicatos o comunidades parroquiales que tienen algún nivel de apoyo a países como éste. El caso de la asociación AESCO en Madrid es un claro ejemplo de la tendencia al surgimiento del codesarrollo que puede darse en Aragón en pocos años. ${ }^{155}$

\subsection{Cooperar en medio del conflicto armado}

\subsubsection{Las organizaciones aragonesas}

Las opiniones de las organizaciones aragonesas presentes en Colombia sobre las dificultades para obtener respaldo en los proyectos de cooperación en este país suele estar vinculadas al contexto social y político del conflicto armado. Para algunas, conseguir financiación para proyectos en

154 Estatutos de la Asociación Colombia Unida, constituida el 18 de abril de 2002 y reconocida por el Gobierno de Aragón en septiembre de 2002.

155 AESCO es una de las pioneras en el codesarrollo hispano-colombiano. En el departamento de Risaralda gestiona un proyecto superior a los 150000 euros con recursos del Ayuntamiento de Madrid y del Ayuntamiento de Alcobendas (AECI, 2006). En el contexto aragonés hay asociaciones de inmigrantes que empiezan a trabajar en dicha modalidad (Aculco-Colombia Unida). 
Colombia es más difícil que para otros países, ya que «cuando se trata de catástrofes sí apoyan, pero por conflictos no» (EE-08); la percepción que tienen algunos cooperantes y voluntarios es que «ante las emergencias todo son facilidades, pero ante algo estructural, nada» (EE-08). Otra persona afirmaba al respecto:

De cara a la cooperación es muy complicado; la gente dice: "¿ayudamos o no donde hay un conflicto?» [...] la perspectiva nuestra ha sido acompañar esos procesos, se sigue trabajando como si no hubiera guerra; si hay gente con proyectos de futuro, hay que seguir apoyando el desarrollo en medio de la guerra; lo que no se puede hacer es la tendencia de "como hay guerra, entonces no se puede apoyar porque se pierde la ayuda». Entonces, ¿qué esperas? ¿A que se acabe la guerra, muera la gente o esperar un convenio nacional o yo qué sé...?, ¿y después ir con ayudas para que la gente empiece de cero? Mientras haya gente nativa en los sitios que esté luchando por la vida, no sólo ayuda humanitaria (si lo piden), sino de proyectos de salud, de una biblioteca, si ellos siguen en ese proyecto de construir futuro, hay que apoyarlos así estén en conflicto (EE-04).

Hay quien incorpora el conjunto de fenómenos sociales que afectan al país como algo "complejo» y «complicado» a la decisión de no trabajar con este país: «no mucha gente, ONG, trabaja con Colombia; el conflicto, la droga debe condicionar el trabajo» (EE-07). Como hemos afirmado en otros apartados, muchas de las personas entrevistadas utilizan el adjetivo «complejo» para calificar a Colombia. Sin embargo, recurriendo a Morin (1990), sabemos que la complejidad no es una atribución intrínseca de los objetos, sino una percepción de los sujetos. Casi por unanimidad, los entrevistados consultados atribuyen el adjetivo a este país, pues el tipo de fenómenos que se suceden se caracterizan no sólo por la dificultad para comprenderlos y explicarlos, sino por la constante presencia de las incertidumbres. También debemos señalar que la capacidad de los voluntarios y cooperantes para hablar del país varía considerablemente en función de si lo han visitado o no, y en segundo lugar, del período de estancia en él. El nivel de las respuestas de las personas indagadas en el estudio permite deducir que cuanto más desconocido es el país, mayor es la sensación de complejidad.

Por otra parte, hay quienes atribuyen la decisión de cooperar en Colombia a un tipo de organización que no está dispuesta a asumir altos riesgos: «Las ONG tradicionales no trabajan allí porque hay un alto riesgo para los cooperantes» (EE-05). No obstante, según una entrevistada, el 
problema se fundamenta en «las financieras» más que en las organizaciones no gubernamentales: «No es fácil que las financieras apoyen a Colombia, por parte de las ONG no hay problema, pero no es fácil que las financieras se decidan, porque tienen un grado de dificultad añadido; para Nicaragua o Guatemala es muy fácil, pero Colombia...» (EE-09). Las reticencias que influyen a "las financieras» tienen que ver principalmente con la preocupación respecto a la posición política e ideológica de las contrapartes y su posible vinculación con los actores armados.

Respecto al desplazamiento de voluntarios, cooperantes y brigadistas, las opiniones están divididas y muy matizadas, no defienden una posición a favor o en contra, sino que condicionan la respuesta a las necesidades específicas del proyecto o actividad y de los objetivos de la entidad.

Se puede ir, pero a la orden de... En los casos de conflictos quien mejor sabe lo que pasa es la gente de allí; hay zonas en las que no hay tejido asociativo y se puede y debe apoyar la formación de ese tejido, pero con un cuidado exquisito, para que no te conviertas en el líder; va alguien de fuera del país y puede haber una sensación de seguridad muy ficticia (EE-03).

Por tanto, frente a este tipo de voluntariado no puede emitirse una valoración generalizada. Ha habido diversas experiencias de voluntariado que han sido consideradas por la propia organización en función de su metodología y concepción de la cooperación. Algunas lo promueven y otras evitan desplazar a estas personas. En algunos casos se han tenido en cuenta situaciones en las que, en lugar de impulsar y fomentar el trabajo de los proyectos, el voluntariado ha representado dificultades en aspectos organizativos. Una de las entrevistadas de una organización colombiana lo resumía de esta forma:

También venían unos voluntarios con la intención de ayudar a la gente, [...] pero no se puede ejercer sobre ellos la misma presión de rendimiento laboral que se le puede pedir a un empleado, [...] en ocasiones no ha habido oferta de voluntarios, entonces teníamos mucha incertidumbre; además, la condición de voluntarios implicaba que se interrumpían procesos y que no había dedicación plena (EC-05).

Hay otras opiniones que están a favor del envío de voluntarios pero bajo condiciones específicas; por ejemplo,

Siempre hay que mirar lo que dice la gente del país, en lo posible; cuando va gente de fuera, tiene que estar claro que el tipo de servicio profesional se multiplique o no pueda ser suplida por alguien del país; yo prefiero que el 
dinero lo organicen desde allí, yo he ido como voluntaria, a integrarme con gente que trabajaba desde allí [...]. [Además], el profesional de allí no siempre quiere desplazarse a una zona de riesgo (EE-04).

En muchos casos ha habido situaciones en las que un profesional colombiano no puede o quiere desplazarse a una zona de enfrentamientos por evitar los riesgos implícitos en el conflicto. Como hemos hecho referencia en otros apartados, la condición de español o europeo se convierte en un factor protector (no de inmunidad) que privilegia determinados tipos de voluntariados o cooperantes. En cuanto a los cooperantes que financian directa o indirectamente las agencias de cooperación, una entrevistada comentó lo siguiente:

Hay un tipo de cooperante que es que pacta Gobierno-Gobierno: De aquí [España] van técnicos a formar en cooperativas a técnicos de allí; eso es una opción que puede estar bien, pero que no puede cuestionar al Gobierno colombiano, porque si eso ocurre, se corta... En esta línea, muchos cooperantes deben ser conscientes que estarán promoviendo un tipo de desarrollo (EE-04).

Un tipo de voluntariado que se ha puesto en práctica en Colombia es el de las brigadas. En este sentido se han realizado brigadas de paz y caravanas como la del sur de Bolívar en 2001. Este tipo de voluntariado se basa en el acompañamiento a procesos llevados a cabo por comunidades y en la denuncia de determinadas situaciones que les afectan.

Para los cooperantes y voluntarios aragoneses que se han desplazado a Colombia existe un código cultural propio del conflicto armado que es necesario aprender a descifrar para desenvolverse en el país. Su experiencia en el terreno les proporciona un tipo de socialización que facilita su desenvolvimiento en las acciones cotidianas y en las situaciones de riesgo. Aunque algunos se preparan previamente, ${ }^{156}$ sólo la estancia en el campo permite adquirir las herramientas necesarias para descifrar dichos códigos.

156 La mayoría de ONGD ofrece formación a sus voluntarios y personal contratado. InteRed ofrece un "curso taller de formación para el voluntariado internacional». Asimismo, el Comité de Solidaridad Internacionalista de Zaragoza ofrece formación a sus voluntarios: «todos los brigadistas reciben formación previa, [...] lectura de documentación que el Comité facilitará». Tríptico del Comité. Otros leen por su cuenta o se entrevistan con personas que han estado allí. El Centro Pignatelli de Zaragoza se ha convertido en un espacio de referencia para talleres, seminarios y conferencias en la materia, así como las cuatro versiones del curso de cooperación que ofrecen la FAS, la Universidad de Zaragoza y el Gobierno de Aragón. 
Por ejemplo, una de las situaciones vividas por voluntarios aragoneses en Colombia ha sido el pago de peajes ilegales ${ }^{157}$ para cobrar un tipo de «impuesto de circulación». En general, corresponde a «una serie de requisitos que se han convertido en habituales en el contexto del conflicto armado. En las brigadas de paz pasamos por peajes ilegales de los "paras" y pagamos 20000 pesos. Además, nos "pidieron" que transportáramos personal armado y materiales de los paras y el ejército, etc.» (EE-01). ${ }^{158}$

Cuando los cooperantes y voluntarios se encuentran en Colombia tienden a normalizar este tipo de situaciones que en un contexto como el español resultarían fuera de lo común. Por otra parte, algunas ONGD colombianas han tenido que pagar «vacunas». El término "vacuna» está asociado en Colombia a un tipo de sacrificio preventivo expresado en el pago de una cantidad de dinero para evitar riesgos inminentes, es decir, secuestros, asesinatos o desplazamientos forzosos. La diferencia entre el peaje ilegal y la vacuna se encuentra no sólo en la cantidad, sino en la finalidad de la acción. El peaje ilegal consiste en el pago de pequeñas cantidades para todos los vehículos o personas que circulan por una vía bajo el control de uno de los grupos armados. En ese sentido tiene un carácter ocasional y aleatorio. Por su parte, la «vacuna» es una estrategia logísticomilitar de captación sistemática de fondos a personas concretas con una supuesta solvencia económica.

En las entrevistas con voluntarios aragoneses se hace una referencia al término «impuesto revolucionario» ${ }^{159}$ en lugar del termino "vacuna». La

157 El cobro de peajes ilegales es una acción bastante frecuente en América Latina. En determinados barrios periféricos los habitantes bloquean las calles a los coches para cobrar una cantidad de dinero que puede constituir una contribución a la reparación de la vía, a fondos comunes del barrio o a un negocio particular de algún vecino. Asimismo, puede tener fines políticos o delincuenciales: según el Centro de Investigaciones Económicas y Políticas de Acción Comunitaria (CIEPAC) de México, la organización Paz y Justicia ha mantenido desde 1995 el cobro de peajes ilegales para la compra de armas. En Argentina, la Coordinadora contra la Represión Policial e Institucional (CORREPI) denuncia la existencia de escuadrones de la muerte que cobran peajes ilegales en compañía de grupos de delincuentes.

158 Como hemos afirmado anteriormente, los "paras» son los paramilitares, y 20000 pesos equivalen a siete euros aproximadamente. El caso descrito ocurrió a finales de los noventa.

159 En España el término «impuesto revolucionario» tiene que ver con la estrategia utilizada por ETA para la captación de fondos. Los métodos de ETA incluyen el envío de cartas amenazantes a empresarios, en las que se exige el pago de una determinada cantidad de dinero a cambio de que su patrimonio, e incluso su integridad física, no corran peligro. 
utilización del primer concepto es una acción que pretende familiarizar una situación ajena, no sólo para entenderla, sino, especialmente, para explicarla en el regreso. El conocimiento de otros contextos pasa por la asociación a situaciones más cercanas o familiares.

La organización Médicos del Mundo Aragón afirma no haber recibido, además de los peajes y exigencias logísticas, presión directa en las zonas de mayor incidencia del conflicto; «sin embargo, la sola presencia armada es intimidatoria por parte de los actores del conflicto. La diócesis de Quibdó [su contraparte], sí recibe amenazas directas, ha sido considerada como blanco por parte de todos los actores armados. Ha sido directa y crítica en la denuncia de la violación de los derechos humanos» (EE-01). ${ }^{160}$

Desde InteRed sí han recibido amenazas directas cuando trabajaban en el Chocó: "La que era delegada de InteRed antes tuvo que salir de Colombia de un día para otro, estaba en Chocó, y vino a España, Aragón, a trabajar como delegada. Y Elia Fleta es colombiana y es nieta del tenor Fleta y tuvo que salir...» (EE-07).

Esta socialización también es facilitada por la cercanía cultural entre España y Colombia. Cercanía que va más allá de las razones a las que frecuentemente se recurre para explicar los fenómenos de integración cultural de los inmigrantes latinoamericanos en España y españoles en América Latina (influencia de los valores religiosos del catolicismo, la similitud lingüística que proporciona el castellano...) y tiene que ver con ciertas formas afines a la racionalidad occidental. ${ }^{161}$ El siguiente apartado de una entrevista ejemplifica esta afirmación con una comparación de otros conflictos:

A pesar de la complejidad y crueldad del conflicto armado, no se puede comparar con otras regiones en conflicto como los Balcanes y África. Y no sólo se trata del idioma, se trata de los esquemas de pensamiento; dentro de lo absurdo de la violencia, la colombiana tiene cierta "lógica interna», hay un

160 Esta es una de las diócesis que más expone a la luz pública sus denuncias. De hecho, protagoniza titulares en el diario de mayor circulación en Colombia: «Iglesia denunció que la fuerza pública es tolerante con los paramilitares en el Chocó. Las diócesis de Quibdó, Istmina-Tadó y la de Apartadó [Antioquia] advirtieron sobre la "grave situación" que soportan las comunidades negras. [...] los obispos cuestionaron la acción de las autoridades, y manifiestan su desconcierto "por unas situaciones absolutamente inaceptables en un Estado de derecho"", El Tiempo, 4 de mayo de 2005.

161 En este contexto hacemos referencia a la racionalidad descrita por Max Weber como elección racional de unos medios para alcanzar determinados fines (Ritzer, 1993). 
tipo de racionalidad que el cooperante español puede entender, puede suponer en los actores del conflicto: el establecimiento de retenes, peajes, puede ser violento, pero lo entiendes. Es una racionalidad violenta, pero se pueden entender las posturas; el choque cultural es menos fuerte que en África o Asia (EE-01).

Este tipo de racionalidad tiene que ver con la previsibilidad de las conductas. Hay un tipo de expectativas sobre las conductas violentas en que el amenazado sabe que, si paga y se expresa oralmente, existe la posibilidad de ser comprendido y de poder recibir, a cambio, el respeto a la vida. Se puede establecer un diálogo no verbal, se interpretan los gestos, se presuponen las posibles reacciones.

Otra de las entrevistadas aragonesas afirmaba que la posibilidad de trabajar en países como Colombia se basa en el entendimiento mutuo. Resaltaba la importancia de coincidir en diversas pautas de interacción; exponía como ejemplo los hábitos de ocio, ya que en los momentos de tensión, propios de los acuerdos entre personas o entidades que intermediaban en el conflicto, el hecho de compartir códigos similares (hacer descansos para tomar un café, disfrutar de la música o de unas bebidas) permitía el acercamiento y la resolución de situaciones cargadas de tensión. "Yo estuve trabajando en el conflicto de la ex Yugoslavia, pero no pude, no sé qué fue, pudo ser la cultura, pero la amargura era tremenda; en Colombia estamos atrapados anímicamente, hay una calidad extraordinaria que construye constantemente vida y paz» (EE-03).

El tema de la seguridad es uno de los que preocupa a los cooperantes y voluntarios aragoneses que viajan a Colombia. Sin embargo, la mayoría de los entrevistados coincidieron en afirmar que ser y parecer español era un factor protector. En el caso del Comité Internacionalista, «siempre es protector, aunque se asumen niveles de riesgo, caerán muchos colombianos antes que cooperantes, [...]. Desde luego no es igual que un colombiano, eso seguro, está claro. [...] es algo que da seguridad a quien está acompañando. Si le pasa algo a un internacionalista, hay un coste político muy fuerte para el Gobierno de Colombia»(EE-05). No obstante, para otros voluntarios ha habido una percepción elevada del riesgo: «los grupos de delincuencia común, o las guerrillas, te ven como una fuente de dinero; alguna vez me sentí observado, tenía que tener muchísimo cuidado en los viajes, los religiosos me decían que si podía ir en avión, aunque fuese mucho más caro, para evitar riesgos» (EE-06). 
A pesar de que la mayoría de los entrevistados está de acuerdo en contratar personal del territorio en lugar de contratar cooperantes aragoneses, también reconoce que en tareas específicas, como los servicios de salud en zonas rurales, "el profesional de allí no siempre quiere desplazarse a una zona de riesgo» (EE-04). Otros sitúan diferentes factores protectores ante el riesgo como el azar, el conocimiento, la habilidad y el soporte institucional. Uno de los entrevistados comentó: «Tuve la fortuna de viajar, ver muchos sitios, por suerte que no me secuestraran, tuve mucha suerte, no me pasó nada» (EE-06).

Sin embargo, en esto coinciden varios cooperantes y voluntarios aragoneses que han estado en Colombia: el problema del riesgo no lo tiene el cooperante, es una situación que afecta a una población y, por extensión, a quienes pertenezcan o se acerquen a ella. En todo caso, dejan claro que la presencia de cooperantes extranjeros no garantiza la inmunidad:

El problema de afrontar la seguridad/inseguridad es un problema del conjunto de los habitantes de la zona que está padeciendo el conflicto, con las dificultades que esto conlleva, pero que esté un «blanquito» no hace nada, salvo que ese blanquito que se plante sea Jimmy Carter (EE-03).

Para la mayoría de las organizaciones fue un gran impacto el asesinato en noviembre de 1999 de Iñigo Eguiluz, cooperante vasco de la ONG Paz y Tercer Mundo (PTM), que navegaba por el Atrato con el sacerdote Jorge Luis Mazo de la diócesis de Quibdó. En este sentido, la organización vasca y su contraparte eclesial también habían recibido presiones por parte del paramilitarismo: ${ }^{162}$

La diócesis de Quibdó y la Organización Internacional Paz y Tercer Mundo desde tiempo atrás venían siendo objeto de una serie de señalamientos por su labor de denuncia y acompañamiento humanitario a favor de las

162 En el informe de la ONG Equipo Nizkor (2002), la organización señala a este grupo armado como culpable: «Los paramilitares estacionaron la embarcación con la que ocasionaron el crimen en una barcaza ubicada a escasos metros del puesto fluvial de la Policía de Quibdó». El Periódico de Aragón, en su edición del 17 de octubre de 2004, recogió la noticia de la sentencia dictada al asesino de Iñigo de esta forma: «Condena al asesino de un español en Colombia. EFE. La sentencia, de 32 años de cárcel, fue dictada ayer por un tribunal colombiano contra Jimmy Matutte Palma, miembro del grupo paramilitar derechista Autodefensas Unidas de Colombia. Matutte ha sido condenado por la muerte del joven cooperante bilbaíno Iñigo Eguiluz Tellería, asesinado en 1999, junto al sacerdote José Luis Mazo». 
comunidades afectadas por los crímenes ocurridos en el medio y bajo Atrato desde 1996, al ser catalogada su actividad evangelizadora y humanitaria como una labor al servicio de la insurgencia (Equipo Nizkor, 2002, 1).

El caso del sacerdote asesinado pasó más desapercibido, pues, como hemos afirmado en otros apartados, las víctimas colombianas tienen menos relevancia mediática que las extranjeras; además, el clero en Colombia se ha convertido en un blanco militar para los actores armados: 32 sacerdotes han sido asesinados entre el año 2000 y el 2005 a manos de los actores del conflicto. ${ }^{163}$ Los actores responsables de estos asesinatos han sido los paramilitares y los grupos guerrilleros. Por ejemplo, los últimos asesinatos (antes de terminar la redacción de este informe) fueron cometidos por el Ejercito Nacional de Liberación: «ELN se responsabiliza y pide perdón por crimen de sacerdotes Jesús Emilio Mora y Vicente Rosso» ( $E l$ Tiempo, 20 de agosto de 2005). Por su parte, los paramilitares han asesinado y amenazado a sacerdotes por ser supuestos colaboradores de las guerrillas. En el mismo texto de la noticia anterior se recoge el caso de un cura español: «el párroco de Uribe (Meta), el español Ricardo Cantalapiedra, fue acusado de colaborar con la guerrilla de las FARC».

El caso de asesinato a cooperantes y voluntarios españoles o de otros países extranjeros no ha sido similar, en términos cuantitativos, a los ataques sufridos por éstos en otros países en conflicto de África u Oriente Medio. Como hemos afirmado, ser y parecer extranjero es un factor de protección para el personal que trabaja con ONG locales y comunidades urbanas y rurales, debido al coste político que implicaría para sus autores cometer este tipo de crímenes.

No obstante, para su «seguridad», la OTC de la Embajada española en Bogotá entrega unos carnés para el registro de los cooperantes y voluntarios españoles que entran a Colombia; con todo, «estos carnés no suponen privilegio o inmunidad algunos para el titular y están sujetos a una serie de normas de buen uso. El titular se compromete a su devolución una vez haya acabado su período de vigencia. Tienen como objetivo la acreditación por motivos de seguridad y son verificables a través del servicio tele-

163 Según cifras de la Conferencia Episcopal Colombiana (CEC), publicadas por la Agencia Católica de Informaciones de América Latina en su página web: <http://www. aciprensa.com/>, ACI digital, Bogotá, 17 de agosto de 2005. 
fónico de 24 horas de la Embajada» (AECI y ACCI, 2003, 42). A pesar de estos dispositivos, en determinadas actuaciones como la Caravana de 2001, la Embajada española «no apoyó la expedición por considerar que no contaba con medidas de precaución necesarias para internarse en esa zona». ${ }^{164}$

\subsubsection{Organizaciones locales}

A diferencia de las entidades aragonesas, la mayoría de sus contrapartes en Colombia sí ha sufrido algún tipo de amenaza o agresión violenta. En este sentido, las organizaciones colombianas tienen un amplio bagaje de experiencias y tragedias debido al trabajo en medio del conflicto armado. Según la CCONG, el papel de las ONG en el conflicto armado se puede resumir en tres frentes de trabajo:

(1) evitar los dolores que toda guerra trae a la población y actuar como muro de contención a los actores ilegales, (2) como escenario para la discusión y planteamiento de distintas alternativas, propuestas e ideas para afrontar el conflicto, reparar a las víctimas y producir ideas de paz, (3) y finalmente, en un eventual postconflicto, para colaborar en la construcción posterior de una sociedad que permita la consolidación de la paz. En efecto, para superar el conflicto curando las heridas y permitiendo salidas éticamente productivas, es necesario fortalecer a la sociedad civil y, dentro de ésta, a las organizaciones no gubernamentales (Querubín, 2003, 8).

Sin embargo, tal como veremos más adelante, incluso las federaciones de ONG tienden a reproducir la polarización política e ideológica que acompaña el conflicto armado, especialmente cuando se debate en torno a temas como la relación con el Gobierno nacional y la forma de entender el propio conflicto.

Precisamente hace unos años surgió la Federación de Organizaciones No Gubernamentales Verdad Colombia, que «fue creada en Bogotá por un grupo de colombianos dedicados al estudio del conflicto armado colombiano, interesados en defender los principios de la democracia y la libertad de empresa». Dicha Federación reúne a un grupo de veintidós ONG radicadas en diferentes regiones, y se dedica «al estudio de grandes

164 «La Caravana por la Vida atravesaba una zona en disputa entre guerrilla y paramilitares», El País, Madrid, 8 de agosto de 2001. 
problemas nacionales como son: i) La agresión armada a la sociedad democrática, [...] v) La desinformación» (Verdad Colombia, 2005). Para esta Federación, la democracia colombiana es «asaltada por organizaciones terroristas que desean imponer por la fuerza sus doctrinas». Dicha postura difiere considerablemente de la CCONG (que agrupa más de 1000 $\mathrm{ONG}$ ), que reconoce la existencia de "grupos insurgentes y de autodefensas» y sostiene que "la paz exige un ordenamiento social justo» en el contexto de «una democracia en construcción» (Querubín, 2003, 9).

En cuanto al trabajo que realizan las contrapartes de las organizaciones aragonesas, debemos resaltar, antes de analizar las situaciones a las que se enfrentan durante la ejecución de los proyectos, y más aún, a través de su presencia en los territorios, que existe una fuerte presión socio-política hacia las entidades locales que se manifiesta en dos sentidos. Por un lado, un tipo de influencia directa por parte de los actores políticos y armados, y por otro, una influencia difusa y múltiple que proviene de su imagen pública entre los ciudadanos.

Los campesinos del medio Atrato (Chocó) consideran que los atropellos por parte de los actores armados contra los líderes de las organizaciones sociales no son hechos aislados ni fortuitos. Por el contrario, aseguran que hay una estrategia para debilitar el tejido social que se ha ido construyendo paulatinamente y de este modo evitar los señalamientos, las críticas y las denuncias que realizan para defender sus derechos respecto a estos grupos violentos:

Allí lo que estorba es que haya gente, y que esté organizada; ellos han ido consiguiendo cosas a partir de una ausencia del Estado, la gente ha conseguido logros políticos con esfuerzo; resistir es mantenerse en el territorio, « inos mantenemos en el territorio porque es nuestro!», porque la experiencia en otros sitios es que, cuando la gente sale, el mismo actor armado que llega trae su gente, tanto los paramilitares como la guerrilla (EE-04).

Asimismo, insisten en que la cooperación internacional debería ser más consciente de esa estrategia para, según ellos, no «seguir el juego» apareciendo en los territorios afectados sólo cuando hay desplazamiento o masacres:

La estrategia del propio conflicto pasa por la desarticulación de los procesos sociales y la cooperación está jugando a eso, y nuestra propuesta política se va a quedar rezagada, tendremos una sociedad civil desorganizada y desarticulada. La cooperación española debe diseñarse a largo plazo; por supuesto 
que la emergencia hay que atenderla, pero, si no va vinculada a una propuesta más amplia, a más largo plazo, cuando pase la emergencia nos vamos a encontrar con una sociedad que no tiene para dónde caminar (EC-03).

La preocupación de las entidades locales está fundamentada en una perspectiva estructural, y, por tanto, temen las consecuencias de un trabajo coyuntural basado en la atención de emergencias.

En el plano económico, las tiendas comunitarias son una estrategia económica y de comercialización. Muchas comunidades a las que les llega la ayuda humanitaria les dicen a los que la proporcionan: «no nos den comida, dennos la plata para montar una tienda comunitaria». Esto es una visión a largo plazo, lo importante es resaltar que esto no se hace en todo el Chocó, porque no se ha ganado en conciencia política, y cuando llegan las ONGD, éstas invierten y hacen lo que les da la gana, y el impacto que dejan no es deseable; en estos casos se cumple con el donante pero no con la comunidad. (EC-03).

Algunas organizaciones aragonesas como ASA y Óscar Romero tienen una larga trayectoria en el apoyo a las tiendas comunitarias; éstas surgieron como una estrategia de supervivencia ante los bloqueos de los sectores armados, y los propios campesinos reconocen la conveniencia de ellas en la región, ya que, aunque hayan surgido como respuesta a una emergencia humanitaria, esta estrategia no ha sido efímera y se ha basado en los procesos organizativos de la comunidad. Dicha estrategia ha permitido el retorno de algunos desplazados o la permanencia de pobladores que han podido resistir. Sin embargo,

Hay una gran dificultad para que los sectores armados entendieran que la gente llevaba un proceso, no es que la gente no llevara nada, a los sectores armados les gusta que no haya nada organizado, para ellos, de alguna manera, ir llevando sus propuestas organizativas. Pero ellos, al encontrarse con un proceso organizativo donde la gente tenía unos planteamientos, incluso hacia el futuro..., entonces eso trae una dificultad con todos, tanto con la guerrilla como con los paramilitares; llegan los paramilitares y ven lo que hay, y dicen: «eso es comunismo, eso no vale», y después llega la guerrilla y dicen: «eso no es nada, tienen que apoyarnos, si no es un problema»... (EE-04).

A algunos líderes locales les preocupa saber lo que podría ocurrir ante el supuesto caso de una negociación entre el Estado y los actores armados ilegales, temen que se interrumpan los procesos, se den por resueltos los problemas sociales y no permanezca una base asociativa sólida que promueva los cambios que reclaman desde hace varias décadas. Por esta razón, y tal como lo afirma Aristizábal $(2004,10)$, «es necesario que, mientras se 
inicia la negociación, se amplíe el apoyo a los esfuerzos que muchas comunidades, movimientos sociales y gobiernos municipales o departamentales están realizando por la democratización de la sociedad, de sus instituciones públicas y de los sistemas productivos».

En el caso de la asociación campesina, insisten en recordar que dicha organización no nació como respuesta a los efectos del conflicto armado, sino por la insatisfacción de la población ante tantas necesidades desatendidas por el Estado (educación, salud, infraestructuras...) y por la defensa histórica de su territorio (lucha por la titulación colectiva de la tierra). Trabajan, y especialmente animan a cooperar, en aras de fortalecer los procesos que generen capacidades locales que trasciendan la coyuntura del desplazamiento o el bloqueo alimenticio. En este sentido, la experiencia de cooperantes aragoneses en las zonas conflictivas también constata los riesgos indirectos de esta situación: el trabajo en cooperación debe girar en torno a un «intento por minimizar impactos negativos de la ayuda humanitaria tales como la dependencia y la destrucción de redes locales de sostenimiento que siempre se dan entre las poblaciones que padecen un conflicto» (Reclusa, 2004, 189).

Asimismo, los propios líderes de la zona del medio Atrato advierten el peligro de intervenciones humanitarias exógenas (que podrían provenir, en la línea argumentativa que venimos desarrollando, tanto de Bogotá como de Zaragoza) que no atiendan los procesos organizativos que se vienen realizando con el tejido social de la región y proporcionen material o apoyo en situaciones puntuales. "Buscamos que las intervenciones humanitarias no dividan a la comunidad; si se atiende a desplazados pero no se atienden a los que ya estaban allí, esto genera divisiones en la comunidad, y así no se puede» (EC-03). En la mayoría de las entrevistas realizadas en el Chocó se exponía como ejemplo la masacre de Bojayá, un municipio del medio Atrato en el que fueron asesinadas 111 personas como resultado del enfrentamiento de la guerrilla y los paramilitares. ${ }^{165} \mathrm{El}$ caso represen-

165 La Oficina en Colombia del Alto Comisionado de las Naciones Unidas para los Derechos Humanos (2002) declaró en su informe: «Las FARC-EP tienen responsabilidad en la muerte violenta de más de 100 civiles, las lesiones de 80 personas y destrucción de bienes civiles, causadas por el lanzamiento de pipetas [bombonas] en el marco de un enfrentamiento armado con un grupo de paramilitares» (p. 17). El grupo paramilitar denominado Autodefensas Unidas de Colombia tiene también responsabilidad de los hechos [...] por haber expuesto a la población civil a los peligros de las acciones militares (p. 20). 
ta una crítica, en cuanto resulta paradójica la posterior presencia en el municipio de varias ONGD nacionales e internacionales a las que se habían pedido intervenciones preventivas ante la inminencia de los hechos; esta paradoja disgustó a algunos miembros de organizaciones sociales y lamentaron la llegada masiva a la zona sin contar con las entidades que venían trabajando en el municipio:

Una muestra fue Bojayá, allá sucede la tragedia, caen integrantes de nuestra red de mujeres, hicimos un SOS internacional y llegaron un montón de ONG, pero llegaron de una vez allá, no se articulan para poder hacer un trabajo coordinado, cada cual dice «lo mío es esto y de ahí no me puedo salir porque mi mandato es éste» (EC-02).

Respecto a las dificultades que afrontan las contrapartes locales de las entidades aragonesas, en primer lugar señalaremos cuál ha sido el tipo de presión al que han estado sometidas y cuáles han sido algunas de las respuestas.

En 1997 la Federación de ONG de Antioquia emitió un comunicado público por el cual expresaba su declaración de neutralidad activa respecto a los actores armados del conflicto.

Considerando que el país vive un conflicto armado irregular, [...] que afecta a la población civil, [...] y que los diversos actores violan los derechos humanos y el Derecho Internacional Humanitario, resolvemos: 1. Declararnos en pacto de neutralidad activa. Esto significa: a) que ninguna organización, ni sus miembros, ni las actividades que realizamos, sirve a los intereses de alguno de los actores armados; y $b$ ) que no somos indiferentes. 2. Exigir a los actores armados el respeto a nuestra decisión. 3. Exigir al Gobierno nacional y departamental las garantías necesarias para el desarrollo de nuestras actividades. 4. Trabajar por la construcción mancomunada del Estado colombiano (ENS, 2004, 42).

De esta declaración podemos resaltar algunos aspectos: por una parte, el reconocimiento, y a la vez denuncia, de que todos los actores violan una serie de derechos, ${ }^{166}$ lo cual le permite demostrar, a quienes sostienen la vin-

166 Jurídicamente, los grupos armados no estatales violan las normas generales del derecho penal, el derecho internacional humanitario, los convenios de Ginebra y sus protocolos adicionales. Por otra parte, la noción de derechos humanos remite esencialmente a la responsabilidad estatal. 
culación de las ONG con la guerrilla, ${ }^{167}$ que también establecen una distancia política y jurídica en la medida de concebir el atropello de este actor. Asimismo, demuestra a las agrupaciones subversivas su carácter crítico con el Estado y el señalamiento a la responsabilidad de éste y los paramilitares en dichas violaciones. De igual manera, compromete a los miembros de la Federación a no vincular sus actividades con ningún grupo armado y a exigir respeto por la libertad de opinión y acción de las entidades.

En Colombia es una constante los esfuerzos de unos sectores (políticos, armados, mediáticos...) por vincular a otros actores en uno de los bandos en conflicto. Las relaciones entre unos y otros se caracterizan por una constante tensión entre "vincular a» y "desvincularse de». Para Reclusa $(2004,190)$, entre los problemas que tiene que resolver una entidad, «una de las más difíciles de afrontar es el constante trabajo de los armados por implicar a campesinos y sus organizaciones en la dinámica bipolar del conflicto, también a las ONG que allí trabajan». No obstante, en un contexto donde el conflicto armado ha colonizado los espacios de la vida civil, también ha habido infiltraciones en el ámbito de la acción no gubernamental. Michael Radu, del Foreing Policy Research Institute, afirmó que "Algunas ONG en Colombia están de hecho, si no intencionalmente, haciéndole el juego a la guerrilla» (Semana, 2003). Por parte de otro actor armado, una entrevistada del estudio comentó: «Dicen que los paramilitares han inventado sus ONG» (EE-04).

Las Fuerzas Militares de Colombia también han realizado declaraciones en las que acusan a las ONG de ser cómplices de la guerrilla. El general Álvaro Valencia Tovar descalificó a las organizaciones protectoras de los derechos humanos porque, según él, han condenado al Estado afirmando que tiene una conducta continua y sistemática de violaciones a los derechos

167 Uno de tantos titulares que han protagonizado los pronunciamientos del presidente del país sobre las ONG lo recogía la revista Semana (Bogotá, n. ${ }^{\circ}$ 1156, 25-06-2004): «El Presidente insiste en su saña contra las ONG». Asimismo, ha habido casos de ONG extranjeras que han apoyado públicamente a las FARC o al ELN. Por ejemplo, la ONG danesa Oproer ('Rebelión') recaudó en un concierto 100000 coronas (8500 dólares) para las FARC (Semana, n. $\left.{ }^{\circ} 1173,26-10-2004\right)$. La misma noticia, reseñada por el principal periódico del país, señalaba el agradecimiento de las FARC solicitando que "Quisiéramos que su ejemplo de rebeldía y solidaridad se extendiera por toda Europa y el mundo. [...] Las FARC agradecen públicamente la donación que les hizo una organización no gubernamental danesa» (El Tiempo, 5 de noviembre de 2004). 
humanos. Dicho general señaló como argumento que existen "casos comprobados de montajes, acusaciones falsas, distorsiones, hechos calumniosos» que utilizan las ONG para «su campaña de descrédito de las Fuerzas Armadas de su país», presentando a nuestra nación "con una monstruosa fisonomía ante la comunidad internacional». Por tanto, deduce que las ONG desfiguran la realidad cumpliendo una función «aviesa y antipatria». ${ }^{168}$

Las organizaciones aragonesas no han sido inmunes a los señalamientos. La «Caravana Internacional por la Vida» en el sur de Bolívar, en la cual participaron varios cooperantes y voluntarios aragoneses, recibieron "hasta acusaciones de ayudar al Ejército de Liberación Nacional (ELN)». ${ }^{169}$

Durante los últimos años fueron varias las entidades que declararon su neutralidad activa. Los antecedentes de la cadena de declaraciones en ese sentido podemos encontrarlos en 1994, cuando la Organización Indígena de Antioquia (OIA), agobiada por la crueldad y el aniquilamiento sistemático de sus miembros, se empeñó en lograr que los actores armados respetasen la integridad personal, la vida y las decisiones de sus autoridades indígenas. De este modo se recogía lo que ellos entendían por esta expresión:

Para nosotros significa no participar en las filas de los grupos armados, no ser informantes para ningún bando, no patrocinar la guerra bajo ninguna circunstancia. Es una manera de aportar a la paz; no significa tranquilidad, quietud o indiferencia [...] vamos a denunciar cualquier atropello [...] (Colina Coirán, 2000).

En los últimos diez años (1994-2004) las organizaciones han tenido que hacer un esfuerzo constante por mantenerse al margen de las vinculaciones a un determinado bando del conflicto. Después de las primeras declaraciones de neutralidad activa (1994-1998) de las federaciones o las organizaciones sectoriales (indígenas, negros...), la Confederación Colombiana de ONG ha trabajado desde el año 2000 en establecer una serie de criterios más sistemáticos y tecnificados que no sólo eviten las sospechas sobre vinculaciones directas con grupos armados, sino que evidencien transparencia en la gestión de sus recursos: «rechazamos las generalizaciones que algunos líderes de opinión expresan sobre las ONG. Caer en la

168 El Colombiano, Medellín, 18 de marzo de 1997.

169 El Tiempo, 13 de agosto de 2001. 
trampa de condenar de manera indiscriminada toda forma de organización social es hacerle el juego a la desestabilización de la sociedad civil» (CCONG, 2002b, 1). De esta forma, anunciaron la "creación de dos instrumentos básicos para esto en otros sectores: los centros de acreditación y los centros de certificación de calidad. El primero genera confianza administrativa y el segundo garantiza el producto»(CCONG, 2002b, 1).

La situación de las ONG del Chocó es más grave que para ONG de otras partes del país: ${ }^{170}$ no sólo esta región se ha caracterizado por una ausencia del Estado, sino que ha sido motivo de disputa de los grupos armados, excepto la capital del departamento ${ }^{171}$ y núcleos urbanos de tamaño medio; las zonas rurales están controladas por estos actores. De esta manera lo apuntaba la presidenta de Federación de ONG del Chocó:

Es una tarea muy dispendiosa, como Federación hay muchos lugares a los que no hemos podido ir, hay sitios a donde no podemos ir por prohibición expresa, nos han llegado notas, también en los correos nos dicen cosas, que somos blanco..., entonces por orden expresa de la Confederación nos dicen una serie de recomendaciones: "procuren no ir a estos sitios, no andar por la noche, procuren que no se les aparquen carros enfrente». Entonces nosotros hacemos toda una serie de ejercicios de autoprotección, nos protegemos en lo que podamos, pero cuando a uno le quieran dar, le dan en cualquier lado (EC-02).

La contraparte del Comité de Solidaridad Internacionalista en el departamento de Bolívar, la corporación Sembrar, ha recibido frecuentes amenazas.

170 Ésta es la percepción de algunos informantes, la cual es respaldada por una gran cantidad de hechos: en el transcurso de la redacción de este apartado del informe, el periódico El Tiempo publicaba la siguiente noticia: «240 representantes de la Ruta Pacífica de las Mujeres que realizarían ayer [26 de noviembre de 2004] una toma pacífica de Quibdó y Tenguí, Atrato medio, para protestar por la crisis humanitaria de las mujeres víctimas del conflicto, no pudieron llegar a su destino. Una facción del Ejército Revolucionario Guevarista (ERG) bloqueó la vía que del Carmen de Atrato conduce a Quibdó con cuatro camiones que luego incineraron", El Tiempo, 27 de noviembre de 2004.

171 Un ejemplo de la excepcionalidad de Quibdó (Chocó) se encuentra en la masiva presencia de policías y militares. Sin embargo, resalta el contraste entre el deterioro del edificio que alberga el hospital público con la imponente y moderna estructura del edificio del DAS (Departamento Administrativo de Seguridad). En cuanto a la posibilidad de visitar zonas rurales para llevar a cabo el estudio, las personas que me asesoraron y ayudaron para la visita al Chocó me advirtieron reiteradamente que, por mi bien, no saliera de la capital del departamento. 
El día jueves, seis de diciembre de 2001, a las 12:30 p. m. allegó [sic] a la sede de [...] Sembrar, una nueva amenaza contra miembros de la corporación. [...] en este correo viene un escrito con el siguiente texto: «Hijueputas no se van a burlar: Por sapos y colavoradores [sic] del E.L.N. perros - malditos + Y. C. = Lista muerte próxima N. U. [sic] B.V., L. G. [,] S. H. [,] D. H. [,] justos por pecadores[,] muy pronto sabrán más» (Equipo Nizkor, 2001). ${ }^{172}$

En este sentido hay que aclarar que los diferentes niveles de la cooperación también incorporan diversos niveles de riesgo. Por una parte están las comunidades rurales que sufren el desplazamiento forzoso, las masacres y los asesinatos selectivos. Por lo general, los medios de comunicación recogen estos hechos como un número, a veces indeterminado, de víctimas, en muchas ocasiones anónimas, a las cuales se refieren como "habitantes de un corregimiento o vereda». Por otra parte están las organizaciones locales que trabajan en nivel intermedio, es decir, entre la ONGD aragonesa y la comunidad. Estas organizaciones también se enfrentan a un elevado riesgo, aunque en condiciones menos vulnerables que las comunidades: sus sedes suelen estar en municipios o ciudades y, por lo general, con más presencia policial o militar que los contextos rurales, y el tipo de amenaza suele ser más nominal que grupal, como ha quedado reflejado en la cita anterior.

Asimismo, el asesinato o la desaparición de los líderes de las organizaciones suele tener más repercusión social, ya que la pertenencia a una organización (fundación, corporación o asociación) con personalidad jurídica, unida a coordinadoras, plataformas o federaciones, evita la exposición generalizada de habitantes anónimos «supuestos colaboradores de la guerrilla o los paramilitares». Además, la vinculación con organizaciones aragonesas (en este caso como el Comité de Solidaridad Internacionalista o de otras comunidades como Nizkor o PTM) se convierte en redes de denuncia y divulgación de estas situaciones que traspasan las fronteras nacionales. Sin embargo, es bastante frecuente que algunas situaciones tengan más repercusión en España y Aragón que en el territorio colombiano o en los propios departamentos donde han ocurrido este tipo de hechos.

172 Respecto al texto de esta amenaza hay que explicar que la expresión «sapos» es una metáfora peyorativa que, aludiendo al anfibio de lengua larga, descalifica a personas que delatan o denuncian a otras. Las iniciales corresponden a los nombres de los amenazados, los cuales se omiten por respeto a ellos. 
Pero ésta no es la única contraparte aragonesa que ha recibido amenazas; casi todas, de una forma más o menos directa, han sido advertidas de los riesgos que corren por su trabajo. Los marianistas que reciben ayuda de AMAT también han tenido problemas, en este caso atribuidos a los grupos guerrilleros, por lo que parte de la ayuda la están dirigiendo para Ecuador:

No ha vuelto gente [a Colombia], pues se ha complicado mucho política y militarmente el país, por el peligro que hay [...], las guerrillas se radicalizaron, y era peligroso, incluso religiosos marianistas han tenido que moverse, cambiarse de comunidades por amenazas, no estaba la cosa para que alguien..., un chico pidió ir, pero se le dijo que no, [...] hay que valorar que no haya un riesgo alto que te pueda pasar cualquier cosa; ahora se está intentando hacer cosas en Ecuador (EE-06).

Otra de las formas de intimidar a las comunidades y organizaciones locales es a través del control que ejercen los grupos armados sobre los proyectos y ayudas en los territorios donde se interviene. Una de las estrategias del conflicto pasa por el control territorial, de tal forma que incluso los grandes núcleos urbanos como Bogotá o Medellín están repartidos por milicias urbanas o bloques urbanos de los actores armados. Dicho control es más evidente en las zonas periféricas, donde se encuentran los barrios más empobrecidos y donde la presencia policial es más efímera: «También están en peligro las ayudas que damos en Medellín, algunas de ellas porque van apareciendo grupos armados presionando, “¿esto de quién es? ¿Y esto qué? ¿Y quién lo financia?” ¡Está tan enredado aquello!» (EE-06).

En general, las organizaciones sociales, y dentro de éstas las ONG, se encuentran en riesgo de padecer ataques violentos por parte de los actores armados. En los últimos años, las amenazas del paramilitarismo a las organizaciones sociales que tienen un discurso crítico ante el Gobierno se han incrementado. ${ }^{173}$ Por su parte, estas organizaciones han ido diseñando

173 En una reciente visita a la ciudad de Zaragoza, un dirigente sindical colombiano afirmó tajantemente: "Hay una estrategia criminal de aniquilamiento de organizaciones sociales y políticas, de comunidades enteras [...] ser un responsable sindical supone estar señalado en los mismos términos de terrorista que la guerrilla y otras organizaciones» (Molino, 2004, 5). El sindicalismo en Colombia tiene una connotación peyorativa: los empresarios y la reducida clase media lo ven como un estorbo para el progreso económico, una actividad que sólo realiza paros y huelgas para conseguir privilegios particulares. En este sentido, la precariedad laboral, en el contexto de un Estado que no logra ofrecer unas 
estrategias de seguridad y protección para evitar o reducir la intensidad de las agresiones que padecen. No obstante, la capacidad de autoprotección depende de su tamaño, sus recursos y su incidencia política.

Las grandes organizaciones sociales a escala mundial, como UNICEF, han diseñado dispositivos especializados para la seguridad de los técnicos que se desplazan a las zonas en las que adelantan proyectos. "Vamos con un security cleaning que hace la Oficina de Seguridad de las Naciones Unidas, que está siempre monitoreando para saber a dónde se puede ir» (EC04). A través de este procedimiento los técnicos pueden desplazarse a zonas en las que, según el monitoreo, no se están llevando a cabo enfrentamientos directos entre los grupos por la conquista de un territorio. Generalmente, las situaciones de riesgo aumentan si se llevan a cabo combates entre los actores armados, especialmente entre la guerrilla y los paramilitares, que luchan por el control de determinados territorios de interés estratégico (producción de droga, cobro de "vacunas», futura implantación de megaproyectos...); una vez lograda la victoria sobre una zona por parte de uno de los bandos, la «tranquilidad» predomina nuevamente. Esta percepción se aprecia claramente en la opinión de una cooperante que habla sobre la zona del alto Atrato: «Es un territorio que está controlado por sólo una parte (los paras) y el ejército y la policía; al menos el territorio no está en disputa, ahora hay que rehacer el trabajo» (EE-03).

Para algunas de estas organizaciones el respaldo social y político externo es un factor de protección y reivindicación fundamental. La vulnerabilidad de una entidad puede depender en muchos casos de las organizaciones nacionales y extranjeras que la respaldan, ya que en «épocas de represión política o conflicto las organizaciones pueden ayudar y de hecho ayudan a nutrir y mantener vivas a las organizaciones locales y a los líderes, que de otro modo sucumbirían ante la presión» (Fowler y Biekart, 1998, 180). Una de las entidades indagadas demandaba de la cooperación

garantías mínimas de bienestar y un sindicalismo desprestigiado y amenazado, se convierte en norma y condición para liberar de muchas «cargas» a las empresas. Por su parte, los paramilitares, con una ideología conservadora del orden social, afirman que el sindicalismo y otros movimientos reivindicativos, cometen «atentados contra el desarrollo de la economía nacional» (Molino, 2004, 5). De hecho, hay demandas contra empresas multinacionales por financiación a grupos paramilitares: «Demandan a la Drummond por conspirar con paramilitares en Colombia», El Tiempo, 14 de marzo de 2002. 
internacional más incidencia política que transferencia de recursos, y lo hacía en estos términos:

Muchas veces es más importante el apoyo político en las propuestas locales que el económico; colocar una empresa comunitaria sin ningún respaldo político, es colocarla a disposición de que la acaben; pero si se sabe que detrás de una tienda comunitaria hay una serie de ONG y agencias internacionales..., un grupo armado sabe que si la daña, el coste económico y militar va a ser poco, pero va a tener un coste político muy importante (EC-03).

Como hemos afirmado, los grupos guerrilleros reciben apoyo económico y político desde diversos puntos y plataformas, de tal manera que el error de una acción armada incluiría, por ejemplo, atentar contra un grupo, población o persona que tiene respaldo social y político significativo en el exterior. Asimismo, el Estado, a través de las Fuerzas Militares, en los últimos años ha medido más las acciones que vulneran los derechos humanos debido a la presión internacional en torno al respeto de éstos en Colombia.

ONGD aragonesas como ASA y el Comité Óscar Romero, con presencia en el bajo Atrato, han desempeñado un papel fundamental en la zona, especialmente cuando ésta ha pasado por situaciones de crisis:

Cuando llega la ofensiva paramilitar, se debilita el tejido; entonces la cooperación ha consistido en acompañar el proceso de organización comunitaria, para poder vivir en mitad del conflicto y amortiguar, en parte, los efectos del conflicto, por ejemplo, el desplazamiento (EE-03).

En este sentido, la cooperación desempeña un papel protector y preventivo ante nuevas arremetidas por parte de los grupos armados, pues fortalecen o al menos ayudan a mantener los logros o beneficios sociales que las acciones violentas pretenden debilitar.

A pesar de todas las acciones en contra de las organizaciones, sus líderes, militantes y cooperantes, la acción social, solidaria y reivindicativa continúa: «en Colombia hay tejido, hay mucha gente con una gran fuerza vitalista, hay muchos que han matado, pero hay un repuesto constante, es una cosa que uno no se explica [...] hay gente que sabe que por sustituir un puesto puede ser asesinada» (EE-03).

En el plano de la imagen pública, las ONGD también se enfrentan a un entorno desfavorable, ya que los señalamientos del Estado y los grupos armados se han trasladado al espacio de las opiniones de los ciudadanos, 
en los cuales han calado algunas de las opiniones radicalmente enfrentadas. El papel de aquéllas, en este sentido, ha sido muy difícil. La guerrilla las señala como instrumentos al servicio del Estado, éste y los paramilitares les acusan de tener vínculos con la insurgencia. Una de las principales revistas de opinión social y política del país recogía de forma metafórica el enfrentamiento de las ONG de derechos humanos:

Hay que admitir que entre las ONG dedicadas a defender los derechos humanos hay unas cuantas que padecen de un mamertismo muy difícil de tragar: Ven por un solo ojo, el izquierdo, y como son tuertos del derecho se les olvida denunciar los secuestros o atentados criminales que comete la guerrilla [...] protestan únicamente por las barbaridades que han sido cometidos por agentes del Gobierno [...]. En este mismo orden, también existen algunas ONG que [...] ven sólo por el lado derecho. Para éstas, los únicos que violan los derechos humanos en este país son los grupos guerrilleros y jamás han notado que las autodefensas [paramilitares] desplacen multitudes o que maten a sangre fría a líderes populares sin nexo alguno con los subversivos (Abad, 2003, 73).

Por tanto, la confianza en las organizaciones se ha convertido en un tema prioritario para la captación de fondos, la rendición de cuentas y la credibilidad de sus intervenciones, ya que el país ha vivido desde los últimos años este proceso de polarización que «contamina» todas las esferas de la vida social. ${ }^{174}$ Esta tendencia ha afectado considerablemente la imagen de las organizaciones, su consideración pública está colmada de prejuicios en su contra.

Las razones por las que es tan fácil prejuzgar negativamente a las organizaciones civiles y solidarias son múltiples. Para empezar, es tradición que las esferas de lo colectivo y lo público en Colombia le incumban al Estado en vez de a los ciudadanos, de ahí que este tipo de organizaciones sean inquietantes.

174 Entre las fases propias de un conflicto se presenta la etapa de polarización por la cual las posturas enfrentadas se atacan y a los «colores grises» se les exige ser «blanco o negro». Al respecto ver Galtung (1998). Antes hacíamos referencia a las ONG «uribistas» y «antiuribistas», debido a que la política del actual Gobierno denominada de «seguridad democrática» ha transmitido la idea de que "quien no está con el Gobierno está contra él», y en esta cuestión hay una exigencia colectiva (a las grandes empresas, las ONG y la Iglesia católica) a tener que tomar parte. El papel de la institucionalidad de la Iglesia católica ha sido, en algunos casos, ambiguo, fruto de la división de posturas en torno a las salidas del conflicto. No obstante, sigue siendo un interlocutor legítimo para los actores del conflicto y una institución con alta credibilidad en el país. Recientemente ha pedido al presidente "virar hacia la búsqueda de una solución negociada del conflicto armado", El Tiempo, 20 de agosto de 2005 . 
De otra parte, la participación ciudadana que realmente se ha valorado y fomentado en los colombianos es la del voto individual y no la de los ciudadanos organizados, lo que explica que las organizaciones de la sociedad civil sean comparativamente escasas. Pero la razón principal por la que creo que estas organizaciones de naturaleza solidaria son tan fácilmente prejuzgadas y subvaloradas es porque, para muchísimos colombianos, ellas hacen parte de una dimensión desconocida. Para la gran mayoría de los colombianos, el desarrollo económico y social depende de las condiciones que crean el Estado y el mercado. Más allá de las fotos de cócteles, los discursos floridos, premios y condecoraciones por iniciativas y donaciones singulares de personas generosas, la solidaridad es una palabra que huele a "pobres", a gente caritativa, o bien a grupos de reivindicación popular, pero nunca a desarrollo (Ruiz-Restrepo, 2004, 2).

Por otra parte, en una visita realizada a Colombia, la premio Nobel de la Paz 2004 Shirin Ebadi ${ }^{175}$ señalaba, con relación al prejuicio frente a las ONG especialmente dedicadas a los derechos humanos,

En algunos países, los defensores son estigmatizados como guerrilleros, terroristas, revolucionarios, contrarrevolucionarios. Eso ocurre especialmente como reacción a sus actividades de denuncia de violaciones y por el acompañamiento que les dan a las víctimas. Esto lo que significa es que los autores de violaciones no aceptan sus responsabilidades y actúan para seguir beneficiados de la impunidad (Semana, 28 de febrero de 2004).

\subsubsection{Las comunidades: ${ }^{176}$ percepción de la cooperación y participación en los proyectos}

Hablar de la percepción de «las comunidades» encierra la dificultad propia de inmiscuirse en el análisis de las subjetividades. Esto significa que cada persona tiene un acervo cultural de representaciones y significados que un estudio de estas características no permite describir. Sin embargo,

175 Su visita a Colombia fue un apoyo moral para las ONG dedicadas a la defensa de los derechos humanos; de hecho, la Nobel criticó las descalificaciones del presidente Uribe sobre las ONG: "Los desafíos en Colombia son tremendos. La situación en general es muy grave. Uno de ellos son obviamente los términos que tuvo el Presidente, en los cuales asimiló a los defensores de derechos humanos como terroristas. Esto es un acto muy grave y peligroso", Semana, n. ${ }^{\circ} 1139,28$ de febrero de 2004.

176 Usamos la expresión «comunidad» tal como los entrevistados del trabajo de campo en Colombia la usaban. Cuando los líderes de las organizaciones hablaban de los beneficiarios o receptores de los proyectos hacían referencia a las comunidades. Sabemos que es una categoría amplia y polisémica en la literatura antropológica y sociológica, pero usaremos la definición "popular» recogida en las entrevistas. 
el propósito de este apartado surgió de la necesidad de considerar la imagen que tenían las "gentes del Sur» respecto a la cooperación de un «Norte» como es Aragón, para proporcionar elementos que ayuden a retroalimentar los enfoques y acciones de la cooperación.

A pesar de que en los otros apartados del trabajo de campo se recogen las percepciones de las comunidades respecto a otros temas vinculados a la ejecución de los proyectos, aquí sólo nos referimos a las opiniones explícitas de la población sobre su visión de la cooperación en su conjunto.

Por una parte, las percepciones de las comunidades en torno a las personas que se han desplazado a Colombia desde Aragón incorporan unos elementos culturales generales que pueden recaer sobre los imaginarios generales que conlleva la categoría de «lo español». En este contexto y bajo premisas subjetivas, los aragoneses son percibidos como gente de un país desarrollado, perteneciente a Europa, en consecuencia, de gente "culta, próspera y liberal». Con España se guarda una estima especial que algunos asocian a la idea de una madre patria que "proporcionó un idioma, una cultura y una religión». Puede decirse que es minoritaria la percepción del «español» en la línea de descendientes de «colonizadores que extrajeron las riquezas y atacaron a los indios».

Recientemente empieza a ser percibida como un nuevo poder hegemónico comercial e industrial a raíz de las millonarias inversiones de los últimos años en el subcontinente latinoamericano. En el Latinobarómetro 2004 (Instituto Elcano de Estudios Internacionales y Estratégicos, 2004), aplicado en 18 países de la región, se concluía que el $68 \%$ de los latinoamericanos tenía una imagen positiva de los españoles (54\% buena, 14\% muy buena). Superaba la imagen de otros lugares de procedencia como Japón y EE. UU., respectivamente. No obstante, todos los sectores sociales no tienen la misma opinión: "en los niveles de estatus bajos, la crítica a España obedecería al factor indígena que hace que perviva el estereotipo del conquistador» (Instituto Elcano de Estudios Internacionales y Estratégicos 2004, 7). Dicho informe recoge una valoración positiva de los colombianos hacia España, aunque ésta ha descendido de 2003 a 2004 debido a la percepción generalizada de la escasa acogida que reciben los inmigrantes colombianos en España.

Las experiencias de los cooperantes y voluntarios aragoneses en Colombia confirman la aceptación de la presencia de estos nacionales en el 
país andino. Incluso se establecen relaciones fraternas y, con menos incidencia, afectivas. El factor socio-relacional también se fortalece, aunque la relación inicial haya sido formal o institucionalizada. La mayoría de los aragoneses entrevistados que habían estado en Colombia mencionaba sensaciones de cariño, afecto, amistad, cercanía o hermanamiento, por el país o los colombianos, lo cual deja entrever una implicación que trasciende las acciones racionales y funcionales de la organización y sus miembros: «y me dijeron que una de las cosas que más les había gustado es que yo era más colombiano que muchos colombianos, me hizo mucha ilusión cuando me lo dijeron» (EE-06). Este componente primario reafirma un elemento que se ha querido resaltar y considerar en otros apartados del estudio y que suele estar al margen de las investigaciones del mundo de la cooperación al desarrollo. En la cooperación al desarrollo existe un valor añadido que impregna las acciones sociales colectivas con un conjunto de sensaciones, emociones y sentimientos subjetivos que en la mayoría de los casos fortalecen y promueven pautas objetivas como la eficiencia, la eficacia o la calidad del trabajo.

En el contexto de la cooperación, esta aceptación de la población hacia la presencia española viene acompañada de expectativas y oportunidades para la mejora de su situación: «los colombianos te ven como un referente, te ven como una esperanza, como una salida del callejón, te tratan de "doctor" y te tratan fenomenal: el cariño, la acogida, la gente es cariñosa, y con un español el idioma es más afín que lo anglosajón» (EE06). Asimismo, las invitaciones de las organizaciones aragonesas a España y Europa ha significado una expresión de cercanía a través del acompañamiento y el ánimo para seguir adelante en el trabajo con sus comunidades. Estos hechos han favorecido una imagen positiva de las comunidades hacia ellos:

Nos ven bien, algunos líderes han estado aquí, vienen a contarnos directamente su proyecto de vida, [...], ellos lo ven con mucha expectativa porque están completamente abandonados, hay organizaciones colombianas que trabajan con ellos, pero tienen el limitante de que son colombianos, el apoyo de fuera es importante, y para las comunidades que resisten y están aisladas, más. [...] los líderes han estado en el Parlamento europeo y regresan y lo cuentan a las comunidades, y cada vez se va a enterar mucha gente, se genera una esperanza, es vital. No es estar mal, y que nadie lo sepa; al menos estás mal, pero alguien lo sabe, se ve algo de luz, da otra trascendencia, porque si no, «aquí acaban con nosotros y nadie se entera». Es como un apadrinamiento con unas comunidades, no los vamos a dejar, vamos a llevar micrófonos, no están solos (EE-05). 
En el taller que se realizó con representantes de las comunidades del medio Atrato, éstos comentaron, frente a otros países europeos, que «en el caso de España la cosa ha sido más flexible» (EC-03), en alusión a que hay organizaciones aragonesas con las que han podido concertar los proyectos y permitir la participación de las comunidades. Esta imagen se encuentra especialmente en las entidades más pequeñas, a las cuales observan como más cercanas a las personas y flexibles en las condiciones de ejecución de los proyectos.

El respaldo institucional de entidades de ámbito nacional e internacional significa una salida del anonimato para algunas comunidades que padecen los efectos del conflicto. De este modo, su trabajo recibe cierto reconocimiento y difusión que puede favorecer su protección ante la vulnerabilidad de la población civil frente a los actores armados:

Es muy importante que el Gobierno de Aragón esté detrás; sus portátiles y teléfonos tienen el logotipo del Gobierno de Aragón, pasan de estar en una situación de olvido, de no presencia del Estado y de bloqueo, a decir que hay alguien que sabe lo que está pasando aquí y además intenta ayudarnos, es algo vital, es oxigenar una zona donde falta ese aire (EE-05).

En cuanto a la participación de las comunidades, existe cada vez más en las organizaciones aragonesas y sus contrapartes una conciencia de su relevancia no sólo durante el ciclo del proyecto, sino en la propia interrelación previa y posterior con los actores de la cooperación. Por ejemplo, UNICEF convoca a líderes de las comunidades para la selección de las zonas de intervención, después de la consideración de los indicadores cuantitativos de desarrollo humano. Basándose en la prioridad del IDH, existe una segunda fase por la cual los líderes de las comunidades complementan dicha información a partir de otros factores que no recogen este tipo de mediciones del desarrollo. De este modo, desde el principio existen niveles importantes de legitimación de los proyectos y mejor control sobre el aprovechamiento de los recursos que eviten, por ejemplo, el uso partidista de los proyectos:

La selección de los municipios se hace en relación al índice de desarrollo humano (Cauca, Chocó...), se invita a los líderes políticos y sociales para identificar, y ellos, con esas variables, seleccionan las zonas específicas de intervención. De esta forma hay un criterio objetivo (los datos) y una apreciación de la población (participación social), para evitar el politiqueo con los programas de UNICEF (EC-04). 
Incluso desde las instancias gubernamentales colombianas como ACCI perciben la necesidad de la intervención de la sociedad civil de tal manera que se mantenga constancia en los programas iniciados ante la variabilidad de las políticas gubernamentales del cuatrienio, en un contexto político que prohíbe la reelección de alcaldes y gobernadores:

En Colombia todo cambia cuando cambian los gobiernos; entonces no se sabe qué pasará en dos años, por eso se busca que sean estrategias que perduren en el tiempo, por eso ha habido participación de la sociedad civil, que ha sido precedida por mesas regionales; entonces esa participación también ejerce un control y garantiza la continuidad de la estrategia (EC-06).

Las organizaciones colombianas han comparado los resultados de la ejecución de proyectos que vienen sustentados por las comunidades y aquellos que no lo han estado. De esta forma han experimentado una ejecución más adecuada de éstos cuando ha habido diálogo previo con las comunidades; por tanto, "los proyectos que [...] vengan concertados con las comunidades garantiza[n] buena parte de la ejecución» (EC-03).

Uno de los puntos que mayor consenso encontró por parte de las organizaciones aragonesas y colombianas, en cuanto a la participación comunitaria, fue el papel que éstas desempeñan (o pueden llegar a desempeñar) en las fases de evaluación y seguimiento de los proyectos. Respecto a la evaluación, hay quien sugiere que, ante la diversidad de modelos de indicadores, las comunidades deberían hacer parte en su diseño: «Los indicadores los debe trabajar la sociedad, no la agencia; en eso debe participar la sociedad» (EC-07). ${ }^{177}$ Asimismo valoran la importancia de medir el impacto a través de evaluaciones participativas: «Para medir los impactos tenemos reuniones periódicas con los beneficiarios, éstas son las 120 comunidades de COCOMACIA, y medimos si el objetivo principal se ha podido alcanzar» (EC-03).

Aunque ha habido avances importantes en la participación, ésta sigue siendo uno de los mecanismos más adecuados para asegurar el uso eficiente de los recursos: «hay que seguir insistiendo, aquí [Aragón], en

177 Sylvia Borren $(2004,228)$ afirma que «resulta de vital importancia que los indicadores de éxito (cuantitativos y cualitativos) los establezca la propia comunidad». 
la participación de los beneficiarios, en qué medida ellos, al menos, conocen el proyecto, para que realmente se garantice que la ayuda llegue a la gente desde abajo» (EE-04). En este sentido muchos entrevistados sugieren que la «mejor auditoría» es la participación de la gente: «Siempre hay que apoyar procesos de base, logramos frenar un proceso por el cual, con dinero de la OIM, se le iba a mandar dinero para una cooperativa de un particular, de un politiquero..., por eso tiene que haber una comunidad» (EE-04).

Un factor considerado por algunas entidades aragonesas se basa en que sus contrapartes cuenten con un respaldo social que lleve a cabo los procesos de transformación de su situación específica, de tal manera que las dificultades que pueda asumir la ONG local, debido por ejemplo a su vulnerabilidad en el conflicto, no comprometan la continuidad de los procesos puestos en marcha:

Nuestra contraparte es un grupo, una comunidad que intenta transformar su realidad. Nuestra contraparte es Sembrar, y hemos tenido dificultades porque Sembrar ha tenido acoso en cuanto a su situación de seguridad, han tenido que salir... y se ha debilitado su capacidad organizativa, pero están trabajando con una coordinadora [...] y se ha dicho: «si Sembrar falla, otra de las organizaciones que está trabajando allí, asumimos el proyecto», no es un proyecto de Sembrar, es de todos, por eso se buscan cuestiones que tienen una amplia base social, se intenta buscar algo amplio, con respaldo [...] (EE-05).

En el caso de los botiquines donados por Médicos del Mundo, «éstos se donan una vez, pero para renovar los medicamentos la comunidad tiene que intervenir, y seguir autoabasteciéndose y ser capaces de administrarlo» (EE-01); de este modo, la participación es un paso fundamental para la consecución de su autonomía.

Un elemento muy valorado es el apoyo de organizaciones pequeñas a otras similares, ya que éstas permiten, según algunos entrevistados, mayor acercamiento a la comunidad y capacidad para asumir los cambios durante la ejecución de los proyectos:

Porque si fueran ONGD más grandes, necesitarían ONG [contrapartes] más grandes; entonces esto ha permitido apoyar procesos más pequeños [...] que son más flexibles con los plazos, son más blandos cuando hay que presentar un informe...; como estas entidades son más pequeñas, tienen aportes propios [...] y eso permite que el proyecto se adapte a las necesidades de la gente, han apoyado procesos de ir a buscar alternativas a la situación social (EE-04). 


\subsubsection{La coordinación entre los actores}

La opinión sobre la coordinación entre las ONGD está en estrecha relación con la experiencia individual o grupal de comunicación y conexión con otras entidades y personas en actividades, campañas o proyectos conjuntos. Para algunos representantes de entidades aragonesas, "no hay coordinación, hay entidades que han tenido problemas, y en lugar de pedirnos ayuda no lo han hecho, todo por no saberlo» (EE-08). De este modo, se detectan las dificultades para crear espacios o canales permanentes de coordinación debido a los pocos integrantes de las entidades más pequeñas, que no logran estar presentes en las variadas plataformas, coordinadoras o federaciones de las que forman parte. Además, en algunas entidades se dan casos de personas que pertenecen a otras organizaciones afines o de carácter político, cívico o religioso, lo cual se convierte en una mayor exigencia para los integrantes de las ONGD. "Yo conozco alguna, pero la dinámica propia de la ONG..., tenemos mucho trabajo como para conocer lo que hacen otras ONG. Si alguien nos pide ayuda, en esto influye la amistad, nos intercambiamos boletines, conoces otros proyectos si conoces a más gente» (EE-07). En esta respuesta aparece de nuevo el componente relacional como una fortaleza para la coordinación. Otras resaltan las dificultades vinculadas a la particularidad de las propias entidades: "Cuesta mucho trabajar en coordinación con las ONG, cada una es un mundo, tiene su estilo, le parecen cosas, pero cualquier esfuerzo es necesario para conseguir esa coordinación; es difícil, pero, si no se hace, se pueden obtener resultados negativos» (EE-03).

Sin embargo, otras, específicamente las que pertenecen y participan activamente en CASCOL, consideran que "hay una buena coordinación entre las ONG aragonesas que tienen presencia en Colombia, sabemos lo que están haciendo y eso se logra a través de CASCOL, no hay competencia en cuanto áreas de trabajo, ni en cuanto a tipos de proyectos, etc.» (EE-05). Además, «la coordinación de estas entidades ha permitido, desde CASCOL, hacer campañas como la del Tribunal Internacional de Opinión, o las Caravanas» (EE-01).

Desde la creación de CASCOL, para la mayoría de los que están inscritos, la coordinación ha mejorado; no obstante, hay otros casos, especialmente en las entidades más pequeñas, en los que se pertenece a la coordinadora pero no logran participar en las reuniones periódicas: «Estamos 
apuntados en CASCOL, pero no llegamos; en las últimas reuniones preguntamos: «¿quién puede ir?, ¿quién puede ir?». Nos envían la información, pero no podemos, necesitaríamos más tiempo» (EE-06).

Uno de los portavoces de una organización consideraba que era necesario mejorar la comunicación entre las entidades presentes en Colombia para obtener información de fuentes claras y precisas que eviten las críticas airadas por parte de otras ONGD: «Deberíamos darle más coordinación a la denuncia, se puede denunciar pero sin crisparse, sin echarle la culpa a todo el mundo de todo, ¡al Gobierno, a no sé quién, a tal empresa!; vamos a ser serios, vamos a analizar primero cómo se actúa allí» (EE-06).

La coordinación en Colombia es vista por algunas organizaciones colombianas desde la idea unificadora y homogeneizadora que equipara a España con Europa. En ese contexto establecen grandes diferencias entre Estados Unidos y el viejo continente. Sin embargo, profundizando en la especificidad de España, observan que, al igual que los otros países del continente, no se aprecia una presencia conjunta o complementaria con otros países de la UE. «Nosotros recibimos ayuda de otros países de Europa; lo primero que hay que apuntar es la atención que la cooperación española debe prestar a la coordinación con otros actores (ONGD y países) que están cooperando, para no duplicar esfuerzos» (EC-03). Asimismo, creen que los proyectos apoyados por ONGD deberían responder a planes comunitarios que se inserten en las aspiraciones de sus habitantes, del territorio y la cultura a la que pertenecen. Es usual en los discursos de las organizaciones colombianas hablar de "proyectos de vida", lo cual sugiere una mirada de futuro que trasciende la satisfacción de las necesidades básicas del presente. En tal dirección, «el plan de etnodesarrollo contempla la cooperación internacional; sin embargo, cuando los cooperantes lleguen tendrán que ceñirse al Plan y de esta manera ganaremos en coordinación y fortalecimiento local» (EC-03). Por tanto, «La diferencia del trabajo de ONG debe coincidir o converger en las comunidades, es construir una propuesta donde la gente se vaya reconociendo, donde se vaya sintiendo identificada» (EC-07).

«Entre las propias ONG nos estamos enfrentando, entre unas que desarrollan y fortalecen procesos a medio y largo plazo, y otras que trabajan por proyectos, que trabajan a demandas de las agencias internacionales que rompen procesos locales y regionales» (EC-07); por tanto, propo- 
nen una convergencia en las comunidades, ellas deben ser el objetivo, no como sectores basados en colectivos específicos, sino ligados a un territorio: «Hay que hablar en términos de construcción de región, hay que trabajar en alianzas estratégicas, nadie puede ir por su cuenta» (EC-07).

\subsection{Evaluar el proyecto: ¿compromiso con el donante o con la comunidad?}

En la actualidad, en Colombia existe un proceso de reflexión y cuestionamiento sobre los modelos de intervención aplicados en los últimos años. El Enfoque del Marco Lógico prevé la consideración de factores de riesgo externos que puedan afectar la ejecución de los proyectos de cooperación; pese a esta previsión, las características del conflicto armado lo configuran como un hecho estructural, es decir, como el contexto social y político desde el cual se parte y bajo el cual se trabaja. Por tanto, el conflicto no es un hecho externo y fortuito que afecta a los proyectos.

Por otra parte, la cooperación en Colombia también se ha percatado en los últimos años de la elevada dependencia hacia los proyectos de desarrollo como principal paradigma posible para trabajar por el desarrollo: "en Colombia hay un mal entendido como "proyectitis", y sólo se trabajaba así. Nosotros [UNICEF-Colombia] queremos demostrar que no todo es con proyectos y que no siempre el problema es de recursos; se pueden hacer cosas sencillas sin dinero" (EC-04).

Del mismo modo, organizaciones de gran trayectoria formativa e investigadora como el CINEP, aunque creen en el trabajo basado en proyectos, enfatizan el peligro de instrumentalizar el trabajo con las comunidades. Advierten la necesidad de privilegiar los procesos sociales, en lugar de las demandas de las agencias y organizaciones externas: «Hay ONG que están abocadas a moverse entre los procesos y los proyectos, tienen que trabajar para prevenir que los proyectos no rompan a los primeros por atender las demandas de una agencia. En ocasiones se pone un recurso que interrumpe su construcción local» (EC-07). Por tanto, organizaciones como ésta advierten sobre el papel que deben tener instrumentos como el Enfoque del Marco Lógico: «Por otra parte, está la transparencia en el manejo de los recursos; por eso los marcos lógicos resultan fundamentales, en 
términos de resultados. El temor es que no miden los procesos; ante esta dificultad se cae en la eficiencia y la eficacia en términos de proyectos» (EC-07).

De la misma forma, proponen que los proyectos apliquen un enfoque que fomente el fortalecimiento territorial, en lugar del sectorial:

El acompañamiento ya no es sectorial, que ha sido un enfoque de intervención sustentado en el desarrollismo. De esta forma se acompañaba a los sindicatos, a los indígenas, a los campesinos, pero no había ninguna gran pregunta por el desarrollo. Desde hace 4 años el CINEP empieza a preguntarse por el estilo de intervención, a cuestionarse el trabajo basado en sectores, y empieza a tener una mirada multi-dimensional y pluri-cultural (EC-07).

En este sentido, han creado un modelo que incorpora un mayor acercamiento con los territorios sin descuidar la rigurosidad de las distintas fases del proyecto. Existe un lenguaje que demuestra cambios profundos en su relación con la población beneficiaria: «antes decíamos que íbamos a "incidir en", ahora decimos que "vamos a trabajar con ellos"” (EC-07).

Asimismo, la formulación de los proyectos precedidos de un trabajo previo con las comunidades beneficiarias ha permitido fortalecer la legitimidad de éstos y reunir algunas condiciones (información sobre los objetivos, repercusiones en la zona, expectativas de las partes...) que han facilitado un impacto concreto y constructivo en la población:

Normalmente los proyectos han respondido a las necesidades de las comunidades porque afortunadamente hay una buena diligencia y unos líderes comunitarios que mantienen unos criterios de información con las personas de la comunidad, eso permite que los proyectos que se definan ya vengan concertados con las comunidades; entonces, cuando el proyecto llega, ya viene legitimado por las comunidades; entonces, esto garantiza buena parte de la ejecución (EC-03).

El proyecto de desarrollo es un instrumento metodológico que permite la consecución de unos recursos y la ejecución de unas acciones planificadas y concretas susceptibles de ser evaluadas. ${ }^{178}$ No obstante, algunas

178 Cada vez son más frecuentes las críticas a la metodología de trabajo basada en proyectos y al Enfoque del Marco Lógico. Al respecto, ver Fowler (1997), Sogge (ed., 1998), González Parada (2001), Nieto (coord., 2001), Ferrero (2003), Stubbs (2004). 
organizaciones son conscientes de que no se trata de un instrumento plenamente objetivo o neutral, en cuanto ha sido confeccionado por personas en determinados contextos culturales. En ese sentido, hay entidades en Colombia que no están de acuerdo con el desarrollo basado en proyectos y no participan de las convocatorias para concursar por unos recursos, aunque esa opción se traduzca en un limitado acceso a los recursos económicos. En la opinión de uno de los líderes entrevistados,

Hay una tensión entre ciertas lógicas que podríamos llamar «occidentales», «racionalistas» que yo y esta institución hemos dicho: «Nosotros nos metemos ahí». Hubiéramos podido decir que no, que no entramos en esta lógica, como lo han hecho otros. Pero hay una consecuencia clara, sólo puedes acceder a recursos muy pequeños (cuatro o cinco mil euros). Si una agencia dona un millón de euros, tiene que poner en marcha todo un sistema de control, seguimiento y supervisión (EC-01).

Esta respuesta pone de relieve la constante fluctuación entre lógicas en la que está inmersa no sólo Colombia, sino América Latina y buena parte de lo que se considera el «Tercer Mundo»; es decir, ¿participar de las lógicas racionalistas asociadas a la idea de Occidente o mantenerse entre la hibridación de tradiciones y modernidades? ${ }^{179}$

Dicha tensión se expresa a través de un discurso que responde a esa lógica que el entrevistado llama "occidental» y que correspondería a métodos como los empleados en el Marco Lógico, y otra lógica distinta, a nuestros ojos más ambigua e informal, pero que se expresa en códigos endógenos que las organizaciones utilizan para continuar su trabajo y explicarse ante sus comunidades. Por tanto, "hay que tener una mirada crítica sobre lo del marco lógico, la planeación, el seguimiento y la evaluación, desde cuándo se hace y por qué. A veces sólo quieren saber en qué se gastó esos recursos» (EC-07). Un reto pendiente en la evaluación consistiría en descifrar esas lógicas endógenas que no se recogen en las evaluaciones con-

179 La idea de «entrar y salir» de ciertas lógicas plantea una ventana interesante al variado panorama de formas culturales implícitas en el trabajo de las organizaciones solidarias en este contexto geográfico; el proyecto inacabado de la modernidad ha tenido sus primeras manifestaciones en América Latina, que fue, de alguna manera, postmoderna antes de ser moderna. Al respecto es muy ilustrativa la obra de García Canclini (1989), cuyo título sugiere la idea de fluctuación cultural: Culturas híbridas: Estrategias para entrar $y$ salir de la modernidad. 
vencionales y que permitirían un mayor acercamiento a las comunidades y facilitarían la rendición de cuentas en sus términos y expectativas. Sin embargo, esto no significa tener que tomar drásticas decisiones respecto a trabajar, o no, con proyectos. No hay que renunciar a ellos para considerar las lógicas nativas o endógenas. Kottak (2000) ha demostrado que el éxito de muchos proyectos de cooperación está en estrecha relación con la compatibilidad cultural entre éstos y las comunidades. En tal dirección, sostiene la necesidad de tener en cuenta que «no es probable que las gentes cooperen con proyectos que les exijan cambios mayores en sus vidas cotidianas, especialmente aquellos que interfieren en demasía con las formas de asegurarse la subsistencia dictadas por la costumbre» (Kottak, 2000, 105).

Esta sutil confrontación de modelos culturales se expresa también en términos cronológicos; es decir, las diferentes concepciones culturales en torno al tiempo atraviesan todo el camino del proyecto desde que se concibe la idea hasta que se evalúan los resultados (Douwe, 1999). En la cultura "occidental» están muy acentuados determinados valores como la eficacia, la productividad o el utilitarismo, que, por supuesto, no son inherentes a todos los seres humanos, sino que se trata de pautas culturalmente construidas a través de procesos históricos concretos, consolidados en el tiempo y en las sociedades. En dicho contexto se han naturalizado expresiones asociadas a esta valoración, tales como el tiempo es dinero o perder el tiempo. De esta forma un entrevistado ejemplificaba una de estas situaciones que afectan a las entidades locales: "A veces te dicen: "si no lo ejecuta en tales fechas, les quitamos el dinero"; entonces, antes de tener la casa, te toca comprar las dotaciones para que no se pierda el dinero, con lo cual no es el ritmo normal del proyecto» (EE-04).

Desde algunas comunidades campesinas y étnicas colombianas es posible que se perciban los ritmos de los proyectos aragoneses como apresurados, inmediatistas, cortoplacistas y estrictos, ya que parten de otras pautas sociales y culturales centradas en otros valores. Sus ritmos, por ejemplo, pueden tener una fuerte vinculación con los tiempos de la naturaleza, con la dependencia de las etapas marcadas por lo divino o sobrenatural, así como por los espacios de encuentro y celebración comunitaria. Por tanto, es muy probable que las ONGD aragonesas pueden pensar que 
algunas de sus contrapartes colombianas son impuntuales, informales o demasiado tranquilas. ${ }^{180}$

En ningún caso podemos afirmar que una de las percepciones y, por ende, los juicios sobre su contraparte sean los verdaderos o reales. Es evidente que predominan los modelos inspirados en la «racionalidad occidental» debido a que es la base en la que se mueve la mayor parte de los actores de la cooperación, y en especial los que financian los proyectos. «Aunque las ruedas de la globalización parezcan girar cada vez más rápido, las ONG deben (re)aprender de las virtudes de la paciencia y la respuesta tranquila, sin intentar que la gente y los procesos vayan más deprisa de lo que pueden ir» (Eade y Ligteringen, 2004, 21).

A pesar de este predominio, los modelos tradicionales e indígenas no desaparecen plenamente; por el contrario, se filtran y emergen de forma esporádica, subrepticia. En lugar de negar su existencia, se deben conocer, entrar en diálogo y aprender de ellos; pueden resultar fundamentales para que el impacto de la cooperación no se mida sólo en los términos de unos actores y para no perder la legitimidad ante los que deben ser protagonistas del desarrollo. En las entrevistas, esta emergencia de otras formas de conocer los resultados y trabajar la evaluación ha sido denominada, como veremos más adelante, «evaluación interna», «evaluación informal» u "otra evaluación»; desestimando la forma de nombrarlas, estas «otras» evaluaciones intentan, básicamente, complementar los métodos convencionales exigidos por las financieras en dos vías interdependientes y hasta ahora secundarias: el análisis cualitativo de los resultados y los indicadores endógenos de la comunidad beneficiada.

Es importante tener en cuenta que los procesos sociales no pueden medirse de la misma forma que los procesos productivos. La organización comunitaria, el empoderamiento y la presión política no son equiparables

180 Cuando realicé el taller grupal con líderes de las comunidades agrupadas en COCOMACIA, no pude aplicar la técnica tal como la había preparado: la hora de inicio y de finalización eran, para los asistentes, sólo orientativas. Algunos venían al grupo, permanecían un rato y se iban. Otros acudían una hora tarde, decían lo que pensaban sobre el tema que se discutía y se marchaban al terminar su intervención. En medio del taller se acercaban personas que no estaban convocadas a saludar y conversar con los asistentes que sí habían sido convocados. Aun así, hubo participación, interés y colaboración, a su manera. 
a los bienes y servicios ofertados en las sociedades de consumo. «Muchos de los donantes hacen mayor hincapié en el impacto, la eficacia y la sostenibilidad. Esta tendencia es en parte producto de las ideologías neoliberales y de la "cultura de la rentabilidad" que dominó gran parte del pensamiento organizativo de los ochenta, y de la competencia por los fondos y el cambio de esquema en el flujo de ayudas que caracterizaron los noventa» (Hailey, 2004, 206).

De este modo, la pretensión de generar unas lógicas evaluativas que den cuenta de la realización de los proyectos sólo desde las expectativas de los donantes o las financieras suscita, sin pretenderlo, una doble vía de respuesta. Desde este punto de vista se intenta satisfacer los contenidos y formatos requeridos por un actor de la cooperación, justificando los recursos empleados y utilizando las herramientas diseñadas para evitar cualquier suspicacia frente a su manejo. Sin embargo, este esfuerzo por ejercer la supervisión, muchas veces al margen de las incidencias sociales, económicas, políticas y culturales del territorio, induce a que algunas organizaciones formulen las respuestas esperadas, aunque la realidad, como las aguas subterráneas, transcurra de otra forma:

Ahora todo el mundo te exige un montón de cosas y viendo los papeles la gente se puede quedar feliz y contento pensando que ya...; yo entiendo que quien da dinero quiere ver lo resultados, pero a veces no se tiene la flexibilidad de entender que hay unas circunstancias..., y eso amarra mucho los proyectos y eso genera una picaresca, pero a veces se presta para que el receptor haga unas cosas para quedar bien con el donante; cuantos más requisitos te piden, más te buscas las formas de responder esos requisitos, y el ideal sería simplificar la responsabilidad (EE-04).

Esta dificultad que describe la persona entrevistada, coincide con el análisis de algunos investigadores sociales que desde hace unos años han revelado los peligros que encierra la aplicación rígida de los modelos relacionados con el ciclo del proyecto y con su evaluación: «el modelo se ha vuelto a veces un fin en sí mismo, donde el objetivo es rellenar una matriz como sea y cumplir rigurosamente los pasos del marco, sin tener en cuenta las verdaderas necesidades de la población y sus ritmos de trabajo». ${ }^{181}$

181 Seufert, citado por L. González (2000, 32). 
Durante el trabajo de campo, las organizaciones entrevistadas dejaron claro que cumplían con los requisitos exigidos por las agencias y ONG «del Norte» a través de la respuesta a las preguntas contenidas en los formularios o impresos elaborados a la luz del Enfoque del Marco Lógico. Sin embargo, transmitían la dificultad para contar sus resultados a sus socios más cercanos y a las poblaciones con las que trabajan en los términos planteados por esa primera lógica. En general, se entreveía la idea de inadecuación entre modelos de trabajo como fruto de códigos culturales diferentes.

Desde el mismo formulario [de evaluación] es una cosa preestablecida de la que no se puede salir; si tú como organización campesina no llenas el formulario como es, tú no tienes acceso, […]. Ellos tienen unos formularios trágicos, trágicos porque son traumatizantes para una organización campesina, y ellos dicen que no pueden rebajarle a ese formulario, es «lo que está ahí lo que hay que presentar». También ellos tienen unas particularidades, que ellos no se salen de ahí, así las comunidades sean de muy baja escolaridad (EC-02).

La forma de narrar su percepción frente a los impresos de evaluación puede sugerir que sólo las organizaciones cuyos miembros tienen una escolaridad alta pueden optar a cumplimentar los requisitos técnicos de la evaluación, $y$, de este modo, se crea un círculo por el cual quienes tienen un nivel de escolaridad mayor (o piensan en términos de eficiencia y productividad) también tendrán más condiciones para optar a nuevos proyectos. Por tanto, hay quienes recomiendan la complementariedad del modelo convencional con otras herramientas o técnicas más flexibles: «el uso del marco (EML) sin complementarlo o combinarlo con otras técnicas más sencillas resulta complejo para organizaciones comunitarias o grupos de bajo perfil académico» (L. González, 2000, 33). Además de este prerrequisito educativo, incomoda la actitud de entidades que, según este informante, imponen las condiciones técnicas de evaluación del proyecto: «Entonces ellos llegan con sus supuestos y dicen “¡lo vamos a hacer así!”. Porque éste es el mandato de nuestros donantes, entonces llegan a imponer» (EC-02).

Además de llenar los respectivos formularios que den cuenta a las entidades que financian, algunas de las organizaciones visitadas realizan una evaluación «interna» para conocer los resultados de las intervenciones desde los criterios a los que atribuyen mayor relevancia para las comunidades. "Hay dos fases de la evaluación, una interna y otra externa. La externa es el seguimiento del proyecto, pero la interna son los cambios que 
percibimos desde la organización» (EC-03). En este sentido, podemos deducir del trabajo de campo, que existe una evaluación «formal» que se prepara para cumplir con las entidades que han financiado el proyecto, $y$ otra, de carácter más interno e informal, a través de la cual se logran dos propósitos: obtener información útil para la retroalimentación de la entidad (la mayoría de las veces de carácter cualitativo) y responder a las expectativas de las comunidades considerando sus propios valores, anhelos y deseos. Es importante recordar que la rendición de cuentas ante las comunidades no es menos importante que hacerlo ante las entidades financieras; «sin rendición de cuentas a los participantes, o sin rendición de cuentas horizontal entre las ONG [...] se corre el riesgo de que la rendición de cuentas acabe haciéndose sólo a los donantes» (Borren, 2004, 221). Además, esta segunda modalidad de evaluación implica cierto «sometimiento voluntario» a un control social que podríamos denominar «auditoría comunitaria».

A las personas que han sido beneficiarias se les pregunta cómo les pareció, etc. Además, estamos atentos a observar los cambios de actitud, ése es un buen indicador de que algo sirvió o no. Por eso no son buenos los proyectos a corto plazo, porque hay que esperar que generen cambios; en menos de un año es muy difícil producir algún cambio y observar el impacto que puede tener un proyecto. De todas maneras, el proyecto lo formulamos con unos indicadores, eso lo miramos con los beneficiarios directos, pero ellos están interactuando en un escenario, y yo tengo que ir allá, para ver cómo están actuando esos beneficiarios directos. Generalmente lo hacemos por observación, pero también por autocalificación (EC-02).

De este modo, las organizaciones locales destacan la importancia de la evaluación ex-post o de impacto, debido a la dificultad de percibir cambios en un período corto de tiempo. Por una parte, observan que poco a poco este tipo de evaluación ha empezado a tenerse en cuenta, pero, por otra, lamentan que se exija de forma precipitada: "Últimamente están pidiendo el impacto, pero quieren ver el impacto al terminar el proyecto, y eso sólo es posible después de unos años, [...] es bueno que lo pidan, pero técnicamente es imposible medirlo inmediatamente» (EE-04). La ONG World Vision Sudan, que trabajaba en medio de un conflicto armado en ese país, inició un proceso de evaluación del impacto de la ayuda humanitaria y de los proyectos de desarrollo; tan sólo «al cabo de dieciocho meses, logramos ver cómo las intervenciones pueden apoyar o socavar los esfuerzos sudaneses para crear las condiciones de su propia paz» (Riak, 
2004, 384). Por su parte, la ONGD ENDA-Zimbabue realizó una evaluación de impacto cuatro años después de haber terminado una serie de proyectos de apoyo a los medios de vida (Roche, 2004, 28-29).

Asimismo, hacen referencia al escenario como espacio de interacción de los beneficiarios en los que salen a flote los cambios logrados y los resultados propios de las actividades; a través de la observación directa y la autoevaluación logran conocer las transformaciones logradas y aquellas en las que tienen que seguir insistiendo. No obstante, éstos son unos criterios generales, pero en temas específicos intentan adecuar las evaluaciones de los proyectos a los ámbitos trabajados en ellos:

En los temas de fortalecimiento organizacional, los resultados se ven en la práctica diaria de la organización; al terminar el proceso de formación, la organización tiene que saber qué es un libro de actas, qué es un libro de caja, cómo se maneja el archivo y la correspondencia, etc. [...] También una forma es saber cómo estaba la organización antes del proyecto, qué cosas iban bien y cuáles no antes de hacer el proyecto: así podemos percibir los cambios (EC-02).

La estrategia adoptada por COCOMACIA se adapta a su forma de organización, ya que en su zona de influencia existen 120 comunidades, la mayoría dispersas por el territorio teniendo como único medio el transporte fluvial. Esta entidad hace una referencia explícita a la evaluación de impacto, ya que hay una preocupación en la zona por generar cambios importantes y visibles que mejoren las condiciones de vida de los habitantes:

Para medir los impactos tenemos reuniones periódicas con los beneficiarios, éstas son las 120 comunidades de COCOMACIA, y medimos si el objetivo principal se ha podido alcanzar. Nosotros trabajamos con planes de acción que trazamos con las comunidades a 4 años; allí está el plan de etnodesarrollo, la situación del territorio, los recursos naturales, la situación ambiental, las actividades productivas. Primero identificamos un punto de partida (evaluación ex-ante) y a medida que vamos interviniendo, vamos apreciando los cambios (EC-03).

Para esta organización no existe una evaluación estandarizada que sea válida para todos los proyectos, debido a que «la evaluación es relativa en función de quien ejecuta» (EC-03). No obstante, hay dos elementos que intentan tener siempre presentes en sus proyectos de desarrollo: «el impacto político del proyecto y el impacto económico o material» (EC-03).

Algunas respuestas también insisten en la dificultad para medir los cambios sociales, debido a la falta de instrumentos e indicadores para lograrlo: 
La evaluación es presentar los resultados de los objetivos; en las memorias se habla de algo más cualitativo, [...] hay dos niveles, un nivel de lo concreto por el cual cumples unos objetivos (un material, un programa de radio, una gira de un invitado...); el otro nivel es cómo los proyectos inciden en la transformación de la realidad: eso es mucho más difícil de evaluar, esto tampoco se está pidiendo, ni se han establecido indicadores, nosotros lo escribimos en la memoria. ¿Cómo se mide eso? No está planteado en los objetivos, número de denuncias, ¿’hubiera habido menos incursiones si...? Eso no se puede medir, depende de la situación política interna, etc. Hay que intentar elaborar indicadores para esto, [...] todas las acciones son objetivables. ¿Cómo la sensibilización incide en la forma de vida de la gente...? (EE-05).

Uno de los denominadores comunes de las organizaciones indagadas tiene que ver con los indicadores de evaluación en el contexto propio de un conflicto armado. Los factores que pueden afectar la ejecución de un proyecto en un contexto bélico están presentes de principio a fin. Por ejemplo, uno de los proyectos realizados por ASA en Pueblo Bello (municipio de Turbo, Antioquia) no pudo culminarse porque la comunidad tuvo que salir intimidada por los grupos armados; esto impidió que se pudieran realizar las acciones proyectadas y, en consecuencia, entregar los justificantes a la institución que financiaba el proyecto (Diputación Provincial de Zaragoza) en los plazos oportunos. Una situación similar sucedió con la contraparte de OSPAAL Aragón, la organización Red Viva, que tuvo que salir de Bucaramanga, lo que obligó a la entidad a trasladar el proyecto a Bogotá.

En ese contexto casi todas las entidades reconocen serias dificultades para avanzar según la previsión del trabajo: «Las dificultades que tenemos es que es un país en guerra, que se alargan los tiempos, tú planificas que esto lo tienes que hacer en un tiempo y luego no son los programados, las dificultades de entrar o de salir...» (EE-05).

En una situación de constantes emergencias producidas por enfrentamientos de los actores armados, agresiones directas de uno de ellos ante la población, etc., los objetivos que se plantean algunos proyectos dejan de intentar la mejora de indicadores sanitarios, formativos $\mathrm{u}$ organizativos para proponerse un objetivo mínimo y fundamental, la supervivencia de una comunidad o su permanencia en el territorio:

[...] entre 1996 y 2000 en el Atrato han asesinado a más de 1000 personas y han sido desplazadas miles de personas; el solo hecho de que muchos hayan regresado a sus tierras y de que en los últimos años no se haya desplazado tanta 
gente demuestra la efectividad de las acciones emprendidas. El hecho de que la gente aún esté en su territorio y se esté reuniendo es una ganancia política de los proyectos (EC-03).

Uno de los aspectos en que más se ha insistido en las entrevistas son los resultados «políticos» de algunos proyectos y colaboraciones. Estas organizaciones atribuyen este logro al hecho de que un grupo humano o comunidad consiga el respeto de algunos derechos fundamentales. Poder tener acceso al derecho a la vida, a la libertad, a la libre circulación o a residir en su territorio se consideran pasos importantes para que los actores armados reconozcan su dignidad. "La gente ha conseguido logros políticos con esfuerzo, resistir es mantenerse en el territorio: “ ¡nos mantenemos en el territorio porque es nuestro!”»(EE-04).

Por ejemplo, otro de los grandes logros que ha registrado la organización campesina del Chocó ha sido ganarse el respeto de los actores armados, lo cual ha repercutido en la consolidación de su presencia en el territorio; esto, a su vez, ha permitido ganar la confianza de las poblaciones vecinas, demostrando compromiso (con los proyectos y sus objetivos), autonomía (respecto a la influencia gubernamental, guerrillera o paramilitar) y teniendo capacidad para enfrentar situaciones extremas. ${ }^{182}$

Otro hecho significativo es que a la organización nunca se le han cerrado los espacios de trabajo a pesar de las distintas presencias militares de los actores armados, a nadie le hemos pedido permiso para actuar en el medio; nos respetan y reconocen nuestro trabajo. Muchas agencias, ONGD, incluso las Naciones Unidas pide el acompañamiento de algunos de los miembros de la organización (EC-03).

Como se puede apreciar, en situaciones de conflicto armado los indicadores para medir los resultados de los proyectos de cooperación y otras actuaciones solidarias pueden encontrarse muy desfasadas de la realidad. En ocasiones, evitar una masacre o un asesinato puede ser un resultado importante de un conjunto de acciones de fortalecimiento de la organiza-

182 Algunos integrantes de COCOMACIA comentaron que esta organización ha intervenido en varias ocasiones para evitar que asesinaran a algún miembro de las comunidades en el preciso instante en que iban a cometer dicho acto. En el contexto colombiano esta acción significa no sólo el valor de enfrentar a un grupo armado, sino el respeto que inspira una entidad con estas capacidades. 
ción comunitaria, tal como lo confirma este voluntario: "Hay datos que sustentan que "en la incursión de tal fecha se ha llamado a la Fiscalía y, en lugar de quemar cuatro caseríos, han quemado uno". El logro es evitar que se arrasen tres caseríos» (EE-05).

No obstante, también hay logros importantes en otros ámbitos, como la protección de la infancia y la cobertura sanitaria y educativa, aunque la sombra permanente de la violencia no siempre permite destacar la relevancia de estos avances. El caso de la educación se resalta especialmente como acciones que garantizan efectos multiplicadores en comunidades específicas:

La mayoría de las personas que hemos becado universitariamente están trabajando de forma social ayudando en las ciudades o en las zonas donde ellos están trabajando, o se han incorporado como monitores voluntarios a otros proyectos, y eso es muy bonito, porque hay arraigo. Hay gente que sabe que puede estudiar gracias a amigos españoles, que pueden comer; estamos muy hermanados, intentamos conocernos mejor. Son pequeños pasos, pero que se van viendo (EE-06).

El caso de las entidades más grandes, caracterizadas por trabajar en todo el territorio nacional y administrar presupuestos más elevados, es diferente en cuanto a la evaluación de los proyectos. Por lo general, la evaluación también tiene un carácter interno y externo, pero la diferencia estriba en los objetivos de cada uno. Externamente hay un objetivo específico de medir los criterios convencionales de la evaluación (eficiencia, eficacia, sostenibilidad...). Ésta corresponde a un control interno de la administración de los recursos y pretende demostrar a las entidades que han apoyado y financiado el proyecto la transparencia y organización de aquéllos. Estas grandes organizaciones suelen contratar auditorías externas para este tipo de evaluaciones:

La evaluación que se realiza es posterior a la ejecución. A los proyectos pequeños nosotros hacemos la auditoría interna. Por lo general, cuando va amarrado a un proyecto grande, como el de la AECI, aplicamos una auditoría, la interventoría, el seguimiento, la rigurosidad de los gastos, la transparencia en la ejecución de los recursos. Por una parte, nosotros hacemos esta auditoria interna, nosotros se lo presentamos a Entreculturas y ellos le rinden cuentas a la AECI. Aparte hemos contado con auditorías externas como la de Price Water House: es contratada en España por la entidad que está financiando el proyecto. Ellos revisan si los recursos llegan a donde tienen que llegar, si se está cumpliendo al pie de la letra con la formulación, si es transparente la ejecución (EC-05). 
Como se aprecia, algunas características de la evaluación de los proyectos difieren considerablemente entre las organizaciones grandes, que trabajan a nivel nacional, y las organizaciones pequeñas, más vinculadas al territorio y a las comunidades. Podríamos afirmar que entidades como Fe y Alegría (Entreculturas) y UNICEF, que coordinan más de un centenar de proyectos, requieren altos niveles de formalización de la evaluación para organizar los volúmenes de recursos técnicos, financieros y humanos que gestionan; no obstante, estos niveles de burocratización (en sentido weberiano) generan niveles de distanciamiento entre la organización y las comunidades en las cuales intervienen. En este caso, los directores de los proyectos hacen visitas ocasionales para conocer los procesos de ejecución de los proyectos, observan las obras de infraestructura creadas, participan de forma esporádica en cursos de formación y reuniones con grupos o asociaciones para informarse de los logros obtenidos y las dificultades encontradas. Con todo, los cargos administrativos y técnicos de este tipo de entidades no pertenecen a los contextos geográficos, culturales o étnicos de los que forman parte los beneficiarios, ya que, por ejemplo, tienen su residencia en un entorno diferente, normalmente en una ciudad o capital administrativa, su grado de escolaridad y renta media supera considerablemente el promedio de las poblaciones con las que trabaja. Por lo general, en las entidades grandes (nacionales e internacionales) los directivos son empleados contratados por su cualificación y experiencia técnica, más que por su trayectoria asociativa y su adscripción a un ideario solidario.

En las organizaciones pequeñas, suelen predominar militantes, activistas y voluntarios que eventualmente son contratados en función de los recursos, tienen una fuerte identidad ideológica con los fines de la organización y viven en los barrios o pueblos donde habitan las propias comunidades a las que dirigen su acción. A pesar de que las entidades pequeñas no disponen de los recursos para contratar auditorías externas o evaluadores, se han dado cuenta de que el conocimiento cercano con su contraparte es, en buena medida, garantía de buenos resultados: «no ha habido problemas para justificar, las evaluaciones de los técnicos son siempre muy buenas, los técnicos van allí y ven cómo evalúan, lo importante es conocer la contraparte $[\ldots] »(\mathrm{EE}-07)$. 
En cuanto a los indicadores de evaluación, cabe señalar que las entidades abordadas sugieren un replanteamiento de aquéllos, pues perciben cierta inadecuación que les impide medir el impacto real y consolidado en el tiempo de las acciones ejecutadas:

Los indicadores deben medir el impacto en la transformación en la vida del otro, hacer 10 reuniones con 15 asistentes no me habla de la transformación. ¿Cómo sé yo que lo que hice está cambiando las condiciones de vida del otro? Ni las entidades internacionales se están preguntando esto [...] (EC-07). 


\title{
7. PLANTEAMIENTOS EN TORNO A LA EVALUACIÓN DE LOS PROYECTOS
}

\begin{abstract}
En la llamada cooperación al desarrollo, el reto consiste en dar responsabilidad a las personas para que sean protagonistas de su propia historia de liberación personal y colectiva. ¿Cuál es, sin embargo, el estado actual de la llamada cooperación al desarrollo y de las ONGD?
\end{abstract}

Foro Social Mundial de Porto Alegre (2002)

Resulta complejo estimar el impacto global que ha tenido la cooperación al desarrollo en la vida de las comunidades del «Sur». Las razones de esta dificultad radican en la heterogeneidad de pueblos y situaciones en las regiones empobrecidas, la pluralidad de actores que intervienen en todo el planeta y el escaso arraigo de las prácticas de evaluación del impacto.

Por lo general, el tipo de mensajes que dirigen las ONGD al público del «Norte» está relacionado con la sensibilización, concienciación y formación de las problemáticas de pobreza, violencia, desnutrición, desigualdad de colectivos, etc., que ocurre en los países del llamado «Tercer Mundo». No obstante, los resultados alcanzados por los programas y proyectos ejecutados son menos difundidos entre el público general (Sogge, ed., 1998).

Por una parte, no todas las organizaciones realizan evaluaciones sistemáticas y objetivas ${ }^{183}$ que determinen los resultados obtenidos en su tra-

183 La OCDE define la evaluación como «Un escrutinio sistemático y objetivo de un proyecto, programa o política en ejecución o terminado» (BID, 1997). La ONU también asigna esas características a su definición de la evaluación (Pichardo Muñiz, 1992). 
bajo cooperante; algunas realizan un informe para la entidad que ha financiado el proyecto.

De otro lado, algunas organizaciones que realizan evaluaciones rigurosas exponen sus alcances a un público especializado que, por lo general, se muestra simpatizante del trabajo cooperante y coincide con los principios de la solidaridad internacional.

Las ONG han adoptado como instrumento preferente el "proyecto de desarrollo»; no obstante, en algunas ocasiones esta forma de intervención «presenta inconvenientes y riesgos muy serios en cuanto al tipo de cooperación que representa (pequeños proyectos dispersos y puntuales sin posibilidad real de continuidad, etc.)» (Malé, 1999, 25).

Una de las principales razones que dificultan la valoración del impacto de la cooperación al desarrollo es el escaso arraigo de una cultura de la evaluación (BID, 1997; Acosta, 1997) y de unos criterios unificados de medición del impacto.

\subsection{La evaluación, ¿un problema para las ONGD?}

En el momento actual, el proceso de la evaluación puede generar a las ONGD tensiones, pero también esperanzas. ${ }^{184}$ Según la concepción predominante que la organización tenga de la evaluación, ésta puede convertirse en una inevitable e incómoda tarea o, por el contrario, en un proceso esperanzador de aprendizaje colectivo.

Según la primera concepción, la evaluación puede representar un problema considerable porque preocupa la neutralidad y objetividad del estudio, la posibilidad de encontrar resultados desalentadores, los criterios que se utilicen para evaluar y las posibles repercusiones en cuanto a la financiación. Además, se teme el nivel de difusión de los resultados (y los destinatarios): puede ocasionar una sensación de que se juzga la competencia de los miembros de la organización, y, si la evaluación es externa, puede

184 En 1991 Oxfam encargó a una institución brasileña una evaluación del trabajo realizado por un movimiento del noreste de Brasil (MOC). Este movimiento escribió el artículo «El hecho de ser evaluado: Tensiones y esperanzas», en el que expresa lo que siente al ser objeto de una evaluación (MOC, 2000). 
provocar la sensación de «invasión externa». En ocasiones, también puede ser vista como una costosa carga que interrumpe y retrasa el trabajo.

Según la segunda concepción, la evaluación permite a las organizaciones y a las comunidades aprender de la propia experiencia, evita que se repitan errores y ayuda a reducir el margen de improvisación. Además, es una oportunidad para que los cooperantes, voluntarios y beneficiarios se cuestionen de forma constructiva, a través de la reflexión de la práctica cotidiana y del examen del trabajo propio. Asimismo, puede proporcionar las bases para establecer una nueva dirección del tipo de trabajo que se realiza. La evaluación resulta imprescindible en un contexto en cual se habla cada vez más de la «calidad de la ayuda» (Alonso, 2004; Prats, 2005).

$\mathrm{Al}$ respecto, Grzybowski (1998), de la ONG brasileña IBASE, señala que, «según la lógica de los proyectos, la cooperación ha podido construir hospitales, crear centros de salud, escuelas [...] todo un conjunto de infraestructuras y de propuestas para hacer frente a la pobreza; pero [muchos de ellos no han estado] asociados a la voluntad de ese pueblo, a su organización, a sus aspiraciones, a sus maneras de actuar y a su capacidad efectiva de participación». De esta manera, la «cultura de la evaluación» también debe constituir parte de la acción transformadora de un pueblo, un barrio o una comunidad, porque permite aprender a corregir las actuaciones que se alejan de los propósitos de los protagonistas de la cooperación.

La evaluación como actitud (no sólo como fase metodológica) fomenta la reflexión de la práctica cotidiana y, por tanto, ayuda a generar una conciencia de aquellos procesos que dificultan el cambio social; en este sentido, la evaluación constituye parte fundamental de las redes de activación del poder local. «Por tanto, para que la evaluación se convierta en parte integral del desarrollo de una experiencia, debe formar parte de la cultura del grupo, de la institución del sector [...] la evaluación requiere, por otra parte, ser contextuada y pertinente culturalmente. Es decir, tanto su concepción como su desarrollo metodológico y técnico tienen que ser coherentes con el mundo cultural de los actores involucrados» (Acosta, 1997, 34).

\subsubsection{La necesidad de la evaluación}

Uno de los primeros foros que debatió el impacto de las ONGD fue el convocado en Inglaterra por Save the Children y el Instituto de Políti- 
ca y Gestión de Desarrollo de la Universidad de Manchester en 1992 y en 1994. En estos espacios buscaban examinar las causas y consecuencias del crecimiento de las ONG, su impacto y su papel en el «nuevo orden mundial».

Michael Edwards y David Hulme (1996) editaron las conclusiones de este foro en tres publicaciones, entre la que cabe destacar la segunda, ${ }^{185}$ en la que «buscan definir los criterios para evaluar el impacto del trabajo de las ONG» (Valderrama, 2002, 2), tarea que ellos reconocían como débil. Señalaban que «la mayor parte de las evaluaciones realizadas se refieren a muestras pequeñas y a sectores y proyectos específicos de ciertas agencias. La vigencia de las ONG en un futuro se asocia a su capacidad de rendición adecuada de cuentas y al desarrollo de mecanismos que permitan verificar su performance» (Edwards y Hulme, 1996, 3).

Otro de los autores que más ha insistido en la importancia de la evaluación de la cooperación ha sido Alan Fowler (1997); para éste, "no existen indicadores adecuados para medir el impacto de las tareas de desarrollo propuestas. Generalmente se pone el énfasis en actividades de proyectos, en resultados puntuales, lo cual resta posibilidades de aprendizaje y de evaluar el verdadero impacto de procesos de desarrollo» (Valderrama, 2002, 4).

En 1996 la OCDE encargó un estudio de síntesis de evaluación de las organizaciones no gubernamentales para estimar el impacto de sus intervenciones y métodos; las conclusiones han permitido conocer que «un cierto número de organizaciones [han] comenzado a prestar atención a sus propios déficits de aprendizaje y a desarrollar mejor los conocimientos y técnicas ya obtenidas» (Sogge, ed., 1998, 9).

Estos primeros estudios demuestran la juventud de la evaluación como instrumento de trabajo para los proyectos de cooperación, ${ }^{186}$ lo que reafir-

\section{Edwards y Hulme (1996).}

186 El año 1996 es una fecha clave en la evaluación de la cooperación: se edita el segundo informe de Edwards y Hulme (cit. en nota 185); la OCDE encarga uno de los principales estudios sobre impacto de la cooperación (Kyllönen, 1997); empieza a funcionar la Sociedad de Evaluación Europea (EES), fundada en La Haya en 1994; el Transnational Institute (TNI) publica el libro Compassion and calculation: The business of private foreign aid. 
ma el hecho de que muchas dificultades e inconvenientes en el conocimiento del impacto de estos proyectos tiene que ver con un lento proceso de inclusión de la evaluación en la ejecución de esta estrategia de trabajo.

Además de la corta trayectoria de la evaluación, hay otras dificultades para que ésta sea un punto débil de los proyectos de cooperación: «Aunque hay indicios de que las cosas están cambiando para mejor, la mayoría de las organizaciones rara vez dominan estos problemas [la escasa evaluación] porque cuestan dinero y tiempo [...] Puede afirmarse que estas dificultades explican por qué se han realizado tan pocos estudios de impacto» (Sogge, ed., 1998, 165).

Antes de la década de los noventa el objeto de la evaluación daba prioridad al análisis costo-beneficio, midiendo resultados a través de índices y tasas; sin embargo, en los últimos años "ha habido un avance conceptual en la disciplina y se ha entendido que, para que la evaluación sea considerada un instrumento esencial en la toma de decisiones, para que convierta a la organización en una organización por el aprendizaje, la valoración económica de los resultados no es suficiente» (Gascó Hernández, 1999). En tal sentido, otros autores especializados en la evaluación del desarrollo como Chris Roche, sostienen que "la evaluación de impacto debe considerarse una parte integral del trabajo del desarrollo, a lo largo del ciclo del proyecto o programa» $(2004,17)$. De forma similar a lo descrito por los entrevistados y los anteriores autores, Sogge (ed., 1998, 135) había afirmado años atrás lo siguiente: «La evaluación se ha convertido en una forma de contabilidad para los donantes, en lugar de ser una de las responsabilidades de quien defiende los intereses de la organización o una base para la autoevaluación. Los requisitos de evaluación de las autoridades que subvencionan pueden minar los procesos de aprendizaje internos y por consiguiente la calidad de las relaciones con los cesionarios del Sur y sus colegas».

\subsection{Un elemento prioritario en la legislación estatal y aragonesa}

La legislación española y, en concreto, la aragonesa han resaltado en su contenido y reglamentación el papel que debe ocupar la evaluación de 
los proyectos de cooperación internacional. Señalan, incluso, en términos generales, los aspectos a tener en cuenta en las evaluaciones.

Por ejemplo, el capítulo III de la Ley 23/1998, de Cooperación Internacional para el Desarrollo, establece, en la sección primera, las funciones de los órganos competentes en la formulación y ejecución de la política española de cooperación internacional para el desarrollo, y asigna a la Secretaría de Estado para la Cooperación Internacional y para Iberoamérica (SECIPI) el papel de evaluar «la política de cooperación para el desarrollo, los programas y proyectos financiados con fondos del Estado en curso de ejecución y los finalizados, desde su concepción y definición hasta sus resultados. La evaluación tendrá en cuenta la pertinencia de los objetivos y su grado de consecución, así como la eficiencia y eficacia alcanzadas, el impacto logrado y la viabilidad comprobada en los programas y proyectos ya finalizados» (Ley 23/1998, cap. III).

Además, en la tercera sección de dicha ley se resalta el papel de los órganos consultivos y de coordinación de cooperación para el desarrollo (el Consejo de Cooperación al Desarrollo, la Comisión Interterritorial de Cooperación para el Desarrollo y la Comisión Interministerial de Cooperación Internacional) y encomienda al primer y al tercer órgano funciones relacionadas con el conocimiento de las evaluaciones de los proyectos.

Por su parte, la normativa aragonesa (Ley 10/2000) en el título 2, respectivo a la planificación de la cooperación internacional, afirma en su artículo $4 .^{\circ}$ que «los planes contendrán los mecanismos y criterios básicos para la medición del impacto de la ayuda, la evaluación de la ejecución de dichos planes y la justificación y control del gasto, adaptados a la realidad de los países receptores».

Asimismo, el Decreto 68/2000 del Gobierno de Aragón, que regula la Cooperación al Desarrollo y la Solidaridad con el Tercer Mundo, designa a una Comisión de Valoración y Evaluación de los Programas y proyectos (capítulo VI, sección 1. a) y establece una serie de elementos valorativos (art. 36), entre los que se encuentra «La capacidad de los programas/proyectos para generar resultados evaluables, perdurables en el tiempo y sostenibles económicamente».

Del mismo modo, el decreto sostiene (art. 38) que esta Comisión «impulsará cuantas acciones estime conveniente para el seguimiento y la 
evaluación sobre el terreno de los programas/proyectos subvencionados, así como para realizar las inspecciones y auditorías que considere de interés, para la correcta consecución de los objetivos y fines de este Decreto».

A pesar de que la tendencia predominante, en la legislación estatal y autonómica, sigue residiendo en los criterios que más interesan a las agencias y a los donantes (control financiero, logros en términos de eficiencia, eficacia y sostenibilidad), es un avance importante que se hayan fortalecido, desde la legislación, los instrumentos y requisitos vinculados a la evaluación de los proyectos y programas. Es de esperar que las agencias y ONGD incrementen la relevancia asignada al cumplimiento de los resultados esperados por las organizaciones locales y, especialmente, las comunidades. Asimismo, se ha dado un paso necesario al hacer referencia a la medición o estudio del impacto, lo cual podría significar que en los próximos años comenzaremos a conocer los resultados consolidados en el tiempo, y no sólo los informes o memorias anuales, que dicen mucho de lo que se ha hecho, pero poco de los cambios que se han arraigado en la vida de las personas y en la estructura socio-económica de las comunidades a través de los años.

\subsection{Propuestas sobre la evaluación de impacto $\mathrm{y}$ sus indicadores}

La insistencia sobre la evaluación de impacto (o evaluación ex-post) en este estudio obedece a que es la mejor forma de exponer los cambios producidos por la acción de las ONGD en las comunidades del «Sur». Otros tipos de evaluación (ex-ante o diagnóstico, supervisión o proceso, evaluación convencional, etc.) han sido más utilizadas en el ciclo del proyecto y no dan cuenta, plenamente, de la forma como afectan (positiva o negativamente) las acciones de una entidad en la vida de un grupo humano (ver cuadro 7.1).

Otra característica de las formas convencionales de realizar la evaluación ha sido la incorporación de métodos descendentes (de arriba hacia abajo) y en exceso tecnificados: Una «forma frecuente de imponer autoridad es la introducción de jerga sofisticada [...]. La valoración de la sabiduría y juicio de las personas comunes es un elemento crucial en cualquier proceso de evaluación de impacto» (Roche, 2004, 46). 
CUADRO 7.1

DIFERENCIAS ENTRE TIPOS DE EVALUACIÓN

Secuencia cronológica: La supervisión se hace frecuentemente y la evaluación periódicamente. Sin embargo, la evaluación de impacto se hace con poca frecuencia, normalmente después de terminar una intervención.

Nivel analítico: La supervisión es principalmente descriptiva y toma nota de los insumos, resultados y actividades. La evaluación es más analítica y examina los procesos, mientras que la evaluación de impacto es principalmente analítica y se interesa por los resultados a más largo plazo.

Especificidad: La supervisión es muy específica y compara un plan en particular y sus resultados. La evaluación hace lo mismo, pero también examina los procesos, mientras que la evaluación de impacto es menos específica y además considera las influencias y eventos externos

FUENTE: Roche $(2004,37)$.

La evaluación de impacto es definida como «el análisis sistemático de los cambios duraderos o significativos - positivos o negativos, intencionados o no- en la vida de las personas, producidos por una acción específica o una serie de acciones» (Roche, 2004, 37). Hasta hace unos años la definición sólo incorporaba la revisión de los cambios duraderos: sin embargo, en situaciones de emergencia o conflicto los cambios producidos no siempre permanecían en el tiempo. De este modo, también se han considerado los cambios que han sido significativos aunque poco duraderos.

La metodología de la evaluación de impacto considera que los cambios sociales no ocurren de forma lineal. No siempre una acción determinada desemboca en el efecto esperado. La forma como interactúan los actores, el tipo de acciones realizadas y el contexto específico que envuelve las anteriores pueden provocar resultados diferentes y a veces inesperados. Por tanto, determinados proyectos o acciones que han tenido éxito con comunidades específicas han fracasado en otros contextos.

Por ende, una de las utilidades de la evaluación del impacto es proporcionar los conocimientos necesarios a todos los participantes (ONGD internacional, ONGD local, beneficiarios) para observar el futuro de tal forma que los proyectos o acciones emprendidas redunden en los aciertos y se aprenda de los errores. Además, en el contexto de este estudio y siguiendo la información suministrada por algunos entrevistados, los proyectos de desarrollo se deberían concebir dentro del marco de los procesos de desarrollo. De este modo, 
El éxito de una intervención, desde el punto de vista del entorno local, se identifica con el propio proceso de desarrollo (evolución positiva o negativa del entorno local en sus diferentes dimensiones: económica, social, política, cultural, medioambiental, institucional) a través de la interacción entre el proyecto y este proceso de desarrollo propio; desde el punto de vista del entorno local, el proyecto es un elemento más que interacciona con la propia realidad, siendo el proceso en su conjunto el centro de gestión y evaluación, en sentido amplio (de las personas, unidades familiares, productivas, organizaciones formales e informales, públicas y privadas) (Ferrero, 2003, 540).

\subsubsection{Fomentar las evaluaciones participativas}

«El desarrollo de procesos de supervisión y evaluación participativos es el elemento básico de la evaluación de impacto. Esto se basa en el punto de vista de que cualquier cambio significativo y duradero en la vida de las personas debe tener en cuenta sus valores, prioridades y opiniones» (Roche, 2004, 46).

Hasta hace pocos años, las comunidades beneficiarias eran consideradas como objeto de intervención por parte de técnicos y entidades especializadas en el desarrollo; de hecho, la bibliografía sobre la metodología de investigación o ejecución de proyectos sociales nos acostumbró a escuchar la expresión "población objeto" (Alvira, 1991). Con tal concepción, era habitual que la relación entre los actores se sustentara en un modelo de conocimiento unidireccional sujeto-objeto. Sujeto pensante («Norte») que conoce, reflexiona e interviene en los problemas del objeto necesitado, susceptible de ser conocido e intervenido («Sur»). Las diversas generaciones en las formas de llevar a cabo la evaluación de los proyectos han significado, la mayoría de las veces, la recopilación de la información necesaria para conocer los resultados de las intervenciones. En ocasiones se ha recurrido a expertos que han aplicado técnicas cuantitativas para emitir un juicio sobre la gestión, sus fortalezas y debilidades. Recientemente, se han dado avances para que las poblaciones beneficiadas por los proyectos tengan mayor cabida en el ciclo del proyecto. Uno de los principales avances en este campo se ha dado a través de la Evaluación Rural Participativa (Roche, 2004). En este sentido, «la cuarta generación de evaluaciones significa una ruptura con las tres anteriores, y se basa fundamentalmente en la participación de los propios beneficiarios en las valoraciones a partir de sus intereses y percepciones intrínsecas» (MAE, 2003, 91).

En esta nueva etapa adquieren relevancia los valores autóctonos de las poblaciones con las que se trabaja, los evaluadores dejan de ser expertos 
con facultad de emitir juicios para convertirse en facilitadores de los procesos de aprendizaje que se producen en la comunidad. Desde este paradigma, la comunidad es artífice del conocimiento, y sus conclusiones se convierten en nuevas agendas que revelan situaciones desconocidas o inadvertidas; con esta concepción, la evaluación pasa a ser un proceso de conocimiento sujeto-sujeto. Es necesario advertir e insistir en que se trata de evaluaciones participativas, no de participación en las evaluaciones. En consecuencia, es prioritario tener presentes algunos principios de la evaluación participativa:

\section{CUADRO 7.2}

\section{PRINCIPIOS DE LA EVALUACIÓN PARTICIPATIVA}

1. El principio de la participación: enfatiza la participación de las partes implicadas en los diferentes momentos de la evaluación (decisión, ejecución y uso de resultados).

2. El principio de aprendizaje: es una evaluación orientada a la práctica y al aprendizaje de la acción. Se trata de una experiencia educativa donde la gente se hace más consciente de sus posibilidades, su realidad social, sus visiones y perspectivas del desarrollo, etc.

3. El principio de negociación: se trata de un proceso social para la negociación entre las diferentes necesidades de la gente, sus expectativas y sus visiones del mundo.

4. El principio de la flexibilidad: los diseños evaluativos gozan de flexibilidad para ser adaptados a cada realidad cambiante y las condiciones del contexto.

FUENTE: L. González (2000, 29).

\subsubsection{Elaborar los indicadores: algunos elementos para considerar}

«La selección de indicadores suele considerarse uno de los pasos más importantes del proceso de evaluación, pero no se ha llegado a un acuerdo sobre el método para hacerlo» (Roche, 2004, 62-65). Las dificultades de establecer una serie de indicadores generalizables radica en la particularidad de los diferentes contextos y personas. Tal como hemos afirmado, la evaluación de impacto considera, más que las evaluaciones convencionales, las características del contexto. Además, la elaboración de los indicadores es un reflejo de la particularidad de cada proyecto, «no poseen vigencia universal» (MAE, 2003, 81). Ante esta dificultad metodológica, podemos sugerir la consideración de las dimensiones básicas para medir el impacto de algunos criterios a tener en cuenta en la elaboración y medición de los indicadores y de los enfoques para su elaboración. 


\section{Dimensiones básicas para medir el impacto (Roche, 2004, 67)}

Riqueza material: Propiedades individuales o colectivas (tierras, ganado, vivienda), ingreso, ahorro y crédito, condición ocupacional, salarios, gastos, seguridad alimenticia y calidad de la dieta, dependencia de prestamistas o de ayuda alimenticia.

Medidas de bienestar social o de capital humano: Se refiere a las condiciones de salud física y psíquica. Por ejemplo, a la mortalidad de bebés y niños, agua y saneamiento y educación, especialmente tasas de alfabetización y de asistencia a las escuelas. En este apartado también pueden entrar la percepción de la paz interior, las posibilidades de celebración de ritos o actos religiosos. Actividades vinculadas con el descanso, el ocio y el juego.

Medidas de empoderamiento $o$ de capital politico: Incluyen la propiedad y control de los bienes, las percepciones de bienestar y calidad de vida, la participación en la toma de decisiones y en las instituciones públicas, el acceso a los recursos públicos, la dependencia y la movilidad, y las tasas de planificación familiar como parámetro del empoderamiento de las mujeres. También se incluyen actos de concienciación, de divulgación, redacción de cartas o escritos a líderes o instituciones, percepción de la seguridad/inseguridad...

\section{Caracteristicas de los indicadores}

Aunque, como hemos afirmado anteriormente, las propiedades de los indicadores dependen del enfoque y tipo de proyecto, suelen emplearse unos criterios mínimos que orienten el proceso y el resultado en la elaboración de los indicadores. En primer lugar, la técnica SMART ${ }^{187}$ ha sido elaborada para ayudar a la planificación y posterior verificación de los indicadores de evaluación del impacto (ver cuadro 7.3). En tal sentido sus propiedades se configuran como requisitos que éstos deben cumplir.

187 Las siglas en inglés SMART equivalen en castellano a 'específicos, medibles, alcanzables, pertinentes y de duración limitada'. 
CUADRO 7.3

PROPIEDADES SMART DE LOS INDICADORES

\begin{tabular}{|l|l|}
\hline Propiedades & Definición \\
\hline Específicos & $\begin{array}{l}\text { Los indicadores deben reflejar lo que el proyecto intenta cambiar, evitando las } \\
\text { cuestiones que están en gran parte sujetas a influencias externas. }\end{array}$ \\
\hline $\begin{array}{l}\text { Medibles e } \\
\text { inequívocos }\end{array}$ & $\begin{array}{l}\text { Los indicadores deben definirse de forma precisa, para evitar la ambigüedad } \\
\text { en su medición e interpretaciones. } \\
\text { Los indicadores deben dar datos objetivos, independientemente de quién haga } \\
\text { la recopilación. } \\
\text { Los indicadores deben poder compararse entre grupos y proyectos, para permitir } \\
\text { que los cambios puedan compararse y agruparse. }\end{array}$ \\
\hline $\begin{array}{l}\text { Alcanzables } \\
y \text { sensibles }\end{array}$ & $\begin{array}{l}\text { Los indicadores deben ser alcanzables por el proyecto y, por tanto, deben ser } \\
\text { sensibles a los cambios que el proyecto desee hacer. }\end{array}$ \\
\hline $\begin{array}{l}\text { Pertinentes } \\
\text { y fáciles de } \\
\text { recopilar }\end{array}$ & $\begin{array}{l}\text { La información sobre los indicadores escogidos debe poder recopilarse en un } \\
\text { tiempo razonable y con un coste razonable. } \\
\text { Los indicadores deben ser relevantes para el proyecto. }\end{array}$ \\
\hline $\begin{array}{l}\text { Duración } \\
\text { limitada }\end{array}$ & \begin{tabular}{l} 
Los indicadores deberían describir cuándo se espera un cambio determinado. \\
\hline
\end{tabular} \\
\hline
\end{tabular}

FUENTE: Roche $(2004,71)$.

CUADRO 7.4

PROPIEDADES SPICED DEL DESARROLLO Y EVALUACIÓN DE INDICADORES

\begin{tabular}{|l|l|}
\hline Propiedades & Definición \\
\hline Subjetivos & $\begin{array}{l}\text { Los entrevistados tienen una posición o experiencia que les proporciona conoci- } \\
\text { mientos únicos, que pueden hacer que el tiempo de los investigadores sea muy pro- } \\
\text { ductivo. En este sentido, lo que para otros puede ser «anecdótico» se convierte en } \\
\text { crucial debido al valor de la fuente. }\end{array}$ \\
\hline Participativos & $\begin{array}{l}\text { Los indicadores deben desarrollarse conjuntamente con aquellos que están en } \\
\text { mejor posición para evaluarlos. Esto significa hacer partícipes a los beneficiarios } \\
\text { finales del proyecto, pero también puede implicar involucrar al personal local y a } \\
\text { otras partes interesadas. }\end{array}$ \\
\hline $\begin{array}{l}\text { Interpretados } \\
\text { y comunicables }\end{array}$ & $\begin{array}{l}\text { Los indicadores definidos localmente pueden no significar mucho para otras } \\
\text { partes interesadas, de forma que con frecuencia es necesario explicarlos. }\end{array}$ \\
\hline $\begin{array}{l}\text { Verificados } \\
\text { y comparados }\end{array}$ & $\begin{array}{l}\text { La validez de la evaluación debe verificarse comparando los diferentes indicadores } \\
\text { y progresos, y utilizando diferentes entrevistados, métodos e investigadores. }\end{array}$ \\
\hline Empoderantes & $\begin{array}{l}\text { El proceso de establecer y evaluar indicadores debe ser empoderante por sí mismo } \\
\text { y permitir que grupos e individuos reflexionen críticamente sobre su situación. }\end{array}$ \\
\hline $\begin{array}{l}\text { Diversos y } \\
\text { desagregados }\end{array}$ & $\begin{array}{l}\text { Debe hacerse un esfuerzo para buscar indicadores de grupos diversos, especial- } \\
\text { mente hombres y mujeres. Esta información debe registrarse de tal manera que las } \\
\text { diferencias puedan rastrearse a lo largo del tiempo. }\end{array}$ \\
\hline
\end{tabular}

FUENTE: Roche $(2004,72)$. 
Por otra parte, la herramienta SPICED ${ }^{188}$ establece una ayuda importante, más dirigida al proceso de elaboración que a los resultados de los requisitos (ver cuadro 7.4 ).

\section{Tres enfoques para la elaboración de los indicadores}

Primer enfoque: El primer enfoque, quizá el más metódico, parte de los indicadores establecidos al inicio del proyecto, se centra principalmente en éste e implica una comparación entre la situación previa y la posterior. Según los casos, se pueden identificar indicadores nuevos o modificar los establecidos. La dificultad de este enfoque radica en que se verifican los indicadores predeterminados, $y$, por tanto, el cambio percibido es el cambio esperado. Por tanto, no siempre es conveniente definir los indicadores de impacto al comienzo del proyecto. Esto excluye los cambios inesperados y aquellas áreas que no han sido reveladoras al inicio del proyecto, es decir, aquellos índices que hemos denominado en este estudio, indicadores endógenos. ${ }^{189}$

Segundo enfoque: Este segundo enfoque, de carácter exploratorio, corresponde al que han sugerido algunas entrevistas del estudio (EC-02, EC-07). En este caso, las ONGD trabajan con las comunidades locales para establecer un conjunto de indicadores — relacionados con los sectores en los que el proyecto había trabajado- que luego podrían utilizarse para evaluar el proyecto. «El equipo [...] desarrolló un conjunto de indicadores a partir de la perspectiva de las personas de las comunidades, mediante entrevistas de grupos de muestra (con representantes de todos los estratos sociales). Se les pidió que expresaran qué indicadores (de acuerdo a cada sector) mostrarían que el proyecto puede retirarse del área. Estos indicadores intangibles fueron con los mejores criterios para evaluar el nivel de logro». (Roche, 2004, 63).

188 Las siglas en inglés SPICED equivalen a 'subjetivo, participativo, interpretado, verificado, empoderador y diverso'.

189 Hay uno, de muchos ejemplos, que es revelador en el texto de Chris Roche: «Al preguntarle a un empleado de Oxfam en África cómo sabía si un proyecto de cultivo de tomates había tenido éxito, respondió: "porque los hombres de la aldea están casándose con una segunda esposa”. Entonces le preguntaron por qué no había mencionado este hecho en el informe anual, a lo que respondió: "porque eso no es lo que ustedes quieren. Ustedes quieren '10 toneladas por hectárea”" $(2004,53)$. 
Tercer enfoque: Este enfoque es abierto y deductivo. Empieza por preguntarle a la gente cuáles han sido los principales cambios en la vida de la comunidad, independientemente de cualquier proyecto o acción. Después de esta identificación, se explora con las personas afectadas cuáles han sido los procesos que han producido dichos cambios, entre los cuales, los proyectos o programas de las ONGD pueden ser un elemento. Sin embargo, son los pobladores los que identifican los cambios y luego atribuyen las causas de éstos.

\subsubsection{Indicadores basados en las percepciones comunitarias,} los valores organizativos y los contextos conflictivos

\section{Las percepciones de la comunidad, un indicador no despreciable}

Las evaluaciones convencionales no han ahondado lo suficiente en las opiniones y percepciones de las poblaciones a las que se dirigen los proyectos. Desde los enfoques cuantitativos, el análisis de las percepciones puede considerarse como una categoría subjetiva y poco rigurosa; sin embargo, cada vez más organizaciones recurren a la elaboración de indicadores basados en las percepciones de la población para estimar el impacto de la cooperación en la vida de los beneficiarios: "Los proyectos no se pueden considerar como un "éxito" o "fracaso" si las percepciones de los supuestos beneficiarios de la intervención son muy diferentes de las que tienen el personal del proyecto o el evaluador externo» (Roche, 2004, 46).

Por tanto, cada vez más evaluaciones contemplan indicadores cualitativos para dar cuenta de otras dimensiones y variables que los indicadores convencionales, de corte más cuantitativo, no logran describir. En este sentido, son cada vez más las propuestas de modelos integrales (L. González, 2000) y enfoques heterodoxos (Ferrero, 2003) que incorporan indicadores de ambos tipos. Los indicadores cualitativos permiten describir «los comportamientos de las comunidades respecto al uso de los bienes y servicios generados por la intervención [...], no expresables en unidades, pero sobre cuyo cumplimiento se puede emitir un juicio, mediante el empleo de declaraciones descriptivas con indicaciones de la dirección de los cambios» (MAE, 2003, 82). Igualmente, el análisis de las percepciones de la comunidades frente a los programas y proyectos de desarrollo proporciona una información muy valiosa para el aprendizaje de los actores que intervienen en la cadena de la cooperación. 
CUADRO 7.5

MATRIZ DE INTERPRETACIÓN Y ANÁLISIS GLOBAL

DE ESCENARIOS DE EVALUACIÓN

\begin{tabular}{|l|l|l|l|l|l|}
\hline $\begin{array}{l}\text { Categoría } \\
\text { de análisis }\end{array}$ & $\begin{array}{l}\text { Percepción } \\
\text { de parte } \\
\text { del programa }\end{array}$ & $\begin{array}{l}\text { Percepción de } \\
\text { parte de la } \\
\text { comunidad }\end{array}$ & $\begin{array}{l}\text { Criterios de } \\
\text { cooperación } \\
\text { internacional }\end{array}$ & $\begin{array}{l}\text { Información } \\
\text { de carácter } \\
\text { estadístico }\end{array}$ & $\begin{array}{l}\text { Sostenibilidad } \\
\text { de las acciones }\end{array}$ \\
\hline $\begin{array}{l}\text { Percepción } \\
\text { del recurso } \\
\text { del agua }\end{array}$ & & & & & \\
\hline $\begin{array}{l}\text { Realización } \\
\text { de la obra } \\
\text { física }\end{array}$ & & & & & \\
\hline $\begin{array}{l}\text { Participación } \\
\text { comunitaria }\end{array}$ & & & & & \\
\hline $\begin{array}{l}\text { Organización } \\
\text { social }\end{array}$ & & & & & \\
\hline $\begin{array}{l}\text { Sostenibilidad } \\
\text { de las acciones }\end{array}$ & & & & & \\
\hline
\end{tabular}

FUENTE: Bolaños, Castelleti y Caicedo $(1998,34)$.

Un ejemplo se puede encontrar en el Departamento de Evaluación de Operaciones y Políticas del Ministerio de Asuntos Exteriores de los Países Bajos, que realizó en 1997 una evaluación que valoraba la cooperación entre Holanda y Bolivia desde 1969 hasta 1996 y dedicó un capítulo a las "percepciones locales de la cooperación al desarrollo». En este capítulo se resaltaban los logros y dificultades desde la perspectiva de los mismos pobladores. Por una parte, éstos elogiaron la posibilidad de trabajar en forma conjunta, manifestaban su agrado por aprender a planificar, a mejorar la coordinación de las actividades, a negociar y a establecer relaciones con entidades externas. Sin embargo, como aspectos negativos encontraron que «algunos actores se sintieron bastante presionados y objeto de comportamientos autoritarios. [...] Al mismo tiempo se vio con gran temor el que la ayuda llegara a amenazar la unidad comunal y creara divisiones internas», especialmente con proyectos productivos, cuyos beneficios se repartían de forma individual (Ministerio de Asuntos Exteriores de los Países Bajos, 1997, 11). 
En Colombia destaca un estudio en el cual se comparaban las percepciones de los integrantes de la organización que gestionaba un programa con las percepciones de varios representantes de la comunidad en torno a una serie de categorías o dimensiones de un Programa de Agua Potable y Saneamiento en la Costa Pacífica (Bolaños, Castelleti y Caicedo, 1998). Además, este trabajo incorporaba otros ámbitos como los criterios de la cooperación internacional, información de carácter estadístico, y la sostenibilidad de los logros alcanzados (ver cuadro 7.5).

\section{Establecer indicadores basados en los valores organizativos}

En los próximos años, con la fuerte incursión de las empresas privadas en el ámbito de la cooperación, uno de los rasgos distintivos que puede diferenciar a las organizaciones solidarias de las organizaciones productivas serán los valores que caracterizan a la organización. Tal como lo afirma Hailey $(2004,205)$, «Se teme que ante este nuevo "gerencialismo" muchos de los valores originales que distinguían la ONG se vean amenazados y acaben dejándose a un lado». Por tanto, propone la elaboración de indicadores, no como atribuciones específicas de los proyectos, sino como características propias de toda la organización. A pesar de que los indicadores enumerados en el cuadro 7.6 no están pensados para una evaluación de impacto, nos pueden sugerir dimensiones novedosas para su elaboración.

Las iniciativas de desarrollo de los medios de acción de una ONGD tienen que reflejar sus propios valores con el fin de expresar y proteger la identidad singular de las entidades como agentes clave de la sociedad civil. Por lo tanto, deben elaborar su propia tipología de indicadores de modo que queden reflejados sus valores fundamentales, y contribuya a diferenciarlas de los valores de las agencias nacionales e internacionales, las empresas privadas y otros actores. Por ejemplo, en el caso colombiano se pueden analizar experiencias como las del Foro Interétnico de Solidaridad Chocó, por el cual las organizaciones comunitarias elevaron una serie de demandas para exigir al Estado, la Iglesia y las ONGD una serie de valores y criterios de actuación para que estos actores puedan continuar trabajando en su territorio. Es una experiencia que puede sugerir la posibilidad de que sean las comunidades quienes evalúen la acción de las organizaciones nacionales e internacionales (ver anexo 4). 
CUADRO 7.6

INDICADORES BASADOS EN VALORES ORGANIZATIVOS

¿Tiene la organización la capacidad de aprender de las experiencias pasadas y pensar en términos criticos sobre si misma?

¿Es esta organización responsable y transparente en su trato con la comunidad?

- Que el personal y la comunidad destinataria sepan cómo se toman las decisiones.

- Que las estrategias, los principios básicos, los objetivos, las cuentas, las escalas retributivas, etc., sean accesibles y se comuniquen a la comunidad de destino, el personal y los miembros del consejo.

- Que la organización publique los artículos con un estilo y lenguaje apropiados para la comunidad destinataria, el personal, los departamentos gubernamentales y los donantes.

- Que se celebren reuniones públicas para la comunidad destinataria de forma regular, en diferentes localidades del programa.

- Que la organización celebre reuniones mensuales con el personal y se comprometa a realizar un ejercicio anual de autoevaluación.

- Que la comunidad destinataria esté representada en las reuniones de toma de decisiones, que participe en el proceso de toma de decisiones o tenga derecho a vetar decisiones.

- Que las decisiones no sean tomadas de forma habitual por altos empleados sin consultar previamente a los grupos destinatarios, a los empleados y a la junta directiva.

¿Tiene esta ONG legitimidad local y arraigo en la sociedad local?

- Que la organización cuente con miembros establecidos en la comunidad local, y que por lo menos un $10 \%$ de éstos asistan a las reuniones públicas.

- Que las reuniones públicas se celebren de forma regular y en diferentes localidades de la comunidad.

- Que la organización mantenga un contacto regular con un mínimo de ONG locales, así como con las redes locales de ONG.

- Que por lo menos dos tercios del personal y de los miembros representen a grupos étnicos, religiosos o idiomáticos locales y que vivan en la comunidad.

- Que la organización divulgue informes con un estilo y lenguaje adecuados para la comunidad destinataria, el personal y los departamentos gubernamentales.

FUENTE: Elaboración propia a partir de un resumen de la propuesta de Hailey (2004, 208-211).

\section{Los indicadores en un contexto de conflicto armado}

Como se ha descrito en el apartado correspondiente al trabajo de campo, los métodos para evaluar el impacto se ven alterados en contextos de emergencias y conflictos. Por tanto, es necesario tener en cuenta algunos elementos de cara a la elaboración de los indicadores en contextos como el colombiano. Para algunos evaluadores, la ejecución de proyectos cortos o de ayuda humanitaria debe incorporar mayor flexibilidad que los proyectos de desarrollo convencionales, ya que «la matriz resulta compleja y poco práctica si se establece con rigidez, dada la flexibilidad requerida por las emergencias y la importancia que cobran los supuestos externos que necesariamente obligan a realizar ajustes permanentes sobre lo planificado en cuanto a resultados e indicadores» (L. González, 2000, 33). 
CUADRO 7.7

\section{EJEMPLO DE INDICADORES PARA LA EVALUACIÓN DEL IMPACTO EN ZONAS CONFLICTIVAS}

\begin{tabular}{|c|c|c|}
\hline Dimensiones & Descripción & Indicadores \\
\hline $\begin{array}{l}\text { Empoderamiento, } \\
\text { incidencia } \\
\text { política } \\
\text { y organización } \\
\text { social }\end{array}$ & $\begin{array}{l}\text { - Percepción de la incidencia política a } \\
\text { nivel local, nacional o internacional } \\
\text { - Capacidad de interlocución con los acto- } \\
\text { res armados } \\
\text { - Cambios en la presencia y cobertura de } \\
\text { organizaciones sociales, religiosas, eco- } \\
\text { nómicas... (locales, nacionales, interna- } \\
\text { cionales) } \\
\text { - Estimación de la presencia del capital } \\
\text { social en la cadena de la cooperación } \\
\text { - Consecución o pérdida de autonomía } \\
\text { respecto al acceso a la alimentación, } \\
\text { sanidad y educación frente al bloqueo de } \\
\text { los grupos armados } \\
\text { Capacidad de incidir en la gestión de los } \\
\text { recursos económicos } \\
\text { Capacidad de movilización de la pobla- } \\
\text { ción por parte de las organizaciones } \\
\text { Elaboración y puesta en marcha de pla- } \\
\text { nes comunitarios } \\
\text { - Creación de espacios de reflexión y } \\
\text { acción sobre las relaciones de género } \\
\text { adecuadas al contexto cultural del terri- } \\
\text { torio }\end{array}$ & $\begin{array}{l}\text { - No, frecuencia... de denuncias, manifiestos, } \\
\text { notas de prensa, repercusión mediática... } \\
\text { - N. }{ }^{\circ} \text { y tipo de encuentros, cartas, reunio- } \\
\text { nes, comunicados... } \\
\text { - N. }{ }^{\circ} \text { nuevos afiliados o socios. Nuevos } \\
\text { proyectos } \\
\text { - Contactos, invitaciones, nuevas contra- } \\
\text { partes, pertenencia a redes, coordinado- } \\
\text { ras..., incremento de la gestión de recur- } \\
\text { sos basados en la confianza... } \\
\text { - Calidad en la alimentación según nivel } \\
\text { nutricional de los habitantes, n. }{ }^{\circ} \text { de nue- } \\
\text { vos médicos, camas, botiquines... } \\
\text { - Reuniones, encuentros con empresas, sin- } \\
\text { dicatos, instancias del gobierno local, } \\
\text { departamental, nacional... } \\
\text { - Concentraciones, foros regionales, cam- } \\
\text { pañas... } \\
\text { - Presentación de un plan plurianual elabo- } \\
\text { rado por los miembros de la comunidad } \\
\text { N. }{ }^{\circ} \text { de mujeres que participan en las reu- } \\
\text { niones. \% respecto al n. }{ }^{\circ} \text { de hombres }\end{array}$ \\
\hline $\begin{array}{l}\text { Seguridad } \\
\text { y Violencia }\end{array}$ & $\begin{array}{l}\text { - Desplazamiento forzado } \\
\text { - Percepción de los posibles desplazamien- } \\
\text { tos evitadps } \\
\text { - Asesinatos, masacres y violaciones a los } \\
\text { DD.HH. } \\
\text { - Repercusión de las agresiones violentas } \\
\text { en las familias } \\
\text { - Percepción del riesgo y del camino en la } \\
\text { vulnerabilidad individual o comunitaria } \\
\text { - Cambios en la incidencia de las violacio- } \\
\text { nes a los DD.HH. y al DIH en el terri- } \\
\text { torio }\end{array}$ & $\begin{array}{l}\text { - N. }{ }^{\circ} \text { de desplazados retornados } \\
\text { - Estimación de las masacres o asesinatos } \\
\text { selectivos evitados } \\
\text { - Reducción o aumento en los homicidios } \\
\text { respecto a otros períodos } \\
\text { - N. }{ }^{\circ} \text { de denuncias de violación a los } \\
\text { DD.HH. } \\
\text { - Incremento o descenso en el número de } \\
\text { viudas, número de huérfanos... } \\
\text { - Sentimiento de seguridad o vulnerabili- } \\
\text { dad }\end{array}$ \\
\hline $\begin{array}{l}\text { Lógicas } \\
\text { endógenas }\end{array}$ & $\begin{array}{l}\text { - Elaborar, con las comunidades, una serie } \\
\text { de indicadores que midan el impacto de } \\
\text { las intervenciones de acuerdo, por una } \\
\text { parte, con sus expectativas y aspiracio- } \\
\text { nes; y, por otra, con sus formas de con- } \\
\text { cebir el desarrollo, la vida, la riqueza, la } \\
\text { felicidad, etc. }\end{array}$ & - A construir por los/las participantes \\
\hline
\end{tabular}

FUENTE: Elaboración propia. 
Como sostiene Roche (2004), la inseguridad, el temor y el trauma podrían hacer que no sólo sea peligroso que las personas afectadas por la emergencia "digan la verdad», sino muy contraproducente. Especialmente en las situaciones de conflicto, varios grupos querrán asegurarse de que su versión de la «verdad» predomine, lo cual tendrá implicaciones para los procesos participativos.

Muchas veces las agencias externas «subestiman las respuestas, el estado de preparación y las capacidades locales y, a veces, las socavan» (Roche, $2004,208)$. Un enfoque integral de la evaluación de impacto en situaciones de emergencia debe incorporar los méritos relativos y el impacto de los actores locales frente a los actores externos, el impacto que tienen entre sí y sus implicaciones en una respuesta a largo plazo, así como el grado de predicción de la emergencia en cuestión.

Las evaluaciones de impacto, particularmente en las emergencias complejas, deben reconocer que los objetivos y las estrategias podrían cambiar a medida que cambian las circunstancias; que muchas veces algunos objetivos no son enunciados o acordados por todas las partes con antelación y que los efectos imprevistos son habituales. Con frecuencia la medición del impacto del proyecto en los medios de vida y en el bienestar de los beneficiarios exige la integración continua de (nuevos) indicadores de impacto durante su ejecución. Es la única forma de saber si el proyecto está teniendo alguna incidencia en los beneficiarios.

En este contexto, adquieren relevancia algunos indicadores que han surgido, explícita o implícitamente, a lo largo de la investigación. En el cuadro 7.7 se exponen varios ejemplos que podrían complementar u orientar la elaboración de los indicadores a las organizaciones y comunidades participantes.

Otras recomendaciones relevantes sugeridas por Chris Roche (2004, 75) se pueden resumir en los siguientes puntos:

- Al inicio de los proyectos, determinar las áreas clave de cambio, así como algunos indicadores específicos de impacto, junto con los beneficiarios finales y el personal local. Esto es necesario para evaluar los avances y puede, en sí mismo, ser un proceso empoderante, pero también es útil para satisfacer las demandas de otras partes interesadas, particularmente los donantes. 
- Asegurarse de que estos indicadores se han obtenido de grupos diferentes (hombres/mujeres, personas acomodadas/menos acomodadas, etc.) y de que esas diferencias son tenidas en cuenta.

- Cuando cambien las circunstancias, actualizar y reformular los indicadores, introduciendo indicadores nuevos y abandonando otros. Esto requiere un seguimiento del contexto y el ambiente del proyecto.

- Reducir la cantidad de indicadores de impacto a una proporción manejable, basada en las áreas clave de cambio. Se pueden usar indicadores dispersos para registrar los cambios en áreas clave de la vida de la gente, aunque no se hayan definido previamente. Quizá haya que interpretarlos para que otros puedan entender su significado.

- Explorar los cambios significativos que tuvieron lugar como consecuencia del proyecto/programa, pero que están fuera de los indicadores iniciales. Utilizar esta información en la preparación de indicadores para el futuro.

- Deliberadamente, comenzar a buscar los cambios negativos y a aquellos que podrían informar sobre ellos, especialmente grupos que suelen estar en desventaja como mujeres, minorías o personas que han quedado fuera del proyecto. 


\section{CONCLUSIONES Y RECOMENDACIONES}

Resumir las principales conclusiones de este estudio en unas cuantas líneas es una tarea larga y minuciosa. Por ello, de forma sintética, presentamos los aspectos que, a nuestro juicio, constituyen los resultados tanto buscados como inesperados de este trabajo. El lector habrá encontrado ya planteamientos e ideas que le permitan extraer sus propias conclusiones.

- Las organizaciones locales y las comunidades analizadas en este estudio, tanto empírica como documentalmente, valoran fundamentalmente el acompañamiento social y político que realizan sus homólogas aragonesas. De tal manera que podemos afirmar que el principal impacto que ha dejado la cooperación aragonesa en Colombia es la incidencia politica nacional e internacional como respaldo a los procesos sociales de las comunidades para resistir la presión de los grupos armados, evitando el desplazamiento forzado, promoviendo su autonomía y la generación de las capacidades locales que reviertan en sus proyectos de vida y en sus planes comunitarios.

- Existe una opinión bastante compartida por la cual se afirma que los proyectos de desarrollo y otras colaboraciones realizadas por las ONGD deberían responder a planes comunitarios elaborados previamente por las poblaciones beneficiarias, de tal manera que los proyectos se inserten en las aspiraciones de sus habitantes, del territorio y la cultura a la que pertenecen. En los casos en los que no exista una comunidad organizada, se debe fomentar la participación de líderes comunitarios durante todo el ciclo del proyecto 
y proponerse, directa o indirectamente, la formación o fortalecimiento de la organización social. Las ONGD que desconozcan el papel de los tejidos asociativos y las pautas culturales de las comunidades pueden poner en peligro los procesos de desarrollo.

- Las organizaciones locales y las comunidades beneficiarias se muestran, en general, más favorables a las intervenciones que pretenden apoyar procesos a largo plazo que ejecutar proyectos a corto plazo. Tienen la percepción de que las organizaciones del «Norte» formulan proyectos a corto plazo y esperan obtener resultados inmediatos.

- Las relaciones entre las ONGD y el Estado colombiano se han movido en un amplio espectro que ha contemplado tendencias que van desde las más duras críticas, el diálogo constructivo y llegando hasta la colaboración mutua. Sin embargo, en el contexto colombiano «los temas políticos» no son tangenciales o complementarios, son el centro de la acción de las ONG como actores de una sociedad civil en construcción que aporta el mayor número de muertos en el conflicto armado. Las ONG de derechos humanos, junto con los sindicatos, siguen siendo las entidades de la sociedad civil más vulnerables.

- Colombia ofrece una serie de experiencias que merecen su divulgación internacional en cuanto expresión globalizadora de la solidaridad. Casos como las comunidades de paz han llegado a conocerse y apoyarse en muchas partes del mundo. Los U'wa, San José de Apartadó, Barranca, Chocó, el sur de Bolívar, Ingrid Betancourt... son nombres de poblaciones, regiones o personas que cada vez suenan más en Aragón, España y el mundo. Además de constituir luchas locales globalizadas, son claros ejemplos de acciones colectivas que las ONG deben divulgar al público general como muestra clara de que es posible lograr algunos cambios sociales.

- Las relaciones de confianza y reciprocidad son un valor añadido de la cooperación no gubernamental. A través del estudio se ha encontrado en el capital social un recurso que dinamiza las relaciones entre las organizaciones aragonesas y sus contrapartes en Colombia. Este componente impregna las acciones sociales colectivas con un conjunto de sensaciones, emociones y sentimientos subjetivos que en la mayoría de los casos fortalecen y promueven pautas objetivas como la eficiencia, la eficacia o la calidad del trabajo. 
Las principales recomendaciones, algunas más ambiciosas que otras, que presentamos a las entidades que han financiado este trabajo como a los lectores vinculados al mundo de la solidaridad y la cooperación al desarrollo, son las siguientes:

- En los próximos años se debe fortalecer la acción política de las ONG, entendida como la búsqueda de la transformación social que pasa a través del fortalecimiento de las organizaciones y su incidencia en las políticas sociales, económicas, sanitarias y de infraestructura. La satisfacción de las necesidades no es un acto de benevolencia, sino de justicia. Dicha transformación social debe pasar por el fortalecimiento de una sociedad civil que tiene la obligación de exigir derechos para todos los ciudadanos. La exigibilidad de éstos es un proceso político lento pero contundente de construcción de la identidad ciudadana.

- Es necesario ampliar la mirada sobre el papel de las empresas privadas que intervienen en Colombia como financieras importantes del desarrollo. Sin embargo, su legitimidad como «actores solidarios» debe estar apoyada sobre la base del respeto a los derechos humanos, en cuanto a las condiciones laborales de sus trabajadores, el respeto por el medio ambiente, la calidad y precio de los bienes y servicios, y la responsabilidad social con los usuarios. Negarse sistemáticamente a recibir sus fondos es tan obtuso como recibirlos indiscriminadamente. Existen casos de empresas privadas que pueden contribuir al desarrollo de los pueblos.

- En los próximos años es prioritario prestar atención al futuro del codesarrollo, como expresión de las comunidades de inmigrantes que han empezado hace algunos años a participar de la cooperación al desarrollo. El caso de Colombia puede resultar significativo, con más de cuatro millones de personas repartidas en todo el continente americano y en Europa.

- Las ONGD aragonesas se enfrentan en los próximos años a un incremento de las organizaciones y una drástica disminución de los voluntarios y los socios. No hay, hasta la fecha, un relevo generacional significativo dentro de las organizaciones que sugiera razones para el optimismo. Se deben emprender acciones que atraigan nuevos voluntarios para mantener la fuerza que han logrado adquirir en los últimos años. 
- Un reto pendiente en la evaluación consistiría en descifrar las lógicas endógenas que no se recogen en las evaluaciones convencionales y que permitirían mayor acercamiento a las comunidades y facilitar la rendición de cuentas en sus términos y expectativas.

- A pesar de que la tendencia predominante, en la legislación estatal y autonómica, sigue residiendo en los criterios que más interesan a las agencias y a los donantes, como son el control financiero y los logros en términos de eficiencia, eficacia y sostenibilidad, es un avance importante que se hayan fortalecido, desde la legislación, los instrumentos y requisitos vinculados a la evaluación de los proyectos y programas. Es de esperar que las agencias y ONGD incrementen la relevancia asignada al cumplimiento de los resultados esperados por las organizaciones locales y, especialmente, las comunidades. También se ha dado un paso necesario al hacer referencia a la medición o estudio del impacto, lo cual podría significar que en los próximos años comenzaremos a conocer los resultados consolidados en el tiempo. No basta con los informes parciales y las memorias anuales; cada vez resulta más relevante conocer los cambios que se han arraigado en la estructura social y económica de las poblaciones beneficiarias a través de los años.

- Promover acciones conjuntas con universidades o institutos de cooperación para la realización de formación en metodologías de la evaluación. Asimismo, fomentar investigaciones evaluativas que den cuenta del conjunto de la cooperación. Es necesario empezar a conocer los resultados de los últimos diez años de la cooperación aragonesa en su conjunto: por países, áreas de intervención o por organizaciones, de tal forma que se generen conocimientos que puedan divulgarse y retroalimentar la cooperación. 


\section{BIBLIOGRAFÍA}

AbaD, H. (2003), «Un país de tuertos», Semana (Bogotá), n. ${ }^{\circ}$ 1115, 15 de septiembre.

ACCI (2003), Informe de gestión: Junio 2002 a mayo de 2003, Bogotá.

- (2004a), Manual de acceso a la cooperación internacional, Bogotá.

- (2004b), El mapa de la cooperación, <http://www.acci.gov.co/web_ acci/mapa_acci.asp >.

- (2004c), Estrategia de cooperación internacional, Bogotá, Presidencia de la República de Colombia y Ministerio de Relaciones Exteriores.

Acosta, Alejandro (1997), Evaluación de proyectos sociales. Maestría en educación $y$ desarrollo comunitario, Medellín, CINDE-USCO.

AECI (2006), El mapa de la cooperación, <www.aecicolombia.org> (consulta: enero de 2007); <http://200.71.50.245/webaeci/mapa_coop_col.html>.

- y ACCI (2003), Acta de la VI Reunión de la Comisión Mixta Hispano-Colombiana de Cooperación Técnica, Tecnológica, Educativa y Cultural. 19 de junio de 2003, Palacio de San Carlos, sede del Ministerio de Relaciones Exteriores, Bogotá.

Aguilera, Mario, y Renán Vega (1998), Ideal democrático y revuelta popular, Bogotá, ISMAC, CEREC.

AlOnSO, José Antonio (2004) «Globalización, sociedad civil y sistema multilateral», en Eade y Ligteringen (2004).

Alto Comisionado de las Naciones Unidas para los Refugiados [ACNUR]. Oficina PARA COlOMBia (2004), Balance de la política pública de prevención, protección y atención al desplazamiento interno forzado en Colombia: agosto 2002-agosto 2004, Bogotá.

Alto Comisionado para la Paz (2005), Lineamientos para el enfoque de los proyectos de cooperación internacional, Bogotá, Presidencia de la República. 
Álvarez, Ricardo, Pedro García y Chaime Marcuello (comps.) (2004), Arados y podaderas. IV Curso de Cooperación al Desarrollo, Zaragoza, Diputación General de Aragón, Federación Aragonesa de Solidaridad y Universidad de Zaragoza.

Alvira, Francisco (1991), Metodología de la evaluación de programas, Madrid, Centro de Investigaciones Sociológicas (Cuadernos Metodológicos, 2).

Amnistía Internacional (2001), Temor por la seguridad. AMR 23/074/2001. Colombia AU 198/01. Bogotá, 2 de agosto.

ANDERSON, Ian (2004), "La incidencia política de las ONG del Norte: percepciones, realidad y retos», en Eade y Ligteringen (2004), pp. 275-288.

ARDILA, Martha (2003), "Colombia y sus vecinos, escenarios de relacionamiento», Policy Papers (Bogotá), n.o 1, pp. 1-8. Proyecto «La inserción de Colombia en un sistema internacional cambiante».

Arellano Sánchez, José, y Margarita Santoyo Rodríguez (2001), «Los nuevos sujetos sociales del neozapatismo», Convergencia (México), n. ${ }^{\circ} 24$, enero-abril, pp. 91-139.

ARENAL, Celestino de (1997), «Los acuerdos de cooperación entre la Unión Europea y América Latina (1971-1977): evolución, balance y perspectivas», Revista Española de Desarrollo y Cooperación, n. ${ }^{\circ}$ 1, pp. 111-138.

ARENAS, L. C. (2004), «La luchas contra la explotación petrolera en territorio U'wa: estudio de caso de una lucha local que se globalizó», en B. Santos y M. García, Emancipación social y violencia en Colombia, Bogotá, Norma.

ARENDT, Hanna (1993), La condición humana, Barcelona, Paidós.

ARISTIZÁBAL GARCÍA, José (2004), "La comunidad internacional y el conflicto armado colombiano", Centro de Investigación para la Paz (CIP-FUHEM), 5 de junio.

AROCHA RodrígueZ, Jaime (1997), «Pensamiento afrochocoano en vía de extinción", Revista Colombiana de Psicología, n. ${ }^{\circ}$ 5/6, pp. 216-223.

ASA (1999), «Asamblea de ASA», Y el Sur. Boletín informativo de Acción Solidaria Aragonesa, n. ${ }^{\circ}$ 44, diciembre, p. 10.

Asociación Colombia Unida (2002), Estatutos de la Asociación "Colombia Unida», constituida el 18 de abril de 2002 y reconocida por el Gobierno de Aragón en septiembre de 2002.

AyUnTAMIENTO DE ZARAGOZA (2000), Las organizaciones de voluntariado en la ciudad de Zaragoza, Zaragoza, Servicio de Juventud del Ayuntamiento de Zaragoza.

BAIGES, Siscu (2002), ONGD. Historia, aciertos y fracasos de quienes quieren ayudar al Tercer Mundo, Barcelona, Plaza \& Janés e Intermón-Oxfam. 
Baiges, Siscu, y otros (1996), Las ONG de desarrollo en España. Dilema de la cooperación, Barcelona, Flor del Viento.

BAQUEDANO, Manuel (1990), «Las tecnologías socialmente apropiadas y su contribución al diseño e implementación de políticas sociales en Chile», Revista del Macetero al Potrero (Santiago de Chile).

Barrero García, John Fernando, y otros (2003), Análisis de experiencias en cooperación internacional al desarrollo de las ONG federadas en Antioquia. Trabajo de grado de la especialización en Gerencia Social de la Facultad de Ciencias Económicas de la Universidad de Antioquia, Medellín.

BAUMAN, Z. (1996). «Modernidad y ambivalencia», en Josetxo Beriain (comp.), Las consecuencias perversas de la modernidad. Modernidad, contingencia y riesgo, Barcelona, Anthropos, pp. 73-118.

BBC MUNDO.COM (2004a), "Uribe critica a eurodiputados», <http://news. bbc.co.uk/hi/spanish/latin_america/newsid_3476000/3476711.stm> (consulta: 10 de febrero).

- (2004b) «Uribe pide ayuda militar a la UE», <http://news.bbc.co.uk/hi/spanish/latin_america/newsid_3480000/3480951.stm> (consulta: 10 de febrero).

BECK, Ulrich (1996), «Teoría de la modernización reflexiva», en Josetxo Beriain (comp.), Las consecuencias perversas de la modernidad. Modernidad, contingencia y riesgo, Barcelona, Anthropos, pp. 223-265.

Bellotti, Magui, y Marta Fontenla (1997), Feminismo y neoliberalismo, Buenos Aires, ATEM.

BERGUA, José Ángel (2007), Lo social instituyente. Materiales para una sociología no clásica, Zaragoza, Prensas Universitarias de Zaragoza.

BERMEJO, Benito (1998), Análisis cualitativo, <http://www2.uiah.fi/projects/ metodi/200.htm> (consulta: octubre de 2004).

BID [Oficina de EVALUACIÓN, EVO] (1997), Evaluación: Una herramienta de gestión para mejorar el desempeño de los proyectos, <www.iadb.org/cont/evo/ spbook/laevalua.htm> (consulta: mayo de 2004).

Bogardus, Emory S. (1947), "The Measurement of Social Distance», en T. M. Newcomb y E. L. Hartley, Reading in Social Psychology, Nueva York, Holt, pp. 490-525.

Bolaños William, Oswaldo CAstelleti y Edison Caicedo (1998), Evaluación del impacto en el área social. Programa de agua potable y saneamiento en la costa Pacífica, Cali, Universidad Externado de Colombia.

Borren, Sylvia (2004), "Organismos de desarrollo: ¿intérpretes de orquesta o solistas?», en Eade y Ligteringen (2004), pp. 213-234.

Bourdieu, Pierre (1998), La distinción. Criterios y bases sociales del gusto, Madrid, Taurus. 
Bourdieu, Pierre (2001), «El capital social. Apuntes provisionales», Zona Abierta, n. ${ }^{\text {94 }}$ /95, pp. 83-87.

Bretón, Víctor (2001), Cooperación al desarrollo y demandas étnicas en los Andes ecuatorianos, Quito, FLACSO Ecuador.

BRUHN, Cecilia (2001), La prevención de conflictos en la agenda de la UE, Madrid, Instituto de Estudios sobre Conflictos y Acción Humanitaria (IECAH).

CARDOSO, F. (1977), «La originalidad de la copia: la CEPAL y la idea del desarrollo", Revista de la CEPAL (Santiago de Chile).

CARRASQUilla, Federico (1999), Antropología del pobre, Medellín.

CASA DE NARIÑo (2004), «Vía libre a la construcción de la central hidroeléctrica de Guapi», en Noticias SNE de la Presidencia de la República de Colombia, 10 de junio, Bogotá, <http://www.presidencia.gov.co/sne/2004/junio/10/131 02004.htm>.

CASAS Buenas, Constantino (1988), Las ONGD y su relación con el Estado y lo "político» en Colombia, Buga, Escuela Nacional Sindical.

CCONG [Confederación Colombiana De ONG] (2002a), Acuerdo programático, Bogotá, CCONG.

- (2002b), «ONG: Organizaciones No Guerra», Boletín de la Confederación Colombiana de ONG (Bogotá), n. ${ }^{\circ}$ 1, 21 de diciembre.

- (2003a), Algunos criterios y propuestas para la cooperación internacional con Colombia en la actualidad, Bogotá, CCONG, 10 de julio.

- (2003b), Coincidencias de la Sociedad Civil. Mesa de Coordinación y Cooperación Internacional en Londres, Bogotá, CCONG, 10 de julio.

- (2003c), Declaración de Asociación Colombiana de Medianas y Pequeñas Industrias-ACOPI y otros. Mesa de Coordinación y Cooperación Internacional en Londres, Bogotá, CCONG, 10 de julio.

- (2003d), Declaración de principios de las organizaciones no gubernamentales de Colombia, Bogotá, CCONG, 4 de mayo.

CE [COMISIÓN EUROPEA] (1998), Orientaciones plurianuales para la ayuda comunitaria: Colombia, Bruselas, 12 de noviembre. IB/1035/98-ES.

Centro de Estudios EConómicos Tomillo (2000), Empleo y trabajo voluntario en las $O N G$ de acción social, Madrid, Ministerio de Trabajo y Asuntos Sociales.

CEPEI [Centro de Pensamiento Estratégico Internacional] (2004), La cooperación internacional en Colombia, documento de análisis 1 (Bogotá).

Certeau, Michel de (1990), Linvention du quotidien, 1. Arts de faire, París, Gallimard.

Clark, John (1991), Democratizing Development: The Role of Voluntary Organisations, Londres, Earthscan. 
CM\& Europa Press (2004), "Graves denuncias del Gobierno de Uribe en el Parlamento Europeo", <http://www.educweb.org/webnews/ColNewsDec04/ Spanish/Articles/ UnionEuropeaanalizaelconf.html> (consulta: 2 de diciembre).

Codesarrollo (2002), Directorio-guía de entidades sin ánimo de lucro 20022004, Medellín.

Coleman, James (1990), Foundations of social theory, Cambridge, Harvard University Press.

Colina CoIrán, Rafael (2000), La neutralidad activa y la mediación en los conflictos armados, Bogotá, Tercer Mundo Editores.

Colussi, Marcelo (2004), «Las ONG, entre la solidaridad y el negocio», La Insignia (Guatemala), agosto.

CORPORACIÓN ViVA LA CiUdAdANía (2004), «Editorial: Crisis humanitaria en Colombia: ¿Para quién gobierna Uribe?», Caja de Herramientas (Bogotá), agosto, p. 2.

Coser, Lewis (1970), Nuevos aportes a la teoría del conflicto, Buenos Aires, Amorrortu.

Delegación de la Comisión Europea para Colombia y Ecuador (2005), Comunicación de la Comisión al Consejo, al Parlamento Europeo y al Comité Económico y Social sobre una nueva Asociación Unión Europea/América Latina en los albores del siglo XXI, <http://www.delcol.cec.eu.int/es/documentos/ comunicación.htm> (consulta: junio).

Demenet, Philippe (2001), «La rebelión de las ONG del Sur», El Correo de la Unesco, julio-agosto, pp. 60-63.

DOPPLER, Stephan (1997), Voluntarios y cooperantes. Guía para el trabajo solidario, Madrid, Delfín.

DOUWE VAN DER Ploeg, Jan (1999), «Sistemas de conocimiento, metáfora y campo de interacción: El caso del cultivo de la patata en el altiplano peruano», en Andreu Viola (comp.), Antropología del desarrollo. Teorías y estudios etnográficos en América Latina, Barcelona, Paidós.

EADE, Deborah, y Ernst LigTeringen (2004), El debate sobre el desarrollo y el futuro de las $O N G$, Barcelona, Intermón Oxfam.

EDWARDS, Michael, y David Hulme (1996), Non Governmental Organisations. Performance and accountability. Beyond the magic bullet, Londres, Earthscan; West Hartford (Conn.), Kumarian Press.

Embajada Española en Colombia y AECI (2004), El mapa de la cooperación en Colombia, <http://www.visualtech.com.co/webaeci/mapa_coop_col.html> (consulta: octubre de 2005).

ENS [Equipo del ÁRea de derechos humanos y laborales] (1997), Programa de derechos humanos: los límites de lo razonable. Medellín, IPC, ENS, REGIÓN. 
ENS [EQUiPO DEL ÁREA DE DERECHOS HUMANOS y LABORALES] (2004), «Resumen ejecutivo sobre la violación a los derechos humanos de los sindicalistas colombianos en el año 2003", Revista Cultura y Trabajo (Medellín), n. ${ }^{o}$ 62, 6 de septiembre.

EQUiPO NizKOR (2001), Continúa la campaña de amenazas y hostigamiento a la Corporación Sembrar, <http://www.derechos.org/nizkor/colombia/doc/sembrar01. html> (documento publicado el 9 de diciembre por el Equipo Nizkor y Derechos Human Rights).

- (2002), Para la impunidad no existen fronteras. Informe jurídico sobre el caso Iñigo Eguiluz y Jorge Luis Mazo Palacio, <http://www.derechos.org/nizkor /colombia/doc/eguiluz.html> (consulta: 15 de noviembre).

Escobar, Arturo (1996), La invención del Tercer Mundo. Construcción y deconstrucción del desarrollo, Bogotá, Grupo Editorial Norma.

- (1999), El final del salvaje. Naturaleza, cultura y política en la antropología contemporánea, Bogotá, ICAN, CEREC.

EURONOTAS (2004), «Apoyo de la UE a Uribe y a la solución pacífica del conflicto", Boletín publicado por la Delegación de la Comisión Europea en Bogotá, enero-marzo.

- (2005) «Unión Europea, un aliado para el desarrollo y la paz de Colombia», Boletín publicado por la Delegación de la Comisión Europea en Bogotá, eneroabril.

European Commission (2004), A world player. The European Union's external relations, Bruselas, Directorate-General for Press and Communication.

Fals Borda, Orlando (1986), Conocimiento y poder popular. Lecciones con campesinos de Nicaragua, México y Colombia, Bogotá, Siglo XXI.

FAS (1997), Documento-memoria de las I Jornadas de Reflexión y Debate. 29 de noviembre de 1997, Zaragoza.

- (1998), Memoria de FAS de 1997, Zaragoza.

- (1999a), Memoria de la FAS de 1999, Zaragoza.

- (1999b), III Jornadas de solidaridad: Hacia nuevas de relación norte-sur, Zaragoza, Federación Aragonesa de Solidaridad.

- (2000), Directorio de la Federación Aragonesa de Solidaridad, Zaragoza, Ayuntamiento de Zaragoza.

- (2003), Informe sobre la cooperación descentralizada al desarrollo en la Comunidad Autónoma de Aragón, Zaragoza, Comisión de Ayuda Oficial al Desarrollo de la FAS.

- (2004), Trayectoria y entidades de la FAS, Zaragoza, 7 de mayo.

FEDERACIÓN ANTIOQUEÑA DE ONG (1997), «Declaración de neutralidad activa de las ONG de Antioquia», Cultura y Trabajo. ENS (Medellín), n. ${ }^{\circ} 42$, mayo. 
Felipe, Ana de, y Lilio Rodríguez (1995), Guía de la solidaridad, Madrid, Temas de Hoy.

FERNÁNDEZ, Rubén (2004), ¿A qué nos referimos cuando hablamos de "ONG»?, Medellín, Corporación Región Medellín.

Ferrero, Gabriel (2003), De los proyectos de cooperación a los procesos de desarrollo. Hacia una gestión orientada al proceso, tesis doctoral del Departamento de Proyectos de Ingeniería, Universidad Politécnica de Valencia.

FISC [Foro Interétnico de Solidaridad Chocó] (2004), «Experiencia de construcción de paz desde las organizaciones en Colombia", Comité Oscar Romero. Documentos del Ocote Encendido (Zaragoza), n. ${ }^{\circ} 30$.

Foro Social Mundial de Porto Alegre (2002), Una cooperación alternativa para otro mundo posible, Porto Alegre (Brasil).

Foster, George M. (1969), Antropología aplicada, México, Fondo de Cultura Económica.

- (1988), Las culturas tradicionales y los cambios técnicos, México, Fondo de Cultura Económica.

Fowler, Alan (1997), Striking a Balance. A Guide to Enhancing the Effectiveness of Non-Guvernamental Organisations in International Development, Londres, Earthscan.

- y Kees BIEKART (1998), "¿Sirven realmente de algo las organizaciones de cooperación no gubernamentales?», en David Sogge (ed.), Compasión y cálculo. Un análisis crítico de la Cooperación No Gubernamental al Desarrollo, Barcelona, Icaria Antrazyt, pp. 153-189.

FurTADO, Celso (1979), El desarrollo desde el punto de vista interdisciplinario, México, Trimestre Económico.

GALTUNG, Johan (1998), Tras la violencia, 3R: reconstrucción, reconciliación, resolución. Afrontando los efectos visibles e invisibles de la guerra y la violencia, Bilbao, Bakeaz; Guernica, Gernika Gogoratuz.

GARCÍA CANCLINI, Néstor (1989), Culturas híbridas: Estrategias para entrar y salir de la modernidad, México, Grijalbo.

García MÁrQuez, Gabriel (2002), Vivir para contarla, Bogotá, Grupo Editorial Norma.

GASCÓ HeRnÁNDEZ, Mila (1999), «Una aproximación a la evaluación de proyectos de desarrollo», Boletín de Educación sin Fronteras (Barcelona), n. ${ }^{\circ} 2$.

Gilhodes, Pierre (2001), «Retos de la Unión Europea. Repercusiones en América Latina», conferencia publicada en el boletín 3 de la ACCI, marzo.

Gimeno, Juan Carlos, y Pilar Monreal (eds.) (1999), La controversia del desarrollo. Críticas desde la antropología, Madrid, Los Libros de la Catarata. 
Gobierno de Aragón (2004), Plan Director de la Cooperación Aragonesa para el Desarrollo (2004-2007), Zaragoza, DGA.

Gómez, J. D. (2004), «El "rebusque", lecciones sobre cómo utilizar el ingenio para no morirse de hambre», Enlace (Zaragoza), n. ${ }^{\circ} 3 / 4$.

- y S. MarTíneZ (2002), "Imágenes del Tercer Mundo. Geografía y etnografía imaginarias en la representación simbólica de la conmiseración contemporánea», en IX Congreso de Antropología, Barcelona, Federación de Asociaciones de Antropología del Estado Español.

Gómez, Manuel, y José Antonio SAnahuja (1999), El sistema internacional de cooperación al desarrollo: Una aproximación a sus actores e instrumentos, Madrid, CIDEAL.

- y José Antonio SANAHUja (coords.) (2001), La cooperación al desarrollo en un mundo en cambio: Perspectivas sobre nuevos ámbitos de interacción, Madrid, CIDEAL.

Gómez GiL, Carlos (1996), El comercio de la ayuda al desarrollo, historia y evaluación de los créditos FAD, Madrid, Los Libros de la Catarata.

GONZÁlEZ, Lara (2000), La evaluación ex-post o de impacto. Un reto para la gestión de proyectos de cooperación internacional al desarrollo, Vitoria, Hegoa.

- (2002), Evaluación de proyectos de desarrollo, análisis crítico, tesis del máster en Gestión del Desarrollo, Medellín, Universidad de Antioquia.

GonzÁlez Bustelo, Mabel (2004), Europa debe proseguir hacia Colombia, Madrid, CIP-FUHEM.

GonZÁlez EsCobar, Luis Fernando (1999), El Darién. Ocupación, poblamiento y transformación ambiental: una revisión histórica, Medellín, CISH y Fundación Natura. Universidad de Antioquia.

GonZÁlez PARADA, José Ramón (2001), «Enfoques de la ayuda al desarrollo», en Nieto Pereira (2001), pp. 65-80.

GRZYBOwsKI, Cándido (1998), «¿Compasión o complicidad? Flores y espinas de las prácticas de Cooperación", Comunicando. Boletín de Informaciones Interorganismos. CEDAL, Área Latina, économie et humanisme, n. ${ }^{\circ} 11$, abril.

Gutiérrez de Pineda, Virginia (1996), Familia y cultura en Colombia, Medellín, Universidad de Antioquia.

HABermas, Jürgen (1989), Teoría de la acción comunicativa. Complementos y estudios previos, Madrid, Cátedra.

HaileY, John (2004), «Indicadores de identidad: las ONG y el imperativo estratégico de determinar los valores fundamentales», en Eade y Ligteringen (2004), pp. 203-212.

Hammersley, Martyn, y Paul AtKinson (1994), Etnografia: Métodos de investigación, Barcelona, Paidós Básica. 
Henao Escovar, Juanita (1991), La cooperación internacional al desarrollo en Colombia, Bogotá, CINEP y Novib.

HeNDERSON, Judy (2004), «Disonancia o diálogo: las relaciones con el sector empresarial están cambiando», en Eade y Ligteringen (2004), pp. 147-158.

HusselbeE, David (2004), «Las ONG como socios de desarrollo de las empresas: niños que cosen pelotas de fútbol en Pakistán», en Eade y Ligteringen (2004), pp. 159-180.

IAEST [Instituto ARAgOnÉs De Estadística] (2004), Financiación destinada a Cooperación para el Desarrollo por el Gobierno de Aragón. Servicio de Cooperación al Desarrollo del Gobierno de Aragón, <http://portal.aragob.es> (consulta: 15 de junio de 2005).

IBARZ, Joaquim (2004), «Noventa ONG critican a Uribe por violar los derechos humanos», La Vanguardia (Barcelona), 12 de septiembre.

InSTITUTO ELCANO DE ESTUDIOS INTERNACIONALES Y ESTRATÉGICOS (2004), La imagen de España en América Latina. Resultados del Latinobarómetro 2004, Madrid, Fundación Real Instituto Elcano.

IRELA [INSTITUTO DE RELACIONES EURO-LaTINOAMERICANAS] (1995), IRELA, 1985-1995: una década de promoción de las relaciones europeo-latinoamericanas, Madrid.

Jimeno Santoyo, Myriam (1996), «Pueblos indios, democracia y políticas estatales en Colombia», en Pablo González Casanova y Marcos Roitman (coords.), Democracia y Estado multiétnico en América Latina, México, La Jornada Ediciones y UNAM, pp. 223-236.

Kaldor, Mary (2003), Global Civil Society: An Answer to War, Cambridge, Polity Press.

KorTEn, David C. (1994), «Ayuda internacional en la era de la postguerra fría: la Fundación Pública de Desarrollo», Pobreza Urbana Desarrollo, año 3, n. ${ }^{\circ} 8$, agosto, monográfico Cooperación Internacional hacia América Latina, nuevos desafios para las $O N G$, pp. 41-52.

KotTAK, Conrad Phillip (2000), «La cultura y el desarrollo económico», en A. Viola (comp.) (2000), pp. 103-126.

Losonczy, Anne-Marie (1997), «Hacia una antropología de lo inter-étnico: una perspectiva negro-americana e indígena», en Antropología en la modernidad: identidades, etnicidades y movimientos sociales en Colombia, Bogotá, Instituto Colombiano de Antropología, pp. 253-277.

MAE [Ministerio de Asuntos Exteriores de España] (2003), Metodología de evaluación de la cooperación española, Madrid, Secretaría de Estado para la Cooperación Internacional y para Iberoamérica.

MAFFESOLI, Michael (1993), El ritual y la vida cotidiana como fundamento de las historias de vida, Barcelona, Icaria. 
MAFFESOli, Michael (1997), Elogio de la razón sensible. Una visión intuitiva del mundo contemporáneo, Barcelona, Paidós.

MALÉ, Jean Pierre (1999), «La realidad económica de la cooperación», ponencia presentada en las Terceras Jornadas de Solidaridad: Hacia nuevas formas de relación norte-sur, Zaragoza, Federación Aragonesa de Solidaridad.

Mansilla Blanco, Roberto (1997), Criterios de acción y legitimación de la cooperación internacional al desarrollo. Una lectura del caso español en Centroaméri$c a$, Zaragoza, Universidad de Zaragoza.

- (2005), «El Plan Colombia y la convulsión andina», Instituto de Estudios sobre Conflictos y Acción Humanitaria,<http://www.iecah.org/espanol/paises/america/crisiscolombiavenezuela.html> (consulta: 2 de febrero).

Marcuello, Chaime (1996), «Identidad y acción de las Organizaciones NoGubernamentales», Gestión Pública y Privada, n.o 1, pp. 103-122.

- y Carmen Marcuello (2000), «El sector de las organizaciones no gubernamentales para el desarrollo en España: estructura y evolución», Revista Internacional de Sociología, n. ${ }^{\circ}$ 25, enero-abril, pp. 99-119.

MarTín Medem, José Manuel (1999), «América Latina: exclusión y democracias controladas», en Mariano Aguirre y Teresa Filesi (eds.), Anuario CIP 1999: Guerras en el sistema mundial, Barcelona, CIP e Icaria, pp. 77-86.

MarTínez, Alejandro (2005), Coyuntura Colombiana y Latinoamericana. Frente de Acciones por Colombia, <http://www.nuevacolombia.de/Voz2/html/espaniol/analisis/analisis $41 . h \mathrm{htm}>$.

Martínez SÁnCheZ, Juan Luis (1998), La imagen de las ONG de desarrollo. Para ir dimensionando el Tercer Sector, Madrid, IEPALA y Gobierno de Navarra.

MAX-NeEF, Manfred (1993), Desarrollo a escala humana. Conceptos, aplicaciones y algunas reflexiones, Montevideo, Nordan Comunidad e Icaria.

Ministerio de Asuntos Exteriores de los Países Bajos (1997), Evaluación del Programa de Cooperación al Desarrollo de los Paises Bajos con Bolivia. Ámsterdam, Departamento de Evaluación de Operaciones y Políticas.

Ministerio del Interior de la República de Colombia (1991), Constitución Política de Colombia, Bogotá, Imprenta del Ministerio.

MOC [Movimiento de OrganizaÇÃo Comunitária] (2000), «El hecho de ser evaluado: Tensiones y esperanzas», en Intermón, Desarrollo y Poder, Barcelona, Icaria.

Molano Bravo, Alfredo (2000), El Plan Colombia y el conflicto armado. Texto leido ante el Parlamento Europeo. Comisión de Cooperación al Desarrollo, Bruselas, 12 de septiembre.

Molano CruZ, Giovanni (1998), «Las contradicciones de las políticas europeas frente a América Latina», Revista de Análisis Político (Bogotá, Instituto de 
Estudios Políticos y Relaciones Internacionales [IEPRI], Universidad Nacional de Colombia), n. ${ }^{\circ}$ 35, sept.-dic.

Molino, Sergio del (2004), «Entrevista a Edgar Alberto Páez», Heraldo de Aragón, 5 de diciembre, pp. 4-5.

Morin, Edgar (1988), El método. 3. El conocimiento del conocimiento, Madrid, Cátedra.

- (1990), Introducción al pensamiento complejo, Barcelona, Gedisa.

Morsolin, Cristiano (2005), «Parlamento europeo e italiano solicitan respeto de los derechos humanos en Colombia», Observatorio Independiente sobre la Región Andina SELVAS, <http://www.choike.org/nuevo/informes/2674. html> (Bogotá, lunes, 28 de marzo).

Mosquera, Salomón (1991), «Cara y cruz de los proyectos de desarrollo. Las ONG's y los proyectos de desarrollo vistos por la organización popular», Ciudad Alternativa (Quito), n.o 5.

Nieto Pereira, Luis (2002), La ética de las ONGD y la lógica mercantil, Barcelona, Icaria.

- (coord.) (2001), Cooperación para el desarrollo y ONG. Una visión crítica, Madrid, Los Libros de la Catarata.

NisBet, Robert (1981), Historia de la idea de progreso, Madrid, Fondo de Cultura Económica.

OBIS, M. ${ }^{a}$ Cruz (2004), «La ayuda oficial al desarrollo aragonesa en el contexto internacional», en Álvarez, García y Marcuello (comps.) (2004), pp. 97-109.

Oficina de Cooperación para el Desarrollo (2004), Memoria del Consejo Aragonés de Cooperación para el desarrollo año 2002, Zaragoza, Gobierno de Aragón.

Oficina en Colombia del Alto Comisionado de las Naciones Unidas para LOS Derechos Humanos (2002), Informe sobre la misión de observación en el medio Atrato. Bojayá.

ONU (2004), 57. a Conferencia Anual DIP/ONG, 10 de septiembre.

Organizaciones Colombianas de Sectores Sociales Populares, de Iniciativas de Paz y de Derechos Humanos (2003), La solución política y la democracia son el camino. Documento presentado a la reunión de Londres del 9 y 10 de julio de 2003. Bogotá, julio.

Organizaciones de la Sociedad Colombiana (2005), Consensos de organizaciones de la sociedad civil colombiana reunidas en Cartagena de Indias, Colombia, el 2 de febrero de 2005, en el marco de la reunión de cooperación internacional y de seguimiento a la declaración de Londres.

OrTEgA, M. ${ }^{a}$ Luz (1994), Las ONGD y la crisis del desarrollo. Un análisis de la cooperación con Centroamérica, Madrid, IEPALA. 
OTC [Oficina Técnica de CoOperación] (2004), Análisis de la cooperación española en Colombia, Bogotá, Embajada de España en Colombia.

PEARCE, Jenny (2002), «El desarrollo, las ONG y la sociedad civil: el debate y su futuro", en Jenny Pearce (coord.), Desarrollo, organizaciones no gubernamentales y sociedad civil, Barcelona, Intermón Oxfam.

PÉREZ GuZMÁN, Diego (2005), «Entre Londres y Cartagena se embolataron los DD. HH.», Dhcolombia, <http:/www.dhcolombia.info/article.php3?id_ article $=3>$ (consulta: 27 de enero).

Pichardo MuñIz, Arlette (1992), Evaluación del impacto social: El valor de lo humano ante la crisis y el ajuste, San José, Universidad Nacional de Costa Rica y Hvmanitas.

PNUD (1993), Informe de desarrollo humano 1993, Bogotá, PNUD.

- (2003), El conflicto, callejón con salida. Informe Nacional de Desarrollo Humano Colombia 2003, Bogotá, PNUD.

PRATS, Joan (2005), "La ayuda externa en busca de calidad», Gobernanza. Revista internacional para el desarrollo humano, n. ${ }^{\circ} 28$, julio.

PREBISCH, Raúl (1962), El desarrollo económico de América Latina y algunos de sus principales problemas, Buenos Aires, Boletín Económico América Latina.

PROCLADE (2004), Justicia, paz y desarrollo para todos los pueblos, <www.ciudadredonda.org/paz/proclade/proyectos/proyectos_mapa.htm >.

Querubín, María Eugenia (2003), «Las Organizaciones No Gubernamentales de cara al conflicto», ponencia de la Confederación Colombiana de ONG durante el Primer Seminario de Acción Integral realizado por la Fuerza Aérea Colombiana, 17 al 19 de octubre de 2003.

Ramírez Prado, Yolanda, y Ricardo Melo ACOSTA (1998), La cooperación internacional: Entre los intereses domésticos y solidarios, Bogotá, Universidad Externado de Colombia.

ReClusA, Montse (2004), "Conflictos, guerras, y organizaciones no gubernamentales de desarrollo», en Álvarez, García y Marcuello (comps.) (2004), pp. 165-192.

Restrepo, Eduardo (1997), "Afrocolombianos. Antropología y proyecto de modernidad en Colombia», en Antropología en la modernidad: identidades, etnicidades y movimientos sociales en Colombia, Bogotá, Instituto Colombiano de Antropología.

RiaK, Abikök (2004), «Proyecto de Capacidades Locales para la Paz: la experiencia de Sudán», en Eade y Ligteringen (2004), pp. 379-386.

Rist, Gilbert (2002), El desarrollo: historia de una creencia occidental, Madrid, Los Libros de la Catarata. 
RITZER, George (1993), Teoría sociológica contemporánea, Madrid: McGraw-Hill. Roche, Chris (2004), Evaluación de impacto para agencias de desarrollo: aprendiendo a valorar el cambio, Barcelona, Intermón Oxfam.

RodrígueZ, María Victoria (1993), «A propósito de la evaluación en las ONGs», en Evaluación de Proyectos de Desarrollo, Bogotá, Dimensión Educativa.

Ruiz OlabuÉnAGa, José Ignacio (dir.) (2000), El sector no lucrativo en España, Madrid, Fundación BBV, Documenta.

Ruiz-Restrepo, A. (2004), "Dimensión desconocida: solidaridad desprestigiada», Semana (Bogotá), n. ${ }^{\circ} 1157,2$ de julio.

SALAMON, Lester (dir.) (1999), La sociedad civil global. Las dimensiones del sector no lucrativo, Bilbao, Fundación BBVA.

SANAHUJA, José Antonio (2004), «La importancia de Colombia en el marco de las relaciones políticas y de cooperación entre la Europa de los 25 y América Latina y el Caribe», conferencia pronunciada en el seminario-taller Balance y Perspectivas de las Relaciones Políticas y de Cooperación entre la UE y Colombia, Lérida, 15 de julio de 2004.

SANDOVAl, Carlos (1998), Curso de investigación cualitativa. Instituto de Estudios Regionales (INER), Medellín, Universidad de Antioquia.

SANín, J. (2004), «Relaciones Colombia-UE: de la incertidumbre política al posicionamiento estratégico», Policy Papers, n. ${ }^{\circ} 4$. pp. 1-8. Bogotá, Proyecto La inserción de Colombia en un sistema internacional cambiante.

- y E. Pastrana (2004), «Las relaciones Colombia-Unión Europea: de la incertidumbre al estancamiento", Policy Papers, n. ${ }^{\circ} 11$, pp. 1-8. Bogotá, Proyecto La inserción de Colombia en un sistema internacional cambiante.

SANTOS, B. de Sousa (2003), La caída del Ángelus Novus: Ensayos para una nueva teoría social y una nueva práctica política, Bogotá, ILSA. Universidad Nacional de Colombia.

SANTOS GÓmEZ, David E. (2005), «El Gobernador busca convenio para disminuir la inequidad", El Colombiano (Medellín), viernes, 4 de febrero.

SAnZ, Antonio (2004), Política Exterior del Partido Popular en Colombia (19962004), Madrid, Proyecto Europa y Colombia: Diplomacia y sociedad civil, CIP-FUHEM.

Segovia Mora, Guillermo (1999), «Semillas fértiles», Utopias (Bogotá), año 7, n. ${ }^{\circ} 70$, nov.-dic., pp. 19-38.

SEMANA (2002), "Controversia: Las ONG: ̨héroes o villanos?», Semana (Bogotá), n. ${ }^{\circ} 1072,15$ de noviembre.

- (2003), "Colombia es la clave para la estabilidad regional», entrevista, Semana (Bogotá), n. ${ }^{\circ} 1122,31$ de octubre. 
SEMANA (2004), «Vengo a respaldar a los defensores de derechos humanos», entrevista a la premio Nobel de la Paz Shirin Evadí en su visita a Colombia, Semana (Bogotá), n. ${ }^{\circ} 1139,28$ de febrero.

SeN, Gita (1995), «National Development and Local Environmental Action: the Case of the River Narmada", en Vinit Bhaskar y Andrew Glyn (eds.), The North, the South and the Environment Ecological Constraints and the Global Economy, Earthscan, United Nations University Press, pp. 184-200.

Serrano, M. (2001), «Donantes, clientes, búsqueda de fondos», en Nieto Pereira (coord.) (2001), pp. 151-175.

SHIVA, Vandana (1989), Staying Alive, Women, Ecology and Development, Londres, Zed Books.

SINALTRAINAL (2002), Historia de un conflicto social en Colombia, Bogotá, Sindicato Nacional de la Industria de la Alimentación de Colombia.

Sogge, David (ed.) (1998), Compasión y cálculo. Un análisis critico de la Cooperación No Gubernamental al Desarrollo, Barcelona: Icaria Antrazyt.

STOREY, Andy (2004), «El Banco Mundial, neoliberalismo y poder: análisis del discurso y consecuencias para los activistas», en Eade y Ligteringen (2004), pp. 131-146.

STUBBS, Josefina (2004), "Género en el desarrollo: Un largo camino que evidencia logros», en Eade y Ligteringen (2004), pp. 441-454.

TAYLOR, Steve J., y Robert BOGDAN (1987), Introducción a los métodos cualitativos de investigación, Buenos Aires, Paidós.

TORRES Rivas, Edelberto (2001), «La sociedad civil en la construcción democrática: notas desde una perspectiva crítica», Instituciones y Desarrollo (Barcelona, Institut Internacional de Governabilitat de Catalunya, Barcelona), n. ${ }^{\circ}$ 8/9, mayo, pp. 143-170.

Touraine, Alain (1998), Igualdad y diversidad. Las nuevas tareas de la democracia, Buenos Aires, Fondo de Cultura Económica.

URÁN, Omar (2000), La ciudad en movimiento: Movimientos sociales, democracia y cultura en Medellín y el área metropolitana del valle de Aburrá, Medellín, IPC.

URIBE, Fernando (coord. general) y otros (1999), Caracterización ambiental del Darién Colombiano. Dimensión social, Medellín, CISH y Fundación Natura. Universidad de Antioquia.

VALDERrama, Mariano (2002), Las ONGS bajo escrutinio. Asociación Latinoamericana de Organizaciones de Promoción (ALOP), San José de Costa Rica, <http://www.alop.or.cr/geraldocs/documentos1.html>.

VARGAS, H., y otros (1992), Acerca de la naturaleza y evolución de los organismos no gubernamentales (ONGs) en Colombia. Bases para la comprensión del fenómeno, Bogotá, Fundación Social. 
VARGAS VelásQueZ, Alejo (2004), «Unión Europea y Colombia: retos y posibilidades», Semana (Bogotá), n. ${ }^{\circ} 1135,30$ de enero.

VERDAD COLOMBIA (2005), <http://www.verdadcolombia.org/nuestraorganizacion> (consulta: julio).

Viola, Andreu (comp.) (2000), Antropología del desarrollo. Teorias y estudios etnográficos en América Latina, Barcelona, Paidós.

Welna, Christopher, y George A. López (2004), Documento de Trabajo. Centro de Investigación para la Paz, Madrid, CIP-FUHEM.

Zambrana, Lourdes (2002), Nuevas militancias para tiempos nuevos, Barcelona, Cuadernos Cristianisme i Justicia.

Zea de Durán, M. ${ }^{a}$ Cristina (2002), Fundamentos jurídicos de la cooperación internacional en Colombia, Bogotá, ACCI. 

ANEXOS 



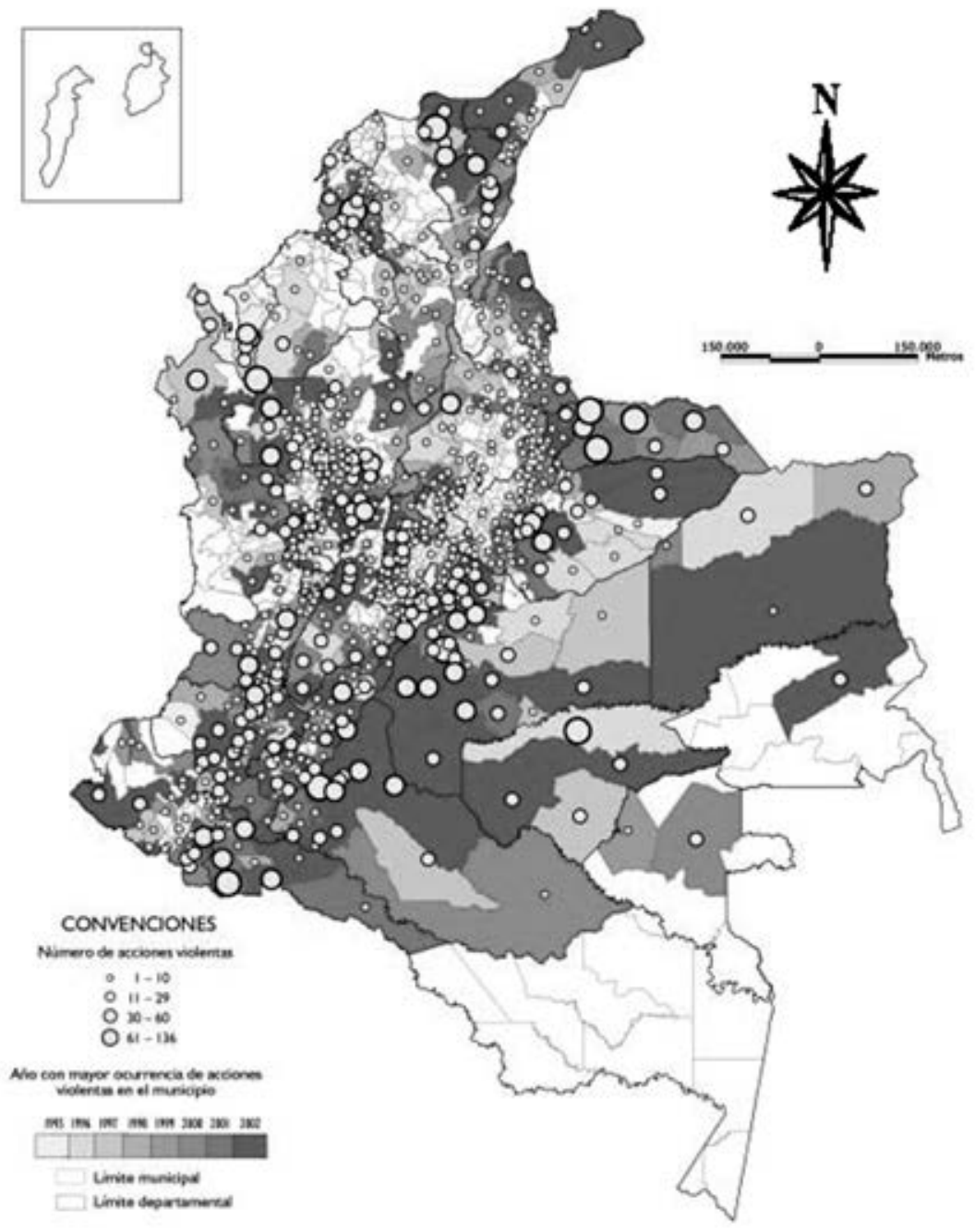

FUENTE: PNUD (2003). 
DISTRIBUCIÓN ESPACIAL DE ACCIONES VIOLENTAS REALIZADAS POR LAS AUTODEFENSAS (PARAMILITARES), 1995-2002

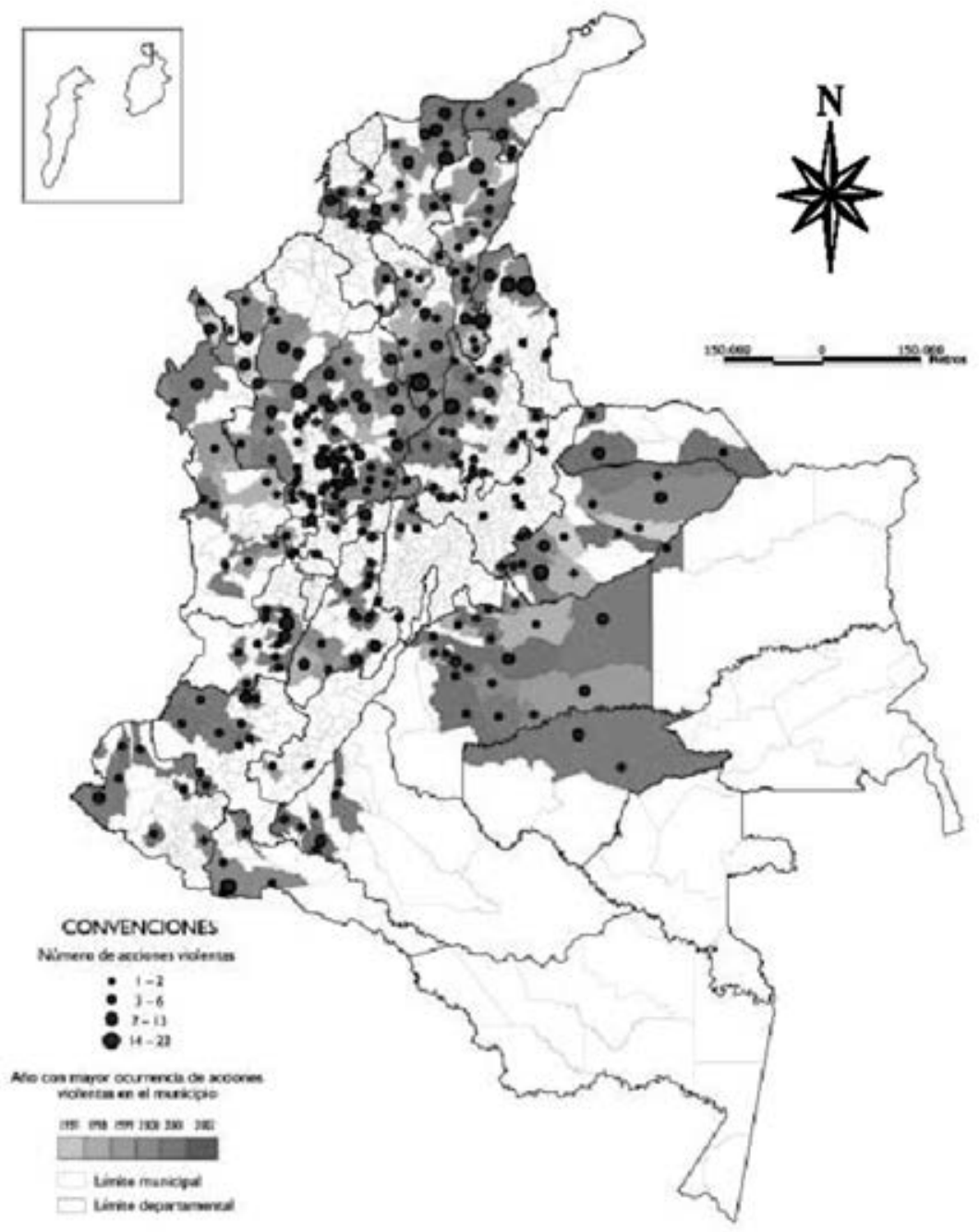

FUENTE: PNUD (2003). 
ANEXO 3

MUESTRA DE LA INVESTIGACIÓN

\begin{tabular}{|r|l|}
\hline \multicolumn{2}{|c|}{\begin{tabular}{|l|} 
Muestra seleccionada entre ONGD aragonesas \\
Entrevistas España (EE-00)
\end{tabular}} \\
\hline 1. & Fundación Juan Bonal \\
2. & Comité Cristiano Óscar Romero \\
3. & Entreculturas (Fe y Alegría) \\
4. & Médicos del Mundo \\
5. & ASA \\
6. & Comité de Solidaridad Internacionalista \\
7. & InteRed \\
8. & AMAT \\
9. & PROCLADE Aragón (Misioneros Claretianos) \\
10. & Manos Unidas \\
11. & UNICEF-Comité Aragón \\
\hline
\end{tabular}

\begin{tabular}{|l|l|}
\hline \multicolumn{2}{|c|}{$\begin{array}{c}\text { Entidades que proporcionaron información complementaria. } \\
\text { Fuentes primarias no recogidas en la muestra en Aragón }\end{array}$} \\
\hline Intermón Oxfam & Director de Intermón Aragón \\
ISCOD & Responsable de ISCOD en Aragón \\
Paz y Solidaridad & Responsable en Aragón \\
Seminario de Investigación para la Paz & Experta en el conflicto colombiano \\
\hline
\end{tabular}

\begin{tabular}{|c|l|}
\hline \multicolumn{2}{|c|}{$\begin{array}{c}\text { Muestra seleccionada entre ONGD colombianas } \\
\text { Entrevistas Colombia (EC-00) }\end{array}$} \\
\hline 1. & COCOMACIA. Quibdó \\
2. & Diócesis de Quibdó \\
3. & Planificación y proyectos. Fe y Alegría Colombia. Bogotá \\
4. & Políticas Básicas de UNICEF Colombia. Bogotá \\
5. & Escuela Nacional Sindical, Medellín. \\
\hline
\end{tabular}

190 El orden de este listado, y de los siguientes, no corresponde a la numeración de las entrevistas a fin de proteger la confidencialidad de las respuestas de las entrevistas. Esta información no debe ser publicada para preservar la confidencialidad de los entrevistados. 


\begin{tabular}{|l|}
\multicolumn{1}{c|}{$\begin{array}{c}\text { Entidades que proporcionaron información complementaria } \\
\text { Fuentes primarias no recogidas en la muestra en Colombia }\end{array}$} \\
\hline Federación Chocoana de ONG \\
Red de Mujeres del Chocó. Quibdó, Chocó \\
Director de la Corporación REGIÓN \\
Subdirector de la Confederación Colombiana de ONG. Medellín \\
Asesora de la subdirección de proyectos de la ACCI. Bogotá \\
CINEP. Bogotá \\
ACARPIN, Medellín \\
Codesarrollo, Medellín \\
\hline
\end{tabular}

Entidades que proporcionaron información complementaria

Fuentes primarias no recogidas en la muestra en Colombia

Federación Chocoana de ONG,

Red de Mujeres del Chocó. Quibdó, Chocó

Director de la Corporación REGIÓN

Subdirector de la Confederación Colombiana de ONG. Medellín

Asesora de la subdirección de proyectos de la ACCI. Bogotá

CINEP. Bogotá

ACARPIN, Medellín

Codesarrollo, Medellín

Taller grupal con líderes campesinos de COCOMACIA (Quibdó, Chocó) 24-08-2004

\begin{tabular}{|c|c|}
\hline & Nueve participantes del taller: \\
\hline 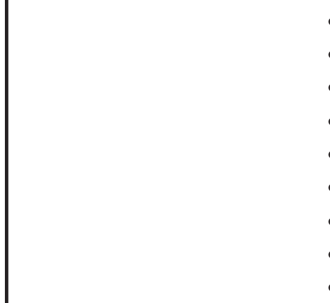 & \begin{tabular}{l|l}
$\bullet$ & A. V. \\
$\bullet$ & J. M. \\
A. R. H. \\
$\bullet$ & C. \\
$\bullet$ & F. R. \\
- & N. P. \\
- & S. P. \\
- & R. M. \\
A. M.a M.
\end{tabular} \\
\hline
\end{tabular}




\section{ANEXO 4 \\ REIVINDICACIONES DE LOS MOVIMIENTOS ÉTNICO-TERRITORIALES DEL CHOCÓ ANTE LAS ONGD NACIONALES Y EXTRANJERAS}

Desde los años setenta los movimientos étnico-territoriales del Chocó (campesinos, indígenas y afrocolombianos) han luchado por la reivindicación de la tierra y consiguieron, en 1993, los resguardos para las comunidades indígenas y los títulos colectivos para las comunidades negras. No obstante, siguen padeciendo el escaso reconocimiento estatal de muchos derechos individuales, económicos, sociales y culturales, encontrándose en medio del conflicto armado que vive Colombia desde hace 50 años (Uribe, coord., y otros, 1999; González Escobar, 1999; Jimeno Santoyo, 1996).

En julio de 2001 ocurrió un acontecimiento sin muchos precedentes en Colombia. ${ }^{191}$ Los movimientos populares redactaron un manifiesto de exigencias a las instituciones presentes en su territorio (la Iglesia, el Estado, los actores armados y las ONGD) por el cual establecían unos criterios que debían estar presentes en sus interrelaciones.

Se constituía de esta forma el Foro Interétnico Solidaridad Chocó (FISC), que ha venido en los últimos tres años fijando unas líneas de actuación que le permitan crecer en autonomía para que las acciones implementadas converjan en Planes de Vida y Etnodesarrollo. "Son más de treinta organizaciones étnico-territoriales tanto negras como indígenas, consejos comunitarios, organizaciones urbanas y rurales que han definido propósitos y temáticas comunes respetando la autonomía local que cada organización tiene» (FISC, 2004, 6). Confían en la ayuda que puede prestar la cooperación internacional, pero bajo una serie de exigencias, de las cuales se extraen las siguientes:

Exigimos que las ONG que trabajan, y las que pretendan trabajar en nuestro territorio, den a conocer sus objetivos, políticas [y] fuentes de financiación a las organizaciones. Que cuando exista más de una ONG trabajando con una misma organización o en un mismo territorio, establezcan acuerdos

191 En otros países como Bangladesh, la ONG Gonoshasthaya (GK) selecciona a los donantes exigiéndoles dos condiciones: «tienen que admitir que no saben nada de Bangladesh y que lo conocemos mejor que ellos. La segunda, deben tener paciencia: el desarrollo es un proceso lento» (UNESCO, 2001, 63). 
de trabajo entre las mismas, para que no dividan las comunidades o las organizaciones. Que todo trabajo que se vaya a realizar dentro del territorio sea concertado con las comunidades, y a la vez sean éstas los principales actores de su ejecución. Que el papel de las ONG sea de acompañamiento, mas no de liderazgo, de tal manera que no se creen paternalismos en los procesos organizativos. Que el trabajo de las ONG respete el proceso de desarrollo y fortalecimiento cultural, así como la idiosincrasia de los pueblos negros e indígenas del Chocó (FISC, 2004, 9). 


\section{ANEXO 5}

MAPA DEL DESPLAZAMIENTO FORZADO EN COLOMBIA, 2001

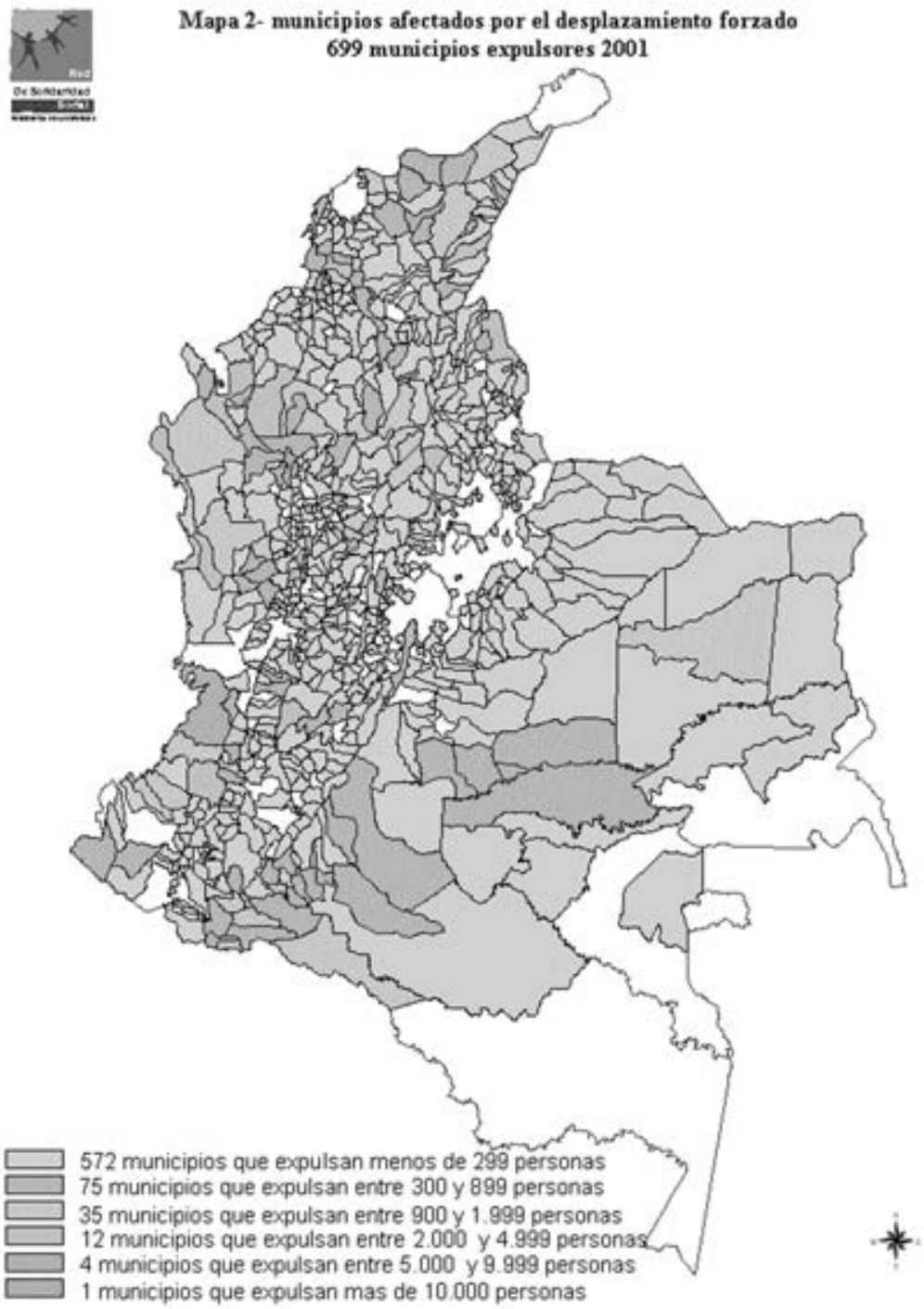

FUENTE: Red de Solidaridad Social. <www.red.gov.co> (2 de noviembre de 2005). 


\begin{tabular}{|c|c|c|c|c|c|}
\hline \multirow{8}{*}{ 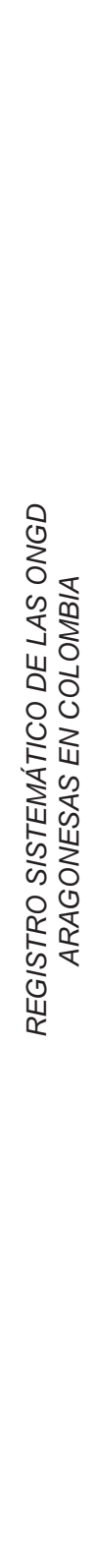 } & $\begin{array}{l}\text { हूँ } \\
\text { ปี } \\
\text { है }\end{array}$ & 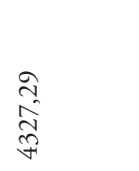 & 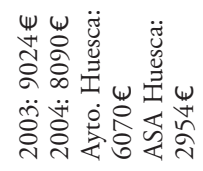 & 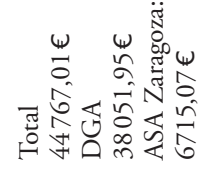 & 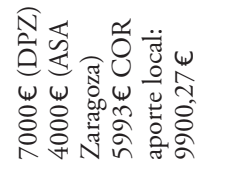 \\
\hline & 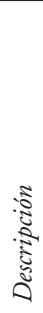 & 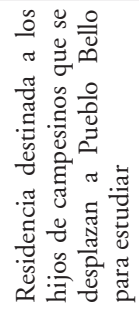 & 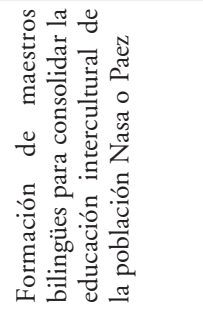 & 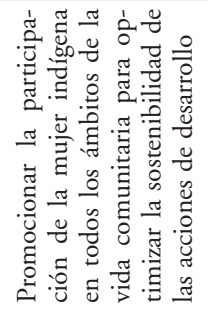 & 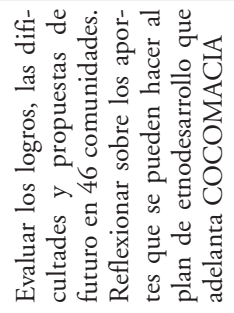 \\
\hline & $\begin{array}{l}5 \\
\text { s }\end{array}$ & 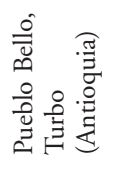 & $\underset{\widetilde{J}}{\stackrel{\widetilde{J}}{J}}$ & 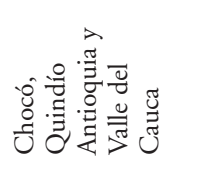 & 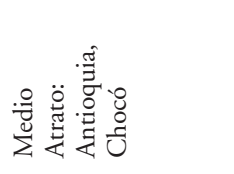 \\
\hline & $\frac{\text { है }}{\text { है }}$ & 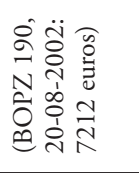 & 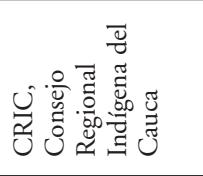 & 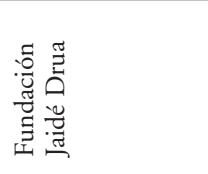 & 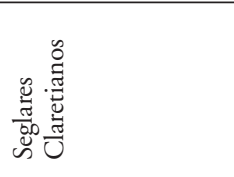 \\
\hline & 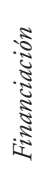 & 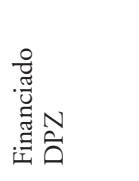 & 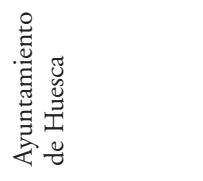 & 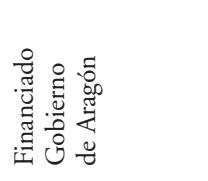 & 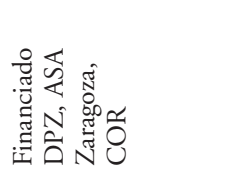 \\
\hline & ș & 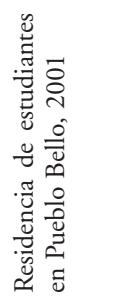 & 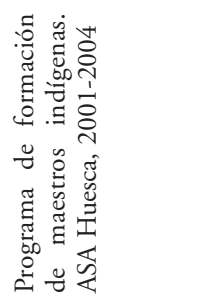 & 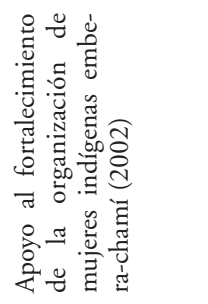 & 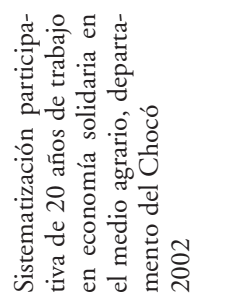 \\
\hline & 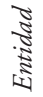 & 岁 & & & \\
\hline & & - & & & \\
\hline
\end{tabular}




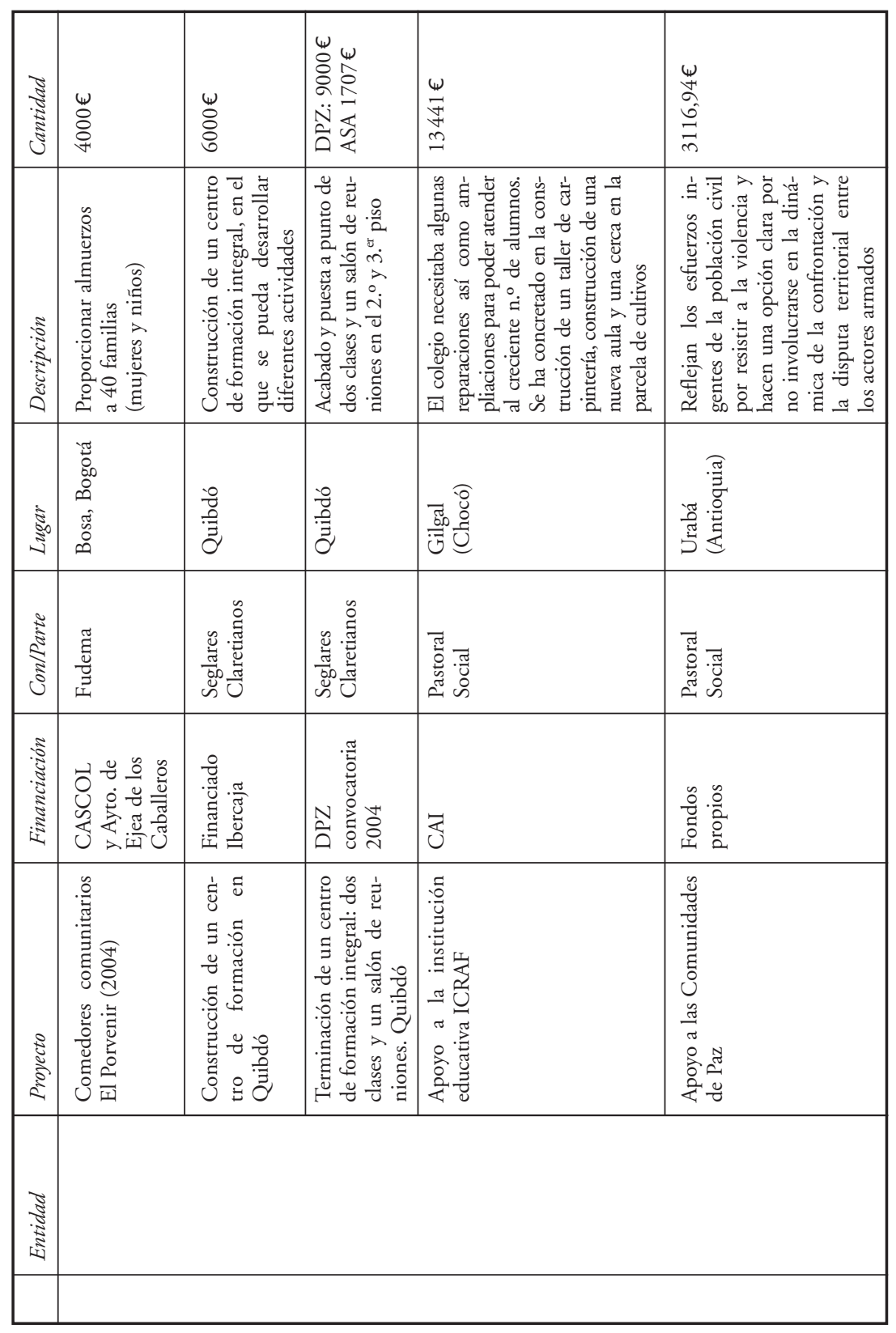




\begin{tabular}{|c|c|c|c|c|c|c|}
\hline 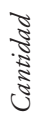 & $\begin{array}{l}4 \\
\ddot{8} \\
\vdots \\
i \\
6\end{array}$ & 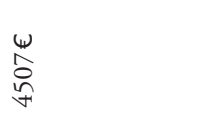 & \begin{tabular}{l}
$w$ \\
$w$ \\
0 \\
$\infty$ \\
$o$ \\
\hdashline
\end{tabular} & $\begin{array}{l}\stackrel{\omega}{0} \\
\stackrel{0}{0}\end{array}$ & 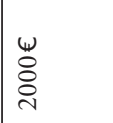 & 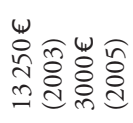 \\
\hline 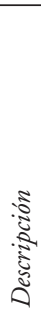 & & 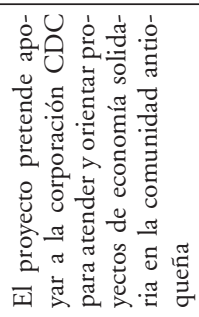 & 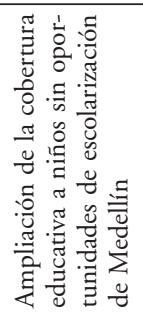 & 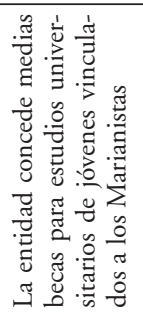 & 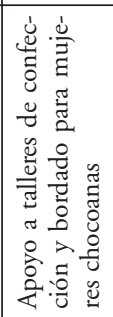 & 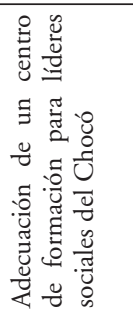 \\
\hline 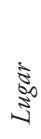 & 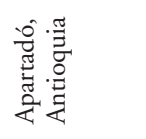 & $\frac{\Xi}{\stackrel{\Xi}{\bar{v}}}$ & $\frac{\Xi}{\stackrel{\Xi}{\bar{v}}}$ & 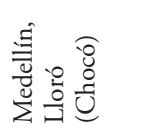 & 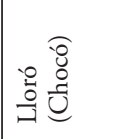 & 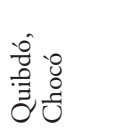 \\
\hline है & & 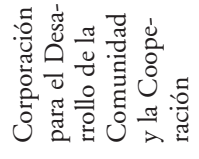 & 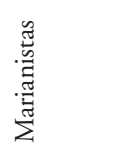 & & & 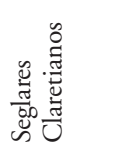 \\
\hline 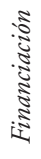 & 岕 & 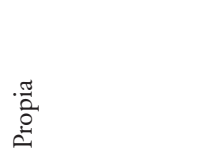 & 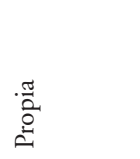 & $\begin{array}{l}\frac{\pi}{0} \\
\frac{0}{2} \\
2\end{array}$ & 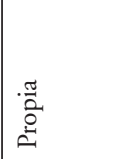 & 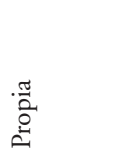 \\
\hline हैँ & 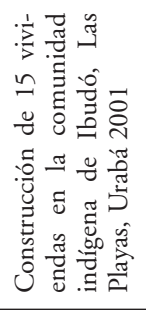 & 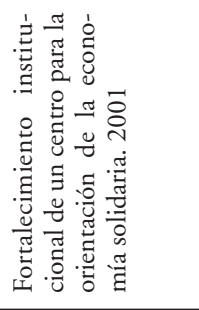 & 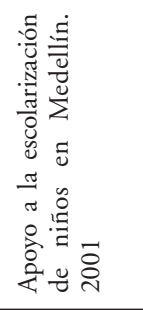 & 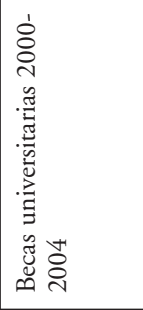 & 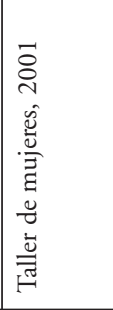 & 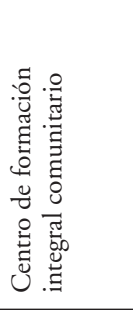 \\
\hline 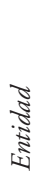 & 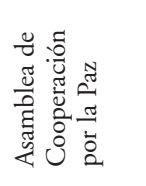 & \multicolumn{4}{|l|}{ 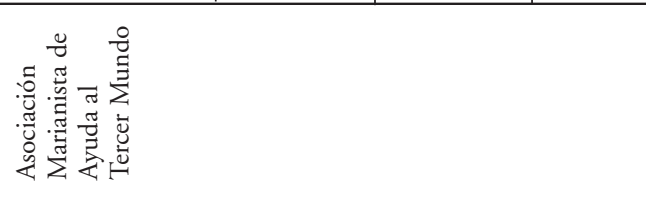 } & 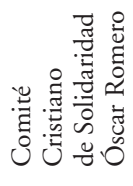 \\
\hline & $\sim$ & \multicolumn{4}{|l|}{$n$} & 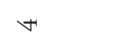 \\
\hline
\end{tabular}




\begin{tabular}{|c|c|c|c|c|}
\hline $\begin{array}{l}\text { है } \\
\text { है }\end{array}$ & 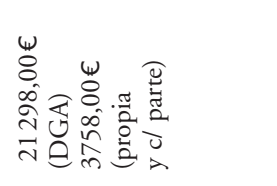 & 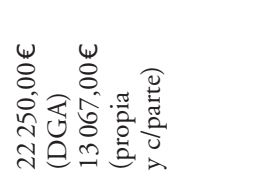 & 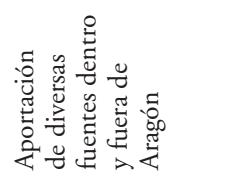 & 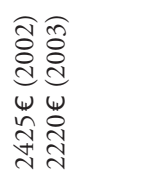 \\
\hline $\begin{array}{c} \\
0 \\
0 \\
0 \\
0 \\
0 \\
0 \\
0\end{array}$ & 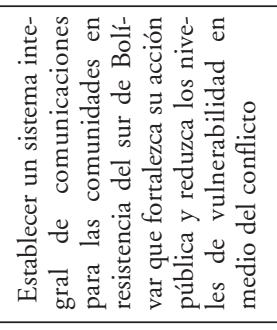 & 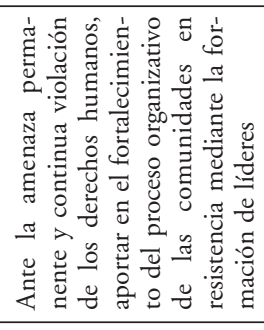 & 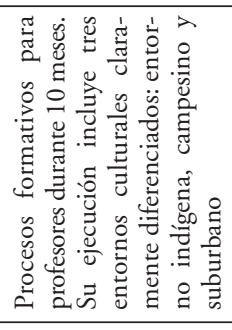 & 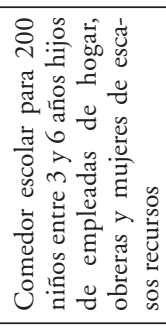 \\
\hline$\stackrel{\$}{3}$ & $\begin{array}{l}\text { 苞 } \\
\text { 急总 }\end{array}$ & 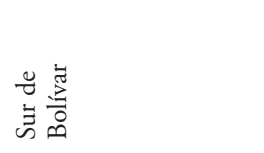 & 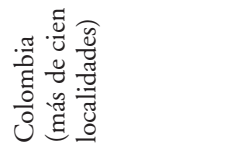 & 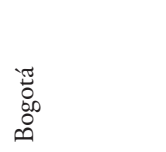 \\
\hline$\overbrace{0}^{\text {है }}$ & 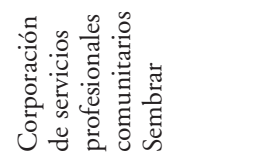 & 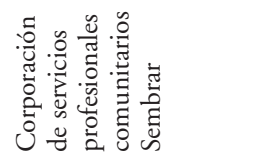 & 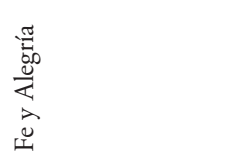 & 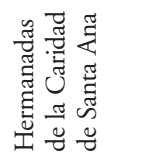 \\
\hline 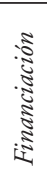 & 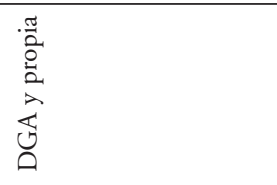 & 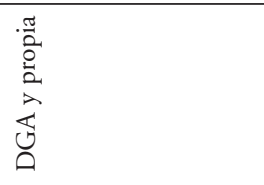 & & 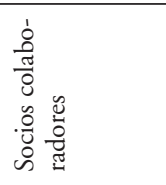 \\
\hline 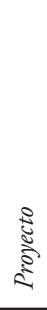 & 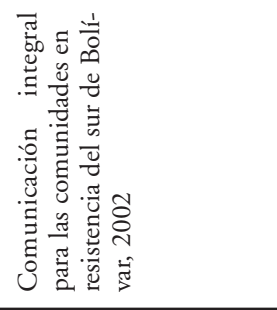 & 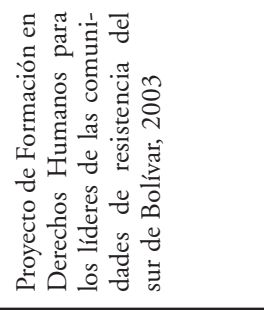 & 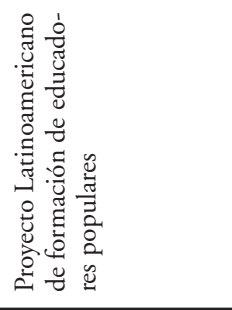 & 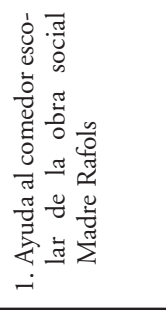 \\
\hline $\begin{array}{l}\text { కี } \\
\text { है }\end{array}$ & \multicolumn{2}{|l|}{ 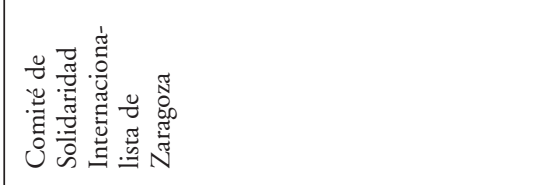 } & 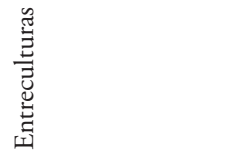 & 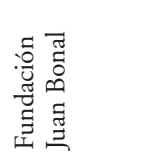 \\
\hline & \multicolumn{2}{|l|}{$n$} & 0 & $\wedge$ \\
\hline
\end{tabular}




\begin{tabular}{|c|c|c|c|c|}
\hline 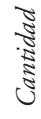 & $\begin{array}{l}\stackrel{\omega}{W} \\
\hat{\tilde{N}} \\
\hat{\sim}\end{array}$ & 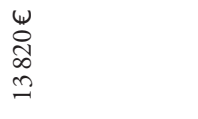 & $\begin{array}{l}\underset{\sim}{\omega} \\
\stackrel{\infty}{\sigma}\end{array}$ & $\begin{array}{l}\stackrel{\omega}{0} \\
\stackrel{\Xi}{\Xi} \\
\Xi\end{array}$ \\
\hline 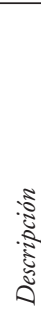 & 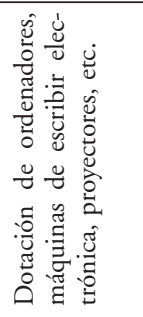 & 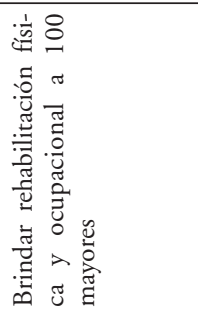 & 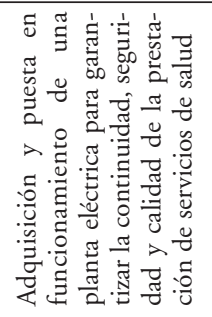 & 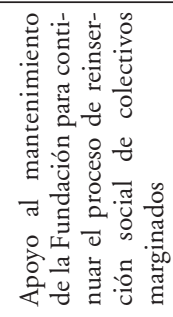 \\
\hline s & 当㓂㺃 & 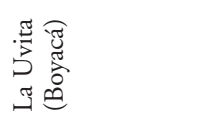 & 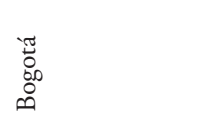 & 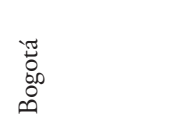 \\
\hline ड̃ & 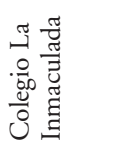 & 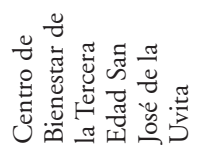 & 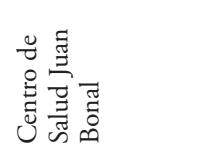 & 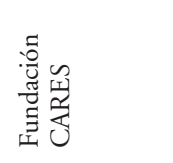 \\
\hline 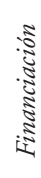 & 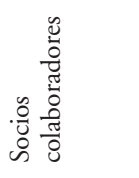 & 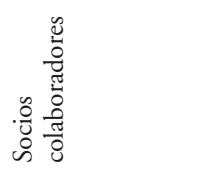 & 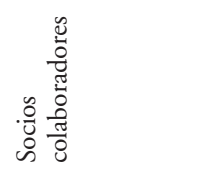 & 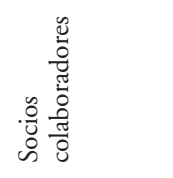 \\
\hline 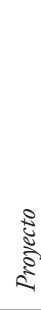 & 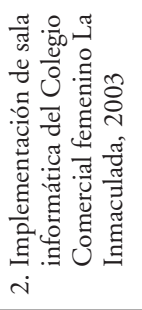 & 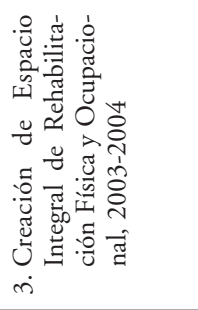 & 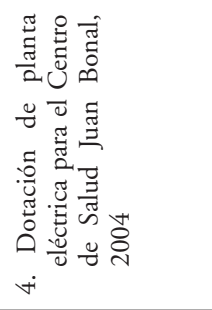 & 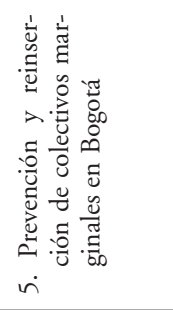 \\
\hline 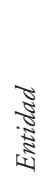 & & & 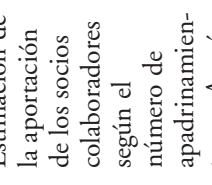 & \\
\hline
\end{tabular}




\begin{tabular}{|c|c|c|c|c|}
\hline 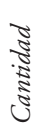 & 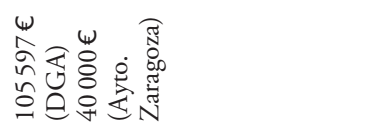 & $\mid \begin{array}{l}\omega \\
\infty \\
\infty \\
\infty \\
\infty \\
\infty \\
\sim\end{array}$ & $\begin{array}{l}w \\
\tilde{D} \\
2 \\
0 \\
0\end{array}$ & 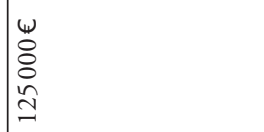 \\
\hline 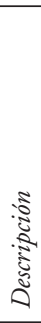 & 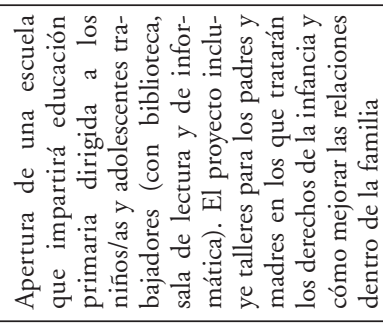 & 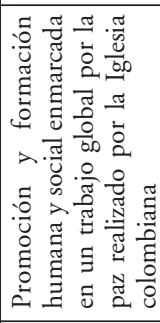 & 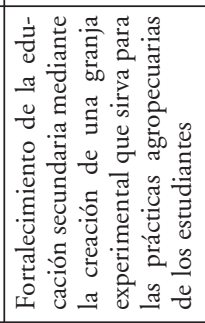 & 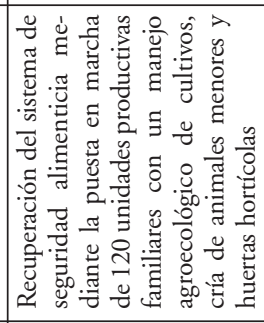 \\
\hline$\stackrel{5}{3}$ & 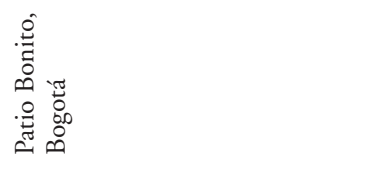 & 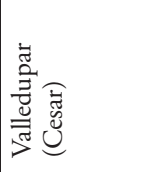 & 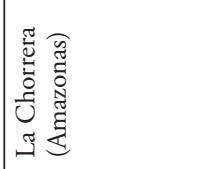 & 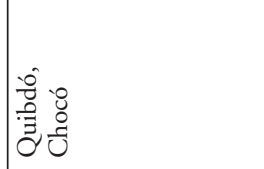 \\
\hline ڤ్ & 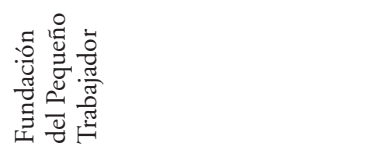 & 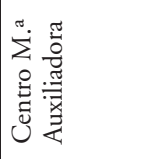 & 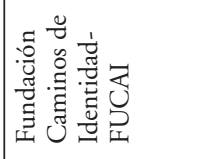 & 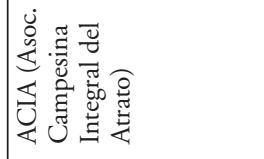 \\
\hline 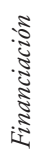 & 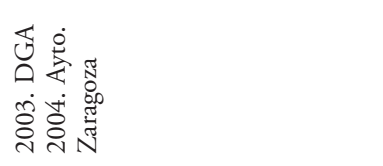 & 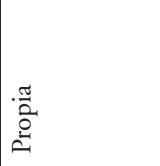 & 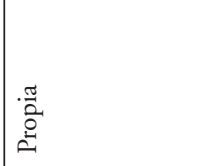 & 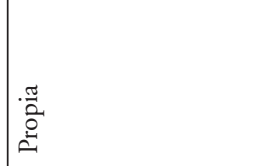 \\
\hline sัँ & 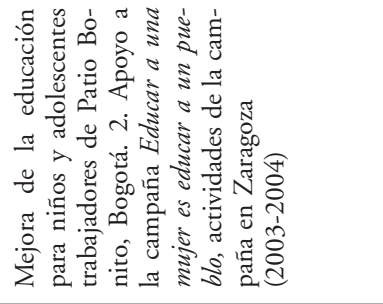 & 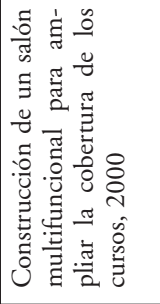 & 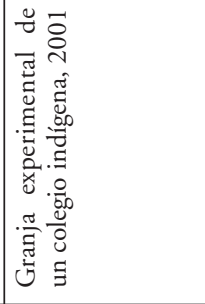 & 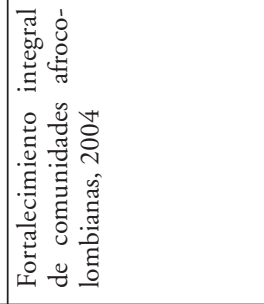 \\
\hline 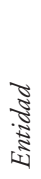 & 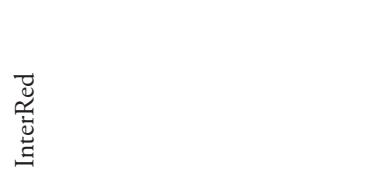 & \multicolumn{3}{|l|}{ 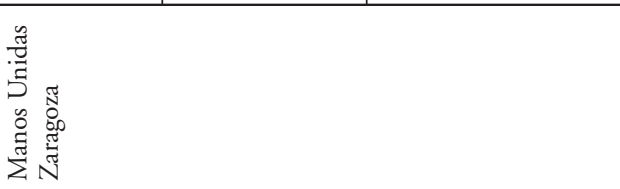 } \\
\hline & $\infty$ & \multicolumn{3}{|l|}{$\sigma$} \\
\hline
\end{tabular}




\begin{tabular}{|c|c|c|c|c|}
\hline 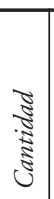 & 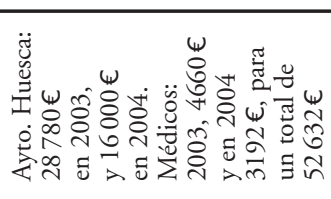 & 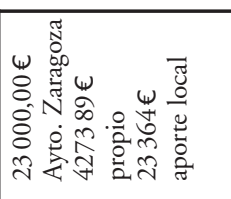 & $\begin{array}{l}\Psi \\
\stackrel{2}{0} \\
\stackrel{8}{2}\end{array}$ & 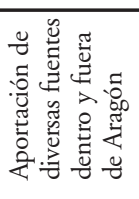 \\
\hline 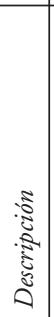 & 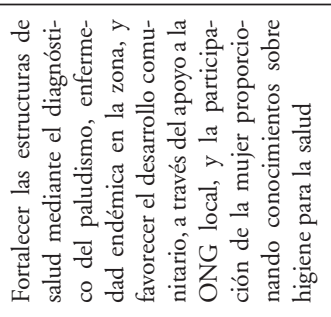 & 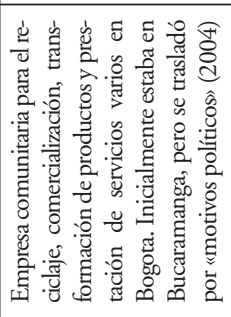 & 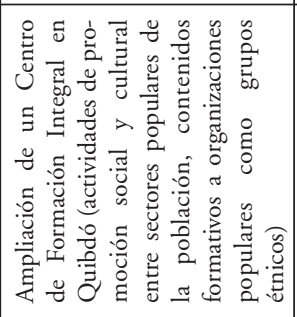 & 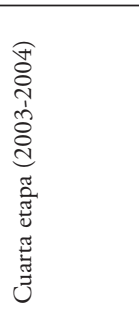 \\
\hline 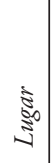 & 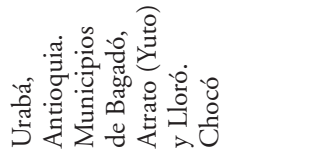 & 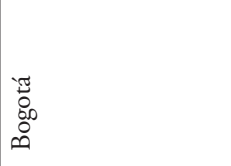 & $\begin{array}{l}\frac{0}{0} \\
\frac{0}{3} \\
\frac{0}{2}\end{array}$ & 。 \\
\hline है & 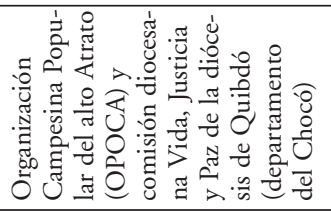 & 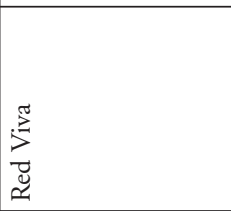 & 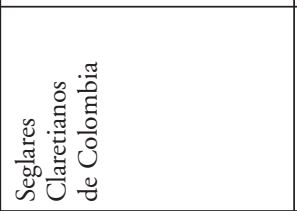 & 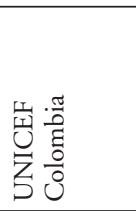 \\
\hline 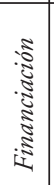 & 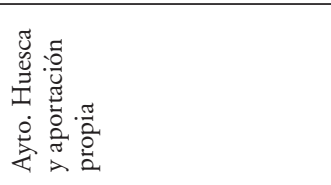 & 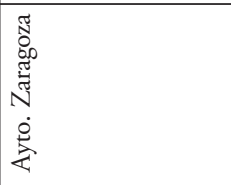 & 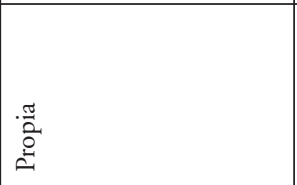 & \\
\hline בั้ & 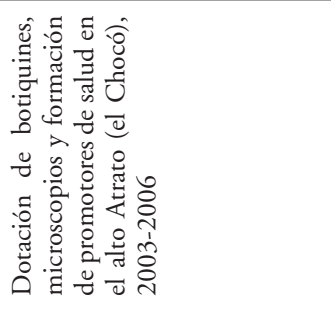 & 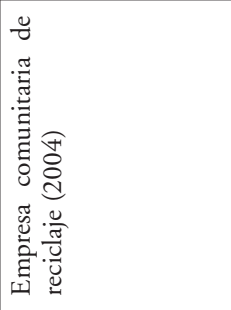 & 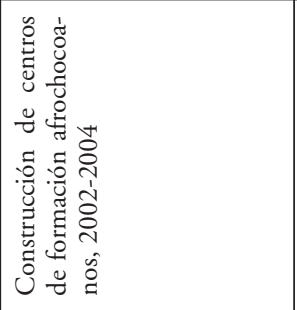 & 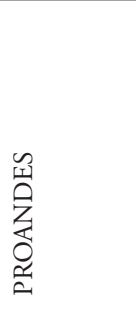 \\
\hline 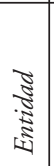 & 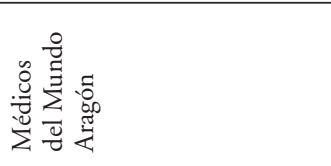 & 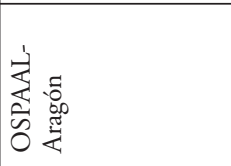 & 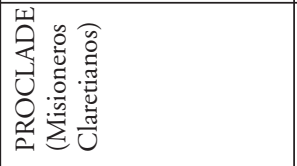 & 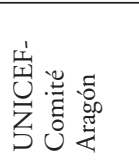 \\
\hline & $\stackrel{\circ}{2}$ & $=$ & $\simeq$ & 2 \\
\hline
\end{tabular}


ÍNDICES 



\section{ÍNDICE DE CUADROS, GRÁFICAS, MAPAS Y TABLAS}

\section{Cuadros}

1.1. Colombia según la Constitución política .......................... 28

2.1. Guión de entrevista a integrantes de ONG de desarrollo. Entidades aragonesas y contrapartes colombianas ............. 44

4.1. Estructura de la Agencia Presidencial para la Acción Social y la Cooperación Internacional ....................................... 107

4.2. La Constitución colombiana y el asociacionismo .............. 115

4.3. Propuestas de la CCONG sobre cooperación internacional en Colombia ................................................................... 136

6.1. Tipología de las ONG colombianas ................................ 175

7.1. Diferencias entre tipos de evaluación ............................... 254

7.2. Principios de la evaluación participativa........................... 256

7.3. Propiedades SMART de los indicadores........................... 258

7.4. Propiedades SPICED del desarrollo y evaluación de indicadores..................................................................... 258

7.5. Matriz de interpretación y análisis global de escenarios de evaluación ....................................................................... 261

7.6. Indicadores basados en valores organizativos .................... 263

7.7. Ejemplo de indicadores para la evaluación del impacto en zonas conflictivas .............................................................. 264 
Gráficas

2.1. Representación gráfica del estudio de caso ....................... 41

4.1. Evolución de la AOD bilateral a Colombia, 1999-2003 ... 61

4.2. AOD bilateral a Colombia, 2003 .................................... 62

4.3. Proyectos de cooperación en Colombia por fuentes de financiación, 2003 ............................................................ 63

4.4. Mecanismos de cooperación de la Comisión Europea con

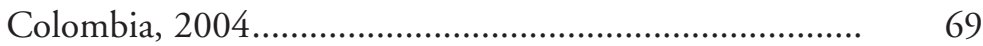

4.5. Evolución de la AOD UE-Colombia, 1998-2005............. 75

4.6. Evolución de la AOD de España a Colombia, 1998-2004 87

4.7. Aportes a la cooperación colombiana por tipo de cooperante (proyectos vigentes en 2004) .................................. $\quad 90$

4.8. Principales sectores CAD de la ayuda española en Colombia por aportaciones, 2004 ............................................

5.1. Evolución de los presupuestos de los proyectos financiados por el Gobierno de Aragón en Colombia, 2000-2005 ...... 148

5.2. Fuente de financiación de los proyectos ejecutados en Colombia, 2000-2004

5.3. Relación entre la financiación pública-propia por entidad, 2000-2004

5.4. Distribución de las entidades aragonesas por proyectos en Colombia, 2000-2004

5.5. Presupuestos de la cooperación aragonesa por departamentos colombianos, 2000-2004 .....................................

5.6. Distribución de la cooperación aragonesa en Colombia por sectores $\mathrm{CAD}$

Mapas

1.1. Identificación de los departamentos colombianos en los que se realizó el trabajo de campo ....................................

4.1. AOD española. Proyectos en ejecución, 2006 .....................

4.2. Distribución de las ONG pioneras en Colombia por departamentos 
5.1. Ubicación de los proyectos ejecutados en Colombia por ONGD aragonesas, 2000-2004 ....................................

5.2. Inversiones de la cooperación aragonesa en Colombia por regiones, 2000-2004 (euros) ......................................... 166

Tablas

4.1. Cronología de las relaciones entre la UE y Colombia........ 67

4.2. Tratados y convenios vigentes entre España y Colombia en materia de cooperación .................................................... 88

4.3. Sectores prioritarios de actuación según el Plan Director de España ........................................................................ 89

4.4. Federaciones de ONG colombianas ................................ 135

5.1. Fuentes de financiación de la cooperación aragonesa en Colombia, 2000-2004 



\section{ÍNDICE}

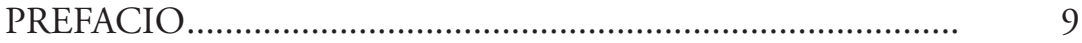

PRÓlOGO ..................................................................... 11

AGRADECIMIENTOS ....................................................... 13

ABREVIACIONES ............................................................ 15

1. PRESENTACIÓN .......................................................... 19

1.1. La cooperación, un objeto difuso de investigación...... 21

1.2. Colombia: un país difícil de explicar.......................... 27

1.2.1. Dos de los múltiples actores del conflicto: «la guerrilla»y «los paramilitares»........................... 31

2. METODOLOGÍA......................................................... 37

2.1. Hipótesis o supuestos iniciales ................................. 38

2.2. El estudio de caso ................................................. 41

2.3. El trabajo de campo............................................... 42

2.4. El análisis de la información .................................... 48

3. EL PANORAMA ACTUAL DE LAS ONGD.................... 51

4. LA COOPERACIÓN INTERNACIONAL EN COLOMBIA 57

4.1. Reseña histórica ..................................................... 57

4.2. La ayuda oficial de la Unión Europea ....................... 62

4.2.1. El contexto latinoamericano ............................. 62

4.2.2. La cooperación con Colombia ......................... 67

4.2.3. La UE y el conflicto armado en Colombia ....... 74 
4.3. La cooperación española ........................................... 86

4.3.1. Las ONGD españolas en Colombia ................. 93

4.3.2. Las relaciones exteriores hispano-colombianas... 98

4.4. La estrategia de cooperación internacional del Gobierno colombiano........................................................ 102

4.4.1. La Agencia Presidencial para la Acción Social y la Cooperación Internacional, ACCI ................ 106

4.5. Las ONGD y la sociedad civil en Colombia.............. 110

4.5.1. Diferencias entre «las colombianas» $\mathrm{y}$ «las españolas»

4.5.2. Los primeros pasos y sus huellas ....................... 122

4.5.3. Los próximos años............................................ 136

5. EL CONTEXTO ARAGONÉS......................................... 141

5.1. La cooperación oficial al desarrollo ............................. 141

5.2. La presencia aragonesa en Colombia......................... 149

5.2.1. ONGD aragonesas federadas con presencia en Colombia

5.2.2. Análisis cuantitativo de la presencia de las ONGD aragonesas en Colombia.......................

6. EL TRABAJO DE CAMPO: FACTORES QUE CARACTERIZAN LOS PROCESOS DE EJECUCIÓN DE LOS PROYECTOS

6.1. El punto de partida ................................................... 169

6.2. Identidad de las ONG: ¿Gestionar recursos o procesos? 174

6.3. Relaciones con la cooperación internacional....

6.3.1. Relaciones instituidas entre los actores de la cooperación

6.3.2. Confianza y reciprocidad: la relevancia del capital social

6.4. Cooperar en medio del conflicto armado................... 203

6.4.1. Las organizaciones aragonesas.......................... 203

6.4.2. Organizaciones locales .................................. 212

6.4.3. Las comunidades: percepción de la cooperación y participación en los proyectos 
6.4.4. La coordinación entre los actores

6.5. Evaluar el proyecto: ¿compromiso con el donante o con la comunidad?

7. PLANTEAMIENTOS EN TORNO A LA EVALUACIÓN DE LOS PROYECTOS

7.1. La evaluación, ¿̨un problema para las ONGD? .......... 248

7.1.1. La necesidad de la evaluación

7.2. Un elemento prioritario en la legislación estatal y aragonesa.

7.3. Propuestas sobre la evaluación de impacto y sus indicadores

7.3.1. Fomentar las evaluaciones participativas

7.3.2. Elaborar los indicadores: algunos elementos para considerar

7.3.3. Indicadores basados en las percepciones comunitarias, los valores organizativos y los contextos conflictivos

Anexo 1. Distribución espacial de acciones violentas realizadas por las FARC, 1995-2002

Anexo 2. Distribución espacial de acciones violentas realizadas por las autodefensas (paramilitares), 1995-2002

Anexo 3. Muestra de la investigación

Anexo 4. Reivindicaciones de los movimientos étnico-territoriales del Chocó ante las ONGD nacionales y extranjeras

Anexo 5. Mapa del desplazamiento forzado en Colombia, 2001

Anexo 6. Registro sistemático de las ONGD aragonesas en Colombia.

ÍNDICES 

Este libro se terminó de imprimir en los talleres gráficos de Linea 2015, S. L., de Zaragoza, en noviembre de 2007 Wo 


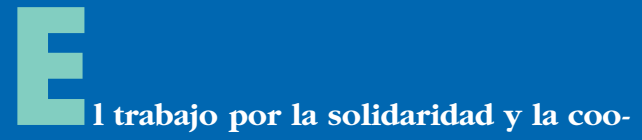

peración internacional es tan urgente que, en ocasiones, no hay tiempo ni recursos para reflexionar y escribir. Sin embargo, el esfuerzo y dedicación de muchos actores, entre los que se encuentran las ONGD aragonesas y colombianas, está consolidando relaciones de apoyo que significan, en muchos casos, la supervivencia y la defensa de la vida para miles de personas que padecen la violencia y la exclusión.

Este libro es una aproximación sociológica a los factores que caracterizan la presencia de las ONGD aragonesas en Colombia a través de los proyectos de desarrollo y otras acciones solidarias. Abarca ámbitos diversos, como la contextualización sociopolítica de la cooperación internacional con Colombia, y ofrece reflexiones y recomendaciones metodológicas sobre la evaluación de los proyectos de desarrollo en el entorno de un conflicto armado.

Hoy, más que hace unos años, el papel de las ONG resulta prioritario en la construcción de la paz en Colombia. Así como la violencia ha colonizado los espacios de la vida social, también la proliferación de organizaciones y el compromiso de muchas de ellas por construir una paz basada en la justicia y los derechos humanos son una muestra de esperanza para las aspiraciones de una nación que lleva más de medio siglo de conflicto, en medio del cual no desfallece el trabajo por la defensa de los derechos de los más vulnerables. En ese sentido, Colombia proporciona una fuente de experiencias tan destacadas como desconocidas.
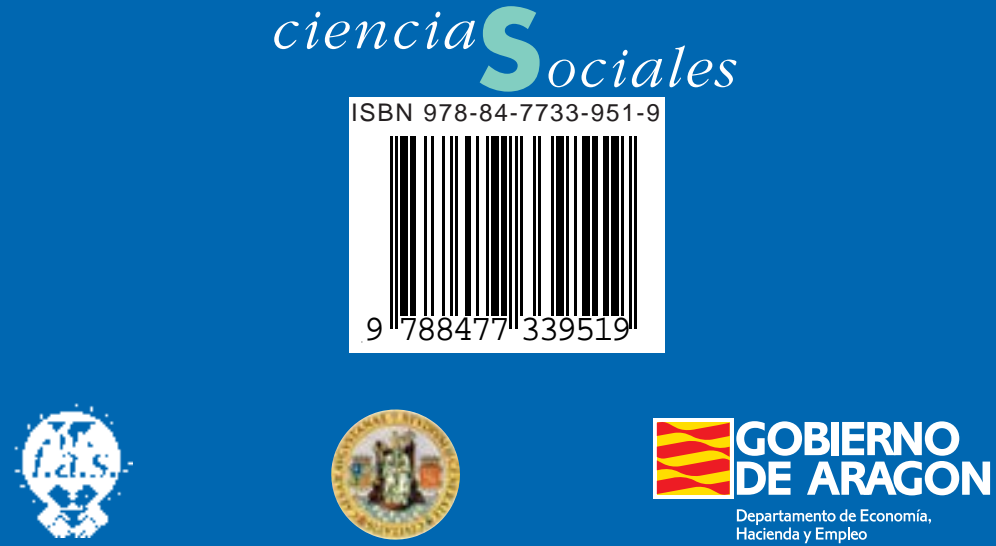